\author{
University of Szeged \\ Faculty of Pharmacy \\ Department of Pharmaceutical Technology and Regulatory Affaires \\ Head: Dr. habil. Ildikó Csóka, Ph.D.
}

Ph.D. Thesis

Design and characterization of mucoadhesive hydroxypropyl cellulose oral films

\author{
By \\ Mihály Gottnek \\ Pharmacist
}

Supervisor:

Dr. habil. Géza Regdon jr., Ph.D.

Szeged

2017 


\section{ARTICLES RELATED TO THE PH.D. THESIS}

I. András Kelemen, Mihály Gottnek, Géza Regdon jr, Klára Pintye-Hódi: New equipment for measurement of the force of adhesion of mucoadhesive films $J$ Adhes Sci Technol 29:(13) pp. 1360-1367. (2015)

\section{IF: 0.863 Citations: Independent: - Dependent: 1 Total: 1}

II. Mihály Gottnek, Klára Pintye-Hódi, Géza Regdon jr: Tracking of the behaviour of lidocaine base containing hydroxypropylcellulose free films with thermoanalytical method J Therm Anal Calorim 120: pp. 201-208. (2015)

\section{IF: $\quad \mathbf{1 . 7 8 1}$}

III. Mihály Gottnek, Károly Süvegh, Klára Pintye-Hódi, Géza Regdon jr: Effects of excipients on the tensile strength, surface properties and free volume of Klucel free films of pharmaceutical importance Radiat Phys Chem 89: pp. 57-63. (2013)

\section{IF: 1.189 Citations: Independent: 3 Dependent: 2 Total: 5}

IV. Gottnek Mihály, Hódi Klára, ifj Regdon Géza: Szájnyálkahártyán alkalmazható mukoadhezív filmek.: I. rész: A szájnyálkahártya és a nyál anatómiai, élettani áttekintése Gyógyszerészet 57:(1) pp. 24-31. (2013)

\section{IF: $-\quad$ Citations: Independent: - Dependent: $2 \quad$ Total: 2}

V. Gottnek Mihály, Hódi Klára, ifj Regdon Géza: Szájnyálkahártyán alkalmazható mukoadhezív filmek.: II. rész: A mukoadhézió mechanizmusa, a mucin funkciói, penetráció a szájnyálkahártyán keresztül, a nyálkahártya barrier funkciója Gyógyszerészet 57:(2) pp. 69-75. (2013)

\section{IF: - Citations: Independent: - Dependent: 2 Total: 2}

VI. Gottnek Mihály, Hódi Klára, ifj Regdon Géza: Szájnyálkahártyán alkalmazható mukoadhezív filmek.: III. rész: Bukkális mukoadhezív filmek esetén alkalmazott polimerek és segédanyagok Gyógyszerészet 57:(5) pp. 274-282. (2013)

\section{IF : - Citations: Independent: - Dependent: $1 \quad$ Total: 1}

VII. Gottnek Mihály, Hódi Klára, ifj Regdon Géza: Szájnyálkahártyán alkalmazható mukoadhezív filmek.: IV. rész: Bukkális mukoadhezív filmekben alkalmazott hatóanyagok. Mukoadhezív filmek előállítása és vizsgálata Gyógyszerészet 57:(6) pp. 323-329. (2013)

IF: - 
VIII. Mihály Gottnek, András Kelemen, Klára Pintye-Hódi, Géza Regdon jr.: Effects of drug substances and excipients on the adhesive force of mucoadhesive buccal films (manuscript under submission for publication)

\section{ABSTRACTS}

I. András Kelemen, Mihály Gottnek, Klára Pintye-Hódi, Géza Regdon jr: Dynamic adhesion force method for measuring the adhesion of mucoadhesive films In: Kasza Gy (szerk.) International Conference on Bio-Friendly Polymers and Polymer Additives: From Scientific Aspects to Processing and Applications: Program and Book of Abstracts. Budapest, Hungary, 2014.05.19-2014.05.21. Budapest: Palatinus Print Kft., 2014. p. 61.

II. András Kelemen, Mihály Gottnek, Géza Regdon jr, Klára Pintye-Hódi: Dynamic adhesion force measurement of mucoadhesive films In: 9th World Meeting on Pharmaceutics, Biopharmaceutics and Pharmaceutical Technology. Lisboa, Portugal, 2014.03.31-2014.04.03.p. TH141.

III. Kelemen András, Gottnek Mihály, ifj Regdon Géza, Hódi Klára: Dinamikus erőmérés mukoadhezív filmek vizsgálata során Gyógyszerészet 58:(S1) pp. 114115. (2014)

IV. Mihály Gottnek, Gabriella Farkas, Tamás Sovány, Ottó Berkesi, Klára Pintye-Hódi, Géza Regdon Jr.: Accelerated stability tests and effects of excipients on the structure of hydroxypropylcellulose free films. Eur J Pharm Sci 50:(S1) Paper PP043. (2013)

V. Gottnek Mihály, Farkas Gabriella, Sovány Tamás, Hódi Klára, ifj Regdon Géza: Mukoadhezív szabad filmek fizikai-kémiai és stabilitás vizsgálata. XVIII. Országos Gyógyszertechnológiai Konferencia és IX. Gyógyszer az Ezredfordulón Konferencia, Előadáskivonatok (EA-10) 20 (2012) (2012)

VI. Mihály Gottnek, Károly Süvegh, Klára Pintye-Hódi, Géza Regdon jr: Formulation and physico-chemical description of bioadhesive films adhering to the oral mucosa In: 8th World Meeting on Pharmaceutics, Biopharmaceutics and Pharmaceutical Technology. Istanbul, Turkey, 2012.03.19-2012.03.22. Paper P29.

VII. Mihály Gottnek, Károly Süvegh, Klára Pintye-Hódi, Géza Regdon jr: Formulation and physico-chemical description of bioadhesive films containing lidocainehydrochloride In: International Conference on Bio-Based Polymers and Composites 2012. Siófok, Hungary, 2012.05.27-2012.05.31.p. 44. 


\section{TABLE OF CONTENTS}

\section{ABBREVIATIONS}

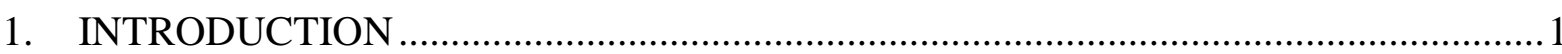

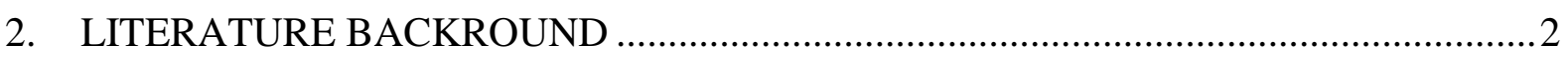

2.1. Short anatomy and physiology review of the oral mucosa ...................................2

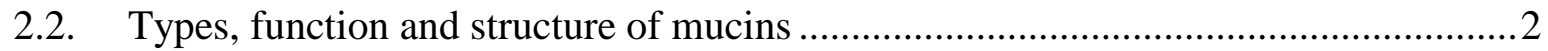

2.3. Permeability and barrier function of the buccal mucosa ..........................................

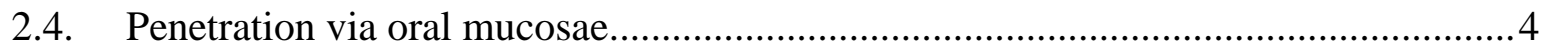

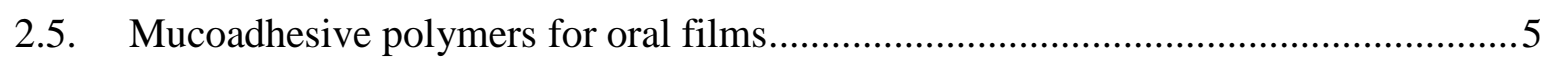

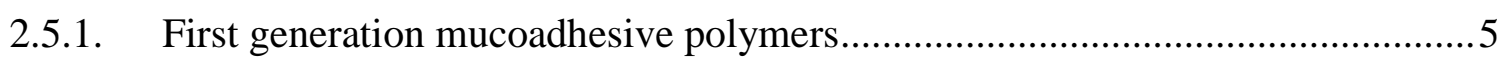

2.5.2. Second generation mucoadhesive polymers ................................................ 6

2.5.3. The ideal properties of mucoadhesive polymers ............................................6

2.6. Definition of mucoadhesion, theories of adhesion and roles that effect the

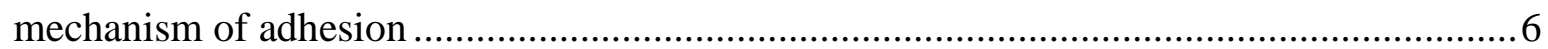

2.6.1. Interaction between the mucoadhesive and the mucosa ................................... 7

2.6.2. Factors that effect mucoadhesion....................................................................

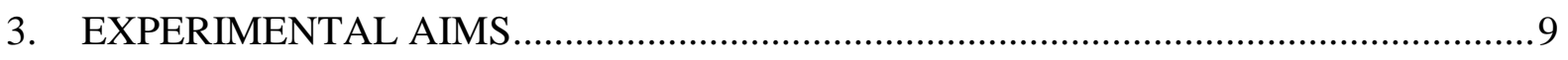

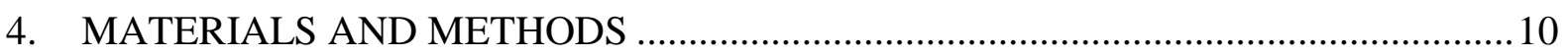

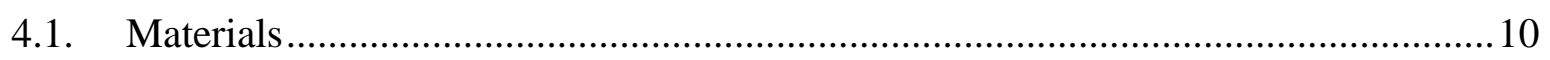

4.1.1. Hydroxypropyl cellulose as film-forming polymer ..................................... 10

4.1.2. Model drugs and other excipients ............................................................... 11

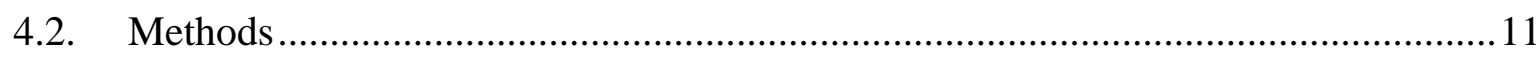

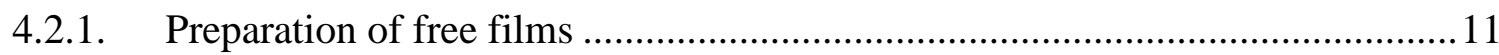

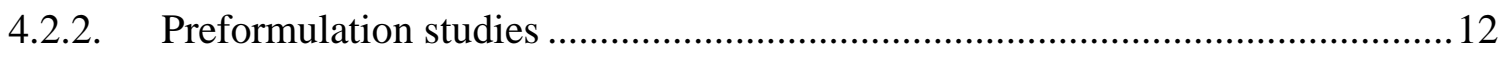

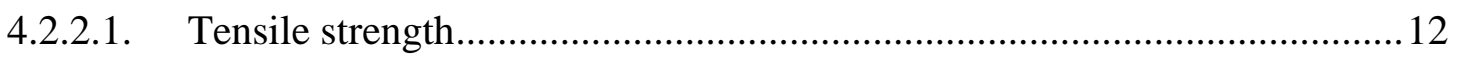

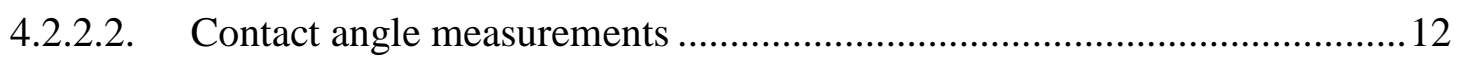

4.2.3. Positron annihilation lifetime spectroscopy (PALS) ...................................... 13

4.2.4. Thermoanalytical measurements .................................................................... 14

4.2.5. Characterization of interaction between excipients and polymer matrix;

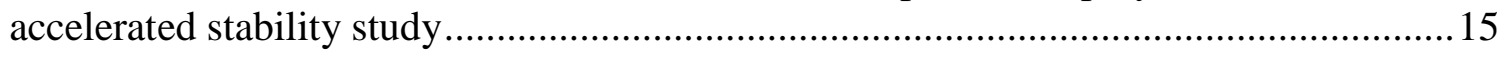

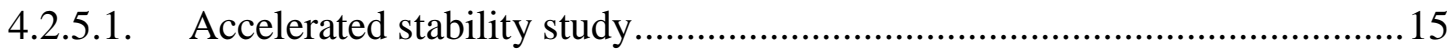

4.2.5.2. Attenuated Total Reflectance Fourier Transform Infrared Spectroscopy .. 15

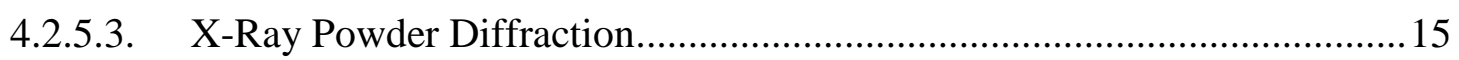

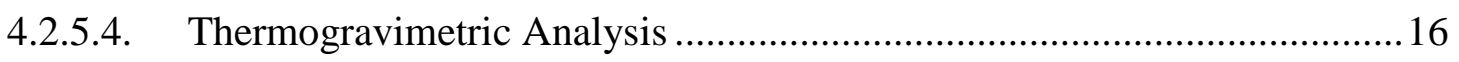

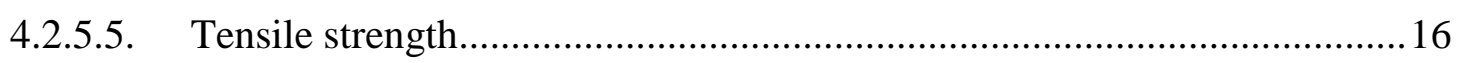




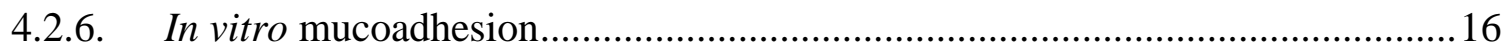

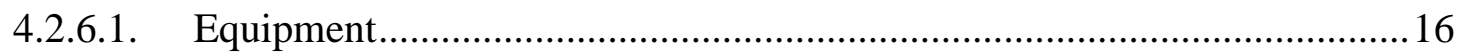

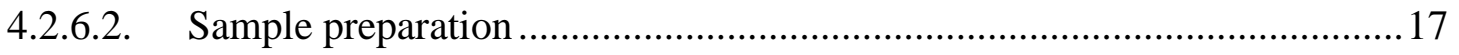

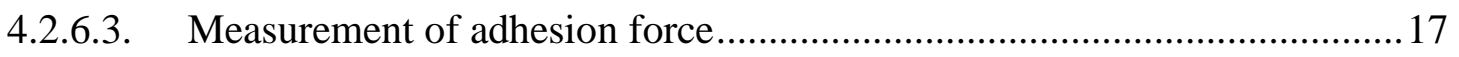

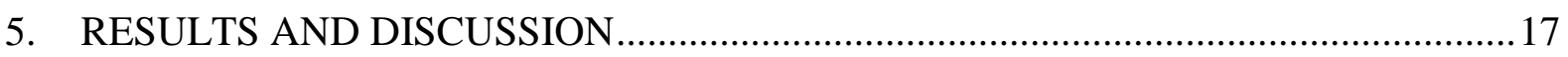

I. OPTIMIZATION AND EARLY CHARACTERIZATION OF HPC FREE FILMS …....................... 17

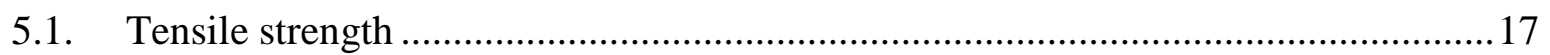

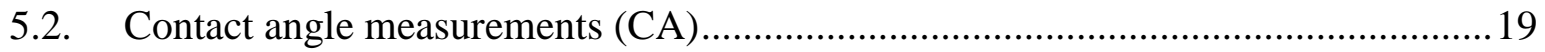

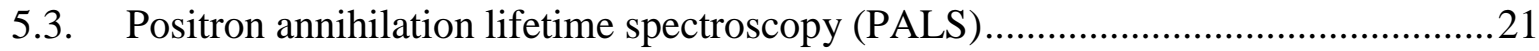

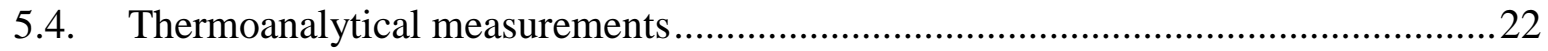

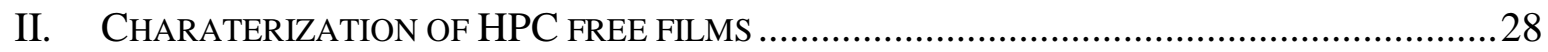

5.5. Interaction between excipients and the polymer matrix, accelerated stability study 29

5.5.1. Attenuated Total Reflectance Fourier Transform Infrared Spectroscopy..........29

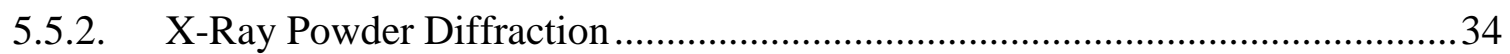

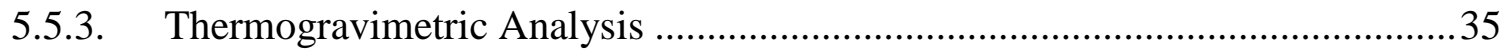

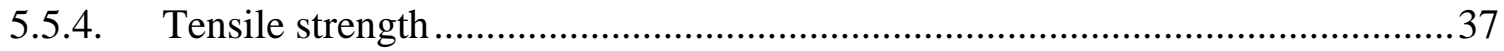

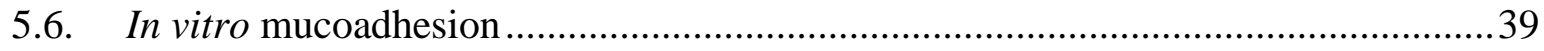

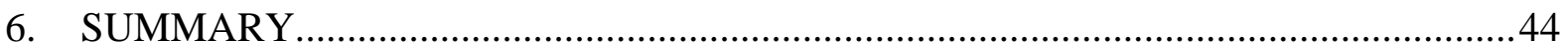

7. FINAL CONCLUSIONS, NOVELTY AND PRACTICAL USEFULNESS .................45

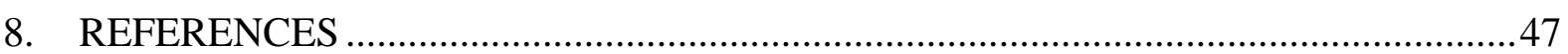

ACKNOWLEDGEMENT 


\section{ABBREVIATIONS}

ATR-FTIR - Attenuated Total Reflectance Fourier Transform Infrared Spectroscopy

$\mathrm{CA}$ - contact angle

deg - degree

DSC - Differential Scanning Calorimetry

Gly - glycerol

HPC - hydroxypropyl cellulose

Lid - lidocaine base

Lid $\mathrm{HCl}$ - lidocaine hydrochloride

Lop $\mathrm{HCl}$ - loperamide hydrochloride

MCG - membrane coating granules

MFG - Klucel ${ }^{\circledR}$ MF with glycerol

MFX - Klucel ${ }^{\circledR}$ MF with xylitol

MFXG - Klucel ${ }^{\circledR}$ MF with xylitol and glycerol

o-Ps - ortho-Positronium

PALS - Positronium Annihilation Lifetime Spectroscopy

$\mathrm{Phe} \mathrm{HCl}$ - phenylephrine hydrochloride

p-Ps - para-Positronium

Ps - Positronium

SFE - surface free energy

SFT - surface free tension

TGA - Thermogravimetric Analysis

TG-MS - Thermogravimetric Analysis coupled with Mass Spectrometry

XRPD - X-Ray Powder Diffraction

Xyl - xylitol 


\section{INTRODUCTION}

Although the most popular mode of administration of medicines for patients is the oral route, the enzymes of the gastrointestinal tract cause serious disadvantages. They decompose many active substances and the first-pass effect of the liver decreases the serum level of active pharmaceutical ingredients.

However, mucoadhesive films applied to the oral mucosa eliminate these problems, and not only local effects (treatment of aphthous ulcer, gum inflammation or toothache), but also system wide effects (management of pain and angina pectoris etc.) can be achieved. Their main advantages are sustained drug delivery and chronic systemic therapy. Oral patches are welcome in paediatrics (children have the worst compliance), films are proper for elderly patients as well who suffer from swallowing disorders or dysphagia. Buccal disks are unique medicines that can be used during travelling as a dose can be taken without water or any liquid. Patient compliance is better which improves the efficacy of the therapy and decreases the cost for both the healthcare system and the patients. Finally, the oral mucosa has high tolerance against potential allergens and has a fast healing capacity for irritation and damages.

Before their technological use, it is very important to determine the mechanical properties of mucoadhesive films because the free films are exposed to large mechanical stress during the preparation process, unpacking and sticking to the oral mucosa. These properties depend on the film-forming polymer, the excipients used and the formulation of the system.

Furthermore, the physicochemical properties of the polymer matrix not only depend on the polymer itself, but also the used excipients have marked effects on the system. These effects can be welcomed and useful, but the excipients can cause disadvantageous effects in drug delivery systems, which must therefore be tested.

In my Ph.D. work, hydroxypropyl cellulose free films were investigated as potential buccal drug delivery systems. The effects of excipients on the polymer matrix were characterized in several ways and physicochemical properties were tested intensively. In vitro mucoadhesion measurement method, equipment and software developed and optimized, and accelerated stability test was evaluated. 


\section{LITERATURE BACKROUND}

\subsection{Short anatomy and physiology review of the oral mucosa}

The main function of the oral mucosa is to protect the underlying tissues against potential harmful agents or microorganisms. It has three main parts (please refer to Fig. 1), from the surface to the deeper regions: epithelium, basement membrane and underlying connecting tissues (lamina propria and submucosa). These can be divide into several parts:

- oral epithelium: mucus, stratum distendum, stratum filamentosum, stratum suprabasale and stratum basale

- basement membrane

- lamina propria: which is an underlying supportive connective tissue layer and

- submucosa [1]

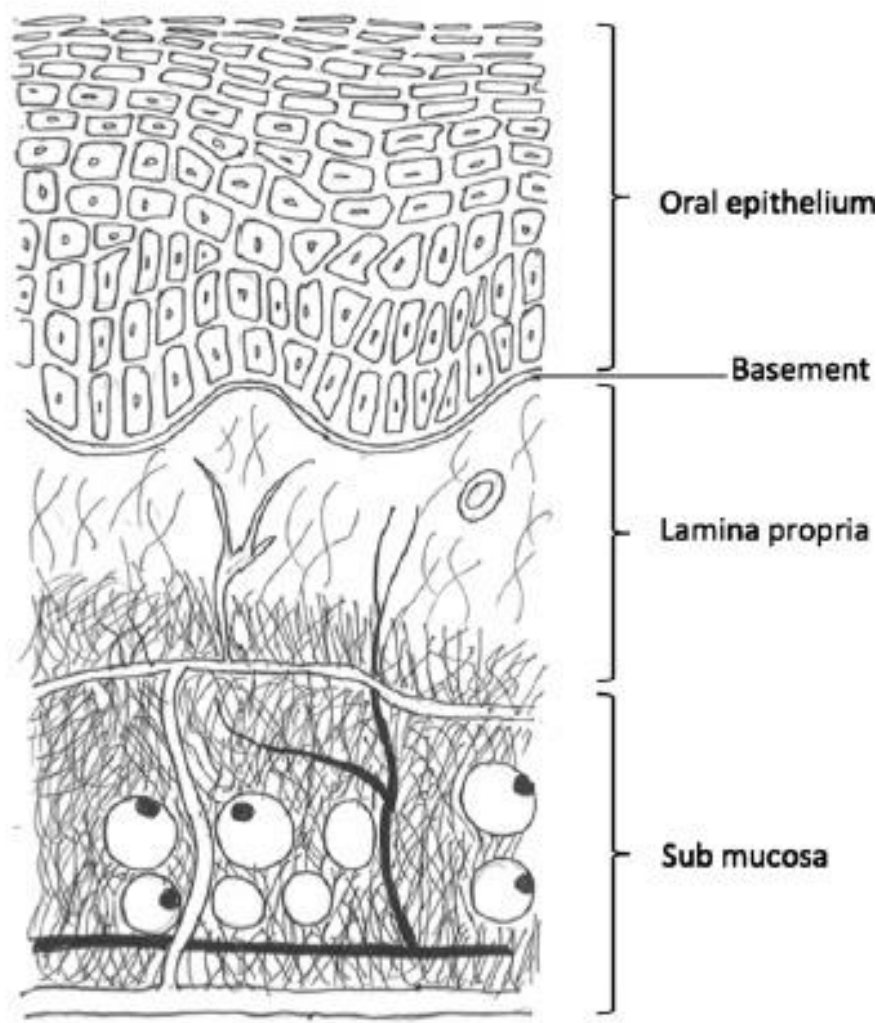

Fig. 1 Schematic diagram of the oral mucosa adapted from [2].

\subsection{Types, function and structure of mucins}

Approximately from 40 to $300 \mu \mathrm{m}$ mucus covers the buccal epithelial cells [3], which contains $95-99 \%$ of water and 1-5\% mucins. Mucins are large molecules with the molecular masses from 0.5 to $20 \mathrm{MDa}$ and rich in carbohydrates: in the gastrointestinal tract mucins have $70-80 \%$ of carbohydrates, $12-25 \%$ of proteins and $5 \%$ of ester sulphates. A basic unit is 
400-500 kDa and linked together up to $50 \mathrm{MDa}$ linear arrays [4-7]. Mucins play an important role as lubricants and this indicates mucoadhesion [8]. At buccal $\mathrm{pH}$ the mucus forms a strong cohesive gel layer which covers the epithelial cells. The joint of mucin lines, hydrogen-bonding, electrostatic and hydrophobic bonds indicate the viscoelastic gel structure [9]. At neutral $\mathrm{pH}$ the mucin acts as an anionic polyelectrolyte (which is indicated by sialic acid $\left(\mathrm{pK}_{\mathrm{a}}=2.6\right)$ at the end of the chains and sulphate groups) $[4-6,10]$. In human saliva two types of mucins are produced $[11,12]$. The main effects of mucins are the following: they act as lubricants [13], help chewing, speaking and swallowing and have antibacterial effect [12]. They also protect teeth against acids [14], keep the integrity of the mucus layer via modulating the intracellular calcium level [11], help the colonization of normal florae, protect soft and hard tissues against mechanical stress, help the remineralization of teeth [4-6, 15].

\subsection{Permeability and barrier function of the buccal mucosa}

The buccal mucosa has 4-4000 times higher permeability compared to the skin [16]. The penetration of an active substance depends on its barrier permeability which is based on the thickness of the membrane, the rate of keratinisation and the physical-chemical properties of the active substance [17]. The membrane-coating granules (MCG) give the permeability barrier function of the buccal mucosa [18]. MCGs are spherical or oval-shaped organelles with a 100-300 $\mathrm{nm}$ of diameter and typical in both keratinised and non-keratinised epitheliums. MCGs come from the cell cytoplasm and migrate with exocytosis into the upper/surface region of the cells. They serve as a barrier and help the cohesion between cells therefore not the keratinising of the epithelia is the main barrier [19]. In the human epidermis MCGs have lamellar structure as opposed to the buccal tissues where they have mainly amorphous forms which indicates the difference between the permeability capabilities of the two different tissues [1, 20-22]. MCGs are situated at the midpoint of the oral epithelium as shown in Fig. $2 A$.

The buccal epithelial barrier is situated at the upper third/fourth part of the cell layers [23]. At non-keratinised regions the main lipid barrier is made by phospholipids, cholesterol-esters and glycosylceramides, whereas at the keratinised area the highly concentrated ceramides are the main barriers [22]. In non-keratinized tissues the MCGs are lamellar and big; keep their nucleus and other cell organelles and finally do not aggregate. In this type of tissue their diameters are $0.2 \mu \mathrm{m}$ [24]. The basal lamina is the main barrier for lipophilic substances/drugs, which easily penetrate via the epithelium [25]. The saliva has a cleaning/washing function in the oral cavity and this phenomenon is important during the 
formulation of buccal drug delivery systems [26]. Another barrier is enzymatic decomposition: there are esterases, amylases and phosphatases in the saliva [27], and there are many proteolytic enzymes on the buccal epithelium [1, 20, 21, 28].
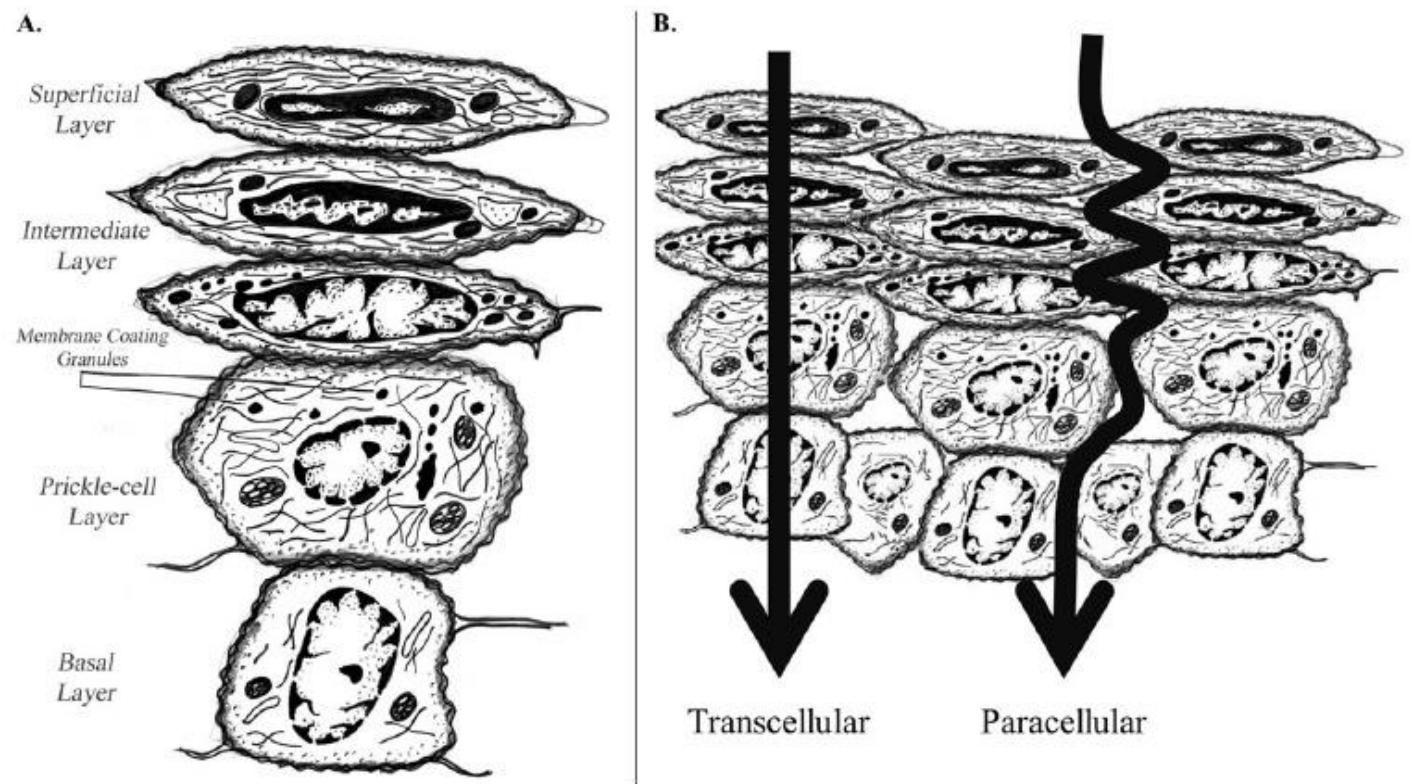

Fig. 2A shows the position of MCGs and 2B describes the transport routes via oral mисоsa, adapted from [29].

\subsection{Penetration via oral mucosae}

The permeability in the oral cavity from the highest to the lowest is the following: sublingual, buccal and soft palatial [30]. Because of lower permeability of the buccal mucosae, this area is quite appropriate for using controlled and/or sustained released systems [1, 20, 31]. The different types of drugs can penetrate the buccal region via the following:

- passive diffusion (para- and transcellular),

- carrier-mediated diffusion,

- active transport and

- pinolendocytosis

The most common way is passive diffusion and the least common is the carrier-mediated diffusion route. The polar lipids situated in the intracellular space are made up of two main parts: the lipophilic part connects to the cell membrane and the hydrophilic part connects to MCGs. This structure allows the paracellular (passing between the cells) and the transcellular (passing via cells) routes (please refer to Fig. 2B) [32]. Molecules with high log $\mathrm{P}$ value easily penetrate throughout the cell membrane [33]. On the other hand, hydrophilic substances penetrate via the intracellular space, which is a much longer and slower route [34- 
36]. Some of them enter by carrier-mediated diffusion via the buccal mucosae [1, 31, 37]. The lipophilicity, geometry and the size of the molecule determinates its penetration route. The paracellular route can be described by this equation:

$$
J_{p}=\frac{D_{p} \cdot \varepsilon}{h_{p}} \cdot C_{d}
$$

wherein: $D_{p}$ is the diffusion coefficient of the permeate in the intercellular space, $h_{p}$ is the path length of the route, $\varepsilon$ is the area fraction and $C_{d}$ is the donor drug concentration.

The transcellular route may be described with the following equation:

$$
J_{c}=\frac{(1-\varepsilon) \cdot D_{c} \cdot K_{c}}{h_{c}} \cdot C_{d}
$$

wherein: $K_{c}$ is the partition coefficient between the lipophilic cell membrane and the water phase, $D_{c}$ is the diffusion coefficient of the drug in the transcellular space and $h_{c}$ is the path length of the route $[1,31,38]$.

The adsorption potency of the buccal mucosae depends on the lipophilicity and the molar weight of the molecule. [39]. Ionizable compounds have $\mathrm{pH}$ dependent adsorption and could penetrate via the transcellular route [40]. Weak acids and weak bases are subjected to $\mathrm{pH}$ dependent ionization. The penetration of the ionized form is weaker than that of the nonionized one. The increase in the amount of non-ionized drug substance increases the penetration via the buccal epithelium and it could be controlled by changing the $\mathrm{pH}$ of the system. The $\mathrm{pH}$ has a strong effect on drug penetration control [1, 31, 41].

The diffusion of active substances does not correlate with the ionization degree related to Henderson-Hasselbalch equation, therefore this does not help to calculate the membrane diffusion of weak acids or weak bases [42]. Peptides penetrate via passive diffusion throughout the buccal mucosae, so do drugs with mono-carboxylic acid residue [37]. Hydrophilic molecules may be transported by carrier-mediated transport via the buccal epithelium [37, 43-46], contrarily, substances with lipophilic character do not have this type of carrier and therefore the possibility of intracellular transport is limited [1, 31].

\subsection{Mucoadhesive polymers for oral films}

\subsubsection{First generation mucoadhesive polymers}

First generation mucoadhesive polymers are not specific for the adhesion mechanism.

The adhesion time depends on the mucus turnover and is usually limited in time. The interactions are not covalent-type, weaker chemical bonds act in the phenomenon (mainly $\mathrm{H}$ bond, hydrophobic and electrostatic interactions). The three main groups are classified based 
on their charge, the classes are: anionic, cationic and non-ionic polymers. Anionic polymers are widely used in the pharmaceutical industry due to their high mucoadhesion capability and low toxicity. Hydrogels and co-polymers belong to the first generation $[1,20]$.

\subsubsection{Second generation mucoadhesive polymers}

On the other hand, the second generation is capable of connecting to the mucus layer and/or epithelial cells via covalent bonds or specific receptors. Thiolated polymers, target-specific, lectin-mediated polymers and bacterial adhesion belong to this generation. The main advantage of this group is that the adhesion time is longer and depends on the force of covalent bonds and targeted, sustained therapy is possible via these systems. Some polymers from the second generation have enzyme inhibitor activities or can enhance the penetration via the oral mucosa $[1,20]$.

\subsubsection{The ideal properties of mucoadhesive polymers}

- the polymer and its degradation products must be inert and non-toxic

- good wetting, swelling, dissolving and biodegradable properties

- biocompatible $\mathrm{pH}$ and good viscoelasticity

- fast sticking to oral mucosa and proper mechanical resistance

- good shearing, peeling and breaking resistance

- shows good bioadhesion properties in wetted and dried conditions too

- shows local enzyme inhibitor and penetration enhancer activities

- adequate turnover

- ideal molecular weight

- active adhesive groups

- optimal conformation

- crosslinking and proper chain flexibility

- protect against second infections

- $\quad$ easy to buy and cheap [1]

\subsection{Definition of mucoadhesion, theories of adhesion and roles that effect the mechanism of adhesion}

Bioadhesion means a continuous attachment of a material or a formulation into a biological surface via interfacial forces. Bioadhesion may be formed between soft and hard tissues, too. Mucoadhesion is a special form of bioadhesion: this phenomenon generates in the mucus layer; mucous membranes [47]. In the last few decades mucoadhesion and its mechanism has 
become of interest because it offers both local (treatment of aphtous ulcer or gum inflammation) and systemic therapy [20,48].

The mucous membranes cover several body cavities such as the oral cavity and the respiratory tract. The epithelium could be mono-layered (e.g. stomach, small intestine and bronchi) or multi-layered (e.g. oral cavity, oesophagus, cornea or the surface of the vagina). Mucus may be produced by specialised goblet cells or exocrine glands such as the salivary glands. Mucus could be present in three forms on the surface: gel layer, luminal soluble or in suspended form [49]. The typical gel-like state of it, the adhesive and cohesive properties are given by glycoproteins. The thickness of mucus depends on the part of the body; in the stomach its average thickness is between 50-450 $\mu \mathrm{m}[50,51]$, while it is the thickest, $1 \mu \mathrm{m}$ in the oral cavity $[20,48,52]$.

\subsubsection{Interaction between the mucoadhesive and the mucosa}

- Chemical bonds: The molecules must be bond to the interface to form adhesion. Adhesion may be formed by strong ionic or covalent, weaker hydrogen-bonds or the weakest Van-der-Waals interaction and finally by the indirect hydrophobic bonds $[20,48,53]$.

- Theories of adhesion: there are six main theories for mucoadhesion [20, 48, 5456].

- The electronic theory suggests electron transfer between the two surfaces which results an electronic double layer at the interface. These help form adhesion between the two layers.

- The wetting theory is based on the interfacial energy between a liquid and a solid system. The liquid is spontaneously spread on the solid surface which is essential for bioadhesion. During the phenomenon the gas, liquid and solid state form equilibrium. It can described by the wetting degree $(\Theta)$. Wetting happens if $\Theta<90 \mathrm{deg}$ and the surface is poorly wetting if $\Theta>90 \mathrm{deg}$. If $\Theta=0$ deg the wetting is complete and if $\Theta=180 \mathrm{deg}$ the liquid is not wetting the solid at all. Therefore, bioadhesion is the best when the wetting degree is closer to 0 deg [57].

- The adsorption theory assumes that the adhesion is formed via hydrogen bonds and Van-der-Waals interaction.

- The diffusion theory suggests an interdiffusion between the polymer chains and the adhesive surface. The concentration gradient leads the phenomenon 
and it is limited by the available molecular chain length and their mobilities. The depth of interpenetration depends on the contact time and the diffusion coefficient.

- The mechanical theory describes the adhesion via an interlocking between a liquid adhesive and a rough surface. Even though the huge surface offers a high interlocking availability, the viscoelastic and plastic dissipation of energy seems to be more important to form adhesion [56].

- The fracture theory differs from the five theories above; it suggests a fracture after adhesion. Typically the weakest component indicates the phenomenon.

- According to John D. Smart the in-vivo mucoadhesion force may be described with four theories:

a. Dry or semi-hydrated dosage forms connect with continuous mucus layers (e.g.articulates via the nasal cavity).

b. Fully hydrated dosage forms with the method above (first generation mucoadhesive system is used in the lower gastrointestinal tract).

c. Dry or semi-hydrated dosage forms connect with discontinuous or thin mucus layers (for example tablets or thin films applied in the oral cavity or the vagina).

d. Fully hydrated dosage forms with the method above (e.g. the use of semisolid, liquid dosage forms in the eye or the oesophagus) [48].

The mechanism of mucoadhesion can be described with two main steps [58] between the mucoadhesive material and the mucus layer. The first step is the contact stage; when the two parts of adhesion have a contact (wetting). The second step is the consolidation stage, when different physical and chemical interactions ensure the prolonged adhesion. In the contact stage the film starts dehydrating the mucus layer meanwhile hydrating itself. During this step the interpenetration starts. At the consolidation stage the force of mucoadhesion depends on the properties of the film-forming polymer and the rate of hydration [20, 48, 59].

\subsubsection{Factors that effect mucoadhesion}

There are many factors have effects on mucoadhesion [47, 54, 60]. Factors which have effect on adhesion in the oral cavity are the following:

- Factors depend on the polymer:

○ molecular weight,

○ flexibility, 
○ hydrogen bonding capacity,

○ cross-linking density,

○ charge,

○ concentration and

○ hydration (swelling) [20],

- Environmental factors:

○ saliva,

○ mucin turnover and

○ the movement of buccal tissues [20].

The optimal molecular weight is between $1 \cdot 10^{4}-4 \cdot 10^{6} \mathrm{Da}$. High molecular weight polymers hydrate slowly and the time for attaching to the surface is not enough. On the other hand, low molecular weight ones form weak gels and dissolve from the surface. The flexibility of polymer chains is very important because it helps penetration and attaching to the mucus layer. With the increase of cross-linking density in water-soluble polymers the flexibility of the chains decreases which protects against over hydration. Functional groups which capable of forming hydrogen-bonding help the mechanism of mucoadhesion [60-64]. These groups are the following: hydroxyl, carboxyl or amine. Typical examples are carbomers, chitosan, sodium-alginate and cellulose derivates [20, 48, 65].

\section{EXPERIMENTAL AIMS}

In my work I characterized hydroxypropyl cellulose (HPC) free films as first generation buccoadhesive polymers, as potential vehicles for oral drug delivery systems.

1. In the first part of my scientific work the film-forming polymer, the excipients were selected, the free film preparation and composition was optimized in order to prepare API loaded local and systemic drug delivery system for potential buccal administration:

a. preformulation studies to optimize the composition;

b. development HPC system suitable for oral use;

c. evaluation of the excipients' effects on the polymer matrix and

d. investigation of the drug-excipients-polymer matrix compatibility and interactions via:

i. tensile test measurements

ii. Positron Annihilation Lifetime Spectroscopy (PALS)

iii. Contact angle (CA) and Surface free energy (SFE) measurements 
iv. thermoanalytical studies

2. In the second part of my work I focused on the characterization of the properties of the HPC free films and on the determination of marked effects of the excipients on the system. The goals were the following:

a. to determine the thermal decomposition and degradation of products by

i. Thermogravimetric Analysis (TGA)

ii. Differential Scanning Calorimetry (DSC) and

iii. Thermogravimetric Analysis coupled with - Mass Spectrometry (TGMS)

b. to evaluate the crystalline/amorphous state of the matrix via X-Ray Powder Diffraction (XRPD).

c. to investigate the possible interactions between the polymer and the incorporated excipients by Attenuated Total Reflectance Fourier Transform Infrared Spectroscopy (ATR-FTIR).

d. to study the effect of accelerated stability test and water uptake on the polymer matrix via TGA, ATR-FTIR, XRPD and tensile test.

e. to design, develop and optimize the in vitro mucoadhesion measurement protocol, software and equipment and in vitro mucoadhesion measurements.

\section{MATERIALS AND METHODS}

\subsection{Materials}

4.1.1. Hydroxypropyl cellulose as film-forming polymer

HPC Klucel ${ }^{\circledR}$ MF and LF (Aqualon; Hercules Inc., Wilmington, U.S.A.) was used as filmforming polymer. The main differences between the two Klucel ${ }^{\circledR}$ products are in the molecular mass and the viscosity of the solution (please refer to Table 1). MF has a higher viscosity in solution and a higher molecular mass. HPC is a non-ionic, water-soluble cellulose ether and its films are appropriately flexible even without any plasticizer. HPC was chosen because it is necessary for bio/mucoadhesion, it must be physiologically inert, and the oral cavity has a water-rich environment. Accordingly, the film is not irritating, discharges without metabolism, is environmentally friendly [66-69], and can adhere to the oral mucosa by connecting to the mucin, which covers the whole mucosal membrane of the oral cavity. 
Table 1. Viscosity (at $25^{\circ} \mathrm{C}$ ) and molar mass of used HPCs; adapted from [70].

\begin{tabular}{c|c|c|c}
\hline Type & \multicolumn{3}{|c}{ w/w\% in water } \\
\hline- & $2 \%$ & $5 \%$ & $\mathrm{Mr}$ \\
$\mathrm{MF}$ & $4000-6500 \mathrm{mPas}$ & - & 850000 \\
$\mathrm{LF}$ & - & $75-105 \mathrm{mPas}$ & 95000 \\
\hline
\end{tabular}

\subsubsection{Model drugs and other excipients}

In the first part of my work the local anaesthetic Lidocaine base (Lid) (Ph. Eur., Società Italiana Medicinali Scandicci, Firenze, Italy) was chosen as the model drug in preformulation study and early characterization of the polymer system. Xylitol (Xyl) (Ph. Eur., Roquette, Lestrem, France) was used as taste improver. This excipient has many advantages: it has an anticaries effect, decreases fur formation, increases dental remineralization and the saliva flow rate, and can be used safely even by patients with diabetes mellitus (its glycaemic index is 7). Glycerol (Gyl) (Ph. Eur., Molar Chemicals Kft., Budapest, Hungary) was used as taste coverer. It is good for masking bitter tastes, it has a sweetening effect (the degree of sweetness is 0.5) and in films it can act as a plasticizer. It is safe for use and environmentally friendly [66].

In the second part of my work the following model drugs were selected in order of interest in potential local and systemic therapy and to determine their effects on the structure of the HPC films. The local anaesthetic Lidocaine hydrochloride ( $\mathrm{Lid} \mathrm{HCl})(\mathrm{Ph}$. Eur.), the selective $\alpha 1$ adrenergic receptor agonist Phenylephrine hydrochloride (Phe $\mathrm{HCl}$ ) (Ph. Eur.) and the antidiarrhoetic Loperamide hydrochloride (Lop $\mathrm{HCl})$ (Ph. Eur.). Also, the mucoadhesion of these samples were tested. Porcine gastric mucin (for biochemistry, Carl Roth $\mathrm{GmbH}+\mathrm{Co}$. $\mathrm{KG}$, Karlsruhe, Germany) was used as an adhesive layer for in vitro mucoadhesion tests.

\subsection{Methods}

\subsubsection{Preparation of free films}

The optimum polymer concentration was first established, and solutions were then made containing 2, 3, 4, 5, 10 or $15 \mathrm{w} / \mathrm{w} \%$ polymer. Overly viscous samples (the 10 and $15 \mathrm{w} / \mathrm{w} \%$ solutions of both MF and LF), which were practically gels, were rejected because they could not be poured to form films. Among the MF samples, because of the high viscosity, only the $2 \mathrm{w} / \mathrm{w} \%$ sample could be poured easily in accordance with the supplier technology package [70], while all the other samples involved difficulties. The solvent was distilled water $(\mathrm{Ph}$. Eur.). Although the 2, 3, 4 and $5 \mathrm{w} / \mathrm{w} \%$ solutions of LF could all be poured [70], the $2 \mathrm{w} / \mathrm{w} \%$ solutions were chosen for both types of Klucel $^{\circledR}$ as we wished to compare their physicochemical properties. Lid was ground in a mill (Retsch RM 100, Retsch GmbH, Haan, 
Germany) and the 100-200 $\mu \mathrm{m}$ powder fraction was incorporated into the solution. Xyl, Lid $\mathrm{HCl}$, Lop $\mathrm{HCl}$ and $\mathrm{Phe} \mathrm{HCl}$ dissolved readily and $\mathrm{Gly}$ compounded well in the water-polymer mixture.

At preformulation study, early characterization and accelerated stability study the model drug Lid and excipients were used in the same concentration $(5,10$ or $15 \mathrm{w} / \mathrm{w} \%$ of the filmforming polymer). Lid $\mathrm{HCl}$, Lop $\mathrm{HCl}, \mathrm{Phe} \mathrm{HCl}$ and the used excipients at in vitro mucoadhesion test were incorporated in the same $-5 \mathrm{w} / \mathrm{w} \%$ of the film-forming polymer concentration.

After the mixing, the solution was deaerated and samples were poured onto either a glass or a non-stick surface (teflon). When a smooth surface was needed for analysis of the surface properties of films, the polymer solution was poured onto a glass slide. However, for all other tests $5 \mathrm{~g}$ of the final mixture were cast into a plastic ring $(5 \mathrm{~cm}$ in diameter) which was on a non-stick surface and dried at room temperature $\left(25^{\circ} \mathrm{C} / 65 \% \mathrm{RH}\right)$ for $24 \mathrm{~h}$ through castingsolvent evaporation method. Films were picked up from the teflon surface and the thickness of each sample was measured with a bolt micrometer with an accuracy of $0.001 \mathrm{~mm}$ (Mitutoyo, Kawasaki, Japan). Measurements were taken at five different places on the free film and an average value calculated $(\sim 30 \mu \mathrm{m})$. Samples on glass slide were also stored at room temperature $\left(25{ }^{\circ} \mathrm{C} / 65 \% \mathrm{RH}\right)$ for a day and then all samples placed into climate chamber for 24 hours $\left(40{ }^{\circ} \mathrm{C} / 50 \% \mathrm{RH}\right)$.

\subsubsection{Preformulation studies}

\subsubsection{Tensile strength}

The tensile strength tester and the software were developed in our research group [71]. This device contains a special holder $(20 \mathrm{~mm}$ in diameter) and a hemispherical indent with a surface area of $201 \mathrm{~mm}^{2}$, and is connected to a computer through an interface. The ultimate deformation force can be measured, and the deformation process (force-time and forcedisplacement curves) can be followed. The circular holder is situated horizontally and the jowl moves vertically. The measuring range was $0-200 \mathrm{~N}$, the speed of the stamp was 20 $\mathrm{mm} / \mathrm{min}$, the sampling rate was $50 \mathrm{~Hz}$, the output was $0-5 \mathrm{~V}$, and the sensitivity was \pm 0.1 digit. The sensor comprised UNICELL force-measuring equipment, calibrated with the C9B $200 \mathrm{~N}$ cell; 10 parallel measurements were performed on each specimen.

\subsubsection{Contact angle measurements}

The SFE of a sample can provide very important information (for example adhesion, spreading coefficient, etc.) concerning the processability of the solid product. This behaviour 
should therefore be known before the formulation. Thus, measurements were carried out with a drop-contour analyser (Dataphysics OCA20, Dataphysics Instruments GmbH, Filderstadt, Germany), by a sessile drop method at room temperature $\left(25^{\circ} \mathrm{C}\right)$. The SFE of the solid was calculated by a literature method [72]. This method determines the amounts of the polar $\left(\gamma^{p}\right)$ and dispersion $\left(\gamma^{d}\right)$ constituents for the solid. The SFE of the solid can be established by measurement of the CAs of two liquids of known polarity and the solution of two equations (one for each liquid) with two parameters:

$$
(1+\cos \Theta) \gamma=\frac{4\left(\gamma_{s}^{d} \gamma_{l}^{d}\right)}{\gamma_{s}^{d}+\gamma_{l}^{d}}+\frac{4\left(\gamma_{s}^{p} \gamma_{l}^{p}\right)}{\gamma_{s}^{p}+\gamma_{l}^{p}}
$$

where $\gamma_{l}$ is the surface free tension (SFT) of the liquid, $\gamma_{s}$ is the SFE of the solid, and $\Theta$ is the solid-liquid surface CA. The extent of polarity, as a percentage, can be derived from the SFE. It is the ratio of the polar part and the total SFE. For the determination of SFE, diiodomethane and distilled water were chosen. The bilateral solid-liquid surface CA was measured with both liquids. CAs were registered at 1-s intervals for $15 \mathrm{~s}$ after drop formation. The circlefitting method was used for the CA assay. For the calculations, we used the mean CA for the fourth second of at least ten continuous measurements. SFEs and polar and disperse surface tension SFTs were calculated from the CAs associated with water (for the polar component of SFT) and diiodomethane (for the disperse component of SFT). According to $W u$ [72], SFT is $72.80 \mathrm{mN} / \mathrm{m}$ for water and $50.80 \mathrm{mN} / \mathrm{m}$ for diiodomethane. The polar part of SFT is 50.20 $\mathrm{mN} / \mathrm{m}$ and $1.80 \mathrm{mN} / \mathrm{m}$ and the disperse part of SFT is $22.60 \mathrm{mN} / \mathrm{m}$ and $49.00 \mathrm{mN} / \mathrm{m}$.

\subsubsection{Positron annihilation lifetime spectroscopy (PALS)}

The positron (Ps), the anti-particle of the electron, undergoes annihilation by combination with an electron, to generate photons with specific energy. The photons emitted have a distribution of energies between 0 and $540 \mathrm{keV}$. The Ps is a positron-electron pair derived from secondary electrons resulting from ionization of the medium.

The Ps has two spin states: the ortho-Ps (o-Ps) (triplet) and the para-Ps (p-Ps) (singlet). The lifetime of the o-Ps in vacuum is approximately $100 \mathrm{~ns}$. In a condensed medium, $75 \%$ of the Ps formed will be o-Ps and $25 \%$ will be p-Ps. There are three theoretical models to describe pick-off annihilation: the Spur, Ore and free volume models [73]. The free volume model of Ps formation stipulates that the Ps is formed only in areas with low electron density. In molecular solids, a trapped Ps is more probable than a delocalized Ps and accounts for between 20 and $70 \%$ of all electrons injected into the medium. Three experimental techniques 
have been developed for the study of positron annihilation: PALS, angular correlation of annihilation radiation and Doppler broadening spectroscopy, in all of which the time of emission, the energies and the moments of positron-electron annihilation photons are measured [73].

Free volumes were measured through determination of the lifetime of o-Ps in the samples. PALS, increasingly applied to polymers in pharmaceutical technology [74-76], makes use of the phenomenon that, if positrons are injected into a polymer, a large number of them form atom-like bound states with electrons.

The lifetime of these Ps particles depends on the size of the free volume holes. The exact dependence can be approximated by a simple model, with the assumption of spherical vacancies [77],

$$
\tau=\frac{1}{2}\left[1-\frac{R}{R+\Delta R}+\frac{1}{2 \pi} \sin \left(\frac{2 \pi R}{R+\Delta R}\right)\right]^{-1}
$$

where $\tau$ is the lifetime of the o-Ps atoms in nanoseconds, $R$ is the radius of voids in Ángströms, and $\Delta R$ is a constant. On a molecular scale, the $R$ data correspond well to the BET and neutron-scattering results. The lifetime spectrometer applied was constructed from $\mathrm{BaF}_{2}$ based detectors and standard ORTEC electronics. Spectra were collected in the 4096 channels of a multichannel analyser. The time/channel value was $\sim 10$ ps and the time resolution of the system was $\sim 210$ ps. As a positron source, carrier-free ${ }^{22} \mathrm{NaCl}$ was used, sealed between kapton foils. The activity of the source was $\sim 5-10^{5} \mathrm{~Bq}$ and only $5-8 \%$ of the positrons were annihilated in the source itself.

\subsubsection{Thermoanalytical measurements}

The thermoanalytical examinations of the materials were carried out with a Mettler-Toledo TG/DSC1 and DSC $821^{\mathrm{e}}$ instruments (Mettler Toledo, Switzerland). During the Differential Scanning Calorimetric (DSC) measurements the start temperature was $-40{ }^{\circ} \mathrm{C}$, the end temperature was $300{ }^{\circ} \mathrm{C}$ and the applied heating rate was $10^{\circ} \mathrm{C} \mathrm{min}^{-1}$. Argon atmosphere was used, and nitrogen was used as drying gas. $10 \pm 1 \mathrm{mg}$ sample was measured into aluminium pan $(40 \mu 1)$. The curves were calculated from the average of three parallel measurements and were evaluated with STARe Software.

For the TGA and the DSC measurements (with TG/DSC1 instrument coupled MS) the start temperature was $+25^{\circ} \mathrm{C}$, the end temperature was $400{ }^{\circ} \mathrm{C}$, the applied heating rate was $10^{\circ} \mathrm{C}$ $\min ^{-1}$. Nitrogen atmosphere was used and $10 \pm 1 \mathrm{mg}$ sample was measured into aluminium 
pan $(100 \mu \mathrm{l})$. The curves were calculated from the average of three parallel measurements and were evaluated with STARe Software.

Thermal characteristics of the sample mass loss were determined with a thermal gravimetric analyzer (Mettler Toledo, model TG/DSC1) coupled with a quadrupole mass spectrometer (Pfeiffer Vacuum, model Thermostar ${ }^{\mathrm{TM}}$ GSD 320), operated under $\mathrm{N}_{2}$ atmosphere (purity = 99.999\%, $70 \mathrm{ml} \mathrm{min}^{-1}$ flow rate). The connection between the TG and the mass spectrometer was done by means of a silica capillary, which was maintained at $120^{\circ} \mathrm{C}$.

\subsubsection{Characterization of interaction between excipients and polymer matrix; accelerated stability study}

\subsubsection{Accelerated stability study}

After the optimized film preparation method (please refer to subsection 4.2.1.) samples were placed into climate chamber for 4 weeks to perform accelerated stability test $\left(40^{\circ} \mathrm{C} / 75 \% \mathrm{RH}\right)$ and stored in open Petri dishes.

\subsubsection{Attenuated Total Reflectance Fourier Transform Infrared Spectroscopy}

FTIR spectra were recorded with a Bio-Rad Digilab Division FTS- 65A/896 FTIR spectrometer (Bio-Rad Digilab Division FTS-65A/869, Philadelphia, USA) between 4000 and $4001 / \mathrm{cm}, 128$ scan size, at an optical resolution of $41 / \mathrm{cm}$; operating conditions Harrick's Meridian SplitPea single reflection, diamond, ATR accessory. The spectra were analyzed with Spectragryph 1.0.2 (F. Menges Sofwareentwicklung, Germany) software. ATR-FTIR was used to investigate the chemical and physical state of the used excipients in free films and to characterise excipients-polymer interaction through bounding. Furthermore, this method was used to evaluate the water uptake in the polymer matrix.

\subsubsection{X-Ray Powder Diffraction}

XRPD analysis was performed with a Bruker D8 Advance diffractometer (Bruker AXS $\mathrm{GmbH}$, Karlsruhe, Germany) system with $\mathrm{Cu} \mathrm{K} \lambda \mathrm{I}$ radiation $(\lambda=1.5406 \AA)$. The samples were scanned at $40 \mathrm{kV}$ and $40 \mathrm{~mA}$ from $3 \mathrm{deg}$ to $40 \mathrm{deg} 2 \Theta$, at a scanning speed of $0.1 \mathrm{deg} / \mathrm{s}$ and a step size of $0.010 \mathrm{deg}$. The amorphous/crystalline state of the tested polymer system and the contingent recrystallization tendency with accelerated ageing was examined with XRPD. Besides, the analysis was used to assess the bound and/or bulk water in HPC free films. 


\subsubsection{Thermogravimetric Analysis}

Please refer to subsection 4.2.4 for TGA measurement and operation parameters. TGA was used to determine the thermal decomposition of the tested films.

\subsubsection{Tensile strength}

Please refer to subsection 4.2.2.1. for Tensile strength measurement and operation parameters. The tensile strength test was used to characterize the mechanical properties of the films and to investigate the water plasticizing effect.

\subsubsection{In vitro mucoadhesion}

\subsubsection{Equipment}

The equipment used to measure the forces of adhesion of polymer films was based on the hardness tester described in detail earlier (please refer to subsection 4.2.2.1.) The pressure is measured through the use of a load cell connected to a locally developed digital acquisition (DAQ) box. This is based on the Silicon Laboratories C8051F124 microcontroller kit. During the measurement, the DAQ box sends the acquired data to the PC side software via an RS232 connection. With this device, the start of data acquisition is controlled manually because the pressure jowl must be positioned exactly on the surface of the material. The end of the data acquisition is also controlled manually, because the breaking point of relatively elastic materials such as films cannot be detected automatically. The original embedded software of the DAQ box was modified so that it would be suitable for the measurement of forces of adhesion.

The adhesion force measurement algorithm performs the following operations:

- At the beginning of the measurement process, the pressure jowl moves downwards and presses against the polymer film until it reaches the predefined pressure (static pressure).

- It holds its position until the desired time-out (static pressure time).

- At this time, the pressure jowl begins to move upwards until the user stops the measurement process (dynamic pressure).

The two parameters which can be set up freely in the algorithm (the static pressure and the static pressure time) have to be set before the measurement via the PC side-software. The measurement range was 0-200 N, the speed of the stamp was $20 \mathrm{~mm} / \mathrm{min}$, and the output was 0-5 V. The sensor was a Unicell force-measuring instrument, calibrated with the C9B $200 \mathrm{~N}$ cell. 


\subsubsection{Sample preparation}

Please refer to subsection 4.2.1. for sample preparation. The films were stored in a climate chamber at $40{ }^{\circ} \mathrm{C} / 50 \mathrm{RH} \%$ for a week.

\subsubsection{Measurement of adhesion force}

Before in vitro adhesion strength experiments, the film thickness was measured with a bolt micrometre with an accuracy of $0.001 \mathrm{~mm}$ (Mitutoyo, Kawasaki, Japan). Mucin gel was in situ prepared before the study: $500 \mathrm{mg}$ mucin was mixed with $5 \mathrm{ml}$ distilled water. Measurement to measurement fresh mucin gel was smeared to the bottom probe. Samples were measured at room temperature $\left(20 \pm 5^{\circ} \mathrm{C}\right)$. The structure of the measurement system was as follows, from top to bottom: a stainless steel holder, a bilayer adhesive tape, a film, mucin gel and a stainless steel table. Each element was measured alone, in pairs and all together. Before the adhesion test, each film was subjected to $50 \mathrm{~N}$, which was held for $45 \mathrm{~s}$, and the holder then pulled up the film up from the mucin gel layer. At least 10 parallel measurements were performed on each specimen.

\section{RESULTS AND DISCUSSION}

\section{OPTIMIZATION AND EARLY CHARACTERIZATION OF HPC FREE FILMS}

The first step in my work was to optimize the composition, preparation and handling of the free HPC films. It is important to understand the mechanical and physicochemical properties of the polymer matrix and to determine the further steps to characterize the system. Finally, these studies helped to choose the type of film-forming material and the proposed composition.

\subsection{Tensile strength}

Films poured onto a non-stick surface were used for the tensile strength measurements. When Xyl was used in the studied samples, the tensile strength of MF films was 2.5-3.5 times higher than that of films which contained only the film-forming polymer without any excipients (Table 2).

Table 2. Tensile strength of Klucel ${ }^{\circledR}$ MF films.

\begin{tabular}{lcc}
\hline Materials & $\begin{array}{c}\text { Dry content } \\
(w / w \%)\end{array}$ & $\begin{array}{c}\text { Force } \\
(N \pm S D)\end{array}$ \\
\hline Kluce ${ }^{(\mathbb{R}} \mathrm{MF}$ & 2 & $5.25 \pm 1.92$ \\
\hline \multirow{3}{*}{$\mathrm{Xyl}$} & 5 & $14.32 \pm 1.84$ \\
& 10 & $16.85 \pm 0.86$ \\
Gly & 15 & $18.49 \pm 1.43$ \\
\hline
\end{tabular}




\begin{tabular}{lcc}
\hline Materials & $\begin{array}{c}\text { Dry content } \\
(w / w \%)\end{array}$ & $\begin{array}{c}\text { Force } \\
(N \pm S D)\end{array}$ \\
\hline & 10 & $12.06 \pm 1.97$ \\
& 15 & $12.17 \pm 0.93$ \\
\hline \multirow{3}{*}{ Xyl+Gly } & 5 & $41.48 \pm 0.47$ \\
& 10 & $43.77 \pm 1.24$ \\
Lid & 15 & $43.79 \pm 3.32$ \\
\hline \multirow{3}{*}{ Lid+Xyl } & 5 & $17.73 \pm 1.26$ \\
& 10 & $13.97 \pm 2.44$ \\
& 15 & $2.73 \pm 0.59$ \\
\hline \multirow{2}{*}{ Lid+Gly } & 5 & $15.48 \pm 1.46$ \\
& 10 & $6.49 \pm 2.77$ \\
& 15 & $3.84 \pm 1.57$ \\
\hline \multirow{2}{*}{ Lid+Xyl+Gly } & 5 & $16.05 \pm 2.82$ \\
& 10 & $7.78 \pm 1.37$ \\
& 15 & $4.72 \pm 1.10$ \\
\hline
\end{tabular}

This result correlates with the PALS finding (please refer to section 5.3.), suggesting that Xyl forms H-bonds between the neighbouring polymer chains, leading to a stronger film structure. Gly was used as taste coverer in these films, but in pharmaceutical technology and the food industry it can also serve as a plasticizer, and when it was present in the samples, the tensile strength of the films was 2-2.5 times higher than that of the empty films. However, the mechanism of this process is different from that in the case of Xyl. Gly causes the films to become more elastic, increasing the tensile strength through the decrease of brittleness. It is interesting that, when the two excipients were combined the tensile strength increased eightfold, which is a very welcome side-effect. During the processes of unpacking and sticking on the oral mucosa the free films are exposed to appreciable mechanical stresses, and hence a low tensile strength is a disadvantage. In the case of the Klucel ${ }^{\circledR}$ MF films, the addition of Lid did not change the effects of Xyl and Gly on the films. Even when both excipients were used together with Lid, the resulting tensile strength was adequate for the films (Table 2).

In contrast, when the Klucel ${ }^{\circledR} \mathrm{LF}$ film-forming polymer was investigated, we did not find any significant changes in tensile strength with variation of the excipients or their concentrations (Table 3). Only when Lid was alone in the samples was the tensile strength of films slightly higher. The films were originally weaker, they broke easily, and it was necessary to pour them several times to obtain sufficient sample for measurements. The reason for this phenomenon is that LF has shorter polymer chains than MF. The thickness of the MF or LF films was $20-40 \mu \mathrm{m}$ in every composition of the samples. 
Table 3. Tensile strength of Klucel ${ }^{\circledR}$ LF films.

\begin{tabular}{|c|c|c|}
\hline Materials & $\begin{array}{c}\text { Dry content } \\
(w / w \%)\end{array}$ & $\begin{array}{c}\text { Force } \\
(N \pm S D)\end{array}$ \\
\hline Klucel ${ }^{(R)}$ LF & 2 & $2.56 \pm 0.82$ \\
\hline \multirow{3}{*}{ Xyl } & 5 & $3.77 \pm 0.88$ \\
\hline & 10 & $2.51 \pm 0.65$ \\
\hline & 15 & $2.78 \pm 0.42$ \\
\hline \multirow{3}{*}{ Gly } & 5 & $3.32 \pm 1.14$ \\
\hline & 10 & $2.46 \pm 0.61$ \\
\hline & 15 & $2.47 \pm 0.65$ \\
\hline \multirow{3}{*}{ Xyl+Gly } & 5 & $2.42 \pm 0.83$ \\
\hline & 10 & $2.80 \pm 1.60$ \\
\hline & 15 & $2.50 \pm 1.11$ \\
\hline \multirow{3}{*}{ Lid } & 5 & $7.81 \pm 2.09$ \\
\hline & 10 & $5.53 \pm 1.92$ \\
\hline & 15 & $4.20 \pm 1.52$ \\
\hline \multirow{3}{*}{ Lid+Xyl } & 5 & $3.88 \pm 1.03$ \\
\hline & 10 & $3.46 \pm 1.34$ \\
\hline & 15 & $2.17 \pm 0.83$ \\
\hline \multirow{3}{*}{ Lid+Gly } & 5 & $1.58 \pm 0.59$ \\
\hline & 10 & $3.05 \pm 1.22$ \\
\hline & 15 & $1.22 \pm 0.41$ \\
\hline \multirow{3}{*}{ Lid+Xyl+Gly } & 5 & $3.13 \pm 1.10$ \\
\hline & 10 & $4.23 \pm 1.72$ \\
\hline & 15 & $2.87 \pm 1.12$ \\
\hline
\end{tabular}

The measured tensile strengths of the films agreed with the expectations. The shorter LF chains resulted in lower tensile strengths. The added excipients increased the tensile strength of the films, but Lid did not. However, together with the excipients, it still provided films with acceptable tensile strengths.

\subsection{Contact angle measurements (CA)}

For the CA measurements, films were poured onto a glass slide. The CA of water (deg) and the SFEs for both Klucel ${ }^{\circledR}$ MF (Table 4) and LF (Table 5) were measured. It was found that the CA of water in general was slightly higher for the MF samples.

Table 4. Surface properties of Klucel ${ }^{\circledR}$ MF films.

\begin{tabular}{|c|c|c|c|}
\hline Materials & $\begin{array}{c}\text { Dry content } \\
(w / w \%)\end{array}$ & $\begin{array}{c}\text { Contact angle of water } \\
(\text { deg } \pm S D)\end{array}$ & $\begin{array}{l}\text { Surface free energy } \\
\quad(m N / m \pm S D)\end{array}$ \\
\hline Klucel $^{(B)} \mathrm{MF}$ & 2 & $53.45 \pm 0.92$ & $58.41 \pm 0.75$ \\
\hline \multirow{3}{*}{ Xyl } & 5 & $59.90 \pm 1.66$ & $56.93 \pm 1.10$ \\
\hline & 10 & $55.94 \pm 1.61$ & $58.73 \pm 0.83$ \\
\hline & 15 & $59.60 \pm 1.13$ & $56.63 \pm 0.88$ \\
\hline \multirow{3}{*}{ Gly } & 5 & $58.56 \pm 1.07$ & $56.79 \pm 1.31$ \\
\hline & 10 & $52.38 \pm 2.26$ & $60.32 \pm 1.33$ \\
\hline & 15 & $53.43 \pm 1.33$ & $60.79 \pm 1.11$ \\
\hline
\end{tabular}




\begin{tabular}{cccc}
\hline Materials & $\begin{array}{c}\text { Dry content } \\
(w / w \%)\end{array}$ & $\begin{array}{c}\text { Contact angle of water } \\
(\text { deg } \pm S D)\end{array}$ & $\begin{array}{c}\text { Surface free energy } \\
(\mathrm{mN} / \mathrm{m} \pm \mathrm{SD})\end{array}$ \\
\hline \multirow{3}{*}{ Xyl+Gly } & 5 & $67.78 \pm 1.21$ & $52.61 \pm 1.54$ \\
& 10 & $55.30 \pm 1.95$ & $58.44 \pm 1.11$ \\
& 15 & $59.56 \pm 2.07$ & $55.43 \pm 1.30$ \\
\hline \multirow{2}{*}{ Lid } & 5 & $48.50 \pm 2.13$ & $62.65 \pm 1.44$ \\
& 10 & $55.67 \pm 0.56$ & $58.30 \pm 1.21$ \\
& 15 & $51.85 \pm 0.07$ & $60.04 \pm 1.18$ \\
\hline \multirow{2}{*}{ Lid+Xyl } & 5 & $57.07 \pm 1.30$ & $58.33 \pm 0.76$ \\
& 10 & $54.63 \pm 0.66$ & $61.02 \pm 0.43$ \\
& 15 & $54.05 \pm 0.97$ & $60.31 \pm 0.76$ \\
\hline \multirow{3}{*}{ Lid+Gly } & 5 & $57.81 \pm 0.89$ & $60.77 \pm 0.53$ \\
& 10 & $56.29 \pm 2.27$ & $58.53 \pm 1.43$ \\
& 15 & $56.73 \pm 1.10$ & $58.64 \pm 1.09$ \\
Lid+Xyl+Gly & 5 & $56.91 \pm 0.47$ & $57.61 \pm 0.60$ \\
& 10 & $55.60 \pm 1.01$ & $59.37 \pm 0.85$ \\
& 15 & $58.84 \pm 1.12$ & $57.35 \pm 0.92$ \\
\hline
\end{tabular}

Only when both excipients were added at $5 \mathrm{w} / \mathrm{w} \%$ was the CA appreciably higher and when Lid was incorporated at 5 or $15 \mathrm{w} / \mathrm{w} \%$, the CA was decreased. The SFE was stable or increased slightly; it decreased if both of the excipients were used in $5 \mathrm{w} / \mathrm{w} \%$. The CA of water increased in each LF free film: the average degree of the rise was $7-10^{\circ}$. If Lid only or both the active substance and Xyl were incorporated at $15 \mathrm{w} / \mathrm{w} \%$, the CA increased appreciably. The SFE was stable or decreased slightly in LF samples. Lower CAs were found in LF free films, and the SFE values were approximately the same. As MF has longer polymer chains, the components could enter the free holes in the polymer matrix and did not have a strong effect on the surface properties of the system. Since LF has shorter chains, the incorporated materials had fewer sites at which to enter the structure of the polymer, and Gly and Xyl present therefore exerted effects on the CA of water. These results confirmed that a macroscopically stable film structure evolved in each case. The constant SFE values indicated good bioadhesion in each case.

Table 5. Surface properties of Klucel ${ }^{\circledR}$ LF films.

\begin{tabular}{lccc}
\hline Materials & $\begin{array}{c}\text { Dry content } \\
(w / w \%)\end{array}$ & $\begin{array}{c}\text { Contact angle of water } \\
(\text { deg } \pm S D)\end{array}$ & $\begin{array}{c}\text { Surface free energy } \\
(\mathrm{mN} / \mathrm{m} \pm \mathrm{SD})\end{array}$ \\
\hline Klucel $^{(B)} \mathrm{LF}$ & 2 & $41.80 \pm 0.37$ & $64.16 \pm 0.81$ \\
\hline \multirow{3}{*}{ Xyl } & 5 & $52.22 \pm 1.87$ & $59.88 \pm 1.24$ \\
& 10 & $52.16 \pm 0.67$ & $60.50 \pm 0.62$ \\
& 15 & $49.00 \pm 1.47$ & $61.21 \pm 0.44$ \\
Gly & 5 & $51.41 \pm 3.03$ & $60.72 \pm 1.88$ \\
& 10 & $50.80 \pm 0.65$ & $61.58 \pm 0.62$ \\
\hline Xyl+Gly & 15 & $47.25 \pm 1.20$ & $63.46 \pm 1.05$ \\
\hline
\end{tabular}




\begin{tabular}{cccc}
\hline Materials & $\begin{array}{c}\text { Dry content } \\
(w / w \%)\end{array}$ & $\begin{array}{c}\text { Contact angle of water } \\
(\text { deg } \pm S D)\end{array}$ & $\begin{array}{c}\text { Surface free energy } \\
(\mathrm{mN} / \mathrm{m} \pm \mathrm{SD})\end{array}$ \\
\hline \multirow{4}{*}{ Lid } & 10 & $50.70 \pm 0.95$ & $61.44 \pm 0.55$ \\
& 15 & $49.73 \pm 0.78$ & $61.21 \pm 0.44$ \\
\hline \multirow{3}{*}{ Lid+Xyl } & 5 & $51.47 \pm 1.25$ & $63.83 \pm 0.83$ \\
& 10 & $51.98 \pm 3.55$ & $60.99 \pm 1.86$ \\
& 15 & $57.35 \pm 0.21$ & $57.04 \pm 0.58$ \\
\hline \multirow{3}{*}{ Lid+Gly } & 5 & $48.92 \pm 1.86$ & $62.16 \pm 1.09$ \\
& 10 & $53.90 \pm 2.97$ & $58.24 \pm 1.72$ \\
& 15 & $60.69 \pm 2.40$ & $54.90 \pm 1.39$ \\
Lid+Xyl+Gly & 5 & $49.60 \pm 0.42$ & $60.13 \pm 0.61$ \\
& 10 & $43.63 \pm 2.07$ & $63.63 \pm 1.21$ \\
& 15 & $47.71 \pm 1.91$ & $64.04 \pm 1.13$ \\
\hline \multirow{3}{*}{} & 10 & $46.30 \pm 0.81$ & $63.65 \pm 0.69$ \\
& 15 & $57.37 \pm 0.90$ & $57.98 \pm 0.82$ \\
& & $54.95 \pm 1.04$ & $59.72 \pm 0.74$ \\
\hline
\end{tabular}

The measured CA demonstrated that macroscopically stable film structures were achieved at all compositions. The measured constant SFEs suggest good bioadhesion.

\subsection{Positron annihilation lifetime spectroscopy (PALS)}

This technique was very important for our study because it yielded information about the free volume structure of the films. It is clearly seen in Fig. 3 that there was not much difference between the two types of Klucel ${ }^{\circledR}$ containing Xyl. As the concentration of Xyl was increased, the average size of the free volume holes decreased quite similarly in the two forms of the polymer. Gly caused different changes in the polymers. It increased the size of the free volume holes, but the effect differed in the two forms of HPC. The most relevant difference between them was that Gly caused a faster change in the LF films. This reflects the fact that LF contains shorter polymeric chains than those in MF. Thus, the plasticizer can move them apart from each other more easily than in the case of the much longer MF chains. In the end, Gly forms the same size of free volumes in both polymers. The most interesting finding from the positron data is the opposite behaviour of Xyl and Gly. Although the two molecules have very similar structures, one of them increased the free volume in HPC whereas the other one decreased it. The explanation of this may be the size difference between the molecules. Both molecules are able to destroy the original H-bonding network in the polymers, which suggests an increase in free volume. However, the longer Xyl molecules may fill the empty spaces or be able to connect the polymeric chains through H-bonding. A free volume decrease can be a serious problem in pharmaceutical technology. It might indicate that certain excipients in these films can become strongly linked to the polymer molecules, changing the properties of the product. 


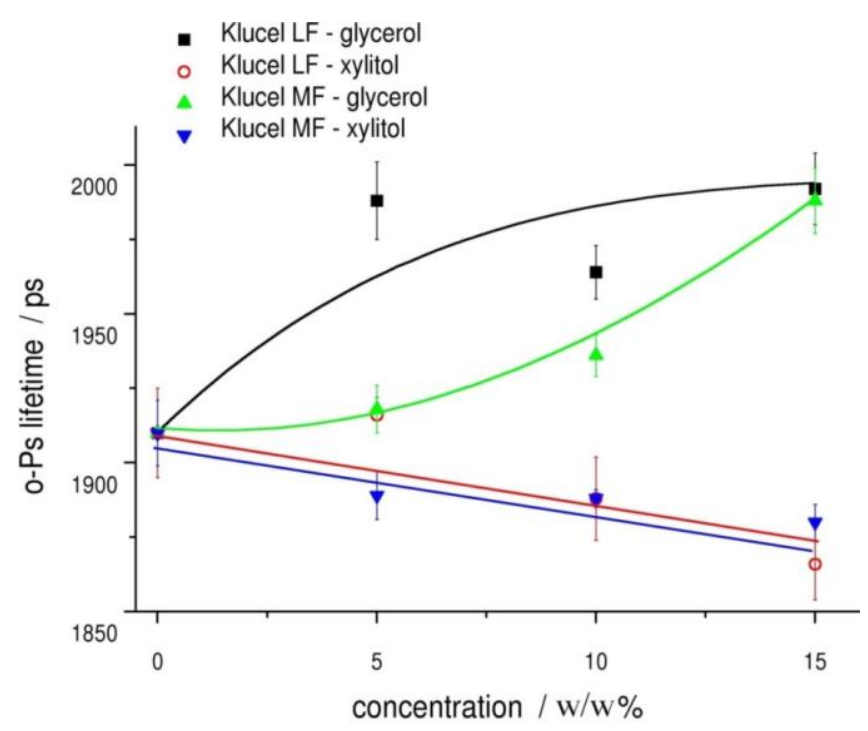

Fig. 3. The lifetime of ortho-positronium in Klucel ${ }^{\circledR}$ films. Lines are given merely to guide the eye.

PALS revealed that the shorter chains of LF reacted more easily to the addition of Gly than did those of the longer MF form. The addition of Gly increased the size of the free volume holes in the polymers, while Xyl decreased it. The cause of this difference may be the difference in the size of the molecules.

\subsection{Thermoanalytical measurements}

The thermal studies were started by studying the film-forming polymers as well as the active ingredient and excipients to be used, and the changes were monitored between 25 and $400{ }^{\circ} \mathrm{C}$ at a constant heating rate. The changes in heat flow were followed with the help of DSC curves. The thermal behaviour of the two film-forming polymers, Lid used as an active ingredient and the two excipients (Gly and Xyl) is shown in Fig. 4. A slight endothermic baseline shift can be observed in the DSC curves of the Klucel ${ }^{\circledR}$ LF and MF polymers between 40 and $100{ }^{\circ} \mathrm{C}$, which can be explained with the removal of the water content of the polymer. The heat flow curves show no difference until $340{ }^{\circ} \mathrm{C}$, and then signs of decomposition appear in both curves. The DSC curve of Gly shows a definite endothermic peak between 50 and $150{ }^{\circ} \mathrm{C}$ due to the higher water content, while at about $200{ }^{\circ} \mathrm{C}$ signs of decomposition can be observed until $300{ }^{\circ} \mathrm{C}$ (see Fig. 5). In the DSC curve of Xyl, an onset value of $92.2{ }^{\circ} \mathrm{C}$ is followed by a peak melting point at $95.6{ }^{\circ} \mathrm{C}$. The enthalpy change of the process is $217.4 \mathrm{~J} \mathrm{~g}^{-1}$. Xyl has much greater thermal stability as the baseline change and the decomposition process start only at about $280{ }^{\circ} \mathrm{C}$ and end over $380{ }^{\circ} \mathrm{C}$ (see Fig. 5). Lid, which is used as an active ingredient, has a lower melting point than the excipients because the onset value is $67.2^{\circ} \mathrm{C}$ and the peak of the melting point appears at $68.6^{\circ} \mathrm{C}$. The enthalpy 
change of the process is $59.1 \mathrm{~J} \mathrm{~g}^{-1}$. The baseline change appears over $180{ }^{\circ} \mathrm{C}$, and then the decomposition process is accelerated over $200{ }^{\circ} \mathrm{C}$ and finishes at about $330{ }^{\circ} \mathrm{C}$.

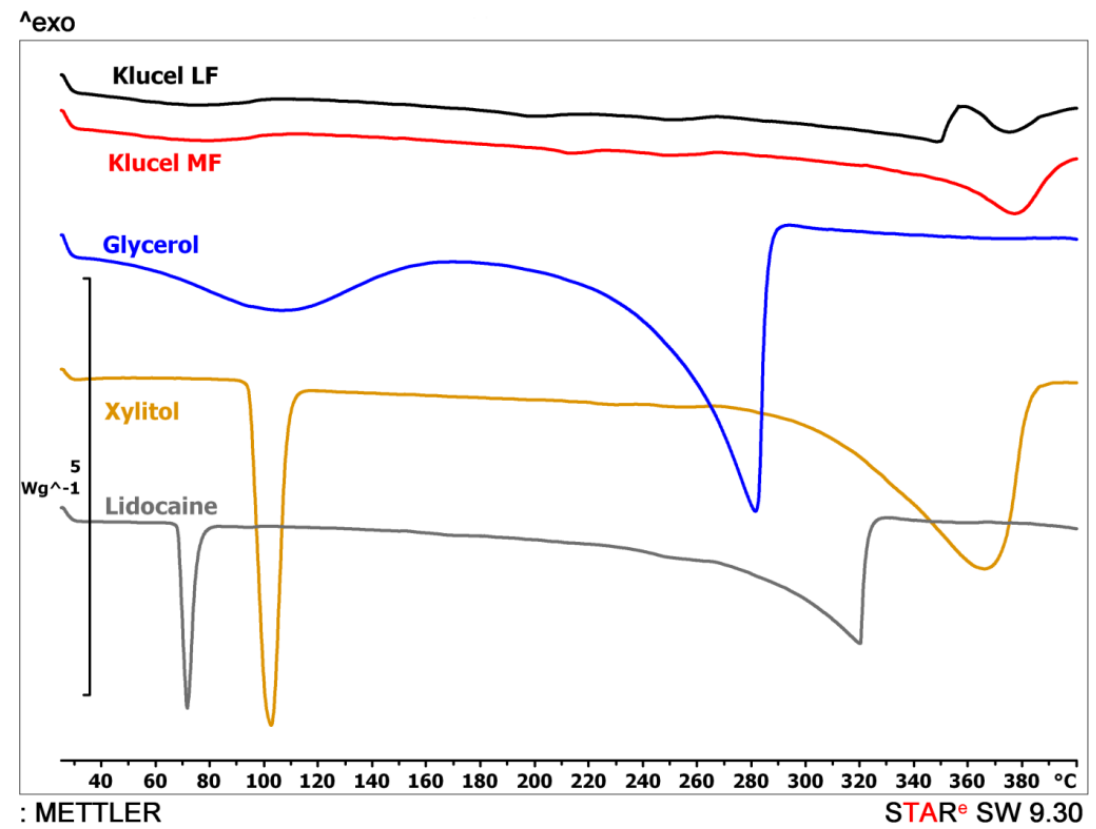

Fig. 4 Thermal properties of Klucel $^{\circledR}$ film-forming materials, active ingredient and excipients as shown by the DSC curves.

The TG curves of the same materials in Fig. 5 show that the two different film-forming materials are thermally stable, a mass loss of only $1-1.5 \%$ can be detected until $100{ }^{\circ} \mathrm{C}$, the decomposition process starts over $300{ }^{\circ} \mathrm{C}$, and mass loss is $85 \%$ for Klucel ${ }^{\circledR} \mathrm{LF}$ and $87 \%$ for Kluce ${ }^{\circledR} \mathrm{MF}$ until $400{ }^{\circ} \mathrm{C}$. However, the rate of the decomposition process is different, and it is faster for the LF product and slower for the MF product. It can be stated that the mass loss of $1.0-1.5 \%$ observed at the beginning of heating can be explained by the removal of water from the film, and then further mass loss starts only at about $300{ }^{\circ} \mathrm{C}$. The thermal behaviour of the two polymers differs significantly between 340 and $400{ }^{\circ} \mathrm{C}$, which can be explained by the different chain lengths of the two polymers. The Klucel ${ }^{\circledR}$ MF product with a longer chain has greater thermal stability, and probably the more stable structure is broken only at higher temperatures. The thermal behaviour of the excipients as shown by their TG curves (see Fig. 5) can be described well and it confirms the information obtained from the DSC curves. Although both excipients were entirely decomposed by the end of the examination, considerable differences can be observed in their behaviour. Xyl proved to be the most stable as the decomposition process actually starts only over $300{ }^{\circ} \mathrm{C}$. Ensuing from its material properties, Gly first loses its water content at the beginning of heating, then its decomposition starts over $180{ }^{\circ} \mathrm{C}$ and finishes at $290{ }^{\circ} \mathrm{C}$. The thermal behaviour of the active ingredient is 
somewhere between those of the two excipients, as in the case of Lid the mass loss curve reveals that decomposition starts at about $180-200{ }^{\circ} \mathrm{C}$.

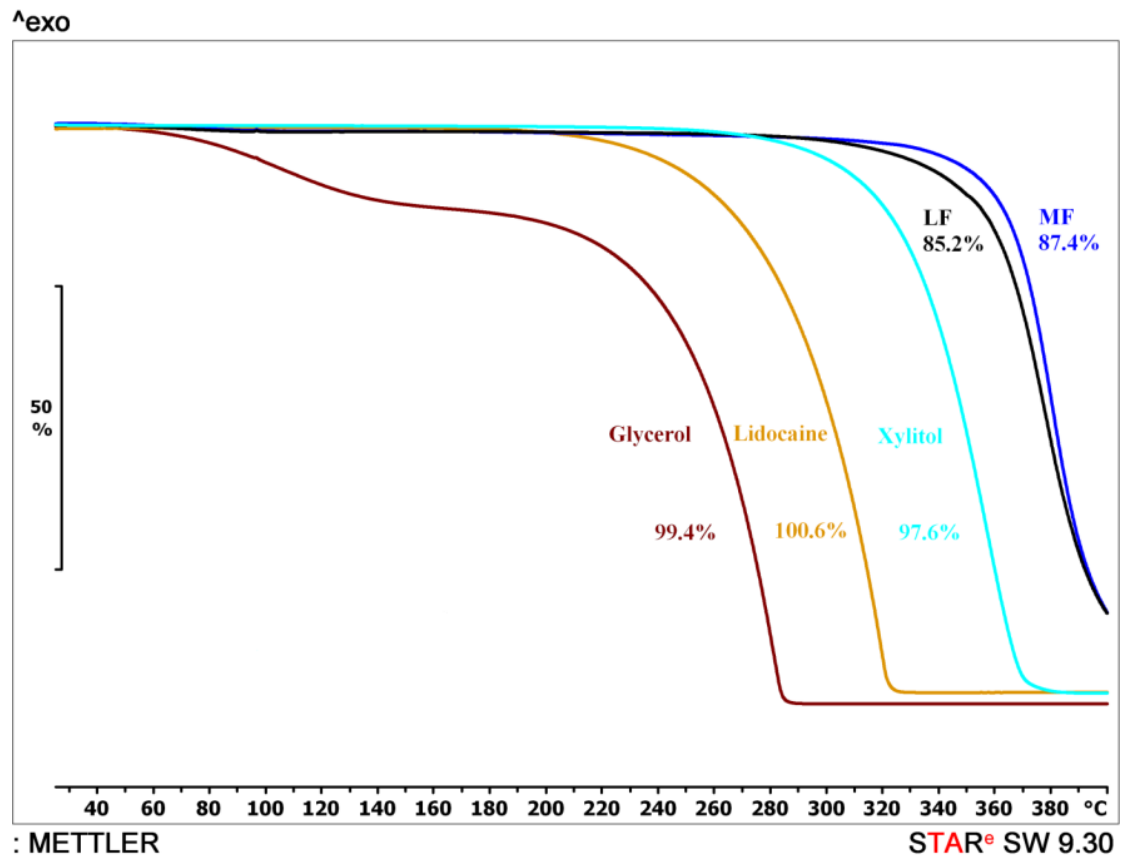

Fig. 5 Thermal properties of Klucel ${ }^{\circledR}$ film-forming materials, active ingredient and excipients as shown by the TG curves.

After studying and learning about the thermal behaviour of the film-forming polymers and the excipients to be used, we wished to study the behaviour of the free films which were prepared from them and contained both excipient and active ingredient. As regards Klucel ${ }^{\circledR}$ LF and MF products, differences in thermal stability were observed only over $300{ }^{\circ} \mathrm{C}$, so they behaved in the same way when applied under the conditions of the oral mucosa. Klucel ${ }^{\circledR}$ LF products were chosen for early characterization via the examination of their thermal stability. The thermal behaviour of Klucel ${ }^{\circledR}$ LF films containing both Xyl and Gly is illustrated in Fig 6. Gly and Xyl were present in the films in the same concentrations (at $0-5-10-15 \mathrm{w} / \mathrm{w} \%$ of the polymer). The shape of the TG curves shows that although the decomposition process changes with the increase in the concentration of the excipients, when heated up to $400{ }^{\circ} \mathrm{C}$ mass loss does not differ significantly compared to Klucel ${ }^{\circledR}$ LF films without excipients. At the beginning of heat treatment, mass loss can be explained by the removal of the water content in each case and it is proportional to the concentration of Gly. However, over 180$200{ }^{\circ} \mathrm{C}$, the decomposition processes start, the TG curves open up more, which is probably due to the fact that the molecules built-in among the polymer chains loosen the structure, which in turn is decomposed more easily. 


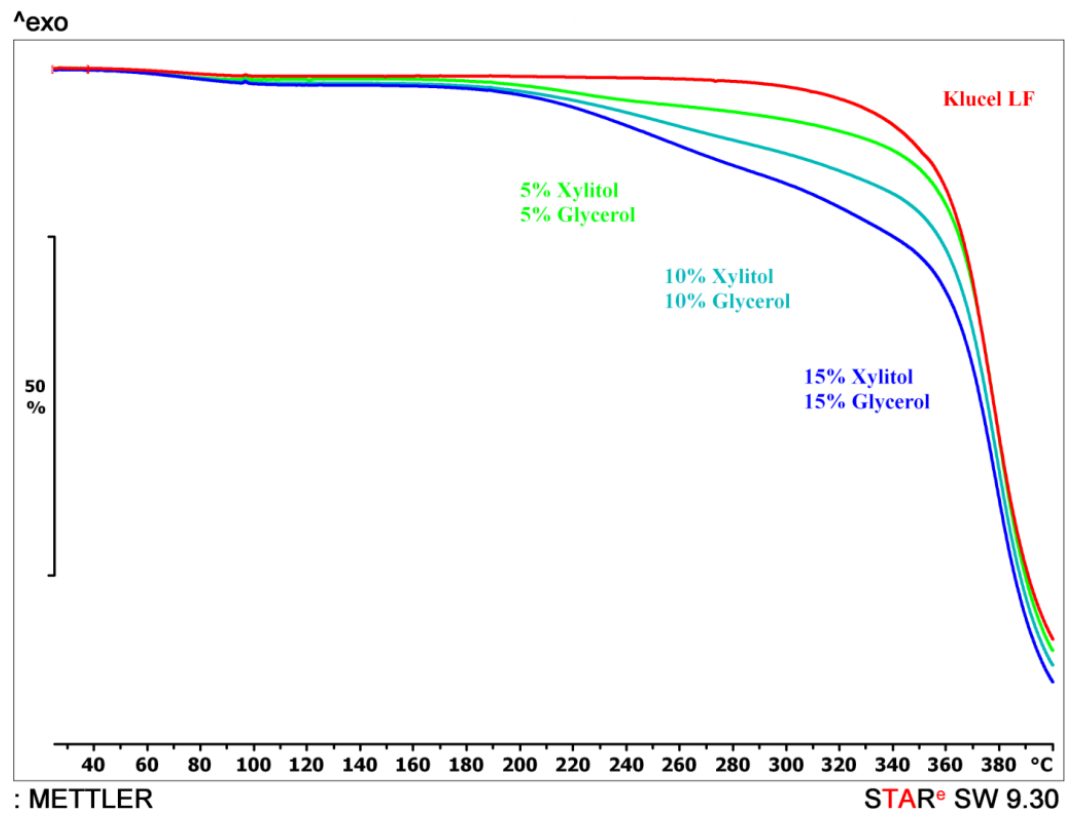

Fig. 6 Thermal properties of films made from Klucel ${ }^{\circledR}$ LF film-forming material containing $X y l$ and Gly as shown by the TG curves.

Then, we studied the thermal behaviour of the drug-containing film. In Fig. 7, the thermal behaviour of Klucel ${ }^{\circledR}$ LF films containing Lid as well Xyl and Gly is presented. The effect of the ratio (quantity) of the components on the shape of the TG curves as well as on the quantity and disproportion of the arising mass loss can be seen clearly. It is remarkable that while a smaller mass loss was observed for the 5 and $10 \%$ films, the mass loss of the loosening effect of Gly and Lid on the polymer structure.

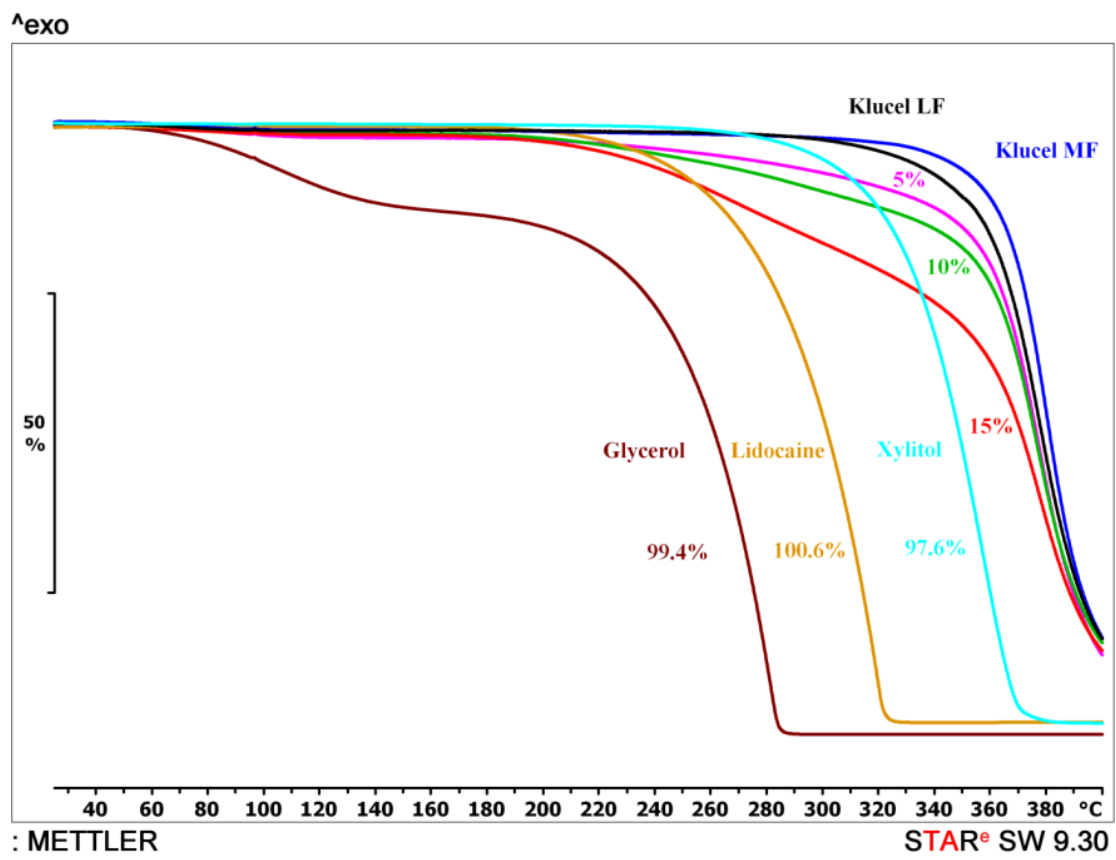

Fig. 7 Thermal properties of films made from Klucel ${ }^{\circledR}$ LF film-forming material containing Lid as well as Xyl and Gly as shown by the TG curves. 
The concentrations of the active ingredient and the excipients in the films were always the same (0-5-10-15\% w/w of the film-forming polymer). The shape of the TG curves is similar to the one shown by films without Lid, but they can be compared really well if the TG curves of films with Lid (continuous line) and without Lid (broken line) are plotted together (see Fig. 8). The temperature range $\left(200-400{ }^{\circ} \mathrm{C}\right)$ of the greatest importance with respect to the phenomenon is focused on here. The shape of the curves shows that in the case of the $5 \%$ and $10 \%$ systems, the presence of Lid practically did not result in a significant difference in thermal stability, while in the concentration of $15 \%$, the films which contained Lid were decomposed more easily, which is due to the greater quantity of the materials used and to the ensuing looser structure. This can probably be explained by the fact that the plasticizer, when used in a lower concentration, can be incorporated in the film structure, which we have already confirmed in the case of Metolose free films [78-80]. However, when it is applied in higher concentrations, the stability of the film structure deteriorates, which is illustrated well by the presented curves, in which $15 \%$ of other components were used besides the polymer. We also performed the TG-MS examination of all the films, we analysed the evolved gases with a mass spectrograph coupled with the TG in order to obtain information about the stability of the film structure.

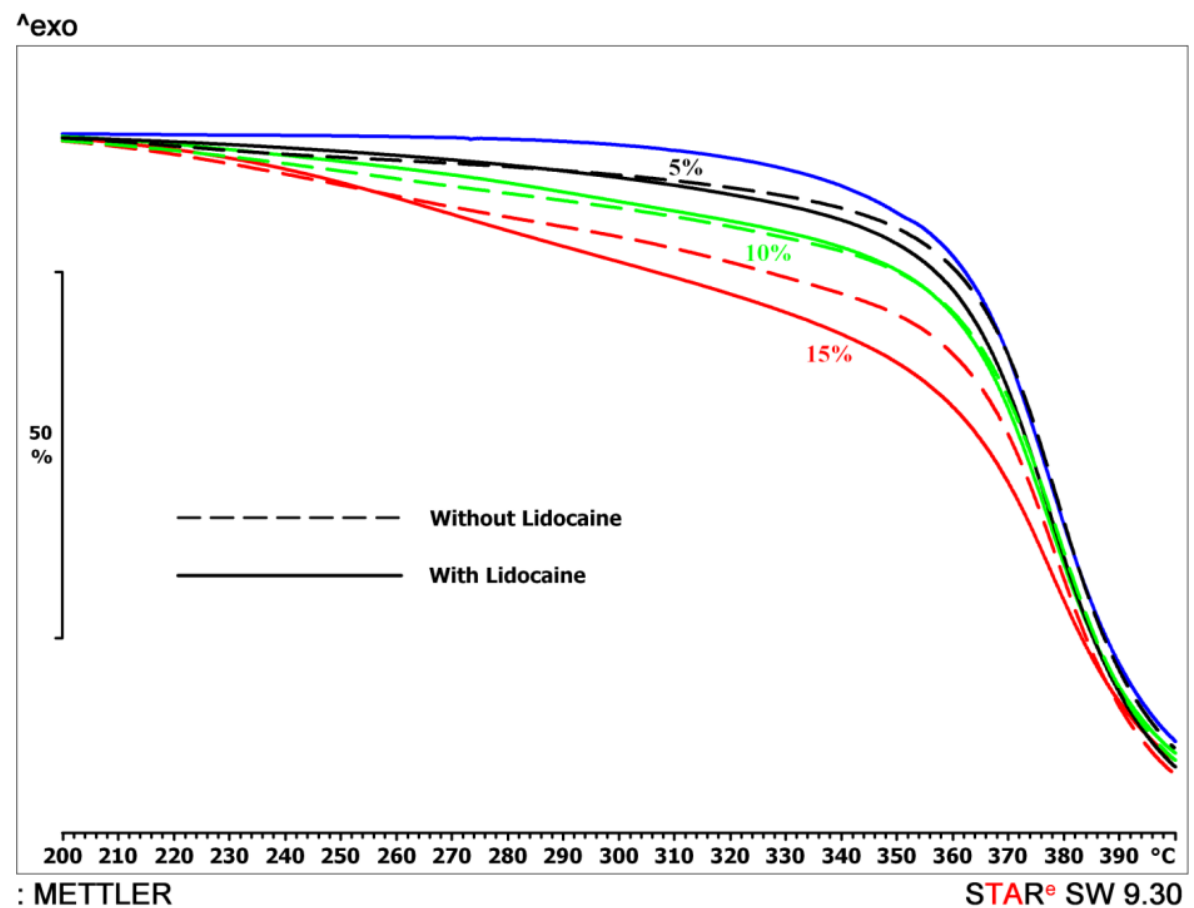

Fig. 8 Comparison of the thermal properties of Xyl and Gly containing Klucel ${ }^{\circledR}$ LF films with and without Lid between 200 and $400{ }^{\circ} \mathrm{C}$ as shown by the TG curves. 
Among the several measurements, the data obtained with films containing 15\% Gly are presented in Fig. 9. Although no change can be observed for the $\mathrm{m} / \mathrm{z}=18$ fragment on axis "Y" with a logarithmic scale, in the case of an absolute scale water removal can be seen between both $40-150$ and $350-400{ }^{\circ} \mathrm{C}$, and with a start of decomposition, a concentration increase was experienced with the start of decomposition for further fragments $(\mathrm{m} / \mathrm{z}=41,42$, $43,44,45$ and 58), starting practically at the same time. The peak intensity of the fragments depicted decreased in the following order: $\mathrm{m} / \mathrm{z}=44-43-42-41-58-45$. All these indicate that carbon dioxide is formed in the greatest concentration, which is confirmed by the increase of $\mathrm{m} / \mathrm{z}=44 . \mathrm{m} / \mathrm{z}=43,45$ may indicate the development of acetic acid and/or isopropyl alcohol, while $\mathrm{m} / \mathrm{z}=43,58$ may be indicative of the formation of acetone. During the study of the bioadhesive films, it was found that the thermal behaviour of Klucel ${ }^{\circledR}$ LF and Klucel ${ }^{\circledR} \mathrm{MF}$ film-forming polymers was different from each other only in the temperature range of 340$400{ }^{\circ} \mathrm{C}$, which is due to the difference in the chain length of the polymer molecule. At the administration temperature $\left(36\right.$ to $37^{\circ} \mathrm{C}$ ) only water loss was detected (below $100{ }^{\circ} \mathrm{C}$ in $\mathrm{TG}$ measurements). Among the active ingredients and excipients used, Gly proved to be the least stable thermally, while Xyl was the most stable. The shape of the TG curves shows that the decomposition process changes with the increase of the concentration of the excipients. In the case of Gly, the decomposition processes start over $180-200{ }^{\circ} \mathrm{C}$, and the TG curves open up more, which is probably due to the fact that the molecules built-in among the polymer chains loosen the structure, which in turn is decomposed more easily.

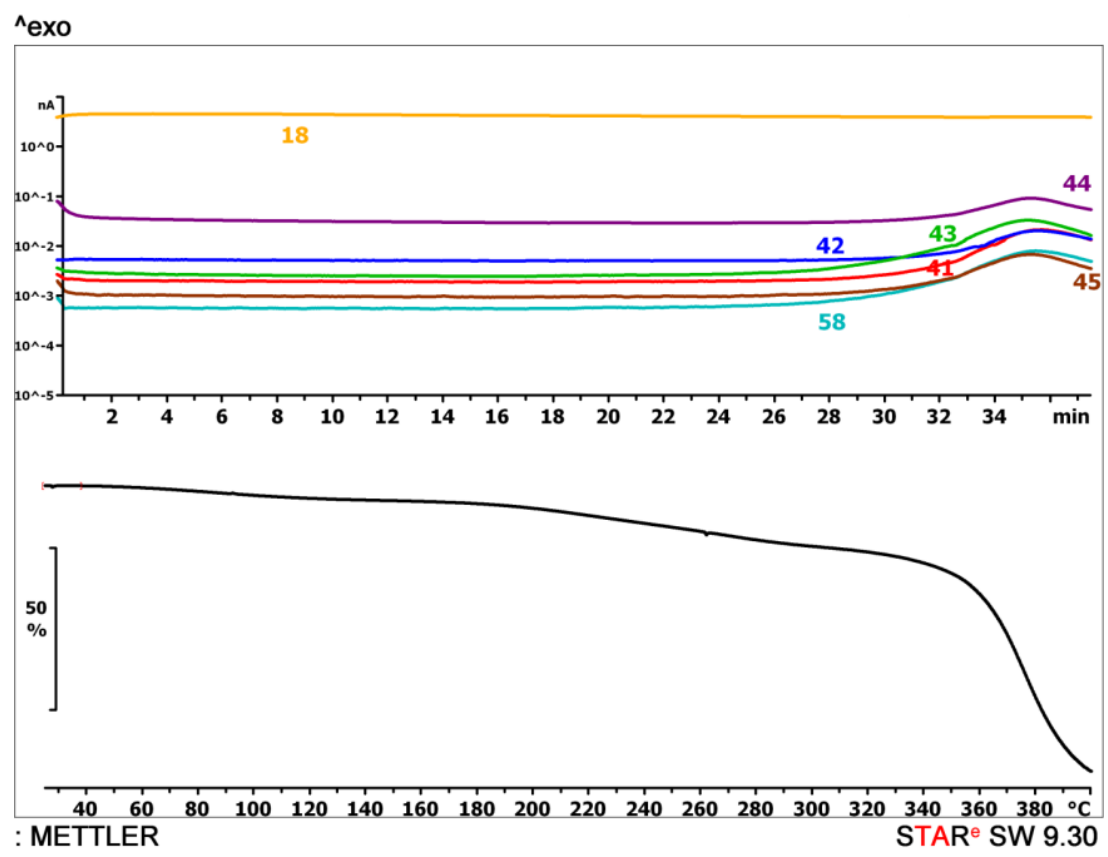

Fig. 9 Thermal properties of films made from Kluce ${ }^{\circledR}$ LF film-forming material containing $15 \%$ Gly as shown by the TG-MS curves. 
The role of the active ingredient Lid in thermal stability was also examined, and it was found that the shape of the curves shows that in the case of the 5 and $10 \%$ systems, the presence of Lid did not result in a significant difference in thermal stability, while in the concentration of $15 \%$ the films which contained Lid were decomposed more easily, which is due to the greater quantity of the materials used and to the ensuing looser structure.

The TG-MS examinations revealed that with the start of decomposition, a concentration increase was seen in the case of $\mathrm{m} / \mathrm{z}=41,42,43,44,45$ and 58 fragments, starting practically at the same time. The peak intensity of the fragments in the highest concentration may indicate the formation of carbon dioxide and also the development of acetic acid, isopropyl alcohol and acetone.

As a summary on early characterization and preformulation study, it can be stated that the thermal stability of free films prepared from Klucel ${ }^{\circledR}$ LF polymer is appropriate, and in the case of the 5 and $10 \%$ systems, the presence of Lid did not result in a significant difference in thermal stability. The results not only help to choose the formulation conditions but also provide useful information concerning the packaging and storage conditions as well as the stability of the final product. With regard to the good workability of the free films and the pharmaceutical technology requirements, Klucel ${ }^{\circledR} \mathrm{MF}$ was chosen as film-forming polymer. Lid and the excipients Gly and Xyl should be used in a concentration of 5 w/w\% ${ }^{1}$. Both Gly and Xyl had marked effects on the tested polymers. In this work these effects were welcomed and useful, but the excipients can cause disadvantageous effects in drug delivery systems, which must therefore be tested.

\section{Charaterization OF HPC FReE FiLMS}

After the optimization of composition, preparation, handling and having chosen the type of film-forming material I focused on the characterization of the system: incorporation of excipients, their effects on the polymer matrix, stability of the HPC free films and in vitro mucoadhesion studies were evaluated. These studies help the deeper understanding of the polymer matrix and the detection of changes in physicochemical and mechanical properties of the tested HPC free films.

\footnotetext{
${ }^{1}$ In accelerated stability study the excipients were used at 5-10-15 w/w\% because I would like to investigate their effects on the polymer matrix in higher concentrations also.
} 


\subsection{Interaction between excipients and the polymer matrix, accelerated stability study}

\subsubsection{Attenuated Total Reflectance Fourier Transform Infrared Spectroscopy}

In case of Gly containing HPC films the following the results below were detected and FTIR spectra were summarised in Fig 10A. The relative intensities of the theoretical spectra may only be used with concerns, since the concentrated Gly exhibits very high absorbance values, and therefore has higher weight in the theoretical spectra than it actually has in reality.

Characteristic peak of $\mathrm{Klucel}^{\circledR} \mathrm{MF}$ at $483,21 / \mathrm{cm}$ has a slight right shift to $4801 / \mathrm{cm}$, concurrently the characteristic peaks of Gly at 567 and $6691 / \mathrm{cm}$ are disappearing (please refer to Fig. 10A). Other less intensive characteristic peaks of Gly are also disappearing in the spectrum of the film. The peak at $9931 / \mathrm{cm}$ may be identified as a mild elevation of the shoulder but less intensively as was expected according to the theoretical spectra. The next characteristic signal of Gly is a wide peak which has a maximum between $852-8651 / \mathrm{cm}$. The appearance of this peak is clearly visible on the spectra of Klucel ${ }^{\circledR}$ MF-Gly (MFG) films but the effect is similar to that found in some cases of Klucel ${ }^{\circledR}$ MF-Xyl MFX films -summarised in Fig. 10-, the 5 and $10 \%$ Gly containing films exhibit the same signal intensity and only the $15 \%$ Gly containing film exhibits higher absorbance.

The characteristic peak of Gly at $9241 / \mathrm{cm}$ exhibits a left shift to $9291 / \mathrm{cm}$. The intensity of the peak at $5 \%$ film is almost the same as the pure Klucel ${ }^{\circledR} \mathrm{MF}$ film, the $10 \%$ film shows a slight elevation, and a considerably higher elevation could be detected for the $15 \%$ film. The same for the peak at $9931 / \mathrm{cm}$.

The peak of Gly at 1041 1/cm overlaps with the peak of Klucel ${ }^{\circledR}$ MF at 1049 1/cm and the common peak is at $10461 / \mathrm{cm}$. The position of the peak exhibits slight right shift with the elevation of the Gly content. The peaks between $990-1060$ 1/cm suggest the $\mathrm{C}-\mathrm{OH}$ stretching vibration of HPC. The peaks at 1111 and $11161 / \mathrm{cm}$ for Gly and Klucel ${ }^{\circledR}$ MF respectively are overlapping, the increment of Gly content may be visible again as slight right shift of the peak position. The presence of the peaks at 1416 and 1457 may be detected only in the $15 \%$ Gly containing sample with a slight $21 / \mathrm{cm}$ right shift in their position which is clearly seen in Fig. 10A and suggest the bending vibration of $-\mathrm{CH}_{2}$ (between 1405 and $14651 / \mathrm{cm}$ ). The $\mathrm{O}-\mathrm{H}$ starching region with $\mathrm{O}-\mathrm{H}$ bridges is clearly seen between $3500-24001 / \mathrm{cm}$. The peaks at 2883 and $29401 / \mathrm{cm}$ are almost undetectable in the MFG films only in the case of $15 \%$ Gly containing peak is there a minor elevation. The increment in the $\mathrm{OH}$ signal at $34001 / \mathrm{cm}$ is only detectable in the case of $15 \%$ Gly containing films. The change in peak shapes is a result 
of the different degree of hydrogen bonds. The Gly bonded to the polymer structure via hydrogen bonds which are characteristic from 3200 to $35501 / \mathrm{cm}$.

The results suggest that the incorporation of Gly into the texture of the HPC film is almost complete even in the case of the $15 \%$ Gly content. The $-\mathrm{OH}$ groups of the polymer and the excipient forms hydrogen bonds. Under the stability it was found that MFG samples linked water during storage because of the hygroscopic behaviour of Gly. These results confirm that Gly affects the water sorption behaviour of the polymer system.

The results of the spectral evaluation of $\mathrm{Klucel}^{\circledR} \mathrm{MF}-\mathrm{Xyl}$ (MFX) samples are listed below (please refer to Fig. 10B). To eliminate the intensity differences due to different film thicknesses, the spectral intensities were normalized to the peak at $9391 / \mathrm{cm}$ in the Klucel ${ }^{\circledR}$ MF spectrum where the Xyl exhibits no/minimal absorption. Xyl has several characteristic peaks in the fingerprint region of the FT-IR spectrum, and three of them may be identified in the spectra of Xyl containing films. The peaks at 520 and $5671 / \mathrm{cm}$ exhibits a slight left shift to 522 and $5731 / \mathrm{cm}$. Xyl has a characteristic peak at $7461 / \mathrm{cm}$ where the Klucel ${ }^{\circledR}$ MF has only minimal absorption. The size of the peak is not so big as was expected on the basis of the theoretical spectra, but it is in accordance with the Xyl concentration in the film. This peak exhibits no shift. There is a double peak of Xyl at 856 and $8851 / \mathrm{cm}$, respectively. The first peak slightly overlaps with the peak of Klucel ${ }^{\circledR} \mathrm{MF}$ at $8401 / \mathrm{cm}$, but in less amount as may be expected on the basis of theoretical spectra. The height of the signal is again in accordance with the Xyl concentration but it is almost unidentifiable in the 5\% Xyl containing film, the signal height in $10 \%$ film is approximately equals with the height of the signal in the $5 \%$ theoretical spectrum, but the signal height is the same in the $15 \%$ theoretical and measured spectrum. The second peak at $8851 / \mathrm{cm}$ exhibits the same phenomenon, and furthermore, the $15 \%$ peak exhibits a slight right shift to $8831 / \mathrm{cm}$. In smaller concentrations, there is no change in the position of this peak. The third peak of this group at $9131 / \mathrm{cm}$ is very small and may be hardly identified in the film spectra.

The Xyl has a characteristic peak at 1009 1/cm which peak slightly overlaps with a wide peak in the Klucel ${ }^{\circledR}$ MF spectrum at $10481 / \mathrm{cm}$ and appears as a shoulder and exhibits a left shift to $10151 / \mathrm{cm}$ in the spectra of the Xyl containing films. These results suggest the $-\mathrm{CH}_{2}$ bending vibration between 990 and 1060 1/cm. The triple peak at 1065, 1091 and $11201 / \mathrm{cm}$ in the Xyl may be identified only in the case of the $15 \%$ Xyl containing film, but exhibits a slight right shift to 1063,1085 and $11111 / \mathrm{cm}$. 

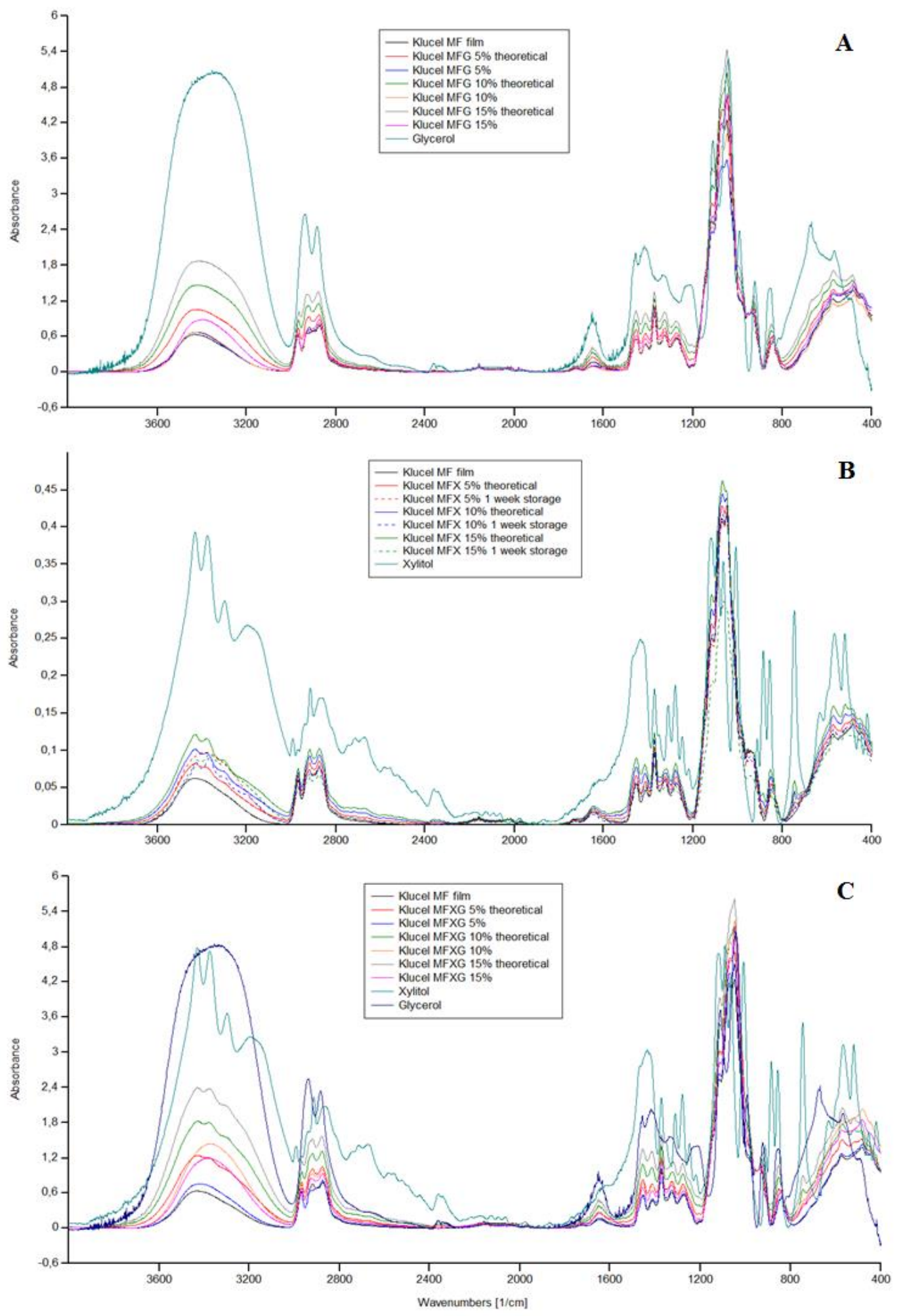

Fig. 10 Summarizes the characteristic peaks of tested samples and raw materials. In $10 \mathrm{~A}$ the fresh MFG films are compared to theoretical spectra and the same was seen in $\mathbf{1 0 C}$ for MFXG samples. In 10B the theoretical spectra are compared to MFX samples stored for a week. 
The next characteristic peak of Xyl which may be identified in the spectra of the films is at $12801 / \mathrm{cm}$, it exhibits no shift, but the 5 and $10 \%$ Xyl containing films have the same peak intensity and only the $15 \% \mathrm{Xyl}$ contacting film shows bigger one. It is clearly seen in Fig. $10 B$ that both Xyl and Klucel ${ }^{\circledR}$ MF have peaks at $13721 / \mathrm{cm}$, and there is no shift for this peak. The O-H starching region with $\mathrm{O}-\mathrm{H}$ bridges were detected from 3500 to $2400 \mathrm{1} / \mathrm{cm}$. There is a characteristic peak of Xyl at 2914 1/cm which appears on the spectra of the films but not in a concentration related way, since there is a small but less characteristic peak in the spectrum of the Klucel ${ }^{\circledR}$ MF film, which exhibits changing intensity during multiple measurements of the raw material. The peak of Xyl at $29921 / \mathrm{cm}$ cannot be identified clearly in the spectrum. There are multiple characteristic peaks of Xyl in the 3000-3600 1/cm region. These characteristic peaks are not detectable in the 5\% Xyl containing film, but are clearly visible in 10 and 15\% Xyl containing films (Fig. 10B). Amongst these peaks the peak at 3298 $1 / \mathrm{cm}$ shows no shift, but the other two peaks at 3375 and $34311 / \mathrm{cm}$ exhibits right shift to 3362 and $34231 / \mathrm{cm}$ respectively. These changes in the shape of peaks suggest the bonding between Xyl and HPC via hydrogen bonds is similar to Gly plasticized samples which result is confirmed by detection of intermolecular hydrogen bonds via peaks from 3200 to 3550 $1 / \mathrm{cm}$.

The above mentioned phenomena suggest that the Xyl is completely incorporated into the HPC film in 5\%, but the incorporation is not complete for the 10 and $15 \%$ samples. Nevertheless, even in the case of these samples strong interaction may be identified due to hydrogen bonds between the non-incorporated fraction of Xyl and the HPC film.

From the aspect of stability it was found that during storage the Xyl containing films bond a considerably high amount of water, which helps the further incorporation of Xyl into the texture of the HPC film, which describes the disappearance of some of the above mentioned characteristic peaks especially in the $\mathrm{OH}$ stretching region (summarised in Fig. 10B). This result confirms that Xyl can act as a softening agent, water supports this behaviour and Xyl helps water sorption and linking to the polymer.

The results of Klucel ${ }^{\circledR}-\mathrm{Xyl}-\mathrm{Gly}(\mathrm{MFXG})$ samples are summarised below and please refer to Fig. 10C. To eliminate the differences from the film thicknesses the spectra were normalized to the peak at $9431 / \mathrm{cm}$ where both Gly and Xyl have minimal absorption.

The peaks of Xyl at 520, 566 and $6331 / \mathrm{cm}$ cannot be identified in the spectra of MFXG films. The peak at $7471 / \mathrm{cm}$ may be identified in the $10 \%$ MFXG film as a slight elevation but in a strongly left shifted position at around $7591 / \mathrm{cm}$. Similarly, only the middle peak of 
the peak triplet at 856,885 and $9131 / \mathrm{cm}$ may be clearly identified and only in $10 \%$ MFXG spectrum, but right shifted to $8801 / \mathrm{cm}$ (in Fig. 10C).

The $\mathrm{C}-\mathrm{OH}$ stretching vibration was detected in MFXG samples also. The peak at $1009 \mathrm{1} / \mathrm{cm}$ may be identified as a new shoulder both in the signals of the 10 and $15 \%$ MFXG films, left shifted to approx. $10171 / \mathrm{cm}$. The strength of elevation is bigger at the $10 \%$ film. None of the peaks from the peak triplet at 1065, 1090 and 1120 1/cm may be clearly identified in the spectra of MFXG films. Other characteristic peaks, at 2914 and 2992 1/cm also cannot be identified in the MFXG spectra, and similarly there are no sign of the peak triplet at 3298, 3373 and 3431 1/cm which belongs to $\mathrm{O}-\mathrm{H}$ stretching region and show the intermolecular hydrogen bonding of the matrix. The signal strength order is $5 \%<15 \%<10 \%$ films as shown in Fig. 10C. The $\mathrm{O}-\mathrm{H}$ bridges are clearly seen on this region and the changes in peak shape suggest the formation of hydrogen bonds.

Amongst the characteristic peaks of Gly the signal at 668 1/cm appears right shifted at 664 $1 / \mathrm{cm}$. The peaks at 923 and $9921 / \mathrm{cm}$ cannot be identified obviously in the MFXG spectra. The peak at $101411 / \mathrm{cm}$ is overlapping with the peak of the Klucel ${ }^{\circledR} \mathrm{MF}$ at $10481 / \mathrm{cm}$. The increment of Gly content in order of the 5, 10 and 15\% films may be determined only from the ratio of the peaks at 1047 and 1072 1/cm. The signals of Gly at 2883 and 2938 1/cm are both right shifted 2878 and $29271 / \mathrm{cm}$ and are strongly overlapped with the Klucel ${ }^{\circledR} \mathrm{MF}$ signals. The increase of the signal intensity of the wide $\mathrm{OH}$ peak in the $3000-36001 / \mathrm{cm}$ region is observable but the signal intensity is the biggest in the case of the $10 \%$ film (summarized in Fig. 10C).

Marks of intermolecular hydrogen bonds were found in all types of samples. Peaks between $3200-35501 / \mathrm{cm}$ suggest that the used excipients incorporated into the polymer matrix and confirmed the hydrogen bonds between the $-\mathrm{OH}$ groups of the HPC and used excipients. Xyl only in $5 \mathrm{w} / \mathrm{w} \%$ incorporated completely into the HPC film meanwhile, in case of Gly the same was found in all concentrations. FTIR analysis revealed the so-called 'synergic' effect of Gly, which helps the bonding of Xyl into the polymer matrix. $10 \mathrm{w} / \mathrm{w} \%$ of Gly is effective for entering Xyl into the polymer chains. FTIR was found a proper and unique technique to detect water sorption and migration in the polymer matrix. Both Xyl and Gly facilitated the water sorption into the tested systems. Xyl is commonly not used as a plasticizer in the field of pharmacy, but our results suggest that Xyl also can act as a plasticizer in any formulation. This result initiates a novel application of Xyl in pharmaceutical technology and the excipient is welcomed in manufacturing, due to both financial and health-care considerations. Furthermore, if Gly and Xyl incorporated into HPC films, less water sorption and migration 
were found. It confirms that the most stable film structure is formed if both excipients are used together which suggests the so-called 'synergic' effect of the two excipients. This result is essential to optimize the composition of a new drug delivery system and demonstrate the importance of design and test different compositions to find the most stable one.

\subsubsection{X-Ray Powder Diffraction}

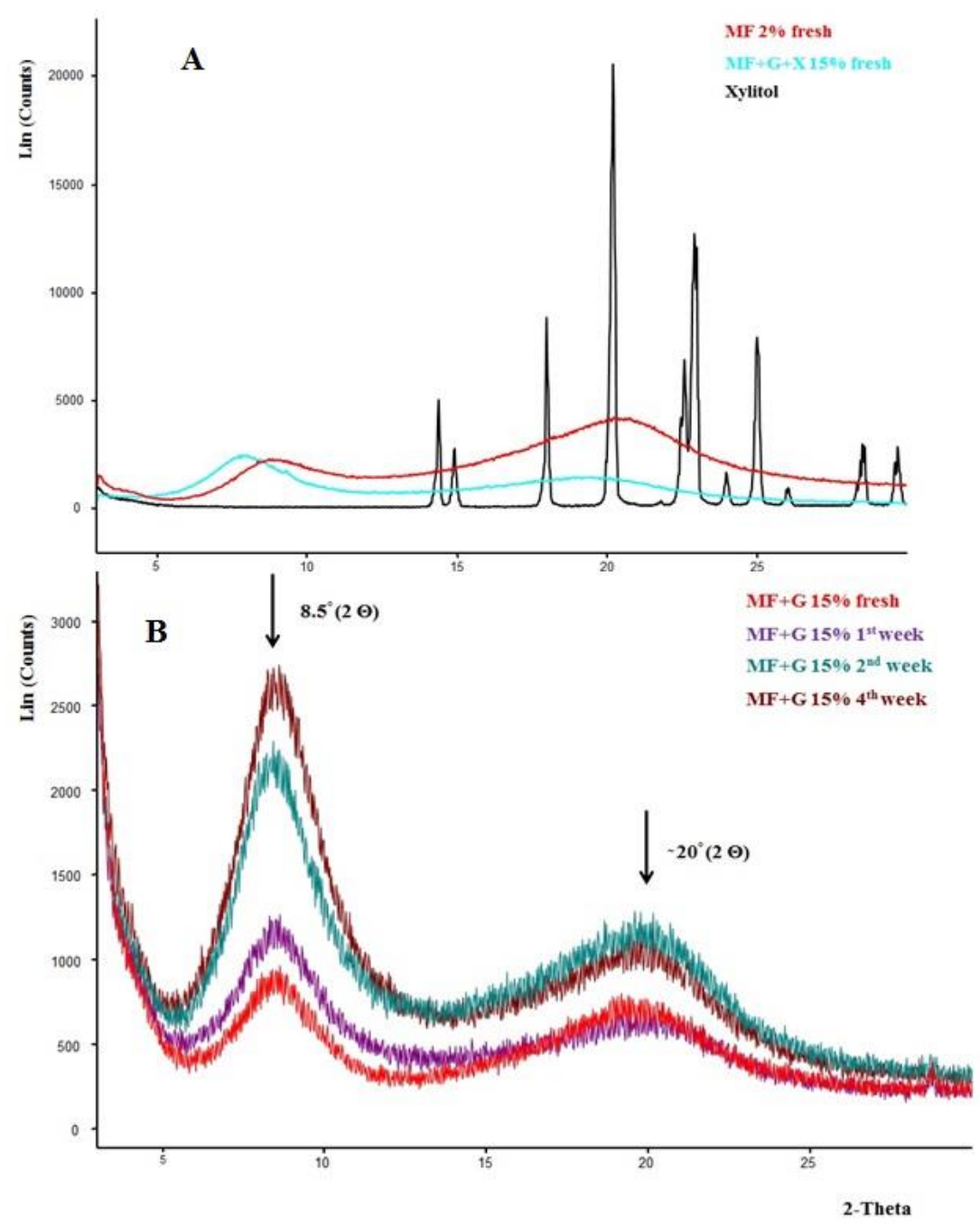

Fig. 11A shows the characteristic crystalline XRPD spectrum of Xyl compared to amorphous spectra of HPC free film and MFXC 15\%. Fig. 11B summarizes the water sorption and migration of Gly plasticized HPC films in XRPD spectra.

XRPD was used to evaluate the crystalline/amorphous nature of fresh and stored free films. No reflections are seen in the diffraction pattern of HPC because of its amorphous nature. The crystalline Xyl has a characteristic XRPD spectrum (clearly seen in Fig. 11A). It was found that $\mathrm{Xyl}$ bonds entirely into the HPC polymer matrix because marks of crystallinity were not found. During the accelerated stability test indication to crystallinity was not found 
in the tested samples. The same results were found in case of MFG and MFXG samples, all samples remained amorphous after four weeks of stability storage.

Water uptake was detected during the storage - the changes in MFG $15 \%$ patterns summarised in Fig. 11B - XRPD showed that films containing Gly and/or Xyl, linked water during accelerated stability study. Small changes in the water content of amorphous polymers can be evident from subtle differences in their XRD patterns. Similar changes were found in the amorphous HPC's XRPD patterns, as Teng at al. described in case of PVP [81]. The shape and the high angle halo displayed a shoulder resembling the halo for bound water. This phenomenon did not have effect to the bonded Xyl, because crystallinity was not found after water uptake, the polymer system stayed amorphous. In case of Gly at $15 \mathrm{w} / \mathrm{w} \%$ the increase of diffraction at about 8.5 and $20 \mathrm{deg}(2 \Theta)$ in the spectra indicated that water sorption proceed (clearly seen on Fig. 11B). Our study confirms the literature findings [81-83] that XRPD is a proper method for the detection of water sorption in polymer systems.

XRPD suggested the results of ATR-FTIR. The polymer system was amorphous, crystallinity was not found in the initial samples and during the accelerated stability test. It suggested that excipients are bounding chemically to the polymer matrix and the system remained amorphous during the whole stability test. Water uptake was found which phenomenon did not affect the amorphous state of HPC free films. XRPD was found a capable and unique method to detect the bulked water sorption via the detection of changes in the shape and halo of XRPD patterns.

\subsubsection{Thermogravimetric Analysis}

In case of four-week-old films the following results were found. Gly at $15 \mathrm{w} / \mathrm{w} \%$ had strong water sorption effect. The thermal stability of the one-week-old films is the least stable. The physical decomposition is the fastest in these samples caused by the absorbed bulk water which was evaporated first. Vapour was detected at 60 to $100{ }^{\circ} \mathrm{C}$. The same results were found in the case of Xyl at $15 \mathrm{w} / \mathrm{w} \%$. The one-week-old film decomposition was the fastest. The reason for this is the vapour of bulk water; after one week the films absorbed higher amount of water which were migrating in the system and had marked effect on their physical decomposition. It was hypostatised that after two weeks the excess water was evaporating from the system and a local equilibrium was formed.

The four-week-old Gly-Xyl plasticized films at $15 \mathrm{w} / \mathrm{w} \%$ were the most stable. In case of using Gly and Xyl together stabilizing effect was found. Naturally, MFXG films also bound water. The percent of thermal decomposition is shown in Table 6. In case of each Gly and/or 
Xyl containing samples the fresh samples have higher water content. In the first step, the absorbed bulk water evaporation was detected. In case of films plasticized with Gly-Xyl together higher percent of decomposition was found, but considerable difference between the samples was not found. The two excipients absorbed higher amount of water, this is the reason for the phenomenon. In the second step, the most stable were the Gly-Xyl plasticized films. Considerable difference was not found when comparing the different samples. TGA measurements showed the thermal decomposition of the plasticized free HPC films. The method in parts was capable to detect the bulked water content via the first step of weight loss; 60 to $100^{\circ} \mathrm{C}$ the evaporation of water was found.

Table 6. Weight loss of the tested free films. Calculated from TGA results.

\begin{tabular}{|c|c|c|c|c|}
\hline Materials & $\begin{array}{l}\text { Dry content } \\
\text { (w/w\%) }\end{array}$ & $\begin{array}{l}\text { Storage time } \\
\text { (week) }\end{array}$ & $\begin{array}{l}\text { Decrease of } \\
\text { weight } 1^{\text {st }} \text { step ( } \% \\
\pm S D)\end{array}$ & $\begin{array}{l}\text { Decrease of } \\
\text { weight } 2^{\text {nd }} \text { step } \\
(\% \pm S D)\end{array}$ \\
\hline \multirow{4}{*}{$\mathrm{HPC}$} & \multirow{4}{*}{2} & 0 (fresh) & $-1.66 \pm 0.56$ & $-99.98 \pm 0.47$ \\
\hline & & 1 & $-1.69 \pm 0.29$ & $-84.30 \pm 0.51$ \\
\hline & & 2 & $-1.25 \pm 0.47$ & $-93.72 \pm 1.49$ \\
\hline & & 4 & $-2.28 \pm 1.09$ & $-92.27 \pm 3.65$ \\
\hline \multirow{4}{*}{ Gly } & \multirow{4}{*}{5} & 0 (fresh) & $-2.83 \pm 1.29$ & $-89.48 \pm 2.84$ \\
\hline & & 1 & $-2.33 \pm 0.34$ & $-93.28 \pm 3.16$ \\
\hline & & 2 & $-1.73 \pm 0.32$ & $-92.72 \pm 1.59$ \\
\hline & & 4 & $-2.26 \pm 1.10$ & $-89.92 \pm 0.77$ \\
\hline \multirow{4}{*}{ Gly } & \multirow{4}{*}{10} & 0 (fresh) & $-4.33 \pm 0.76$ & $-89.37 \pm 0.18$ \\
\hline & & 1 & $-1.63 \pm 0.05$ & $-91.98 \pm 3.81$ \\
\hline & & 2 & $-1.51 \pm 0.02$ & $-87.98 \pm 0.30$ \\
\hline & & 4 & $-1.35 \pm 0.08$ & $-92.46 \pm 0.56$ \\
\hline \multirow{4}{*}{ Gly } & \multirow{4}{*}{15} & 0 (fresh) & $-3.65 \pm 0.08$ & $-89.93 \pm 0.75$ \\
\hline & & 1 & $-3.29 \pm 0.15$ & $-87.85 \pm 1.02$ \\
\hline & & 2 & $-3.43 \pm 1.66$ & $-87.86 \pm 1.40$ \\
\hline & & 4 & $-1.90 \pm 0.30$ & $-87.83 \pm 2.05$ \\
\hline \multirow{4}{*}{ Xyl } & \multirow{4}{*}{5} & 0 (fresh) & $-2.32 \pm 0.32$ & $-98.22 \pm 1.64$ \\
\hline & & 1 & $-1.48 \pm 0.72$ & $-99.92 \pm 0.03$ \\
\hline & & 2 & $-1.12 \pm 0.06$ & $-99.89 \pm 0.10$ \\
\hline & & 4 & $-1.43 \pm 0.09$ & $-91.83 \pm 0.54$ \\
\hline \multirow{4}{*}{ Xyl } & \multirow{4}{*}{10} & 0 (fresh) & $-1.43 \pm 0.28$ & $-90.23 \pm 3.23$ \\
\hline & & 1 & $-2.36 \pm 0.14$ & $-89.40 \pm 2.81$ \\
\hline & & 2 & $-0.97 \pm 0.01$ & $-95.08 \pm 4.27$ \\
\hline & & 4 & $-1.38 \pm 0.22$ & $-86.58 \pm 1.29$ \\
\hline \multirow{2}{*}{ Xyl } & \multirow{2}{*}{15} & 0 (fresh) & $-2.02 \pm 0.25$ & $-86.96 \pm 3.18$ \\
\hline & & 1 & $-1.87 \pm 0.06$ & $-84.88 \pm 4.45$ \\
\hline
\end{tabular}




\begin{tabular}{|c|c|c|c|c|}
\hline Materials & $\begin{array}{l}\text { Dry content } \\
\text { (w/w\%) }\end{array}$ & $\begin{array}{l}\text { Storage time } \\
\text { (week) }\end{array}$ & $\begin{array}{l}\text { Decrease of } \\
\text { weight } 1^{\text {st }} \text { step (\% } \\
\pm S D)\end{array}$ & $\begin{array}{l}\text { Decrease of } \\
\text { weight } 2^{\text {nd }} \text { step } \\
(\% \pm S D)\end{array}$ \\
\hline & & 2 & $-2.38 \pm 2.09$ & $-87.49 \pm 2.78$ \\
\hline & & 4 & $-2.35 \pm 0.11$ & $-89.25 \pm 1.74$ \\
\hline \multirow{4}{*}{ Gly+Xyl } & \multirow{4}{*}{5} & 0 (fresh) & $-2.35 \pm 0.06$ & $-80.83 \pm 4.19$ \\
\hline & & 1 & $-4.16 \pm 1.37$ & $-88.59 \pm 0.65$ \\
\hline & & 2 & $-2.04 \pm 0.10$ & $-88.34 \pm 0.08$ \\
\hline & & 4 & $-3.17 \pm 1.55$ & $-88.98 \pm 0.12$ \\
\hline \multirow{4}{*}{$\mathrm{Gly}+\mathrm{Xyl}$} & \multirow{4}{*}{10} & 0 (fresh) & $-2.73 \pm 0.29$ & $-89.44 \pm 0.75$ \\
\hline & & 1 & $-3.82 \pm 1.71$ & $-83.13 \pm 3.15$ \\
\hline & & 2 & $-3.63 \pm 0.72$ & $-84.41 \pm 4.24$ \\
\hline & & 4 & $-3.43 \pm 1.59$ & $-85.98 \pm 2.17$ \\
\hline \multirow{4}{*}{ Gly+Xyl } & \multirow{4}{*}{15} & 0 (fresh) & $-4.74 \pm 0.82$ & $-86.32 \pm 1.10$ \\
\hline & & 1 & $-4.11 \pm 0.65$ & $-87.85 \pm 0.71$ \\
\hline & & 2 & $-2.59 \pm 0.07$ & $-87.16 \pm 2.28$ \\
\hline & & 4 & $-2.20 \pm 0.04$ & $-86.97 \pm 0.16$ \\
\hline
\end{tabular}

\subsubsection{Tensile strength}

Because of the highly hygroscopic behaviour of Gly, films plasticized at 15 w/w\% with Gly were chosen to investigate the effect of accelerated stability conditions into the mechanical properties of samples and the results were compared to HPC films without any plasticizer in Table 7. In case of films plasticized with Gly at $15 \mathrm{w} / \mathrm{w} \%$ the following results were found. After one week of storage - under accelerated stability test parameters in climate chamber the tensile strength of films decreased dramatically. The initial (fresh) film tensile strength decreased by $83 \%$ after the end of the first week. The reason for this phenomenon was water absorption. The linked water can form H-bounding with the available chains of the HPC and increase their mobility [84]. Because of Gly hygroscopic behaviour, the plasticizer helped to absorb water to the polymer structure. This water content acts as a plasticizer and the high amount of water caused over-plasticizing effect in the films which event was detected via the tensile strength decrease. The polymer structure was destroyed via the water-Gly plasticizing duo which is clearly seen in decreased tensile strength values.

After two weeks of storage the excess amount of water was evaporating from the system and equilibrium could be formed. The tensile strength of films normalized and higher tensile strength value was detected compared to the initial force values. After four weeks of storage the initial tensile strength force was measured. These results confirm, that after one week of 
storage higher amount of water was absorbed into the polymer system, then the excess part of bulk water evaporated after two weeks and the system reached its equilibrium state. The used plasticizer had marked effect on the polymer system. After 1 week of storage the tensile strength of HPC films increased with 2-fold, not decreased as in case of Gly plasticized ones. The films did not contain any plasticizer and the absorbed water acts as a plasticizer in the polymer matrix. The entering water forms $\mathrm{H}$-bounds between the polymer chains and caused a plasticizing effect which phenomenon was detected via the increase in tensile strength. Under the whole storage time (two and four weeks) approximately 2-fold tensile strength increase was detected in case of these samples. The absorbed water content shows constant values via the tensile strength data.

Table 7. Compare the tensile strength of HPC and Gly plasticized HPC films.

\begin{tabular}{llll}
\hline Materials & $\begin{array}{l}\text { Dry content } \\
(\mathrm{w} / \mathrm{w} \%)\end{array}$ & $\begin{array}{l}\text { Storage time } \\
(\text { week })\end{array}$ & $\begin{array}{l}\text { Tensile strength } \\
(\mathrm{N} \pm S D)\end{array}$ \\
\hline \multirow{3}{*}{ HPC } & & 0 (fresh) & $5.25 \pm 1.92$ \\
& 2 & 1 & $9.90 \pm 0.90$ \\
& 2 & $12.32 \pm 1.28$ \\
Gly & 4 & $11.48 \pm 1.35$ \\
& \multirow{2}{*}{15} & 0 (fresh) & $12.17 \pm 0.93$ \\
& & 1 & $2.03 \pm 0.96$ \\
& 2 & $15.44 \pm 2.05$ \\
\end{tabular}

Significant difference was not found between the tensile strengths during the storage. HPC described as having less water affinity in the literature [70] and this behaviour of filmforming polymer was evidenced with tensile strength measurement, because the Gly content of the films dramatically decreased the tensile strength of films via increasing of water absorption which is also written in the literature [85-87].

The tensile strength results confirm that water can act as plasticizer alone in polymer films and has marked effects on the systems investigated. If any plasticizer is used in the filmforming procedure the water uptake of the system increases which can cause disadvantageous effects on the polymer matrix. It highlighted the importance of the selection the proper excipients - in this case plasticisers - to the formulation, and also, paying special attention to the manufacturing, packaging and storage conditions of the drug to avoid disadvantageous effects.

Tensile strength measurements evidenced the plasticization effect of water. The plasticizerfree HPC films absorbed water during climate chamber storage which acts as a plasticizer in the system. The force of tensile strength increased 2-fold after water sorption. When Gly was 
used at $15 \mathrm{w} / \mathrm{w} \%$ the absorbed water and the plasticizer destroyed the polymer matrix; over plasticization was found. After two weeks of storage the initial tensile strength results were found. In the pharmaceutical field these results reveal the importance of the excipients used and their effects on the drug delivery system. The storage condition is one of the most critical parts of technology.

The system was found physically stable after four weeks accelerated stability test. Xyl is not traditionally used as a plasticizer in pharmaceutical technology, but the results suggest its novel application as a plasticizer. The softening effect of bulked water is unpleasant in the field of pharmacy and it is crucial to avoid water uptake during storage.

\subsection{In vitro mucoadhesion}

The total deformation process involved in the measurement of the force of adhesion of a film is illustrated in Fig 12. The curves are observed to comprise three sections. (The limit of sections can be seen at the top of Fig. 12.)

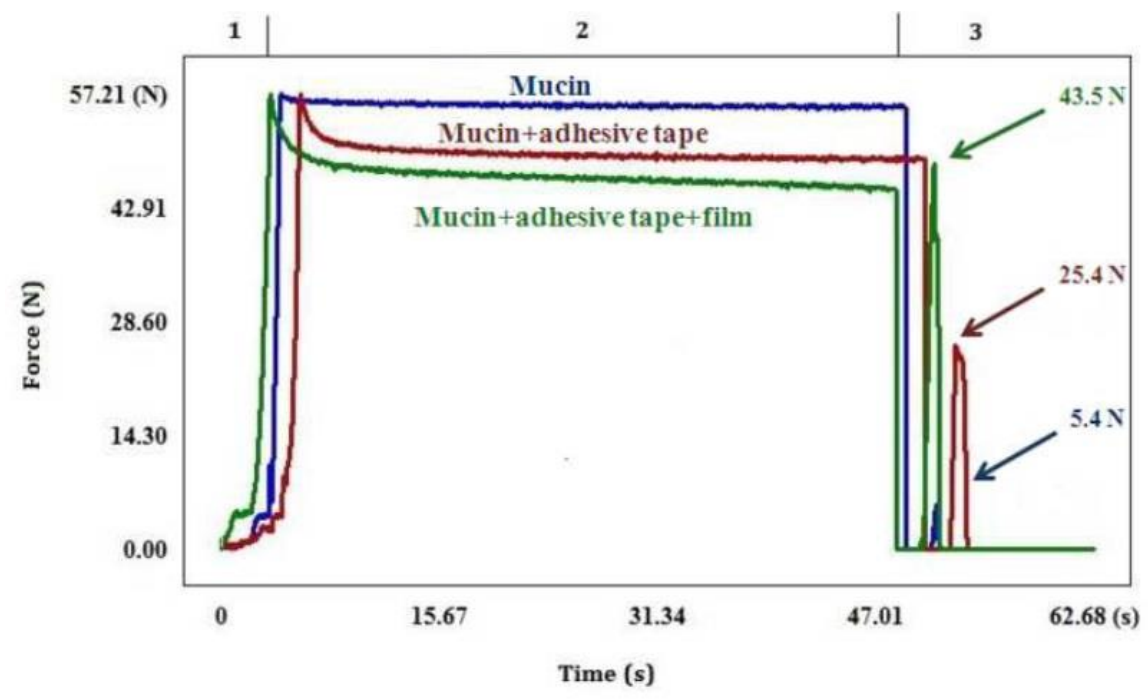

Fig. 12. Process of measurement of the force of adhesion of a free film.

During the pressing procedure, each non-steel part of the system (the bilayer adhesive tape, the mucin and the film) undergoes a deformation: section 1 of the curves reflects these phenomena. The almost horizontal parts of the curves (section 2) relate to the period when contact with the bottom at $50 \mathrm{~N}$ is maintained for $45 \mathrm{~s}$. After the $45 \mathrm{~s}$ holding time, the motor is reversed and starts to pull up the film. This is shown by the vertical line, followed by a 2-s pause. The peaks in the last part of the curves (section 3) relate to the force of adhesion (43.5 $\mathrm{N}$ ), which covers the elastic recovery of the sample (the bilayer adhesive tape, the mucin and the film together). Finally, correction of three-layered adhesion force by subtraction of the forces of adhesion of the tape and mucin leads to the force of adhesion of the sample: $18.1 \mathrm{~N}$. 
The software also permits magnification of the different sections of the curve, and it is therefore possible to study the deformation of the samples better, especially in sections 1 and 3 (Fig. 13 and 14). Fig. 13, depicts the initial deformation of a sample during static loading, with a short elastic and longer plastoelastic deformation.

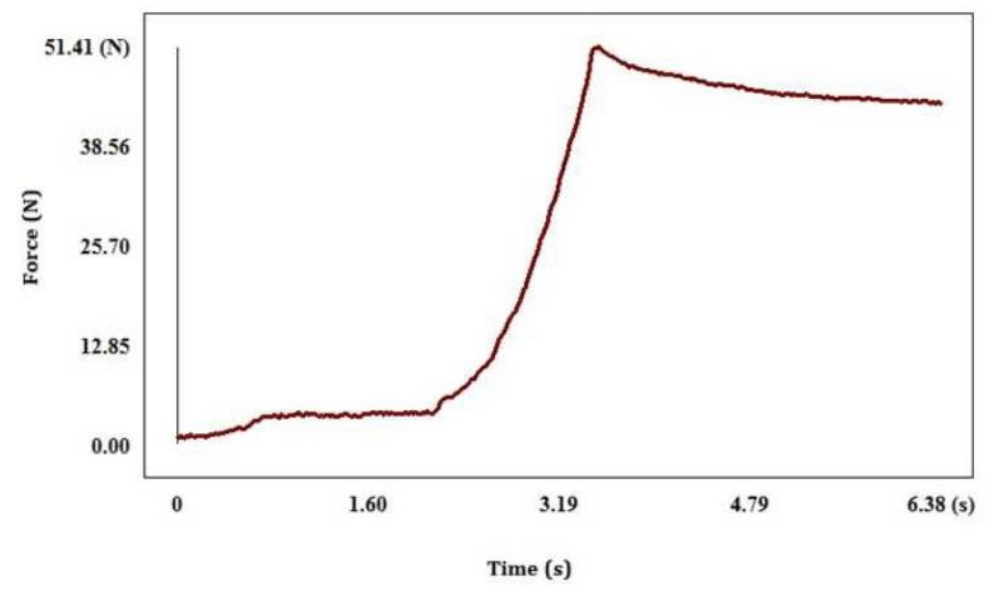

Fig. 13. Detail of the static loading of the curve

Fig. 14 demonstrates the deformation during the dynamic (tensile) process when the force of adhesion is involved. The curve indicates elastic behaviour until the termination of the adhesion. The descending section shows that the contact between the mucin and the film is partially broken.

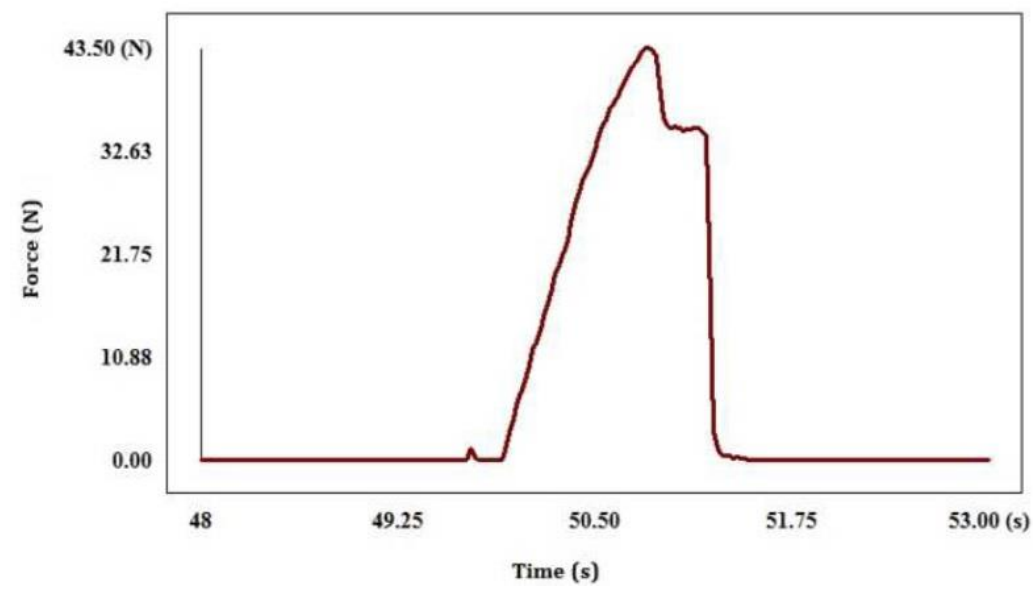

Fig. 14. Detail of the force of adhesion of curve.

The first comparison point was the pure film (unloaded films: without excipients and/or active substance), in this case the detected adhesive force is the character of the HPC. The pure films had higher adhesive force than the excipient loaded samples. The movable hydroxypropyl chains of the empty film easily form adhesive bonds with the chains of mucin and indicate higher adhesiveness. Contrarily, both of the excipients decreased the force of adhesion (Table8.). Xyl had the strongest effect on adhesion; a change of more than $60.0 \%$ 
was detected. Gly also indicated a considerable change in adhesion force. In case of both excipients the force decreased by a third. Gly is a well-known plasticizer in the pharmaceutical and food industry and Xyl is an optionally used plasticizer in food industry. It was found in the preformulation study, early characterization phase that $\mathrm{Xyl}$ forms H-bonds between the neighbouring polymer chains, leading to a stronger film structure. Xyl occupied the empty volumes in the polymer matrix and bonded the movable polymer chains. This phenomenon caused the high decrease in adhesion force; the occupied chains could not form adhesive bonds with the chains of mucin.

Table 8. In vitro force of adhesion

\begin{tabular}{l|c|c|c}
\hline Sample & $\begin{array}{c}\text { Force of adhesion } \\
(\mathrm{N} \pm S D)\end{array}$ & $\begin{array}{c}\text { Difference from } \\
\text { pure film }(\mathbf{N})\end{array}$ & $\begin{array}{c}\text { Difference from } \\
\text { pure film }(\%)\end{array}$ \\
\hline Pure film $^{1}$ & $23.26 \pm 6.21$ & - & - \\
Gly & $12.43 \pm 4.35$ & -10.83 & -46.56 \\
Xyl & $8.58 \pm 2.18$ & -14.68 & -63.11 \\
Gly+Xyl & $15.28 \pm 1.82$ & -7.98 & -34.26 \\
Phe HCl+Gly+Xyl & $20.70 \pm 6.00$ & -2.56 & -11.01 \\
Lid+Gly+Xyl & $11.55 \pm 4.50$ & -11.71 & -50.34 \\
Lid HCl+Gly+Xyl & $34.57 \pm 6.18$ & +11.31 & +48.62 \\
Lop HCl+Gly+Xyl & $25.53 \pm 6.88$ & +2.27 & +9.76 \\
\hline
\end{tabular}

${ }^{1}$ Pure film means the empty samples (without drug substance and/or excipients).

Gly as a plasticizer causes the films to become more elastic, increasing the tensile strength through the decrease of brittleness. The smaller Gly molecules let more polymer chains form adhesive bonds and it indicates less decrease in adhesiveness. When both excipients were used, the negative change was smaller. Fig. 15 shows the force of adhesion curves. The peaks in the last part of the curves relate to the force of adhesion $(\mathrm{N})$, which covers the elastic recovery of the sample (the bilayer adhesive tape, the mucin and the film together).

The force of adhesion of the samples is calculated by subtracting the forces of adhesion of the tape and mucin from the adhesion force of the three layers (summarised in Table 8). The differences in adhesive forces are clearly seen on the second peaks. The shapes of curves are very similar to each other because of the same film-forming polymer, which mainly determines the deformational behaviour of the samples during the measurement. The comparison of pure film adhesiveness to drug substance loaded samples revealed the following findings. Lid and Phe $\mathrm{HCl}$ decreased, meanwhile $\mathrm{Lid} \mathrm{HCl}$ and $\mathrm{Lop} \mathrm{HCl}$ increased 
the force of adhesion. The effect of $\mathrm{Phe} \mathrm{HCl}$ (approx. -10.0\%) and $\mathrm{Lop} \mathrm{HCl}$ (approx. $+10.0 \%$ ) was slight compared to Lid (approx. $-50.0 \%$ ) and $\mathrm{Lid} \mathrm{HCl}$ (approx. $+50.0 \%$ ). Lid was in a suspended form in the polymer matrix, while on the other hand the $\mathrm{HCl}$ salts were absolutely dissolved. The homogenous distribution of HCls indicates higher adhesiveness.

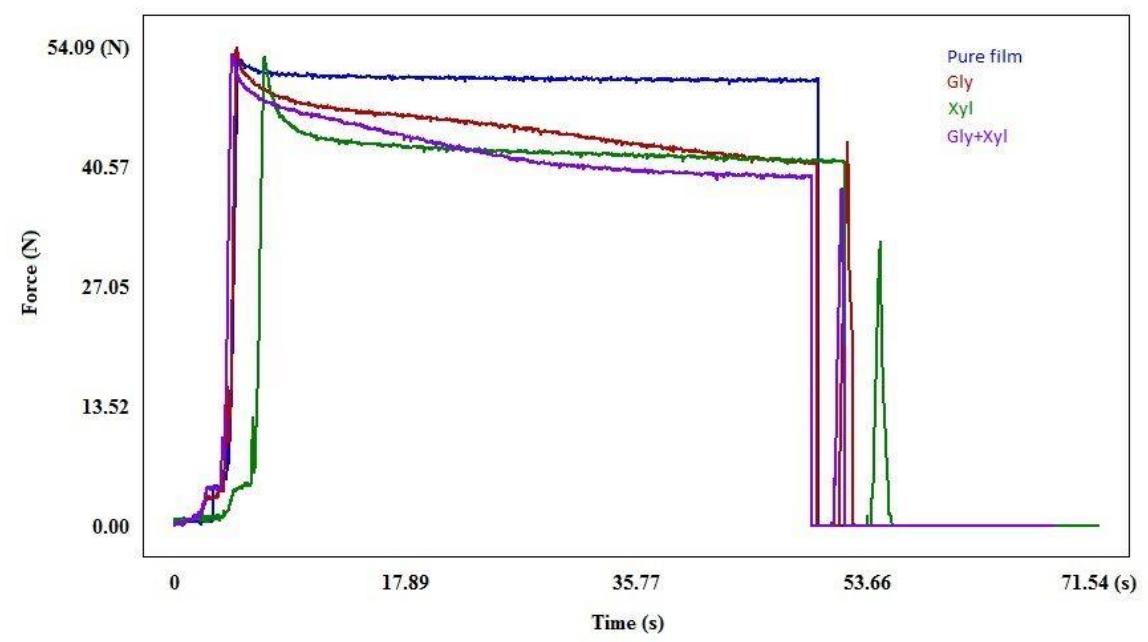

Fig. 15. Adhesive curves of films with excipients.

The phenomenon may be in parallel with the free and movable polymer chains and the cohesion of the mucin chains. Although all formulations contained both Gly and Xyl, the main effect on adhesion force was indicated by the active pharmaceutical ingredients. It clearly shows that adhesiveness was absolutely based on the formulation and determined not only by the used film-forming polymer. Fig. 16 clearly shows that the adhesive curves are similar to each other; only the Lop $\mathrm{HCl}$ deformational behavior was different. The comparison of the adhesive force of drug substance loaded films to the Gly and Xyl loaded samples was also made. In this case the three $\mathrm{HCl}$ salts showed an increase in the adhesiveness and only Lid had a decreasing effect on the adhesive force. The highest adhesive peak was found in Lid $\mathrm{HCl}$ loaded samples. These films had approx. 126\% higher adhesive force than excipient loaded samples. The second highest adhesive force was found in Lop $\mathrm{HCl}$ films; an approx. $67 \%$ increase was detected in adhesive force. The third HCL salt (Phe $\mathrm{HCl}$ ) showed more than 35\% increase in adhesiveness. Contrarily, Lid caused 24\% decrease in the adhesiveness. The adhesive force of $\mathrm{Lid} \mathrm{HCl}$ was three times higher than in the case of Lid. The thickness of the films was $20-40 \mu \mathrm{m}$ in every composition of the samples.

The results revealed that this equipment with the new software is suitable for studying the deformation of a mucoadhesive films successively during static loading and constant loading, and for the determination of the force of adhesion. The results demonstrate that the 
characterization of mucoadhesive films is possible. The findings were utilized to create a theoretical model suitable for prediction of the optimum film composition that ensures the required adhesion to the mucous membrane. The adhesiveness of the pure polymers served as the base for comparison in the evaluation. It was found that all formulations loaded with excipients decreased the adhesive force. The drug substance loaded samples were first compared to the pure film, then to samples with Gly-Xyl.

$\mathrm{Phe} \mathrm{HCl}$ and $\mathrm{Lid}$ decreased; contrarily, $\mathrm{Lid} \mathrm{HCl}$ and $\mathrm{Lop} \mathrm{HCl}$ increased the force of adhesion as compared to the pure films. However, compared to the films with excipients, an increased force of adhesion was found in case of the $\mathrm{HCl}$ salts, only Lid decreased the adhesiveness.

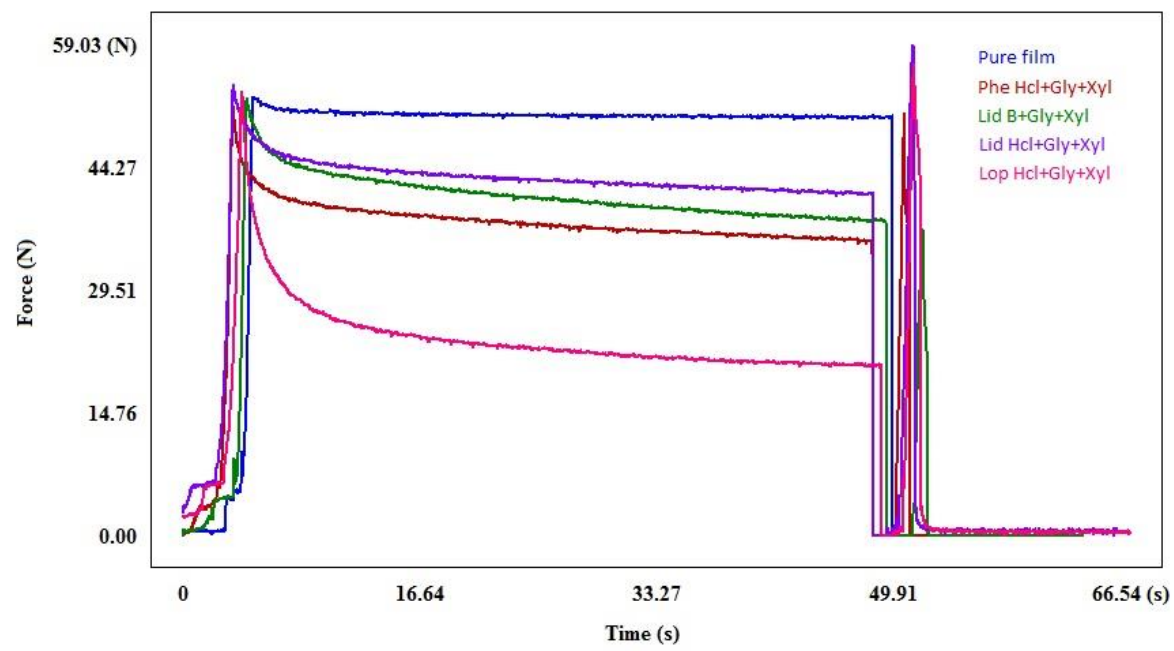

Fig. 16. Adhesive curves of films with drug substances and excipients

It is clear that the in vitro mucoadhesion of the investigated samples absolutely depends on the final composition of the product, i.e. excipients, drug substances and salt forms. It is always important to take into account the variability of the compositions, which determines adhesiveness. The used film-forming polymer had less effect on the mucoadhesive force of the evaluated samples. The interaction of the free, movable polymer chains and the mucin chains is very important in adhesion and the incorporated substances could decrease the adhesion force through occupying the chains. 


\section{SUMMARY}

In my work I focused on the characterization of HPC free films as potential mucoadhesive drug delivery systems. The preformulation study and early characterization stage helped to optimize the polymer matrix. Excipients used together resulted in good tensile strength. The measured CA demonstrated that macroscopically stable film structures were achieved at all compositions and constant SFEs suggest good bioadhesion. PALS revealed that the shorter chains of LF reacted more easily to the addition of Gly than did those of the longer MF form. The addition of Gly increased the size of the free volume holes in the polymers, while Xyl decreased it. The results confirmed that a macroscopically stable film structure evolved in each case. The thermal stability of the tested films was appropriate. With regard to the good workability of the free films and the pharmaceutical technology requirements, Klucel ${ }^{\circledR} \mathrm{MF}$ was chosen as film-forming polymer and the results highlighted that both Gly and Xyl had marked effects on the tested polymers.

It is very important to evaluate the incorporation of used excipients and to test the stability of the polymer matrix. Marks of intermolecular hydrogen bonds were found in all types of samples. The FTIR analysis revealed the so-called 'synergic' effect of Gly, which helps the bonding of Xyl into the polymer matrix. Both excipients facilitated the water sorption into the tested systems. Xyl is commonly not used as a plasticizer in the field of pharmacy, but our results suggest that Xyl also can act as a plasticizer in any formulation. XRPD suggested that the polymer system was amorphous, marks of crystallinity were not found. It suggested excipients' bounding chemically to the polymer matrix. Water uptake was detected via the changes in the shape and halo of patterns. Tensile strength measurements evidenced the plasticizing effect of water. The system was found physically stable after four weeks of accelerated stability test and the most stable film structure was acquired if both excipients were incorporated. Finally, a new in vitro mucoadhesion measurement protocol, equipment and software were designed, tested and optimised. The results revealed that this equipment with the new software is suitable for studying the deformation of a mucoadhesive films successively during static loading and constant loading, and for the determination of the force of adhesion. The results demonstrate that the characterization of mucoadhesive films is possible. The findings were utilized to create a theoretical model suitable for prediction of the optimum film composition that ensures the required adhesion to the mucous membrane. 


\section{FINAL CONCLUSIONS, NOVELTY AND PRACTICAL USEFULNESS}

Mucoadhesive free films offer innovative drug delivery systems for both local and systemic targets. It is very important to deeply study and understand the evaluated system.

Based on the preformulation study and early characterization the following can be summarised as main findings:

- Tensile strength suggested that Xyl forms hydrogen bonds and the strongest structure is resulted if both excipients were used together.

- CA measurements demonstrated that macroscopically stable film structures were achieved at all compositions and constant SFEs suggest good bioadhesion.

- PALS suggested that Xyl forms hydrogen bonds and Gly increases while Xyl decreases the free volumes of the HC films.

- Thermal study suggested that excipients in low concentration incorporated into the system. Carbon dioxide, acetic acid and/or isopropyl alcohol formed during TG-MS study. The tested systems were thermally stable, below $100^{\circ} \mathrm{C}$ only water loss was detected.

From the accelerated stability study and the incorporation tests of free films the main findings are listed below:

- FTIR confirmed that both excipients incorporated to the polymer system via hydrogen bonds. It highlighted the so-called 'synergic' effect of Gly and Xyl used together. Water uptake and migration were detected. Xyl was found to be a potential plasticizer which finding offers a new indication for Xyl in the field of pharmacy.

- XRPD also confirmed the incorporation of the excipients used, the system remained amorphous. Water uptake and migration were detected and confirmed via the changes of shape and angle halo of patterns.

- TGA confirmed the presence of bulk water.

- Tensile strength highlighted the softening behaviour of water and the over plasticization effect of it with Gly.

The in vitro mucoadhesive study showed that this equipment with the new software is suitable for studying the deformation of a mucoadhesive film and for the determination of the force of adhesion. The results demonstrate that the characterization of mucoadhesive films is possible. The findings were utilized to create a theoretical model suitable for the prediction of the optimum film composition. 
The novelties of my work are as follows:

- PALS demonstrated that Gly increases and Xyl decreases the free vacancies of the HPC films via moving the polymer changes.

- Tensile strength measurement and FTIR highlighted the so-called 'synergic' effect of Gly and Xyl used together. Samples with the two excipients showed the best mechanical, physicochemical properties and these were the most stable in each case.

- Xyl is commonly not used as a plasticizer in the field of pharmacy, but our results suggest that $\mathrm{Xyl}$ also can act as a plasticizer in any formulation. FTIR highlighted the potential novel application of $\mathrm{Xyl}$ in pharmaceutical technology and this finding is welcomed in manufacturing, financial and also health-care considerations.

- The novel in vitro adhesion measurement protocol, equipment and software offer a great tool to study and evaluate both the deformation of the tested system and the adhesion of free films. 


\section{REFERENCES}

[1] Sudhakar, Y., Kuotsu, K., Bandyopadhyay, A.K., J. Control. Release 114, 15-40, (2006).

[2] Lam, J.K.W., et al., Adv. Drug Deliv. Rev. 73, 50-62, (2014).

[3] Allen, A., in: Forte, J.G. (Ed.) Handbook of Physiology, Vol. III Section 6, American Physiological Society, Bethesda, MD, 1989, pp. 359-382.

[4] Andrews, G.P., Laverty, T.P., Jones, D.S., Eur. J. Pharm. Biopharm. 71, 505-518 (2009).

[5] Madhav, N.V.S., Shakya, A.K., Shakya, P., Singh, K., J. Control. Release 140, 2-11 (2009).

[6] Humphrey, S.P., RDH, MSEd, Williamson R.T., DMD., J. Proshet. Dent. 85, 162-169 (2001).

[7] Norris, D.A., Puri, N., Sinko, P.J., Adv, Drug Deliv. Rev. 34, (2-3), 135-154 (1998).

[8] Castellanos, M.R., Zia, H., Rhodes, C.T., Drug Dev. Ind. Pharm. 19, (1 and 2), 143-194 (1993).

[9] Kocevar-Nared, J., Kristl, J., Smid-Korbar, J., Biomaterials 18, 677-681 (1997).

[10] Capra, R., Baruzzi, A., Quinzani, L., Strumia, M., Sensors Actuators B 124, 466-476 (2007).

[11] Slomiany, B.L., Murty, V.L., Poitrowski, J., Slomiany, A., Gen. Pharmacol. 27, 761-771 (1996).

[12] Tabak, L.A., Crit. Rev. Oral. Biol. Med. 1, 229-234 (1990).

[13] Edgar, W.M., Br. Dent. J. 172, 305-312 (1992).

[14] Iontcheva, I., Oppenheim, F.G., Troxler, R.F., J. Dent. Res. 76, 734-743 (1997).

[15] Tabak, L.A., Levine, M.J., Mandel, I.D., Ellison, S.A., J. Oral. Pathol. 11, 1-17 (1982).

[16] Lee, J., Kil, S., Choi, Y.W., Arch. Pharm. Res. 25, (4), 546-549 (2002).

[17] Shakya, P., Madhav, N.V.S., Shakya, A.K., Singh, K., J. Control. Release 151, 2-9 (2011).

[18] Gandhi, R.B., Robinson, J.R., Adv. Drug Deliv. Rev. 13, 43-74 (1994).

[19] Squier, C.A., Hall, B.K., Arch. Oral. Biol. 29, 45-50 (1984).

[20] Salamat-Miller, M., Chittchang, M., Johnston, T.P., Adv. Drug Deliv. Rev. 57, 1666$1691(2005)$

[21] Morales, O.J., McConville, J.T., Eur. J. Pharm. Biopharm. 77, 187-199 (2011).

[22] Law, S., Wertz, P., Swartzendruber, D., Squier, C., Arch. Oral Biol. 40, 1085-1091 (1995)

[23] Squier, C., J. Ultrastruct. Res. 43, 160-177 (1973).

[24] Squier, C., Cox, P., Wertz, P., Downing, D., Arch. Oral Biol. 31, 741-747 (1986). 
[25] Wolff, K., Honigsmann, H.J.: J. Ulrtrastruct. Res. 36, 176-190 (1971).

[26] Patel, V.F., Liu, F., Brown, M.B., J. Control. Release 153, 106-116 (2011).

[27] Robinson, J.R., Yang, X., Absorption enhancers, Swarbrick, J., Boylan, J.C., (Eds.), Encyclopedia of Pharmaceutical Technology, vol. 18, Marcel Dekker, Inc., New York, 2001, pp. 1-27.

[28] Veuillez, F., Kalia, Y.N., Jacques, J., Deshusses, J., Buri, P., Eur. J. Pharm. Biopharm. 51, 93-109 (2001).

[29] Paderni, C., Compilato, D., Giannola, L.I., Campisi, G., Oral Surg. Oral Med. Oral Pathol. Ora Radiol. 114, e25-e34 (2012).

[30] Petelin, M., Marjeta, S., Stolic, Z., Skaleric, U., Int. J. Pharm. 173, 193-202 (1998).

[31] Hangerstrom, H., Edsman, K., J. Pharm. Pharmacol. 53, 1589-1599 (2001).

[32] Wertz, P., Squier, C., Critical Reviews in Therapeutic Drug Carrier Systems 8, 237-269 (1991).

[33] Nicolazzo, J.A., Reed, B.L., Finnin, B.C., J. Control. Release 150, 1-15 (2005).

[34] Banett, M., Szabo, G., J. Period. Research 8, 117-126 (1973).

[35] Harris, D., Robinson, J., J. Pharm. Sci. 81, 117-126 (1992).

[36] Senel, S., Hincal, A., J. Control. Release 72, 133-144 (2001).

[37] Utoguchi, N., Watanabe, Y., Suzuki, T., Maehara, J., Matsumoto, Y., Matsumoto, M., Pharm. Res. 14, 320-324 (1997).

[38] Shijaei, A.H., Li, X., Proc. Int. Symp. Control. Release Bioact. Mater. 24, 427-428 (1997).

[39] Nielsen, H.M., Rassing, M.R., Int. J. Pharm. 185, 215-225 (1999).

[40] Zhang, H., Robinson, J.R., in J. Swarbrick, J.C. Boylan (Eds.), Oral Mucosal Drug Delivery, 1 st edition, vol. 74, Marcel Dekker, INC, New York, 1996, pp. 85-100.

[41] Mashru, R., Sutariya, V., Sankalia, M., Sankalia, J., J. Pharm. Pharmaceut. Sci. 8, (1), 54-62 (2005).

[42] Randhawa, M.A., Malik, S.A., Javed, M., Park. J. Med. Res. 42, (2), (2003).

[43] Manning, A.S., Evered, D.F., Clin. Sci. Mol. Med. 51, 127-132 (1976).

[44] Sadoogh-Adasian, F., Evered, D.F., Br. J. Nutr. 42, 15-20, 1979.

[45] Evered, D.F., Sadoogh-Abasian, F., Patel, P.D., Life Sci. 27, 1649-1651 (1980).

[46] Utoguchi, N., Watanabe, Y., Takase, Y., Suzuki, T., Matsumoto, M., J. Pharm. Sci. 88, 142-146 (1999).

[47] Gu, J.M., Robinson, J.R., Leung, S.H.S., Crit. Rev. Ther. Drug Carr. Syst. 5, 21-67 (1988). 
[48] Smart, J.D., Adv. Drug Deliv. Rev. 57, 1556-1568 (2005).

[49] Marriott, C., Gregory, N.P., in: VA. Lenaerts, R. Gurney, (Eds.), Bioadhesive Drug Delivery Systems, CRC Press, Florida, 1990, pp. 1-24.

[50] Allen, A., Cunliffe, W.J., Pearson J.P., Venables, C.W., J. Intern. Med. 228, 83-90 (1990).

[51] Kerss, S., Allen, A., Garner, A., Clin. Sci. 63, 187-195 (1990).

[52] Sonju, T., Cristensen, T.B., Kornstad, L., Rolla, G., Caries Res. 8, 113-122 (1974).

[53] Laidler, K.J., Meiser, J.H., Sanctuary, B.C.: Physical Chemistry, Fourth edition, Houghton Mifflin Company, Boston, (2003).

[54] Ahuja, Khar, R.P., Ali, J., Drug Dev. Ind. Pharm. 23, 489-515 (1997).

[55] Mathiowitz, E., Chickering, D.E., in: Mathiowitz, ED., Chickering, D.E.R., Lehr, C.M. (Eds.), Bioadhesive Drug Delivery Systems: Fundamentals, Novel Approaches and Development, CRC Press, New York, 1999, pp. 1-10.

[56] Peppas, N.A., Sahlin, J.J., Biomaterials 17, 1553-1561 (1996).

[57] Erős, I., in Révész, P.: Gyógyszertechnológia, JATEPress, Szeged, 2009, pp. 92-93.

[58] $W u, S .:$ Formation of bioadhesive bond, Plymer Interface and Adhesion, Marcel Decker Inc, New York, 1982, pp. 359-447.

[59] Morales, O.J., McConville, J.T., Eur. J. Pharm. Biopharm. 77, 187-199 (2011).

[60] Lee, J.W., Park, J.H., Robinson, J.R., J. Pharm. Sci. 89, 850-866 (2000).

[61] Chen, J.L., Cyr, G.N., in: R.S. Manly (Ed.), Adhesion in Biological Systems, Academic Press, New York, 1970, pp.163-181.

[62] Smart, J.D., Kellaway, I.W., Worthington H.E.C., J. Pharm. Pharmacol. 36, 295-299 (1984).

[63] Harding, S.E., Davis, S.S., Deacon, M.P., Fiebrig, I., Biotechnol. Genet. Eng. Rev. 16, 41-85 (1999).

[64] Smart, J.D., Adv. Drug Deliv. Rev. 11, 253-270 (1993).

[65] Andrews, G.P., Laverty, T.P., Jones, D.S., Eur. J. Pharm. Biopharm. 71, 505-518 (2009).

[66] Rahman, M., Brazel, C.S., Prog. Polym. Sci. 29, 1223-1248 (2004).

[67] El-Din, H.M.N., Alla, S.G.A., El-Naggar, A.W.M., Radiat. Phys. Chem. 79, 725-730 (2010)

[68] Haji-Saeid, M., Safrany, A., de OSampa, M.H., Ramamoorthy, N., Radiat. Phys.

Chem.79, 255-260 (2010).

[69] Lj Tomić, S., Mićić, M.M., Dobić, S.N., Filipović, J.M., Suljovrujić, E.H., Radiat. Phys. Chem. 79, 643-649 (2010). 
[70]http://www.ashland.com/file_source/Ashland/Product/Documents/Pharmaceutical/PC_11 229_Klucel_HPC.pdf download 16/March/2017

[71] Bajdik, J., Fehér, M., Pintye-Hódi, K., Appl. Surf. Sci. 253, 7303-7308 (2007).

[72] Wu, S., J. Polym. Sci. 34, 19-30 (1971).

[73] Pethrick, R.A., Prog. Polym. Sci. 22, 1-47 (1997).

[74] Hiemenz, P.C., 1984. Polymer Chemistry. Marcel Dekker, New York.

[75] Süvegh, K., Klapper, M., Domján, A., Mullins, S., Wunderlich, W., Vértes, A., Macromolecules 32, 1147-1151 (1999).

[76] Kilburn, D., Bamford, D., Lüpke, T., Dlubek, G., Menke, T.J., Alam, M.A., Polymer 43, 6973-6983 (2002).

[77] Eldrup, M., Lightbody, D., Sherwood, J.N., Chem. Phys. 63, 51-58 (1981).

[78] Pintye-Hódi, K., Regdon, G. Jr., Erös, I., Süvegh, K., Marek, T., Kéry, I., Zelkó R., Int. J. Pharm. 313, 66-71 (2006).

[79] Marek, T., Süvegh, K., Kéry, I., Zelkó, R., Regdon, G. Jr., Pintye-Hódi, K., Vértes, A., Radiat. Phys. Chem. 76, 165-8 (2007).

[80] Regdon, G. Jr., Zsellér, B., Pintye-Hódi, K., Compos Interfaces. 17, 581-94 (2010).

[81] Thakral, S., Terban, M.W., Thakral, N.K., Suryanarayanana, R., Adv. Drug Deliv. Rev. 100, 183-193 (2016).

[82] Shaikh, M., Choudhury, N.R., Knott, R., Kanwar, J.R., Garg, S., Eur. J. Pharm. Biopharm. 101, 82-89 (2016).

[83] Tian, B., Zhang, L., Pan, Z., Gou, J., Zhang, Y., Tang, X., Int. J. Pharm. 475, 385-392 (2014).

[84] Paisana, M.C., Wahl, M.A., Pinto, J.F., Eur. J. Pharm. Sci. 97, 257-268 (2017).

[85] Agiurre, A., Borneo, R., León, A.E., Industrial Corps and Products 50, 297-303 (2013).

[86] Tapia-Blácido, D-R., do Amaral Sobral, P.J., Menegalli, F.C., LWT - Food Sci. Techn. 50, 392-400 (2013).

[87] Epure, V., Griffon, M., Pollet, E., Avéros, L., Carbohydrate Polymers 83, 947-952 (2011). 


\section{ACKNOWLEDGEMENT}

I wish to thank Prof. Dr. Piroska Szabó-Révész, Head of Pharmaceutical Technology Educational Program of Doctoral School of Pharmaceutical Sciences and Dr. Ildikó Csóka, Head of the Department of Pharmaceutical Technology and Regulatory Affairs for providing me with the opportunity to work in the department and to complete my assignments.

I would like to express my grateful thanks to Prof. Dr. Klára Pintye-Hódi and to my supervisor Dr. Géza Regdon jr., for their guidance and for their useful advices during my Ph.D. work.

I express my kindest gratitude to Gabriella Farkas and Dr. Tamás Sovány for their huge help in the measurement and evaluation of the FTIR and XRPD spectra.

I am very appreciative to Dr. András Kelemen for his tremendous work in design and development of the novel in vitro adhesion measurement protocol, equipment and software.

I am likewise greatly indebted to Dr. Károly Süvegh for his huge help in the measurement and evaluation of PALS.

I say thank you to Jutka Fehérné and Magdolna Monostori for their help and friendship during my work.

I thank all members of the Department of Pharmaceutical Technology for their help.

I owe my biggest thanks to my wife Ibolya for her support, tremendous help and patience and for ensuring a peaceful background. I would like to thank to my parents, grandmother and brother for their encouragement and understanding. 
ANNEX 


$$
\text { I. }
$$




\title{
New equipment for measurement of the force of adhesion of mucoadhesive films
}

\author{
András Kelemen ${ }^{\mathrm{a}}$, Mihály Gottnek ${ }^{\mathrm{b}}$ (D), Géza Regdon Jr. ${ }^{\mathrm{b}}$ and Klára Pintye-Hódi ${ }^{\mathrm{b}}{ }^{2}$ \\ ${ }^{a}$ Department of Applied Informatics, University of Szeged, Boldogasszony sgt. 6, H-6725 Szeged, \\ Hungary; ${ }^{b}$ Department of Pharmaceutical Technology, University of Szeged, Eötvös u. 6, H-6720 \\ Szeged, Hungary
}

(Received 26 November 2014; final version received 8 March 2015; accepted 10 March 2015)

\begin{abstract}
A better recognition of the properties of materials is of great interest in pharmaceutical technology, and especially in the development of modern solid dosage forms. As an example, a knowledge of the force of adhesion of a mucoadhesive preparation is of considerable importance. The aim of the present study was to develop the calibrated equipment suitable for determination of the force of adhesion and for following the process of film deformation during testing. A new instrument is introduced, and the results are presented.
\end{abstract}

Keywords: adhesion; polymer; hydroxypropyl cellulose; Klucel ${ }^{\circledR}$ MF; mucoadhesive films

\section{Introduction}

As a consequence of their advantages,[1] mucoadhesive therapeutic preparations (tablets, films, patches and gels) are currently at the focus of research work. The buccal region of the mouth is a possible area for drug penetration; when the 'first-pass effect', the acidic $\mathrm{pH}$ of the stomach and the action of different enzymes in the gastrointestinal tract may be avoided. This is a popular mode of administration for the patients, and especially children, because the preparations are small and flexible, and easy to apply. The level of patient compliance may therefore be appropriate. During application, the mucoadhesive film should be carefully placed in the mouth and pressed gently with one finger onto the mucosa for several seconds until weak chemical bonds are formed between the polymer and the mucin chains, and the film adheres to the mucosa. Three processes are involved: (1) the wetting and swelling of the polymer, (2) the penetration of moisture into the polymer and (3) the formation of weak chemical bonds between the chains.[2]

Bioadhesion involves a lasting connection between a biological surface (both hard and soft tissues) and a medicine form. Bioadhesion on mucous membranes is called mucoadhesion. The external surfaces of body cavities are covered by mucous membranes. As an example, the oral cavity possesses a multi-layered epithelium. Saliva, produced by the salivary glands, is rich in mucins. The thickness of the mucin layer in the oral cavity is $1 \mu \mathrm{m}$.[3]

*Corresponding author. Email: klara.hodi@pharm.u-szeged.hu 
The mechanism of mucoadhesion is quite complex. The chemical bonds that develop to give rise to the adhesion can be strong ionic or covalent, weaker H-bonding or the weakest van der Waals interactions, and indirect hydrophobic bonds.[4] The mechanism of mucoadhesion comprises two main steps: the contact stage and the consolidation stage. During the consolidation stage, the film-forming polymer and the degree of hydration determine the strength of mucoadhesion. Many factors affect mucoadhesion. These factors can be polymeric (molecular weight, flexibility, H-bonding capacity, rate of polymerization, charge, concentration and hydration) or environmental (saliva, mucin turnover and the movement of the buccal tissues).[4-6]

The ideal polymer has one or more of the following properties: a molecular weight between $1 \times 10^{4}$ and $4 \times 10^{6} \mathrm{Da}$, high flexibility of the polymer chains [7] and end groups capable of forming H-bonds,[6,8-11] i.e. hydroxyl, carboxyl or amino groups.[12]

Mucins are highly glycosylated glycoproteins, which at physiological $\mathrm{pH}$ are negatively charged.[13] Cationic polymers can be electrostatically coupled to mucin via the negatively charged sialic acid, but anionic polymers have better bioadhesive properties. Any medicine form should be in contact with the buccal tissue for a maximum of 12-24 h.[14]

Several methods are used to quantify the mucoadhesive properties of pharmaceutical dosage forms.[15] These methods may be direct or indirect. A direct technique involves determination of the force required to detach a formulation from a mucosal tissue or examination of the time needed to remove a formulation from the mucosa. Techniques which evaluate the interactions between the polymer and the mucus layer are indirect measurements.[16,17] Methods based on mechanical force determination include texture analyser,[6,18-26] modified balance/modified surface tensiometry, $[9,27,28]$ tensile measurement, $[15,29,30]$ tensile stress tester $[29,31]$ and atomic force microscopy.[29,32-34] These techniques examine the force needed to break adhesive bonds. Among the measurements based on particle interactions are the mucin particle method and BIACORE,[35,36] rheology,[37,38] ellipsometry,[37,39] colloidal gold staining method,[39,40] the flow channel method [41] and falling liquid film method.[42-44] Texture analyser is most frequently applied to investigate pharmaceutical films that are used to analyse the amount of polymer adhering to mucosal tissue.[16]

An earlier investigation of the in vivo bioadhesive properties of hydroxypropyl cellulose (HPC) films containing seven excipients on the epidermis of 12 human subjects, including two ethnic sub-groups revealed that the force of adhesion, the elongation at adhesive failure and the modulus of adhesion are functions of the excipients in the extruded HPC films.[45] The adhesion of HPC, xanthan gum (XG), tamarind gum (TG) and polyvinyl alcohol (PVA) in powder form to the nasal mucosa of rabbits was investigated both in vivo and in vitro. XG exhibited the best adhesion, followed by TG, HPC and PVA in this sequence. The same phenomenon was found in adhesion to agar plates. It was suggested that all these polymers could serve as useful bases for mucoadhesive powder formulation.[46]

Our work has focused on the preparation and investigation of mucoadhesive films, and we have developed the calibrated equipment suitable for determination of the force of adhesion, which also allows the process of film deformation to be followed during testing. The novelty of this system is that the total deformation curve of the sample can be analysed. 


\section{Experimental}

\subsection{Equipment}

The equipment used to measure the forces of adhesion of polymer films was based on the hardness tester described in detail earlier (Figure 1).[47]

The pressure is measured through the use of a load cell connected to a locally developed digital acquisition (DAQ) box. This is based on the Silicon Laboratories C8051F124 microcontroller kit. During the measurement, the DAQ box sends the acquired data to the PC side software via an RS232 connection. With this device, the start of data acquisition is controlled manually because the pressure jowl must be positioned exactly on the surface of the material. The end of the data acquisition is also controlled manually because the breaking point of relatively elastic materials such as films cannot be detected exactly.

The original embedded software of the DAQ box was modified in order for it to be suitable for the measurement of forces of adhesion. The adhesion force measurement algorithm performs the following operations:

- At the beginning of the measurement process, the pressure jowl moves downwards and presses against the polymer film until it reaches the predefined pressure (static pressure).

- It holds its position until the desired time out (static pressure time).

- At this time, the pressure jowl begins to move upwards until the user stops the measurement process (dynamic pressure).

The two parameters which can be set up freely in the algorithm (the static pressure and the static pressure time) have to be set before the measurement via the PC side software. The measurement range was $0-200 \mathrm{~N}$, the speed of the stamp was $20 \mathrm{~mm} / \mathrm{min}$ and the output was $0-5 \mathrm{~V}$. The sensor was a unicell force-measuring instrument, calibrated with the C9B $200 \mathrm{~N}$ cell.

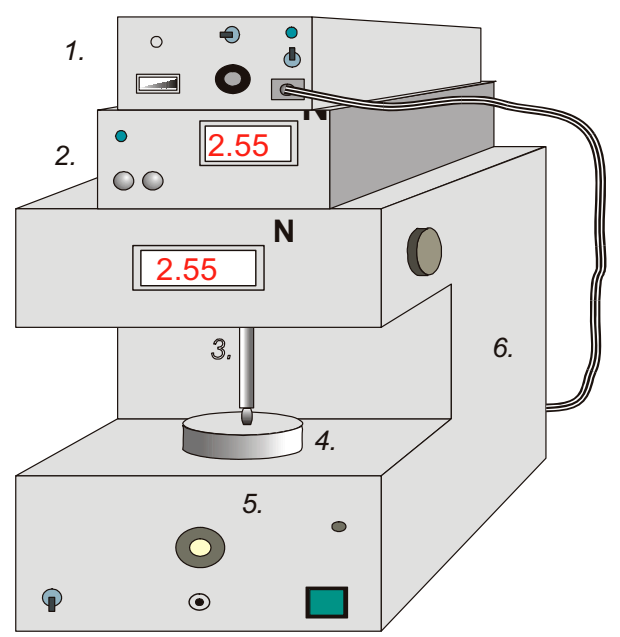

Figure 1. Hardness tester. 1: DAQ unit; 2: current force display; 3: pressure jowl; 4: sampling holder; 5: force measurement unit; 6: motor and analogue velocity control for pressure jowl. The sample holder and pressure jowl are suitable for polymer films. 


\subsection{Materials}

HPC (Klucel MF) (Aqualon; Hercules Inc., Wilmington, USA) was used as a film-forming material and glycerine (Ph Eur) as a plasticizer.

\subsection{Preparation of free films}

$2 \mathrm{w} / \mathrm{w} \%$ film-forming polymer was used in aqueous solution. The films were made by casting technology on a teflon surface. The samples were dried in the air at room temperature $\left(25^{\circ} \mathrm{C} / 60 \mathrm{RH} \%\right)$ for $24 \mathrm{~h}$.

\subsection{Storage of films}

The films were stored in a climate chamber at $40{ }^{\circ} \mathrm{C} / 50 \mathrm{RH} \%$ during a week.

\subsection{Measurement of force of adhesion}

The structure of the measurement system was as follows from top to bottom: a stainless steel holder, a bilayer adhesive tape, a film, mucin gel and a stainless steel table. Each element was measured alone, in pairs and all together (see Section 2.1). Before the adhesion test, each film was subjected to $50 \mathrm{~N}$, which was held for $45 \mathrm{~s}$, and the holder then pulled up the film from the mucin gel layer.

A minimum of 10 parallel measurements were made.

\section{Results and discussion}

The total deformation process involved in the measurement of the force of adhesion of a film is illustrated in Figure 2. The recoil of the spring under the stainless table can be seen at the beginning of the curves. The curves are observed to comprise three sections (the limit of sections can be seen at the top of Figure 2). During the pressing

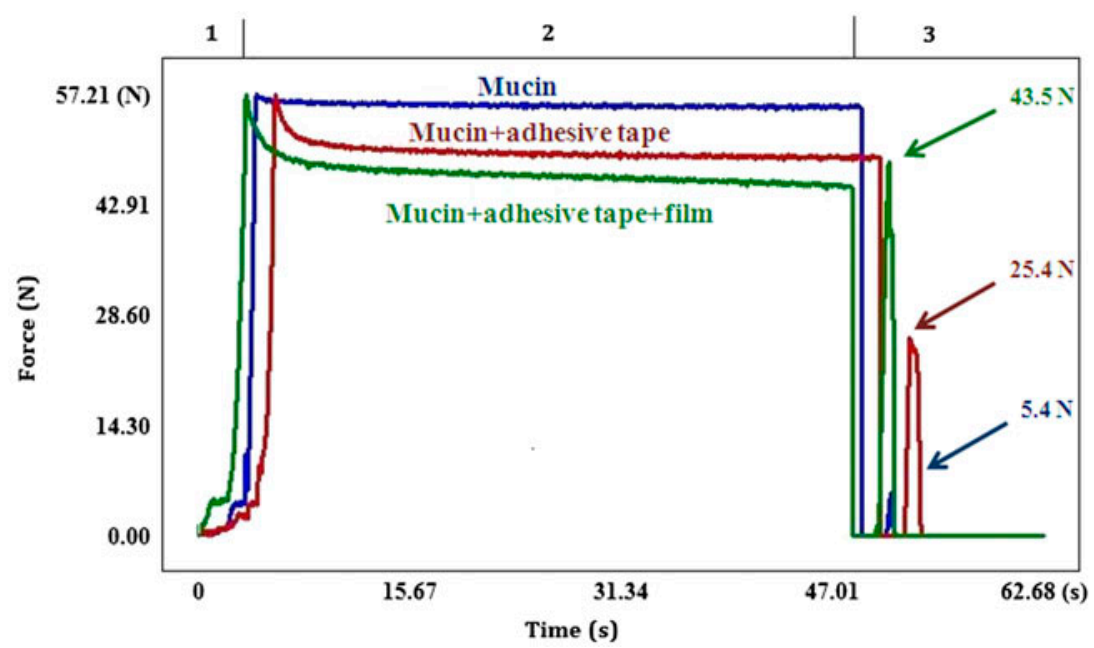

Figure 2. Process of measurement of the force of adhesion of a free film. 
procedure, every non-steel part of the system (the bilayer adhesive tape, the mucin and the film) undergoes a deformation: Section 1 of the curves reflects these phenomena. The almost horizontal parts of the curves (Section 2) relate to the period when contact with the bottom at $50 \mathrm{~N}$ is maintained for $45 \mathrm{~s}$. After the 45 -s holding time, the motor is reversed and starts to pull up the film. This is shown by the vertical line, followed by a 2-s pause. The peaks in the last part of the curves (Section 3) relate to the force of adhesion $(43.5 \mathrm{~N})$, which covers the elastic recovery of the sample (the bilayer adhesive tape, the mucin and the film together). Finally, correction of three-layered adhesion force by subtraction of the forces of adhesion of the tape and mucin leads to the force of adhesion of the sample: $18.1 \mathrm{~N}$.

The software also permits magnification of the different sections of the curve, and it is therefore possible to study the deformation of the samples better, especially in Sections 1 and 3 (Figures 3 and 4).

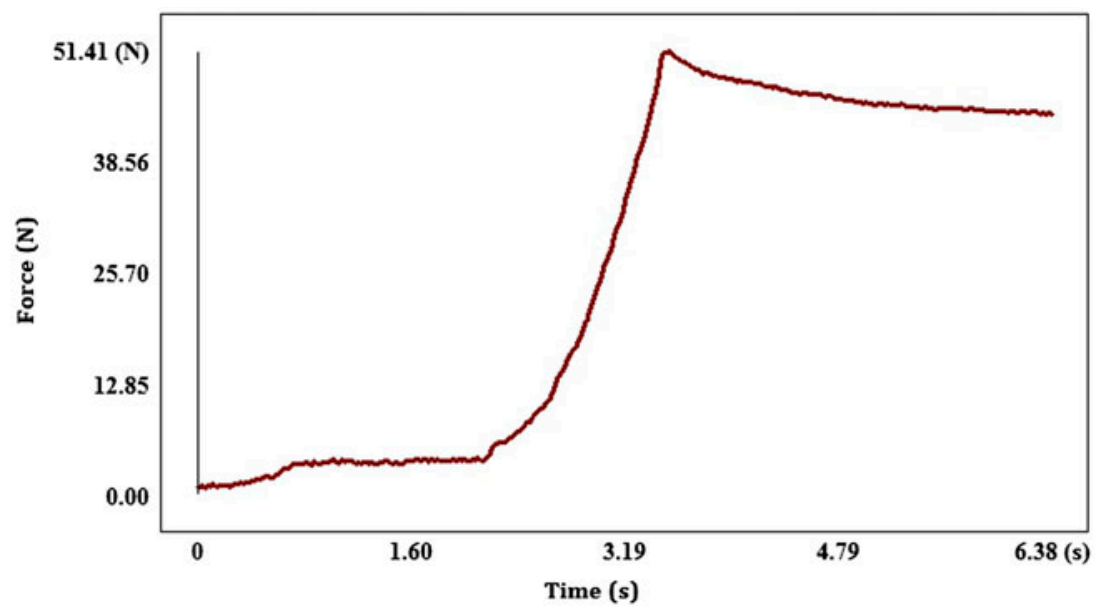

Figure 3. Detail of the static loading section of the curve.

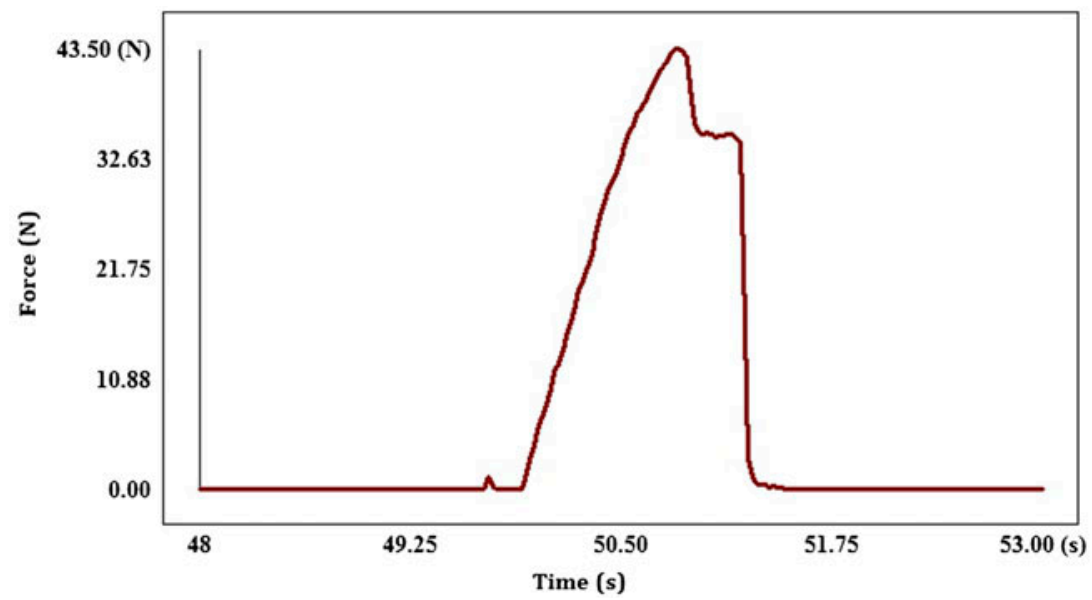

Figure 4. Detail of the force of adhesion of the curve. 
Figure 3 depicts the initial deformation of a sample during static loading, with a short elastic and longer plastoelastic deformation.

Figure 4 demonstrates the deformation during the dynamic (tensile) process when the force of adhesion is involved. The curve indicates elastic behaviour until the termination of the adhesion. The descending section shows that the contact between the mucin and the film is partially broken.

\section{Conclusions}

This work has revealed that this equipment with the new software is suitable for the study of the deformation of a mucoadhesive film successively during static loading and constant loading, and for determination of the force of adhesion. The results demonstrate that the characterization of mucoadhesive films is possible. The findings were utilized to create a theoretical model suitable for prediction of the optimum film composition that ensures the required adhesion to the mucous membrane.

\section{Disclosure statement}

The authors have no conflict of interest to declare.

\section{Funding}

The publication is supported by the European Union and co-funded by the European Social Fund. Project number: TÁMOP-4.2.2.A-11/1/KONV-2012-0047.

\section{ORCID}

Mihály Gottnek (D) http://orcid.org/0000-0002-3585-6349

\section{References}

[1] Boddupalli BM, Mohammed ZNK, Nath RA, Banji D. Mucoadhesive drug delivery system: an overview. J. Adv. Pharm. Technol. Res. 2010;1:381-387.

[2] Sriamornsak P, Wattanakorn N, Nunthanid J, Puttipipatkhachorn S. Mucoadhesion of pectin as evidence by wettability and chain interpenetration. Carbohydr. Polym. 2008;74:458-467.

[3] Sönju T, Christensen TB, Kornstad L, Rölla G. Electron microscopy, carbohydrate analyses and biological activities of the proteins adsorbed in two hours to tooth surfaces in vivo. Caries Res. 1974;8:113-122.

[4] Ahuja A, Khar RP, Ali J. Mucoadhesive drug delivery systems. Drug Dev. Ind. Pharm. 1997;23:489-515.

[5] Gu JM, Robinson JR, Leung SHS. Binding of acrylic polymers to mucin/epithelial surfaces: structure property relationships. Crit. Rev. Ther. Drug Carrier. Syst. 1988;5:21-67.

[6] Lee JW, Park JH, Robinson JR. Bioadhesive-based dosage forms: the next generation. J. Pharm. Sci. 2000;89:850-866.

[7] Smart JD, Mortazavi SA. An investigation of the $\mathrm{pH}$ within the hydrating gel layer of a poly(acylic acid) compact. J. Pharm. Pharmacol. 1995;47:1099.

[8] Chen JL, Cyr GN. Compositions producing adhesion trough hydration. In: Manly RS, editor. Adhesion in biological systems. New York (NY): Academic Press; 1970. p. 163-181.

[9] Smart JD, Kellaway IW, Worthington HEC. An in vitro investigation of mucosa-adhesive materials for use in controlled drug delivery. J. Pharm. Pharmacol. 1984;36:295-299.

[10] Harding SE, Davis SS, Deacon MP, Fiebrig I. Biopolymer mucoadhesives. Biotechnol. Genet. Eng. Rev. 1999;16:41-86. 
[11] Smart JD. Drug delivery using buccal adhesive systems. Adv. Drug Delivery Rev. 1993;11:253-270.

[12] Andrews GP, Laverty TP, Jones DS. Mucoadhesive polymeric platforms for controlled drug delivery. Eur. J. Pharm. Biopharm. 2009;71:505-518.

[13] Gandhi RB, Robinson JR. Oral cavity as a site for bioadhesive drug delivery. Adv. Drug Delivery Rev. 1994;13:43-74.

[14] Forstner JF. Intestinal mucins in health and disease. Digestion. 1978;17:234-263.

[15] Taylan B, Capan Y, Güven O, Kes S, Hincal A. Design and evaluation of sustained-release and buccal adhesive propranolol hydrochloride tablets. J. Controlled Release. 1996;38:11-20.

[16] Woertz C, Preis M, Breitkreutz J, Kleinebudde P. Assessment of test methods evaluating mucoadhesive polymers and dosage forms: an overview. Eur. J. Pharm. Biopharm. 2013;85:843-853.

[17] Davidovich-Pinhas M, Bianco-Peled H. Mucoadhesion: a review of characterization techniques. Expert Opin. Drug Delivery. 2010;7:259-271.

[18] Tobyn MJ, Johnson JR, Dettmar PW. Factors affecting in vitro gastric mucoadhesion I. Test conditions and instrumental parameters. Eur. J. Pharm. Biopharm. 1995;41:235-241.

[19] Jones DS, Woolfson AD, Brown AF. Textural, viscoelastic and mucoadhesive properties of pharmaceutical gels composed of cellulose polymers. Int. J. Pharm. 1997;151:223-233.

[20] Jones DS, Woolfson AD, Brown AF, O'Neill MJ. Mucoadhesive, syringeable drug delivery systems for controlled application of metronidazole to the periodontal pocket: in vitro release kinetics, syringeability, mechanical and mucoadhesive properties. J. Controlled Release. 1997;49:71-79.

[21] Hägerström H, Edsman K. Interpretation of mucoadhesive properties of polymer gel preparations using a tensile strength method. J. Pharm. Pharmacol. 2001;53:1589-1599.

[22] Repka MA, Gutta K, Prodduturi S, Munjal M, Stodghill SP. Characterization of cellulosic hot-melt extruded films containing lidocaine. Eur. J. Pharm. Biopharm. 2005;59:189-196.

[23] Thirawong N, Nunthanid J, Puttipipatkhachorn S, Sriamornsak P. Mucoadhesive properties of various pectins on gastrointestinal mucosa: an in vitro evaluation using texture analyzer. Eur. J. Pharm. Biopharm. 2007;67:132-140.

[24] Hagesaether E, Hiorth M, Sande SA. Mucoadhesion and drug permeability of free mixed films of pectin and chitosan: an in vitro and ex vivo study. Eur. J. Pharm. Biopharm. 2009;71:325-331.

[25] Abruzzo A, Bigucci F, Cerchiara T, Cruciani F, Vitali B, Luppi B. Mucoadhesive chitosan/ gelatin films for buccal delivery of propranolol hydrochloride. Carbohydr. Polym. 2012;87:581-588.

[26] Sogias IA, Williams AC, Khutoryanskiy VV. Chitosan-based mucoadhesive tablets for oral delivery of ibuprofen. Int. J. Pharm. 2012;436:602-610.

[27] Duchěne D, Touchard F, Peppas NA. Pharmaceutical and medical aspects of bioadhesive systems for drug administration. Drug Dev. Ind. Pharm. 1988;14:283-318.

[28] Park H, Robinson JR. Physico-chemical properties of water insoluble polymers important to mucin/epithelial adhesion. J. Controlled Release. 1985;2:47-57.

[29] Gurny R, Meyer JM, Peppas NA. Bioadhesive intraoral release systems: design, testing and analysis. Biomaterials. 1984;5:336-340.

[30] Ponchel G, Touchard F, Wouessidjewe D, Duchene D, Peppas NA. Bioadhesive analysis of controlled-release systems. III. Bioadhesive and release behavior of metronidazole-containing poly(acrylic acid)-hydroxypropyl methylcellulose systems. Int. J. Pharm. 1987;38:65-70.

[31] Ferrari F, Bertoni M, Rossi S, Bonferoni MC, Caramella C, Waring MJ, Aulton ME. Comparative rheomechanical and adhesive properties of two hydrocolloid dressings: dependence on the degree of hydration. Drug Dev. Ind. Pharm. 1996;22:1223-1230.

[32] Sudhakar Y, Kuotsu K, Bandyopadhyay AK. Buccal bioadhesive drug delivery - a promising option for orally less efficient drugs. J. Controlled Release. 2006;114:15-40.

[33] Carvalho FC, Bruschi ML, Evangelista RC, Gremiao MPD. Mucoadhesive drug delivery systems. Braz. J. Pharm. Sci. 2010;46:1-17.

[34] Cleary J, Bromberg L, Magner E. Adhesion of polyether-modified poly(acrylic acid) to mucin. Langmuir. 2004;20:9755-9762.

[35] Takeuchi H, Thongborisute J, Matsui Y, Sugihara H, Yamamoto H, Kawashima Y. Novel mucoadhesion tests for polymers and polymer-coated particles to design optimal mucoadhesive drug delivery systems. Adv. Drug Delivery Rev. 2005;57:1583-1594. 
[36] Thongborisute J, Takeuchi H. Evaluation of mucoadhesiveness of polymers by BIACORE method and mucin-particle method. Int. J. Pharm. 2008;354:204-209.

[37] Ivarsson D, Wahlgren M. Comparison of in vitro methods of measuring mucoadhesion: ellipsometry, tensile strength and rheological measurements. Colloids Surf., B. 2012;92:353-359.

[38] Hassan EE, Gallo JM. A simple rheological method for the in vitro assessment of mucinpolymer bioadhesive bond strength. Pharm. Res. 1990;7:491-495.

[39] Malmsten M, Ljusegren I, Carlstedt I. Ellipsometry studies of the mucoadhesion of cellulose derivatives. Colloids Surf., B. 1994;2:463-470.

[40] Park K. A new approach to study mucoadhesion: colloidal gold staining. Int. J. Pharm. 1989;53:209-217.

[41] Mikos AG, Peppas NA. Bioadhesive analysis of controlled-release systems. IV. An experimental method for testing the adhesion of microparticles with mucus. J. Controlled Release. 1990;12:31-37.

[42] Teng CLC, Ho NFH. Mechanistic studies in the simultaneous flow and adsorption of polymer-coated latex particles on intestinal mucus I: methods and physical model development. J. Controlled Release. 1987;6:133-149.

[43] Hasçiçek C, Gönül N, Erk N. Mucoadhesive microspheres containing gentamicin sulfate for nasal administration: preparation and in vitro characterization. Farmaco. 2003;58:11-16.

[44] Nielsen LS, Schubert L, Hansen J. Bioadhesive drug delivery systems. Eur. J. Pharm. Sci. 1998;6:231-239.

[45] Repka MA, McGinity JW. Bioadhesive properties of hydroxypropylcellulose topical films produced by hot-melt extrusion. J. Controlled Release. 2001;70:341-351.

[46] Nakamura F, Ohta R, Machida Y, Nagai T. In vitro and in vivo nasal mucoadhesion of some water-soluble polymers. Int. J. Pharm. 1996;134:173-181.

[47] Kelemen A. Dynamic force measurements in preformulation of solid dosage forms [PhD thesis]. Szeged: University of Szeged; 2012. 
Copyright of Journal of Adhesion Science \& Technology is the property of Taylor \& Francis Ltd and its content may not be copied or emailed to multiple sites or posted to a listserv without the copyright holder's express written permission. However, users may print, download, or email articles for individual use. 
II. 


\title{
Tracking of the behaviour of lidocaine base containing hydroxypropylcellulose free films with thermoanalytical method
}

\author{
Mihály Gottnek • Klára Pintye-Hódi • \\ Géza Regdon Jr.
}

Received: 19 November 2014 / Accepted: 6 January 2015/Published online: 30 January 2015

(C) Akadémiai Kiadó, Budapest, Hungary 2015

\begin{abstract}
The excipients proved to exert strong effects on the physicochemical properties of the tested systems, and it is very important to study them intensively in preformulation studies in pharmaceutical technology. In our earlier paper, we already described the structure of $\mathrm{Klucel}^{\circledR}$-containing films with various physicochemical examinations (tensile strength, surface properties and positron annihilation lifetime spectroscopy). The aim of our present investigations was to study the thermal behaviour of the filmforming polymers with two different chain lengths, of the taste-enhancing and plasticizing excipients and also of the films prepared from them. The thermal behaviour of Klucel $^{\circledR}$ LF and Klucel ${ }^{\circledR}$ MF film-forming polymers was found to differ only in the range of $340-400{ }^{\circ} \mathrm{C}$, which is due to the different chain lengths of the polymer molecules. Among the active ingredients and excipients used, glycerol had the smallest while xylitol showed the greatest thermal stability. The shape of the TG curves shows that the decomposition process changes with the increase in the concentration of the excipients. The TG curves open up more, which is probably due to the fact that the molecules built-in among the polymer chains loosen the structure, which in turn is decomposed more easily. The TG-MS examinations revealed that during decomposition, carbon dioxide was formed in the highest concentration and that acetic acid, isopropyl alcohol and acetone also developed. The shape of the TG curves shows that in the case of the 5 and $10 \%$ systems, the presence of lidocaine did not result in a significant difference in thermal stability.
\end{abstract}

M. Gottnek · K. Pintye-Hódi · G. Regdon Jr. ( $₫)$

Department of Pharmaceutical Technology, University of

Szeged, Eötvös utca 6, Szeged 6720, Hungary

e-mail: geza.regdon@pharm.u-szeged.hu
Keywords Klucel $^{\circledR}$ LF/MF $\cdot$ Xylitol · Glycerol · Lidocaine base $\cdot$ DSC $\cdot$ TG-MS

\section{Introduction}

Differential scanning calorimetry (DSC) is a widely used method to determine different properties of pharmaceuticals: glass transition in polymers $\left(T_{\mathrm{g}}\right)$ [1-5]; amorphicity and crystallinity [1, 6-9]; polymorphism [1, 10-14]; drug solubility in polymers [1, 15-18]; characterization of polymers and bio-polymers [1, 19-22]; and pharmaceutical dosage forms [23, 24]. Thermogravimetry (TG) is also used to characterize pharmaceuticals $[18,25-31]$.

Innovative pharmaceutical production has recently placed great emphasis on developing drug-containing bioadhesive films. In line with this, many of the increasing number of papers published in the literature report the investigation of thermal behaviour.

A novel organic-inorganic hybrid transdermal filmforming system was designed by a modified poly(vinyl alcohol) (PVA) gel plasticized with glycerol (GLY), using c-(glycidyloxypropyl)trimethoxysilane (GPTMS) as an inorganic-modifying agent, and poly( $N$-vinyl pyrrolidone) (PVP) as a tackifier. DSC was used to determinate the thermal behaviour of the samples. The system was first heated at a rate of $10{ }^{\circ} \mathrm{C} \mathrm{min}^{-1}$ from 20 to $200{ }^{\circ} \mathrm{C}$ and kept there for $10 \mathrm{~min}$ then cooled down to $50{ }^{\circ} \mathrm{C}$ at a rate of $20{ }^{\circ} \mathrm{C} \mathrm{min}{ }^{-1}$. The second heating scan from 50 to $200{ }^{\circ} \mathrm{C}$ at $10{ }^{\circ} \mathrm{C} \mathrm{min}{ }^{-1}$ was applied to determinate the glass transition temperature. It was found that all PVA-GPTMSPVP-GLY samples exhibit the soft-hard segment microphase separation. The good skin adhesive properties of the films come from the flexible soft segments composed of uncross-linked PVA chain, PVP and GLY, which 
influenced the viscoelastic properties and low-temperature performance of the films. The hard segments (PVAGPTMS and self-cross-linked GPTMS) give the mechanical strength and appropriate film-forming properties to the system [32].

For transdermal controlled drug delivery, a flurbiprofen (FB)-inorganic nanohybrid system was made. TG-DTA was used to investigate the samples; the temperature was increased from ambient to $800{ }^{\circ} \mathrm{C}$ at a heating rate of $2{ }^{\circ} \mathrm{C} \mathrm{min}{ }^{-1}$ under $100 \mathrm{~mL} \mathrm{~min}^{-1}$ airflow. The TG-DTA was used on the dry powder. Three mass losses were detected. The first mass loss of $6.51 \%$ with a weak endothermic response at around $71.9{ }^{\circ} \mathrm{C}$ originated from the removal of absorbed water from the surface of the system. The second mass loss, approximately $8.03 \%$ with an endothermic peak at around $166.26{ }^{\circ} \mathrm{C}$, was connected to the dehydration of co-intercalated water in samples. The third mass loss around $47.06 \%$ was associated with an exothermic reaction in the range from 225 to $520{ }^{\circ} \mathrm{C}$ [33].

Ibuprofen (IBU) mucoadhesive tablets containing chitosan and its half-acetylated derivative as excipients were compared. Polymer-IBU interactions and the degree of IBU crystallinity were investigated by DSC. Samples were heated under a nitrogen atmosphere at $5{ }^{\circ} \mathrm{C} \mathrm{min}{ }^{-1}$ from 25 to $90{ }^{\circ} \mathrm{C}$. DSC was used to determine the effect of co-grinding and chitosan on IBU crystallinity. The onset of IBU melting was observed at $73.9^{\circ} \mathrm{C}$, and the enthalpy was $125.4 \mathrm{~J} \mathrm{~g}^{-1}$. In the co-ground mixture with chitosan, IBU's onset melting point decreased by approximately $3{ }^{\circ} \mathrm{C}$ and the enthalpy was $121.6 \mathrm{~J} \mathrm{~g}^{-1}$ of IBU. Chitosan did not show any thermal changes over this temperature range. The decreased enthalpy on co-grinding equates to a $4 \%$ loss in IBU crystallinity [34].

Matrix-type mucoadhesive tablet from a mixture of hard fat, ethylcellulose and polyethylene glycol, containing indomethacin, was developed. The thermal behaviour of matrix bases was investigated with DSC. Samples were heated at a rate of $10{ }^{\circ} \mathrm{C} \mathrm{min}{ }^{-1}$ from 20 to $170{ }^{\circ} \mathrm{C}$ in air. In the DSC curve, an endothermic peak was observed at approximately $150{ }^{\circ} \mathrm{C}$ [35].

Development of novel mucoadhesive pellets containing valsartan (VAL) was the goal of a study of Caoa et al. Two types of drug-loaded core pellets were prepared by different technology, namely extrusion/spheronization method. Pellets were dry-coated with a mixture of hydroxypropylmethylcellulose and carbomer at different ratios. The thermal properties of VAL, Povidone ${ }^{\circledR} \mathrm{K} 30$, Poloxamer, Avicel ${ }^{\circledR} \mathrm{PH} 101, \mathrm{NaOH}$ and core pellet powders (F1 and F2) were determined with DSC. The samples were heated from 25 to $200{ }^{\circ} \mathrm{C}$ at a heating rate of $10{ }^{\circ} \mathrm{C} \mathrm{min}^{-1}$ under nitrogen atmosphere. A broad single endothermic peak was found in case of pure VAL, while no melting peak was detected in the cases of both
$\mathrm{F} 1$ and $\mathrm{F} 2$ pellets. This phenomenon confirmed that there was some impact between VAL and additives during extrusion process [36].

Pressure-sensitive IBU-containing adhesive was investigated by DSC. Samples were heated from 130 to $100{ }^{\circ} \mathrm{C}$ at a heating rate of $10 \mathrm{~K} \mathrm{~min}^{-1}$ under nitrogen atmosphere. The second heating runs were evaluated. It was found that IBU increasing in the formulation caused the decrease in the $T_{\mathrm{g}}$, which phenomenon was connected to the plasticization effect of IBU on the product [37].

A hydrophobic mucoadhesive thiolated chitosan for pipirine (PIP) delivery was designed. The thermal degradation behaviour of the samples was determined with TG. The mass loss curves were recorded with a heating rate of $25{ }^{\circ} \mathrm{C} \mathrm{min}{ }^{-1}$ under nitrogen flow from 50 to $600{ }^{\circ} \mathrm{C}$. For chitosan, the highest thermal decomposition stage occurred at $326{ }^{\circ} \mathrm{C}$ with a mass loss of $41.8 \%$. The TG curves of PIP revealed the highest thermal decomposition occurred at $363{ }^{\circ} \mathrm{C}$. The chitosan-PIP microparticles curve showed a maximum decomposition rate at $293{ }^{\circ} \mathrm{C}$, which was lower than the pure chitosan and may indicate a lower thermal stability of the PIP-chitosan microspheres than the chitosan ones [38].

Buccal poly(ethylene oxide) (PEO) film with (2hydroxypropyl)- $\beta$-cyclodextrin (CD) was evaluated. Films were prepared at different $\mathrm{PEO} / \mathrm{CD}$ ratios. The degree of crystallinity was determined by DSC. The degree of crystallinity was roughly constant for platform with a $C D$ content $\leq 60 \% \mathrm{w} / \mathrm{w}$. On the other hand, PEO/CD75 and $\mathrm{PEO} / \mathrm{CD} 80$ platforms showed a drastic decrease in the degree of crystallinity [39].

Novel sildenafil citrate (SC)-loaded PVA-polyethylene glycol (PEG) graft copolymer (Kollicoat1 IR)-based orally dissolving films (ODFs) were designed. The thermal properties and physicochemical behaviour of samples were evaluated using DSC. Kollicoat1 IR, sodium alginate (ALG-Na) and glycerol were combined. The films were heated at a rate of $10{ }^{\circ} \mathrm{C} \mathrm{min}{ }^{-1}$ from 10 to $250{ }^{\circ} \mathrm{C}$ under nitrogen flow. A sharp endothermic peak of SC was found at $198{ }^{\circ} \mathrm{C}$, which was connected to the melting point of SC [40]. Melting SC peak was not detected in the curves of SC-loaded ODF. This indicated that interactions between $\mathrm{SC}$ and excipients had occurred in the preparation process of the film [40].

The goal of a study was to investigate the potential of isothermal calorimetry to monitor and characterize crystallization in indomethacin (IND)-loaded fast-dissolving PVP oral films. Subsequent analysis of the crystals with DSC was made. Samples were heated from 25 to $190{ }^{\circ} \mathrm{C}$ at $200{ }^{\circ} \mathrm{C} \mathrm{min}{ }^{-1}$ with nitrogen flow. It was found that isothermal calorimetry is able to monitor IND crystallization in polymer films [41]. 
Lidocaine (LID)-loaded mucoadhesive buccal patches for controlled release in different formulations were studied. Films were loaded with LID-Compritol solid dispersion in the form of microspheres, and the effects of the composition were evaluated by DSC. Samples were heated at a rate of $10{ }^{\circ} \mathrm{C} \mathrm{min}{ }^{-1}$ between 30 and $300{ }^{\circ} \mathrm{C}$. Melting points at $82{ }^{\circ} \mathrm{C}$ for lidocaine and at $75^{\circ} \mathrm{C}$ for the main peak of Compritol were found. An irregularly shaped melting endotherm main peak at $73{ }^{\circ} \mathrm{C}$ was found for the microsphere samples. It suggested that the solid "microsphere" system was heterogeneous in nature [42].

Enrofloxacin (ENR)-loaded PVP thin films were formulated for enhanced drug delivery and were evaluated using DSC. Samples were heated from 25 to $300{ }^{\circ} \mathrm{C}$ with a heating rate of $10{ }^{\circ} \mathrm{C} \mathrm{min}-1$ in argon atmosphere. An endothermic peak of ENR was found at $222^{\circ} \mathrm{C}$ corresponding to the melting point of the drug. A large endothermic peak of ENR-PVP at $94.57{ }^{\circ} \mathrm{C}$ was found. The absence/reduction in ENR peaks suggested that the drug is amorphous. The result indicated that there was good compatibility between ENR and PVP [43].

The excipients proved to exert strong effects on the physicochemical properties of the tested systems, and it is very important to study them intensively in preformulation studies in pharmaceutical technology. For this reason, in our earlier paper, we already reported our various physicochemical examinations with Klucel $^{\circledR}$-containing films (tensile strength, surface properties and the measurement of the free volume with positron annihilation lifetime spectroscopy), which were performed to study and to describe the resulting film structure [44].

The aim of our present investigations was to study the thermal behaviour of the film-forming polymers with two different chain lengths, of the taste-enhancing and plasticizing excipients and also of the films prepared from them, as these data can provide useful information on the storage conditions and stability of drug-containing films.

\section{Materials}

HPC (Klucel ${ }^{\circledR}$ MF and LF) (Aqualon; Hercules Inc., Wilmington, USA.) was used as a film-forming polymer. The main differences between the two Klucel ${ }^{\circledR}$ products are in the molecular mass and the viscosity of the solution. MF has a higher viscosity in solution and a higher molecular mass. HPC is a non-ionic, water-soluble cellulose ether, and its films are appropriately flexible even without any plasticizer.

The local anaesthetic lidocaine base (Lid) (Ph. Eur., Società Italiana Medicinali Scandicci, Firenze, Italy) was chosen as the active ingredient. Xylitol (Xyl) (Ph.Eur., Roquette, Lestrem, France) was used as the taste improver.
Glycerol (Gly) (Ph. Eur., Molar Chemicals Kft., Budapest, Hungary) was used as a plasticizer, and in films it can act as a taste coverer.

\section{Methods}

Preparation of free films

The optimum polymer concentration was first established, $2 \%$ w/w solutions were chosen for both types of Klucel ${ }^{\circledR}$ as we wished to compare their physicochemical properties. Lidocaine (Lid) was grounded in a mill (Retsch RM 100, Retsch GmbH, Haan, Germany), and the 100-200- $\mu \mathrm{m}$ powder fraction was incorporated into the solution. Xylit (Xyl) dissolved readily, and glycerol (Gly) compounded well in the water-polymer mixture. Lid, Gly and Xyl were all used in the same concentration $(5,10$ or $15 \% \mathrm{w} / \mathrm{w}$ of the film-forming polymer). Samples were poured onto a non-stick surface. All the films were made by the same solvent-casting technology and stored at room temperature $\left(25^{\circ} \mathrm{C} / 65 \% \mathrm{RH}\right)$ for a day and then placed into a climate chamber for $24 \mathrm{~h}\left(40{ }^{\circ} \mathrm{C} / 50 \% \mathrm{RH}\right)$.

\section{Thermoanalytical measurements}

The thermoanalytical examinations of the materials were carried out with a Mettler Toledo TG/DSC1 instrument (Mettler Toledo, Switzerland). During the DSC measurements, the start temperature was $-40{ }^{\circ} \mathrm{C}$, the end temperature was $300{ }^{\circ} \mathrm{C}$, and the applied heating rate was $10{ }^{\circ} \mathrm{C} \mathrm{min}{ }^{-1}$. Argon atmosphere was used, and nitrogen was used as drying gas. $10 \pm 1$-mg sample was measured into an aluminium pan $(40 \mu \mathrm{l})$. The curves were calculated from the average of three parallel measurements and were evaluated with STARe software.

For the TG and the DSC measurements, the start temperature was $+25^{\circ} \mathrm{C}$, the end temperature was $400{ }^{\circ} \mathrm{C}$, and the applied heating rate was $10{ }^{\circ} \mathrm{C} \mathrm{min}{ }^{-1}$. Nitrogen atmosphere was used. $10 \pm 1$-mg sample was measured into an aluminium pan $(100 \mu \mathrm{l})$. The curves were calculated from the average of three parallel measurements and were evaluated with STARe Software.

The thermal characteristics of the sample mass loss were determined with a thermal gravimetric analyzer (Mettler Toledo, model TG/DSC1) coupled with a quadrupole mass spectrometer (Pfeiffer Vacuum, model Thermostar ${ }^{\mathrm{TM}}$ GSD 320 ), operated under $\mathrm{N}_{2}$ atmosphere (purity $=99.999 \%$, $70 \mathrm{~mL} \mathrm{~min}^{-1}$ flow rate). The connection between the TG and the mass spectrometer was made by means of a silica capillary, which was maintained at $120^{\circ} \mathrm{C}$. 


\section{Results and discussion}

The thermal studies were started by studying the filmforming polymers as well as the active ingredient and excipients to be used, and the changes were monitored between 25 and $400{ }^{\circ} \mathrm{C}$ at a constant heating rate. The changes in heat flow were followed with the help of DSC curves. The thermal behaviour of the two film-forming polymers, lidocaine used as an active ingredient and the two excipients (glycerol and xylitol) is shown in Fig. 1.

A slight endothermic baseline shift can be observed in the DSC curves of the Klucel ${ }^{\circledR}$ LF and MF polymers between 40 and $100{ }^{\circ} \mathrm{C}$, which can be explained with the removal of the water content of the polymer. The heat flow curves show no difference until $340^{\circ} \mathrm{C}$, and then signs of decomposition appear in both curves.

The DSC curve of glycerol shows a definite endothermic peak between 50 and $150{ }^{\circ} \mathrm{C}$ due to the higher water content, while at about $200{ }^{\circ} \mathrm{C}$ signs of decomposition can be observed until $300{ }^{\circ} \mathrm{C}$.

In the DSC curve of xylitol, an onset value of $92.2{ }^{\circ} \mathrm{C}$ is followed by a peak melting point at $95.6{ }^{\circ} \mathrm{C}$. The enthalpy change of the process is $217.4 \mathrm{~J} \mathrm{~g}^{-1}$. Xylitol has much greater thermal stability as the baseline change and the decomposition process start only at about $280^{\circ} \mathrm{C}$ and end over $380^{\circ} \mathrm{C}$.

Lidocaine, which is used as an active ingredient, has a lower melting point than the excipients because the onset value is $67.2^{\circ} \mathrm{C}$ and the peak of the melting point appears at $68.6{ }^{\circ} \mathrm{C}$. The enthalpy change of the process is $59.1 \mathrm{~J} \mathrm{~g}^{-1}$. The baseline change appears over $180{ }^{\circ} \mathrm{C}$, and then the decomposition process is accelerated over $200{ }^{\circ} \mathrm{C}$ and finishes at about $330{ }^{\circ} \mathrm{C}$.

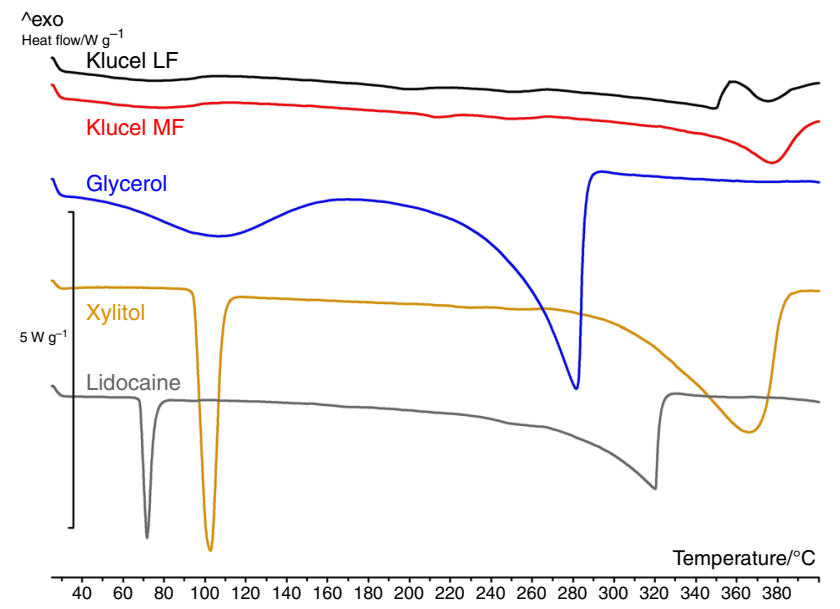

Fig. 1 Thermal properties of Klucel $^{\circledR}$ film-forming materials, active ingredient and excipients as shown by the DSC curves

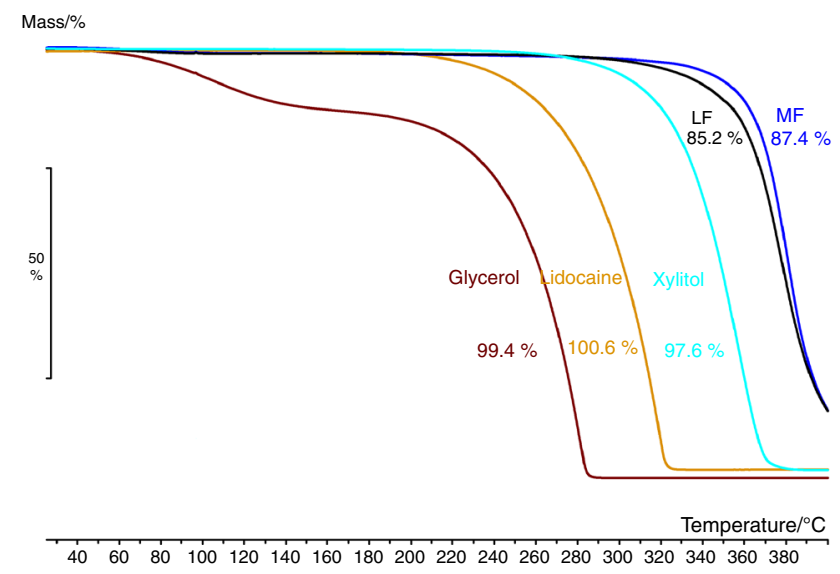

Fig. 2 Thermal properties of Klucel ${ }^{\circledR}$ film-forming materials, active ingredient and excipients as shown by the TG curves

The TG curves of the same materials in Fig. 2 show that the two different film-forming materials are thermally stable, a mass loss of only $1-1.5 \%$ can be detected until $100{ }^{\circ} \mathrm{C}$, the decomposition process starts over $300{ }^{\circ} \mathrm{C}$, and mass loss is $85 \%$ for Klucel ${ }^{\circledR} \mathrm{LF}$ and $87 \%$ for Klucel ${ }^{\circledR}$ MF until $400{ }^{\circ} \mathrm{C}$. However, the rate of the decomposition process is different, and it is faster for the LF product and slower for the MF product, which is also shown clearly by the numerical data of the mass loss of the two polymers (see Table 1).

From the data, it can be stated that the mass loss of $1.0-1.5 \%$ observed at the beginning of heating can be explained by the removal of water from the film, and then further mass loss starts only at about $300{ }^{\circ} \mathrm{C}$. The thermal behaviour of the two polymers differs significantly between 340 and $400{ }^{\circ} \mathrm{C}$, which can be explained by the different chain lengths of the two polymers. The Klucel $^{\circledR}$ MF product with a longer chain has greater thermal stability, and probably the more stable structure is broken only at higher temperatures.

The thermal behaviour of the excipients as shown by their TG curves (see Fig. 2) can be described well, and it confirms the information obtained from the DSC curves. Although both excipients were entirely decomposed by the end of the examination, considerable differences can be observed in their behaviour. Xylitol proved to be the most stable as the decomposition process really starts only over $300{ }^{\circ} \mathrm{C}$. Ensuing from its material properties, glycerol first loses its water content at the beginning of heating, and then its decomposition starts over $180^{\circ} \mathrm{C}$ and finishes at $290{ }^{\circ} \mathrm{C}$. The thermal behaviour of the active ingredient is somewhere between those of the two excipients, as in the case of lidocaine, the mass loss curve reveals that decomposition starts at about $180-200{ }^{\circ} \mathrm{C}$ (see Table 1.). 


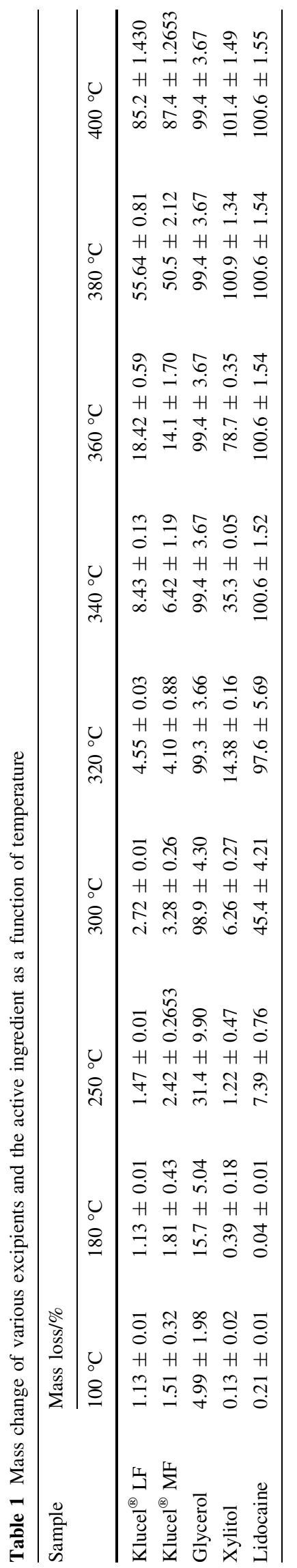

After studying and learning about the thermal behaviour of the film-forming polymer and the excipients to be used, we wished to study the behaviour of the free films which were prepared from them and contained both excipient and active ingredient. As regards Klucel ${ }^{\circledR} \mathrm{LF}$ and MF products, differences in thermal stability were observed only over $300{ }^{\circ} \mathrm{C}$, so they behaved in the same way when applied under the conditions of the oral mucosa. Klucel ${ }^{\circledR}$ LF products were chosen for the formulation of bioadhesive films and the examination of their thermal stability, and these results are presented in this paper.

The thermal behaviour of Kluce ${ }^{\circledR}$ LF films containing both xylitol and glycerol is illustrated in Fig. 3.

Glycerol and xylitol were present in the films in the same concentrations (at $0-5-10-15 \%$ w/w of the polymer). The shape of the TG curves shows that although the

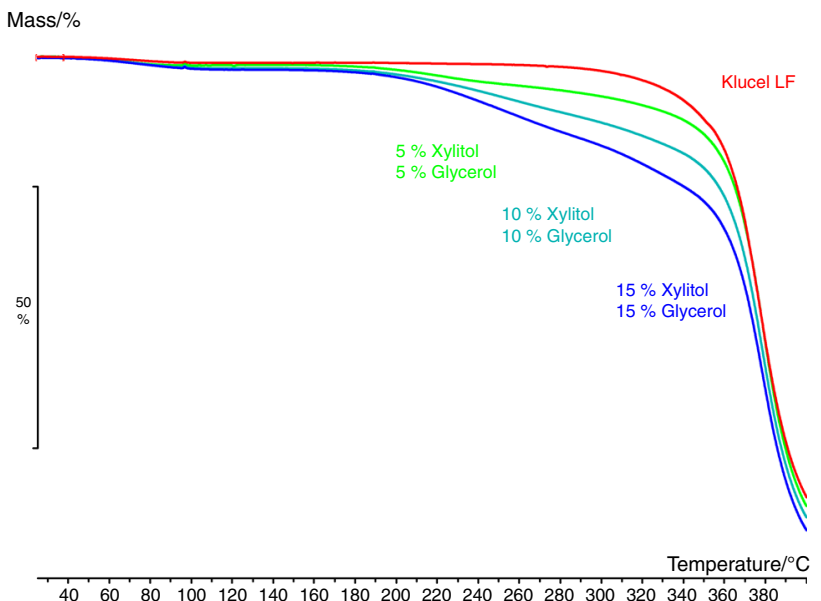

Fig. 3 Thermal properties of films made from Klucel ${ }^{\circledR}$ LF filmforming material containing xylitol and glycerol as shown by the TG curves

Mass $/ \%$

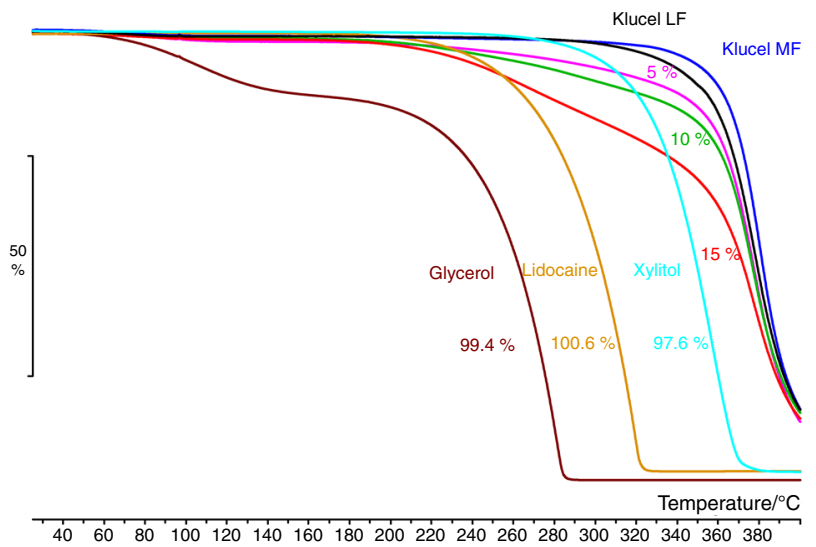

Fig. 4 Thermal properties of films made from Klucel ${ }^{\circledR}$ LF filmforming material containing lidocaine as well as xylitol and glycerol as shown by the TG curves 
decomposition process changes with the increase in the concentration of the excipients, when heated up to $400{ }^{\circ} \mathrm{C}$, mass loss does not differ significantly compared to Klucel ${ }^{\circledR}$ LF films without excipients. At the beginning of heat treatment, mass loss can be explained by the removal of the water content in every case and it is proportional to the concentration of glycerol. However, over $180-200{ }^{\circ} \mathrm{C}$, the decomposition processes start, and the TG curves open up more, which is probably due to the fact that the molecules built-in among the polymer chains loosen the structure, which in turn is decomposed more easily.

Then, we studied the thermal behaviour of drug-containing films. In Fig. 4, the thermal behaviour of Klucel ${ }^{\circledR}$

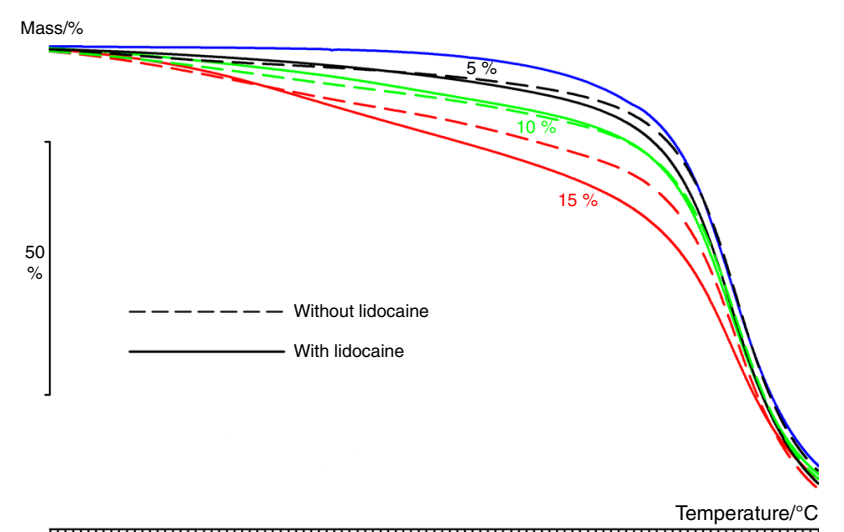

200210220230240250260270280290300310320330340350360370380390

Fig. 5 Comparison of the thermal properties of xylitol and glycerol containing Klucel ${ }^{\circledR}$ LF films with and without lidocaine between 200 and $400{ }^{\circ} \mathrm{C}$ as shown by the TG curves
LF films containing lidocaine as well xylitol and glycerol is presented. The effect of the ratio (quantity) of the components on the shape of the TG curves as well as on the quantity and disproportion of the arising mass loss can be seen clearly. It is remarkable that while a smaller mass loss was observed for the 5 and $10 \%$ films, the mass loss of the $15 \%$ film was greater, which can be explained by the loosening effect of glycerol and lidocaine on the polymer structure.

The concentrations of the active ingredient and the excipients in the films were always the same (0-5-10-15\% w/w of the film-forming polymer). The shape of the TG curves is similar to the one shown by films without lidocaine, but they can be compared really well if the TG curves of films with lidocaine (continuous line) and without lidocaine (broken line) are plotted together (see Fig. 5). The temperature range $\left(200-400{ }^{\circ} \mathrm{C}\right)$ of the greatest importance with respect to the phenomenon is focussed on here. The shape of the curves shows that in the case of the 5 and $10 \%$ systems, the presence of lidocaine practically did not result in a significant difference in thermal stability, while in the concentration of $15 \%$, the films which contained lidocaine were decomposed more easily, which is due to the greater quantity of the materials used and to the ensuing looser structure.

This can probably be explained by the fact that the plasticizer, when used in a lower concentration, can be incorporated into the film structure, which we have already confirmed in the case of Metolose free films [45-47]. However, when it is applied in higher concentrations, the
Fig. 6 Thermal properties of films made from Klucel $^{\circledR}$ LF film-forming material containing $15 \%$ glycerol as shown by the TG-MS curves
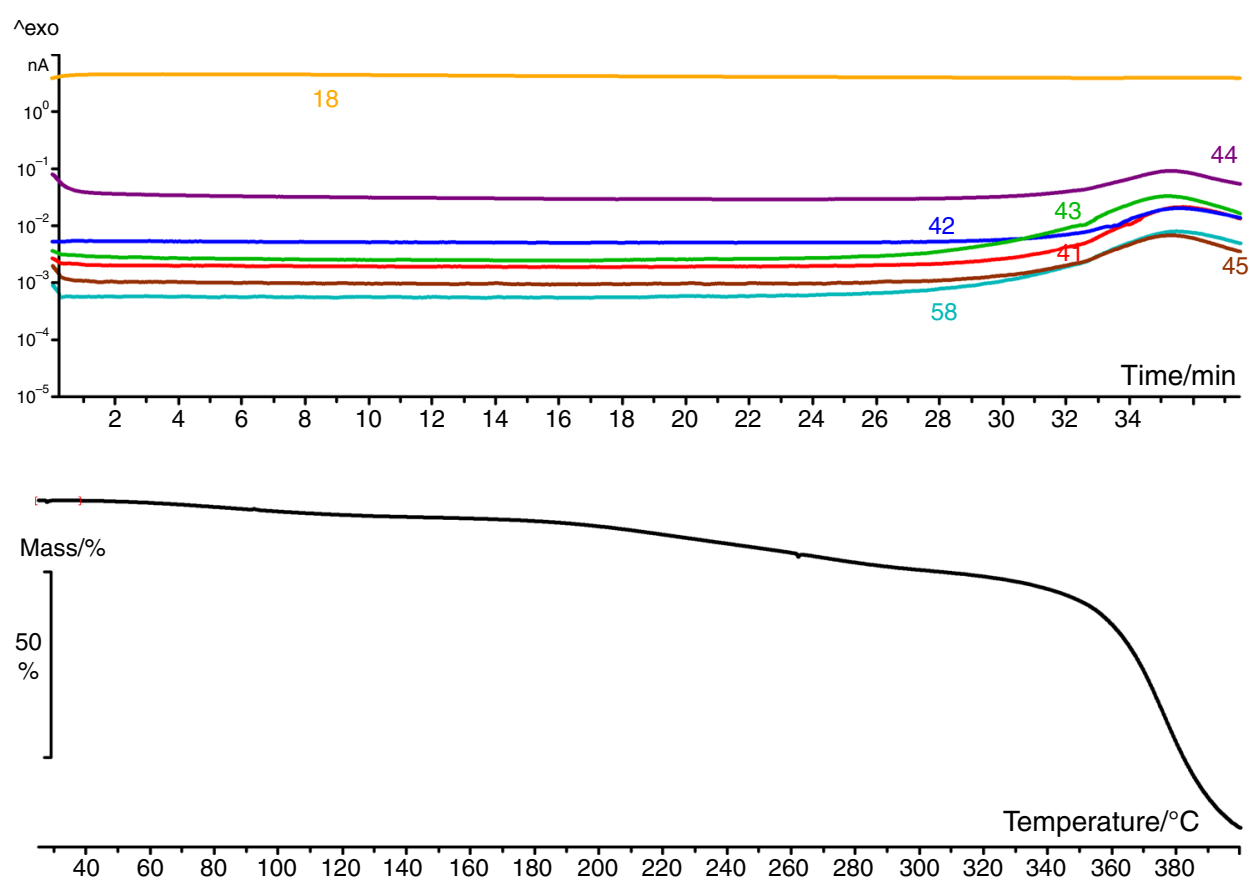
stability of the film structure deteriorates, which is illustrated well by the presented curves, when $15 \%$ of other components were used besides the polymer.

We also performed the TG-MS examination of all the films, we analysed the evolved gases with a mass spectrograph coupled with the TG in order to obtain information about the stability of the film structure. Among the several measurements, the data obtained with films containing $15 \%$ glycerol are presented in Fig. 6. Although no change can be observed for the $m / z=18$ fragment on axis "Y" with a logarithmic scale, in the case of an absolute scale water removal can be seen between both $40-150$ and $350-400{ }^{\circ} \mathrm{C}$, and with the start of decomposition, a concentration increase was experienced for further fragments $(\mathrm{m} / \mathrm{z}=41,42,43,44$, 45 and 58), starting practically at the same time. The peak intensity of the fragments depicted decreased in the following order: $m / z=44-43-42-41-58-45$. All these indicate that carbon dioxide is formed in the greatest concentration, which is confirmed by the increase of $\mathrm{m} /$ $z=44 . m / z=43,45$ may indicate the development of acetic acid and/or isopropyl alcohol, while $\mathrm{m} / \mathrm{z}=43,58$ may be indicative of the formation of acetone.

\section{Conclusions}

In the course of our experiments, free films were prepared from Klucel ${ }^{\circledR}$ film-forming materials with various chain lengths for buccal administration, with glycerol and/or xylitol taste enhancer excipient and lidocaine active ingredient incorporated in various concentrations. During the study of the bioadhesive films, it was found that the thermal behaviour of Klucel ${ }^{\circledR}$ LF and Klucel ${ }^{\circledR}$ MF filmforming polymers was different from each other only in the temperature range of $340-400{ }^{\circ} \mathrm{C}$, which is due to the difference in the chain length of the polymer molecule.

Among the active ingredients and excipients used, glycerol proved to be the least stable thermally, while xylitol was the most stable. The shape of the TG curves shows that the decomposition process changes with the increase in the concentration of the excipients. In the case of glycerol, the decomposition processes start over $180-200{ }^{\circ} \mathrm{C}$, and the TG curves open up more, which is probably due to the fact that the molecules built-in among the polymer chains loosen the structure, which in turn is decomposed more easily.

The role of the active ingredient lidocaine in thermal stability was also examined, and it was found that the shape of the curves shows that in the case of the 5 and $10 \%$ systems, the presence of lidocaine did not result in a significant difference in thermal stability, while in the concentration of $15 \%$, the films which contained lidocaine were decomposed more easily, which is due to the greater quantity of the materials used and to the ensuing looser structure.

The TG-MS examinations revealed that with the start of decomposition, a concentration increase was seen in the case of $m / z=41,42,43,44,45$ and 58 fragments, starting practically at the same time. The peak intensity of the fragments in the highest concentration may indicate the formation of carbon dioxide and also the development of acetic acid, isopropyl alcohol and acetone.

As a summary, it can be stated that the thermal stability of free films prepared from Klucel ${ }^{\circledR} \mathrm{LF}$ polymer is appropriate, and in the case of the 5 and $10 \%$ systems, the presence of lidocaine did not result in a significant difference in thermal stability. The results not only help to choose the formulation conditions but also provide useful information concerning the packaging and storage conditions as well as the stability of the final product.

Acknowledgements The publication is supported by the European Union and co-funded by the European Social Fund. Project number: TÁMOP-4.2.2.A-11/1/KONV-2012-0047.

\section{References}

1. Ford JL, Mann TE. Fast-Scan DSC and its role in pharmaceutical physical form characterisation and selection. Adv Drug Deliv Rev. 2012;64:422-30.

2. Bley O, Siepmann J, Bodmeier R. Importance of glassy-to-rubbery state transitions in moisture-protective polymer coatings. Eur J Pharm Biopharm. 2009;73:146-53.

3. Saklatvala RD, Saunders MH, Fitzpatrick S, Buckton G. A comparison of high speed differential scanning calorimetry (Hyper-DSC) and modulated differential scanning calorimetry to detect the glass transition of polyvinylpyrrolidone: the effect of water content and detection sensitivity in powder mixtures (a model formulation). J Drug Deliv Sci Technol. 2005;15:257-60.

4. Buckton G, Adeniyi AA, Saunders M, Ambarkhane A. HyperDSC studies of amorphous polyvinylpyrrolidone in a model wet granulation system. Int J Pharm. 2006;312:61-5.

5. Gombás Á, Szabó-Révész P, Regdon G Jr, Erős I. Study of thermal behaviour of sugar alcohols. J Therm Anal Calorim. 2003;73:615-21.

6. Saunders M, Podluii K, Shergill S, Buckton G, Royall P. The potential of high speed DSC (Hyper-DSC) for the detection and quantification of small amounts of amorphous content in predominantly crystalline samples. Int J Pharm. 2004;274:35-40.

7. Lappalainen M, Pitkänen I, Harjunen P. Quantification of low levels of amorphous content in sucrose by HyperDSC. Int $\mathbf{J}$ Pharm. 2006;307:150-5.

8. Mártha $\mathrm{C}$, Jójárt-Laczkovich $\mathrm{O}$, Ulrich J, Szabó-Révész P. Investigation of the crystallinity of sugar alcohols co-ground with polymeric excipients. J Therm Anal Calorim. 2014;115:2479-86.

9. Gombás Á, Szabó-Révész P, Kata M, Regdon G Jr, Erős I. Quantitative determination of crystallinity of alpha-lactose monohydrate by Differential Scanning Calorimetry (DSC). J Therm Anal Calorim. 2002;68:503-10.

10. Buanz ABM, Parkinson GN, Gaisford S. Characterization of carbamazepine-nicatinamide co-crystal polymorphs with rapid Heating DSC and XRPD. Cryst Growth Des. 2011;11:1171-81. 
11. Giron D. Thermal analysis and calorimetric methods in the characterisation of polymorphs and solvates. Thermochim Acta. 1995;248:1-59.

12. Ford JL, Mann TE. High speed differential scanning calorimetry of polymorphic transitions in nifedipine. J Pharm Pharmacol. 2002;54:S48.

13. McGregor $\mathrm{C}$, Bines $\mathrm{E}$. The use of high speed differential scanning calorimetry (Hyper-DSC ${ }^{\mathrm{TM}}$ ) in the study of pharmaceutical polymorphs. Int J Pharm. 2008;350:48-52.

14. Gaisford S, Buanz ABM. Pharmaceutical physical form characterisation with fast $\left(>200{ }^{\circ} \mathrm{C} \mathrm{min}^{-1}\right)$ DSC heating rates. J Therm Anal Calorim. 2011;106:221-6.

15. Theeuwes F, Hussain A, Higuchi T. Quantitive analytical method for determination of drugs dispersed in polymers using differential scanning calorimetry. J Pharm Sci. 1974;63:427-9.

16. Andrews GP, Zhai H, Tipping S, Jones DS. Characterisation of the thermal, spectroscopic and drug dissolution properties of mefenamic acid and polyoxyethylene-polyoxypropylene solid dispersions. J Pharm Sci. 2009;98:4545-56.

17. Oladiran GS, Batchelor HK. Determination of ibuprofen solubility in wax: a comparison of microscopic, thermal and release rate techniques. Eur J Pharm Biopharm. 2007;67:106-11.

18. Nikowitz K, Pintye-Hódi K, Regdon G Jr. Study of the recrystallization in coated pellets: effect of coating on API crystallinity. Eur J Pharm Sci. 2013;48:563-71.

19. Liu P, Yu L, Liu H, Chen L, Li L. Glass transition temperature of starch studied by a high-speed DSC. Carbohydr Polym. 2009;77:250-3.

20. Mlčoch T, Kučerík J. Hydration and drying of various polysaccharides studied using DSC. J Therm Anal Calorim. 2013;113: 1177-85.

21. Regdon G Jr, Hegyesi D, Pintye-Hódi K. Thermal study of ethyl cellulose coating films used for modified release (MR) dosage forms. J Therm Anal Calorim. 2012;108:347-52.

22. Regdon G Jr, Kósa A, Erős I, Pintye-Hódi K. Study of thermoanalytical behaviour of some coating films. J Therm Anal Calorim. 2007;89:793-7.

23. De Mendonca CMS, De Barros LIP, Aragao CFS, Gomes APB. Thermal compatibility between hydroquinone and retinoic acid in pharmaceutical formulations. J Therm Anal Calorim. 2014;115: 2277-85.

24. Davoudi ET, Noordin MI, Javar HA, Kadivar A, Ashjari M, Chermahini SH. Stability study of the gastric floating dosage form of capecitabine. J Therm Anal Calorim. 2014;115:2495-9.

25. Chatterjee K, Hazra A, Dollimore D, Alexander KS. Estimating vapor pressure curves by thermogravimetry: a rapid and convenient method for characterization of pharmaceuticals. Eur $\mathbf{J}$ Pharm Biopharm. 2002;54:171-80.

26. Elder JP. Sublimation measurements of pharmaceutical compounds by isothermal thermogravimetry. J Therm Anal Calorim. 1997;49:897-905.

27. Price DM, Hawkins M. Calorimetry of two disperse dyes using thermogravimetry. Thermochim Acta. 1998;315:19-24.

28. Chatterjee K, Dollimore D, Alexander KS. A new application for the Antoine equation in formulation development. Int J Pharm. 2001;213:31-44.

29. Chatterjee K, Dollimore D, Alexander KS. Thermal analysis study of hydroxy benzoic acid derivatives using rising temperature thermogravimetry. J Therm Anal Calorim. 2001;63:629-39.

30. Chatterjee K, Dollimore D, Alexander KS. Calculation of vapour pressure curves for ethyl, propyl, and butyl parabens using thermogravimetry. Instrum Sci Technol. 2001;29:133-44.
31. Lacerda LG, Filho MASC, Bauab T, Demiate IM, Colman TAD, Andrade MMP, Schnitzler E. The effects of heat-moisture treatment on avocado starch granules. J Therm Anal Calorim. 2014. doi:10.1007/s10973-014-3987-9.

32. Guo R, Du X, Zhang R, Deng L, Dong A, Zhang J. Bioadhesive film formed from a novel organic-inorganic hybrid gel for transdermal drug delivery system. Eur J Pharm Biopharm. 2011;79:574-83.

33. Kim MH, Park DH, Yang JH, Choy YB, Choya JH. Drug-inorganic-polymer nanohybrid for transdermal delivery. Int J Pharm. 2013;444:120-7.

34. Sogias IA, Williams AC, Khutoryanskiy VV. Chitosan-based mucoadhesive tablets for oral delivery of ibuprofen. Int J Pharm. 2012;436:602-10.

35. Ikeuchi-Takahashi Y, Sasatsu M, Onishi H. Evaluation of matrix type mucoadhesive tablets containing indomethacin for buccal application. Int J Pharm. 2013;453:454-61.

36. Cao QR, Liu Y, Xu WJ, Lee BJ, Yang M, Cui JH. Enhanced oral bioavailability of novel mucoadhesive pellets containing valsartan prepared by a dry powder-coating technique. Int $\mathrm{J}$ Pharm. 2012;434:325-33.

37. Michaelis M, Brummer R, Leopold CS. Plasticization and antiplasticization of an acrylic pressure sensitive adhesive by ibuprofen and their effect on the adhesion properties. Eur J Pharm Biopharm. 2014;86:234-43.

38. Pengpong T, Sangvanich P, Sirilertmukul K, Muangsin N. Design, synthesis and in vitro evaluation of mucoadhesive p-coumarate-thiolated-chitosan as a hydrophobic drug carrier. Eur J Pharm Biopharm. 2014;86:487-97.

39. Miro A, d'Angelo I, Nappi A, La Manna P, Biondi M, Mayol L, Musto P, Russo R, La Rotonda MI, Ungaro F, Quaglia F. Engineering poly(ethylene oxide) buccal films with cyclodextrin: a novel role for an old excipient? Int J Pharm. 2013;452:283-91.

40. Xu LL, Shi LL, Cao QR, Xu WJ, Cao Y, Zhu XY, Cui JH. Formulation and in vitro characterization of novel sildenafil citrateloaded polyvinyl alcohol-polyethylene glycol graft copolymerbased orally dissolving films. Int J Pharm. 2014;473:398-406.

41. Gaisford S, Verma A, Saunders M, Royall PG. Monitoring crystallisation of drugs from fast-dissolving oral films with isothermal calorimetry. Int J Pharm. 2009;380:105-11.

42. Cavallari C, Fini A, Ospitali F. Mucoadhesive multiparticulate patch for the intrabuccal controlled delivery of lidocaine. Eur J Pharm Biopharm. 2013;83:405-14.

43. Kumar GP, Phani AR, Prasad RGSV, Sanganal JS, Manali N, Gupta R, Rashmi N, Prabhakara GS, Salins CP, Sandeep K, Raju DB. Polyvinylpyrrolidone oral films of enrofloxacin: film characterization and drug release. Int J Pharm. 2014;471:146-52.

44. Gottnek M, Süvegh K, Pintye-Hódi K, Regdon G Jr. Effects of excipients on the tensile strength, surface properties and free volume of $\mathrm{Klucel}^{\circledR}$ free films of pharmaceutical importance. Radiat Phys Chem. 2013;89:57-63.

45. Pintye-Hódi K, Regdon G Jr, Erős I, Süvegh K, Marek T, Kéry I, Zelkó R. Metolose-PEG interaction as seen by positron annihilation spectroscopy. Int J Pharm. 2006;313:66-71.

46. Marek T, Süvegh K, Kéry I, Zelkó R, Regdon G Jr, Pintye-Hódi $\mathrm{K}$, Vértes A. The effect of plasticizer on the ageing of Metolose films. Radiat Phys Chem. 2007;76:165-8.

47. Regdon G Jr, Zsellér B, Pintye-Hódi K. Physical-chemical investigations of Metolose coating films. Compos Interfaces. 2010;17:581-94. 
III. 


\title{
Effects of excipients on the tensile strength, surface properties and free volume of Klucel ${ }^{\circledR}$ free films of pharmaceutical importance
}

\author{
Mihály Gottnek ${ }^{\mathrm{a}}$, Károly Süvegh ${ }^{\mathrm{b}}$, Klára Pintye-Hódi a, Géza Regdon Jr.,* \\ a Department of Pharmaceutical Technology, University of Szeged, Eötvös utca 6, H-6720 Szeged, Hungary \\ ${ }^{\mathrm{b}}$ Laboratory of Nuclear Chemistry, Eötvös Loránd University, P.O. Box 32, H-1518 Budapest 112, Hungary
}

\section{H I G H L I G H T S}

- Glycerol increases, whereas xylitol decreases the free volume of both LF and MF HPC.

- Both xylitol and glycerol increase the tensile strength of MF films.

- The tensile strength of the MF product makes it suitable for pharmaceutical use.

- The surface properties reveal a macroscopically stable film structure.

- All measurements indicate a macroscopically homogeneous film structure.

\section{A R T I C L E I N F O}

\section{Article history:}

Received 19 March 2013

Accepted 12 April 2013

Available online 19 April 2013

Keywords:

Positron annihilation lifetime spectroscopy Free volume

Hydroxypropylcellulose

Free films

Glycerol

Xylitol

\begin{abstract}
A B S T R A C T
The physicochemical properties of polymers planned to be applied as mucoadhesive films were studied. Two types of Klucel $^{\circledR}$ hydroxypropylcellulose (LF and MF) were used as film-forming polymers. Hydroxypropylcellulose was incorporated in $2 \mathrm{w} / \mathrm{w} \%$ with glycerol and xylitol as excipients and lidocaine base as an active ingredient at 5,10 or $15 \mathrm{w} / \mathrm{w} \%$ of the mass of the film-forming polymer. The free volume changes of the films were investigated by positron annihilation lifetime spectroscopy, the mechanical properties of the samples were measured with a tensile strength tester and contact angles were determined to assess the surface properties of the films. It was found that the Klucel ${ }^{\mathbb{R}}$ MF films had better physicochemical properties than those of the LF films. Klucel ${ }^{\circledR}$ MF as a film-forming polymer with lidocaine base and both excipients at $5 \mathrm{w} / \mathrm{w} \%$ exhibited physicochemical properties and good workability. The excipients proved to exert strong effects on the physicochemical properties of the tested systems and it is very important to study them intensively in preformulation studies in the pharmaceutical technology in order to utilise their benefits and to avoid any disadvantageous effects.
\end{abstract}

(c) 2013 Elsevier Ltd. All rights reserved.

\section{Introduction}

Although the most popular mode of administration of medicines for patients is the oral route, the enzymes of the gastrointestinal tract cause serious disadvantages. They decompose many active substances and the first-pass effect of the liver decreases the serum level of active pharmaceutical ingredients. However, mucoadhesive films applied to the oral mucosa eliminate these problems, and not only local effects, but also systemwide effects can be achieved. The numerous examples of systemwide drug delivery systems include the following active substances: enalapril maleate (Semalty et al., 2010), flufenamic acid (Mura et al., 2010), nitrendipine (Nappinnai et al., 2008),

\footnotetext{
* Corresponding author. Tel.: +36 62 545574; fax: +36 62545571 .

E-mail address: geza.regdon@pharm.u-szeged.hu (G. Regdon Jr.).
}

glipizide (Semalty et al., 2008), atenolol (Satishbabu and Srinivasan, 2008), indomethacin (Tanabe et al., 2008), progesterone (Jain et al., 2008), etc. There are likewise many agents for local use: lidocaine hydrochloride (Pignatello et al., 2009), valdecoxib (Averineni et al., 2009), beclomethasone dipropionate (Yanagi et al., 2008), metronidazole benzoate (El-Kamel et al., 2007), nystatin (Llabot et al., 2007a), etc. Various types of polymers may be used as film-forming materials, e.g. hydroxypropylmethylcellulose (Kundu et al., 2008; Nappinnai et al., 2008; Semalty et al., 2008; Averineni et al., 2009; Semalty et al., 2010), hydroxyethylcellulose (Semalty et al., 2010), ethylcellulose (Satishbabu and Srinivasan, 2008; Tanabe et al., 2008), sodium carboxymethylcellulose (Llabot et al., 2007a; Nappinnai et al., 2008; Semalty et al., 2008; El-Din et al., 2010; Semalty et al., 2010), chitosan (El-Kamel et al., 2007; Averineni et al., 2009; Pignatello et al., 2009; Lavorgna et al., 2010; Mura et al., 2010; Li et al., 2011), (sodium) alginate (Nappinnai et al., 2008; Satishbabu and Srinivasan, 2008; Skulason 
et al., 2009; Ashikin et al., 2010,), and hydroxypropylcellulose (HPC) (Nappinnai et al., 2008).

The main function of plasticizers is to augment the workability and flexibility of polymers by reducing the second-order transition temperature (Rosen, 1993). Plasticizers are expected to decrease the volume resistivity, electrostatic chargeability, glass-transition temperature, melt viscosity, density, hardness, tensile strength and modulus of a polymer, while at the same time improving its power factor, dielectric constant, toughness, elongation at break and flexibility (Mathews, 1996). Some plasticizers are harmful or have a health risk potential. Phthalate plasticizers may display potential carcinogenicity and endocrine modulating effects (Tickner et al., 2001). In mammals, di-(2-ethylhexyl) phthalate can exhibit hepato, cardio-, nephro-, embryonal, pulmonary, ovarian and testicular toxicity (Craver and Carraher, 2000). In 1980, the International Agency for Research on Cancer classified it as 'possibly carcinogenic to humans'. In 1998, the European Union Scientific Committee of Toxicity, Ecotoxicity and the Environment announced that there were safe migration limits for phthalate plasticizers (Murphy, 2001). Biodegradable polymers are to be preferred if health-promotion and environmentally-friendly approaches are considered (Rahman and Brazel, 2004; El-Din et al., 2010; Haji-Saeid et al., 2010; Lj Tomić et al., 2010). The same requirements apply to plasticizers (Rahman and Brazel, 2004; Vieira et al., 2011). Health and safety issues predominate in this field (Rahman and Brazel, 2004). The strictest rules are in force in the pharmaceutical and food industries. The most frequently plasticized polymers include cellulose and its derivates (Rahman and Brazel, 2004).

Polyols, such as glycerol (Gly), have been found to be especially effective plasticizers for hydrophilic polymers (Zhang and Han, 2006). Gly has been almost methodically incorporated in most hydrocolloid films (Cuq et al., 1997), and is a highly hygroscopic molecule commonly added to film-forming solutions to eliminate film rigidity (Karbowiak et al., 2006; Kristo and Biliaderis, 2006). Many studies have focused on the use of Gly (Galietta et al., 1998; Jangchud and Chinnan, 1999; Fishman et al., 2000; Kim and Ustunol, 2001; Sobral et al., 2002; Audic and Chaufer, 2005; Mali et al., 2005; Suyatma et al., 2005; Thomazine et al., 2005; Cheng et al., 2006; Colla et al., 2006; Moore et al., 2006; Zhang and Han, 2006; Bergo and Sobral, 2007; Talja et al., 2007; Bergo et al., 2008; Müller et al., 2008; Galdeano et al., 2009a; Galdeano et al., 2009b Lavorgna et al., 2010; Raphaelides et al., 2011) as a plasticizer fit to eat and/or in biodegradable films. Hydrophilic compounds such as Gly are commonly used in starch films (Mali et al., 2005; Cheng et al., 2006; Zhang and Han, 2006; Talja et al., 2007; Bergo et al., 2008; Müller et al., 2008; Galdeano et al., 2009a; Vieira et al., 2011). Gly and xylitol (Xyl) have been commonly utilised plasticizers in the food industry. When they were used either alone or together to plasticize low and high amylose starches, it was found that in films in which Gly was incorporated alone films had greater pliability/flexibility and their fracture was much slower than in the case of films plasticized with Xyl. The best mechanical results were obtained for starch films plasticized with a combination of Gly and Xyl (Muscat et al., 2012).

Before their technological use, it is very important to determine the mechanical properties of mucoadhesive films because the free films are exposed to large mechanical stresses during the preparation process, unpacking and sticking to the oral mucosa. These properties depend on the film-forming polymer and excipients used and the formulation of the system (Llabot et al., 2007b; Kundu et al., 2008; Satishbabu and Srinivasan, 2008; Averineni et al., 2009; Skulason et al., 2009; Mura et al., 2010).

Positron annihilation lifetime spectroscopy (PALS) is an analytical method that allows examinations of the free volumes of films, wherein the active substance can enter the structure (Bölcskei et al., 2011). PALS gives a measure of positron and positronium (Ps) annihilation times and is the method most commonly applied to study polymers. Many types of cellulose have been investigated by PALS and it has been found that substitution on cellulose has little effect on the lifetime, but a major effect on the probability of formation of the ortho-Ps (o-Ps) (Pethrick, 1997).

The sensitivity of PALS in measuring nanoscale layer structures in thin polymeric films has been demonstrated (Jean et al., 2005), and PALS has been shown to be a useful technique for the quantitative analysis of the size and distribution of free volume holes in multilayer thin film polymers (Jean et al., 2008). In studies of novel interfacially-polymerized polyamide thin-film composite membranes, PALS was used to detect the correlation of the variations in the free volume of the polyamide active layers with the pervaporation performance (Chao et al., 2011). It has been established through PALS studies that electron irradiation modifies the microstructure of poly(methyl methacrylate) films (Ismayil et al., 2010). The use of PALS confirmed the dependence of the macroscopic properties of polymeric coatings on the microscopic properties (Li et al., 2003). PALS has revealed correlations between the radius of the cavities, the effective fractional free volume, the drug release rate and the composition of vinyl polymers with and without a cross-linker used as artificial lens implants in ophthalmology. Besides the size of the drug molecules, the drug release rate also depended on the radius of the cavities, the functional free volume and the interconnectivity of the cavities (Marques et al., 2003).

PALS combined with classical drug release measurements was used to investigate the stability of polymeric matrix tablets containing famotidine with the distributions of their physical mixtures. This technique proved useful not only as a method for stability tests, but also for temperature compatibility studies, which is of great interest in the preformulation of pharmaceutical drug delivery systems containing polymeric excipients (Szente et al., 2009). An exponential relationship has been found between the relative humidity of the storage medium and the mean dissolution time of theophylline from polyvinylpyrrolidone tablets and the size of the free volume holes. PALS measurements performed in parallel with the drug release study demonstrated that the main reason for this correlation was the realignment of the vacancies in polyvinylpyrrolidone (Zelkó and Süvegh, 2005). A PALS investigation of the microstructural changes in the different layers of levonorgestrel-releasing intrauterine systems led to this technique being recommended as a sensitive stability test of drug delivery systems during preformulation (Patai et al., 2010).

Real-time PALS was applied to investigate the transition from hydrogel to film in sodium alginate and Carbopol gels. It was found that the method was capable of detecting the gel-film transition in hydrocolloid gels on the basis of o-Ps lifetime changes. This technique could promote the design of drug delivery systems based on polymer coatings, free films and hydrogels (Szabó et al., 2012). When PALS was used to detect the changes in the free volume holes in amorphous pharmaceutical polymeric excipients under different storage conditions, it was found that the positron lifetime repartition revealed the changes in free volume during the absorption-dissolution transition. The dissolution starts the leaking of water into free volume holes (Zelkó et al., 2006). An investigation of the correlation between the free volumes and the release of metoprolol tartrate from Metolose patches indicated that the groups on Metolose allow the formation of H-bonds, which initiates the penetration of water into the patch (Papp et al., 2010). The spreading swelling increases the size of vacancies in the patch, which enhances the rate and extent of metoprolol tartrate release (Papp et al. 2009). The active substance release properties and the free volume of the films were found to be very similar (Papp et al., 2010). PALS measurements revealed an increase in the average size of the free volume holes in free Eudragit films containing plasticizer sebacic acid dibutyl ester. Both the positron 
and o-Ps lifetimes increased. As the excipient concentration increased, its plasticisation effect changed the primarily compact structure of the polymer molecules, the new structure permitting larger free vacancies, which allow more space for molecular movements (Zelkó et al., 2002). Thus, free volume is a most important parameter in determining the properties of mucoadhesive films.

However, the surface properties of films are also very important in this respect because they afford information on the degree of polarity and surface free energy (SFE), which indicate the extent of mucoadhesion. In an attempt to forecast the mucoadhesive phenomenon via the spreading coefficient, through the use of SFE parameters (polar and non-polar components), spreading coefficient and Wu's interaction parameter, it was concluded that SFE and spreading processes play the predominant role in the formation of mucoadhesive bonds (Lehr et al., 1993). The modelling of mucoadhesion by using SFE revealed correlations between the mucoadhesion force and the calculated SFE of interaction (Rillosi and Buckton, 1994). It has been reported that the interfacial free energy influences both the bioadhesion and the biocompatibility characteristics of various polymers, but the resulting effects should not be considered to be directly correlated (Esposito et al., 1994).

The aim of the present study was to determine the physicochemical properties and free volumes of different Klucel ${ }^{\circledR}$ free polymer films containing lidocaine base (Lid) as an active pharmaceutical ingredient in the presence of various concentrations of Gly and Xyl as excipients.

\section{Experimental}

\subsection{Materials}

HPC (Klucel ${ }^{\circledR}$ MF and LF) (Aqualon; Hercules Inc., Wilmington, USA.) was used as the film-forming polymer. The main differences between the two Klucel ${ }^{\circledR}$ products are in the molecular mass and the viscosity of the solution. MF has a higher viscosity in solution and a higher molecular mass. HPC is a non-ionic, water-soluble cellulose ether and its films are appropriately flexible even without any plasticizer. HPC was chosen because it is necessary for bio/ mucoadhesion, it must be physiologically inert, and the oral cavity has a water-rich environment. Accordingly, the film is not irritating, discharges without metabolism, is environmentally friendly, and can adhere to the oral mucosa by connecting to the mucin, which covers the whole mucosal membrane of the oral cavity. The local anaesthetic Lid (Ph. Eur., Società Italiana Medicinali Scandicci, Firenze, Italy) was chosen as the active substance. Xyl (Ph. Eur., Roquette, Lestrem, France) was used as the taste improver. This excipient has many advantages: it has an anticaries effect, decreases fur formation, increases dental remineralization and the saliva flow rate, and can be used safely even by patients with diabetes mellitus (its glycaemic index is 7). Gly (Ph. Eur., Molar Chemicals Kft., Budapest, Hungary) was used as the taste coverer. It is good for masking bitter tastes, it has a sweet effect (the degree of sweetness is 0.5 ) and in films it can act as a plasticizer. It is safe for use and environmentally friendly.

\subsection{Preparation of free films}

The optimum polymer concentration was first established, and solutions were then made containing $2,3,4,5,10$ or $15 \mathrm{w} / \mathrm{w} \%$ polymer. Overly viscous samples (10 and $15 \mathrm{w} / \mathrm{w} \%$ solutions of both MF and LF), which were practically gels, were rejected because they could not be poured to form films. Among the MF samples, because of the high viscosity, only the $2 \mathrm{w} / \mathrm{w} \%$ sample could be poured easily, while all the other samples involved difficulties. The solvent was distilled water (Ph. Eur.). Although 2, 3, 4 and 5 w/w\% solutions of LF could all be poured, $2 \mathrm{w} / \mathrm{w} \%$ solutions were chosen for both types of Klucel $^{\mathbb{R}}$ as we wished to compare their physicochemical properties. Lid was ground in a mill (Retsch RM 100, Retsch GmbH, Haan, Germany) and the 100-200 $\mu \mathrm{m}$ powder fraction was incorporated into the solution. Xyl dissolved readily and Gly compounded well in the water-polymer mixture. Lid, Gly and Xyl were all used in the same concentration $(5,10$ or $15 \mathrm{w} / \mathrm{w} \%$ of the film-forming polymer). Samples were poured onto either a glass or a non-stick surface. When a smooth surface was needed for analysis of the surface properties of films, the polymer solution was poured onto a glass slide. However, for tensile strength tests, films were picked up from a teflon surface. All the films were made by the same pouring technology and stored at room temperature $\left(25^{\circ} \mathrm{C} / 65 \%\right.$ R.H. $)$ for a day and then placed into a climate chamber for $24 \mathrm{~h}\left(40{ }^{\circ} \mathrm{C} / 50 \%\right.$ R.H.).

\subsection{Positron annihilation lifetime spectroscopy}

The positron, the anti-particle of the electron, undergoes annihilation by combination with an electron, to generate photons with specific energy. The photons emitted have a distribution of energies between 0 and $540 \mathrm{keV}$. The Ps is a positron-electron pair derived from secondary electrons resulting from ionisation of the medium (Fig. 1). The Ps has two spin states: the o-Ps (triplet) and the para-Ps (p-Ps) (singlet). The lifetime of the o-Ps in vacuum is approximately $100 \mathrm{~ns}$. In a condensed medium, 75\% of the Ps formed will be o-Ps and $25 \%$ will be p-Ps. There are three theoretical models to describe pick-off annihilation: the Spur, Ore and free volume models (Pethrick, 1997). The free volume model of Ps formation stipulates that the Ps is formed only in areas with low electron density. In molecular solids, a trapped Ps is more probable than a delocalised Ps and accounts for between $20 \%$ and $70 \%$ of all electrons injected into the medium. Three experimental techniques have been developed for the study of positron annihilation: PALS, angular correlation of annihilation radiation and Doppler broadening spectroscopy, in all of which time of emission, energies and moments of positron-electron annihilation photons are measured (Pethrick, 1997).

Free volumes were measured through determination of the lifetime of o-Ps in the samples. PALS (Fig. 2), increasingly applied to polymers in the pharmaceutical technology (Hiemenz, 1984; Süvegh et al., 1999; Kilburn et al., 2002), makes use of the phenomenon that, if positrons are injected into a polymer, a large number of them form atom-like bound states with electrons. The lifetime of these Ps particles depends on the size of the free volume holes. The exact dependence can be approximated by a simple

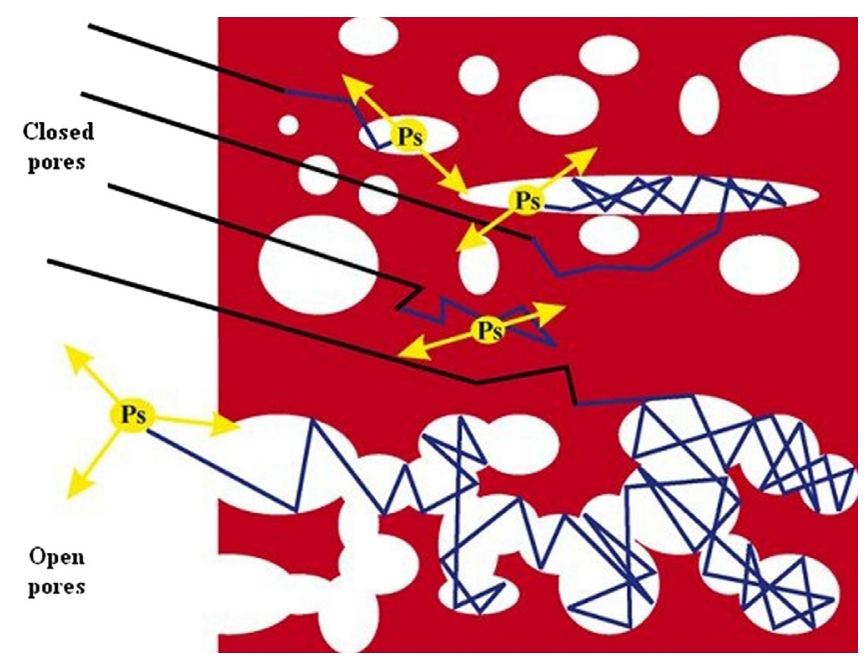

Fig. 1. Positronium formation in porous thin films (Peng et al., 2007). 


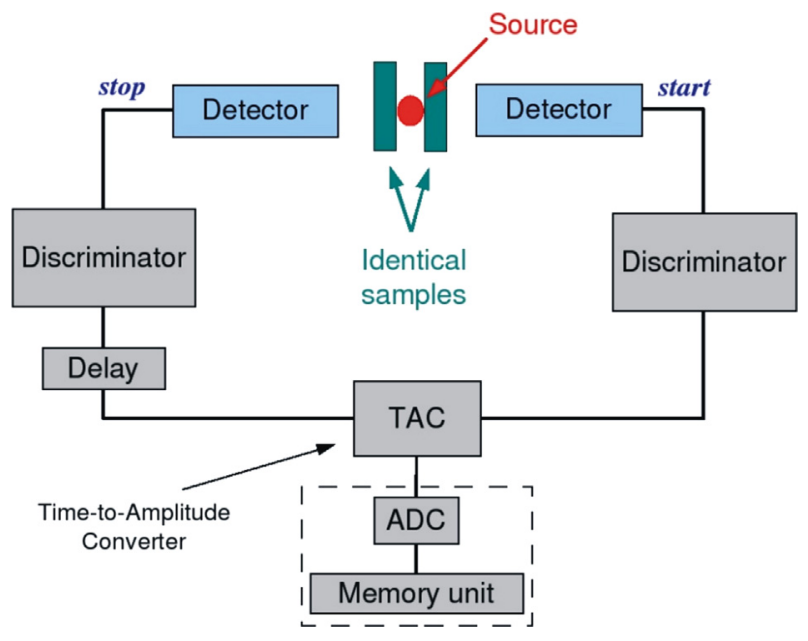

Fig. 2. Structural framework of a positron annihilation lifetime spectrometer.

model, with the assumption of spherical vacancies (Eldrup et al., 1981)

$\tau=\frac{1}{2}\left[1-\frac{R}{R+\Delta R}+\frac{1}{2 \pi} \sin \left(\frac{2 \pi R}{R+\Delta R}\right)\right]^{-1}$

where $\tau$ is the lifetime of the o-Ps atoms in nanoseconds, $R$ is the radius of voids in Ångströms, and $\Delta R$ is a constant. On a molecular scale, the $R$ data correspond well to the BET and neutron-scattering results. The lifetime spectrometer applied was constructed from $\mathrm{BaF}_{2}$ based detectors and standard ORTEC electronics. Spectra were collected in the 4096 channels of a multichannel analyser. The time/ channel value was $\sim 10 \mathrm{ps}$ and the time resolution of the system was $\sim 210$ ps. As a positron source, carrier-free ${ }^{22} \mathrm{NaCl}$ was used, sealed between kapton foils. The activity of the source was $\sim 5-10^{5} \mathrm{~Bq}$ and only $5-8 \%$ of the positrons were annihilated in the source itself.

\subsection{Determination of mechanical properties of films}

The tensile strength tester and the software were developed in our institute (Bajdik et al., 2007). This device contains a special holder (20 $\mathrm{mm}$ in diameter) and a hemispherical indent with a surface area of $201 \mathrm{~mm}^{2}$, and is connected to a computer through an interface. The ultimate deformation force can be measured, and the deformation process (force-time and force-displacement curves) can be followed. The circular holder is situated horizontally and the jowl moves vertically. The measuring range was 0-200 N, the speed of the stamp was $20 \mathrm{~mm} / \mathrm{min}$, the sampling rate was $50 \mathrm{~Hz}$, the output was $0-5 \mathrm{~V}$, and the sensitivity was \pm 0.1 digit. The sensor comprised an UNICELL force-measuring equipment, calibrated with the C9B $200 \mathrm{~N}$ cell; 10 parallel measurements were performed on each specimen. Before tensile strength experiments, the film thickness was measured with a bolt micrometre with an accuracy of $0.001 \mathrm{~mm}$ (Mitutoyo, Kawasaki, Japan).

\subsection{Contact angle (CA) measurements}

The SFE of a sample can provide a very important information (for example adhesion, spreading coefficient, etc.) concerning the processibility of the solid product. This behaviour should therefore be known before the formulation. Thus, measurements were carried out with a drop-contour analyser (Dataphysics OCA20, Dataphysics Instruments $\mathrm{GmbH}$, Filderstadt, Germany), by a sessile drop method at room temperature $\left(25^{\circ} \mathrm{C}\right)$. The SFE of the solid was calculated by a literature method ( $\mathrm{Wu}, 1971)$. This method determines the amounts of the polar $\left(\gamma^{p}\right)$ and dispersion $\left(\gamma^{d}\right)$ constituents for the solid. The SFE of the solid can be established by measurement of the CAs of two liquids of known polarity and the solution of two equations (one for each liquid) with two parameters:

$(1+\cos \Theta) \gamma l=\frac{4\left(\gamma_{s}^{d} \gamma_{l}^{d}\right)}{\gamma_{s}^{d}+\gamma_{l}^{d}}+\frac{4\left(\gamma_{s}^{p} \gamma_{l}^{p}\right)}{\gamma_{s}^{p}+\gamma_{l}^{p}}$

where $\gamma_{l}$ is the surface tension (SFT) of the liquid, $\gamma_{s}$ is the SFE of the solid, and $\Theta$ is the solid-liquid surface CA. The extent of polarity, as a percentage, can be derived from the SFE. It is the ratio of the polar part and the total SFE. For the determination of SFE, diiodomethane and distilled water were chosen. The bilateral solid-liquid surface CA was measured with both liquids. CAs were registered at $1 \mathrm{~s}$ intervals for $15 \mathrm{~s}$ after drop formation. The circlefitting method was used for the CA assay. For the calculations, we used the mean CA for the fourth second of at least 10 continuous measurements. SFEs and polar and disperse surface tension SFTs were calculated from the CAs associated with water (for the polar component of SFT) and diiodomethane (for the disperse component of SFT). According to $\mathrm{Wu}$ (1971), SFT is $72.80 \mathrm{mN} / \mathrm{m}$ for water and $50.80 \mathrm{mN} / \mathrm{m}$ for diiodomethane. The polar part of SFT is $50.20 \mathrm{mN} / \mathrm{m}$ and $1.80 \mathrm{mN} / \mathrm{m}$ and the disperse part of SFT is $22.60 \mathrm{mN} / \mathrm{m}$ and $49.00 \mathrm{mN} / \mathrm{m}$.

\section{Results and discussion}

\subsection{Positron annihilation lifetime spectroscopy}

This technique was very important for our study because it yielded information about the free volume structure of the films. It is clearly seen in Fig. 3 that there was not much difference between the two types of Klucel ${ }^{\circledR}$ containing Xyl. As the concentration of Xyl was increased, the average size of the free volume holes decreased quite similarly in the two forms of the polymer. Gly caused different changes in the polymers. It increased the size of the free volume holes, but the effect differed in the two forms of HPC. The most relevant difference between them was that Gly caused a faster change in the LF films. This reflects the fact that LF contains shorter polymeric chains than those in MF. Thus, the plasticizer can move them apart from each other more easily than in the case of the much longer MF chains. In the end, Gly forms the same size of free volumes in both polymers.

The most interesting finding from the positron data is the opposite behaviour of Xyl and Gly. Although the two molecules

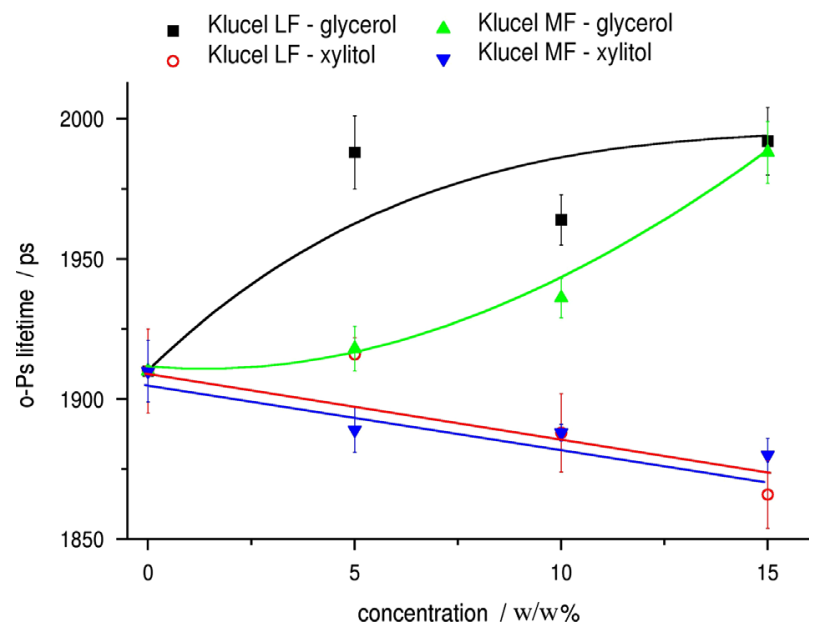

Fig. 3. The lifetime of ortho-positronium in Klucel ${ }^{\mathbb{R}}$ films. Lines are given merely to guide the eye. 
have very similar structures, one of them increased the free volume in HPC whereas the other one decreased it. The explanation of this may be the size difference between the molecules. Both molecules are able to destroy the original H-bonding network in the polymers, which suggests an increase in free volume. However, the longer Xyl molecules may fill the empty spaces or be able to connect the polymeric chains through $\mathrm{H}$-bonding. A free volume decrease can be a serious problem in the pharmaceutical technology. It might indicate that certain excipients in these films can become strongly linked to the polymer molecules, changing the properties of the products.

\subsection{Mechanical properties}

Films poured onto a non-stick surface were used for the tensile strength measurements. When Xyl was used in the studied samples, the tensile strength of MF films was 2.5-3.5 times higher than that of films which contained only the film-forming polymer without any excipient (Table 1 ). This result correlates with the PALS finding, again suggesting that Xyl forms $\mathrm{H}$-bonds between the neighbouring polymer chains, leading to a stronger film structure. Gly was used as a taste coverer in these films, but in the pharmaceutical technology and the food industry it can also serve as a plasticizer, and when it was present in the samples, the tensile strength of the films was 2-2.5 times higher than that of the empty films. However, the mechanism of this process is different from that in the case of Xyl. Gly causes the films to become more elastic, increasing the tensile strength through the decrease of brittleness. It is interesting that, when the two excipients were combined the tensile strength increased eightfold, a very welcome side-effect. During the processes of unpacking and sticking on the oral mucosa the free films are exposed to appreciable mechanical stresses, and hence a low tensile strength is a disadvantage. In the case of the Klucel ${ }^{\circledR}$ MF films, the addition of Lid did not change the effects of Xyl and Gly on the films. Even when both excipients were used together with Lid, the resulting tensile strength was adequate for the films (Table 1 ).

In contrast, when the Klucel ${ }^{\circledR}$ LF film-forming polymer was investigated, we did not find any significant changes in tensile

Table 1

Tensile strength of Klucel ${ }^{\mathbb{R}}$ MF films.

\begin{tabular}{lrr}
\hline \multicolumn{1}{c}{ Materials } & Dry content $(\mathrm{w} / \mathrm{w} \%)$ & Force $(\mathrm{N} \pm \mathrm{SD})$ \\
\hline Klucel $^{\circledR} \mathrm{B}$ MF & 2 & $5.25 \pm 1.92$ \\
Xyl & 5 & $14.32 \pm 1.84$ \\
& 10 & $16.85 \pm 0.86$ \\
& 15 & $18.49 \pm 1.43$ \\
Gly & 5 & $13.64 \pm 1.53$ \\
& 10 & $12.06 \pm 1.97$ \\
& 15 & $12.17 \pm 0.93$ \\
Xyl+Gly & 5 & $41.48 \pm 0.47$ \\
& 10 & $43.77 \pm 1.24$ \\
Lid & 15 & $43.79 \pm 3.32$ \\
& 5 & $17.73 \pm 1.26$ \\
Lid+Xyl & 10 & $13.97 \pm 2.44$ \\
& 15 & $2.73 \pm 0.59$ \\
Lid+Xyl+Gly & 5 & $15.48 \pm 1.46$ \\
& 10 & $6.49 \pm 2.77$ \\
& 15 & $3.84 \pm 1.57$ \\
& 5 & $16.05 \pm 2.82$ \\
& 10 & $7.78 \pm 1.37$ \\
& 15 & $4.72 \pm 1.10$ \\
& 5 & $44.78 \pm 1.89$ \\
& & $5.12 \pm 2.24$ \\
\hline
\end{tabular}

strength with variation of the excipients or their concentrations (Table 2). Only when Lid was alone in the samples was the tensile strength of films slightly higher. The films were originally weaker, they broke easily, and it was necessary to pour them several times to obtain sufficient sample for measurements. The reason for this phenomenon is that LF has shorter polymer chains than MF. The thickness of the MF or LF films was $20-40 \mu \mathrm{m}$ in every composition of the samples.

\subsection{CA measurements}

For the CA measurements, films were poured onto a glass slide. The CA of water (deg) and the SFEs for both Klucel ${ }^{\circledR}$ MF (Table 3) and LF (Table 4) were measured. It was found that the CA of water in general was slightly higher for the MF samples. Only when both excipients were added at $5 \mathrm{w} / \mathrm{w} \%$ was the CA appreciably higher and when Lid was incorporated at 5 or $15 \mathrm{w} / \mathrm{w} \%$, the CA was decreased. The SFE was stable or increased slightly; it decreased if both of the excipients were used in $5 \mathrm{w} / \mathrm{w} \%$. The CA of water increased in every LF free film: the average degree of the rise was $7-10^{\circ}$. If Lid only or both the active substances and Xyl were incorporated at $15 \mathrm{w} / \mathrm{w} \%$, the CA increased appreciably. The SFE was stable or decreased slightly in LF samples. Lower CAs were found in LF free films, and the SFE values were approximately the same. As MF has longer polymer chains, the components could enter the free holes in the polymer matrix and did not have a strong effect on the surface properties of the system. Since LF has shorter chains, the incorporated materials had fewer sites at which to enter the structure of the polymer, and Gly and Xyl present therefore exerted effects on the CA of water. These results confirmed that a macroscopically stable film structure evolved in every case. The constant SFE values indicated good bioadhesion in every case.

\section{Conclusions}

PALS revealed that the shorter chains of LF reacted more easily to the addition of Gly than did those of the longer MF form.

Table 2

Tensile strength of Klucel ${ }^{\mathbb{R}}$ LF films.

\begin{tabular}{|c|c|c|}
\hline Materials & Dry content (w/w\%) & Force $(\mathrm{N} \pm \mathrm{SD})$ \\
\hline Klucel $^{\mathbb{R}}$ LF & 2 & $2.56 \pm 0.82$ \\
\hline Xyl & $\begin{array}{r}5 \\
10 \\
15\end{array}$ & $\begin{array}{l}3.77 \pm 0.88 \\
2.51 \pm 0.65 \\
2.78 \pm 0.42\end{array}$ \\
\hline Gly & $\begin{array}{r}5 \\
10 \\
15\end{array}$ & $\begin{array}{l}3.32 \pm 1.14 \\
2.46 \pm 0.61 \\
2.47 \pm 0.65\end{array}$ \\
\hline Xyl+Gly & $\begin{array}{r}5 \\
10 \\
15\end{array}$ & $\begin{array}{l}2.42 \pm 0.83 \\
2.80 \pm 1.60 \\
2.50 \pm 1.11\end{array}$ \\
\hline Lid & $\begin{array}{r}5 \\
10 \\
15\end{array}$ & $\begin{array}{l}7.81 \pm 2.09 \\
5.53 \pm 1.92 \\
4.20 \pm 1.52\end{array}$ \\
\hline Lid + Xyl & $\begin{array}{r}5 \\
10 \\
15\end{array}$ & $\begin{array}{l}3.88 \pm 1.03 \\
3.46 \pm 1.34 \\
2.17 \pm 0.83\end{array}$ \\
\hline Lid+Gly & $\begin{array}{r}5 \\
10 \\
15\end{array}$ & $\begin{array}{l}1.58 \pm 0.59 \\
3.05 \pm 1.22 \\
1.22 \pm 0.41\end{array}$ \\
\hline Lid+Xyl+Gly & $\begin{array}{r}5 \\
10 \\
15\end{array}$ & $\begin{array}{l}3.13 \pm 1.10 \\
4.23 \pm 1.72 \\
2.87 \pm 1.12\end{array}$ \\
\hline
\end{tabular}


Table 3

Surface properties of Klucel ${ }^{\mathbb{R}}$ MF films.

\begin{tabular}{|c|c|c|c|}
\hline Materials & $\begin{array}{l}\text { Dry content } \\
(\mathrm{w} / \mathrm{w} \%)\end{array}$ & $\begin{array}{c}\text { Contact angle of water } \\
\quad(\operatorname{deg} \pm \mathrm{SD})\end{array}$ & $\begin{array}{l}\text { Surface free energy } \\
(\mathrm{mN} / \mathrm{m} \pm \mathrm{SD})\end{array}$ \\
\hline Klucel ${ }^{\mathbb{R}}$ MF & 2 & $53.45 \pm 0.92$ & $58.41 \pm 0.75$ \\
\hline Xyl & $\begin{array}{r}5 \\
10 \\
15\end{array}$ & $\begin{array}{l}59.90 \pm 1.66 \\
55.94 \pm 1.61 \\
59.60 \pm 1.13\end{array}$ & $\begin{array}{l}56.93 \pm 1.10 \\
58.73 \pm 0.83 \\
56.63 \pm 0.88\end{array}$ \\
\hline Gly & $\begin{array}{r}5 \\
10 \\
15\end{array}$ & $\begin{array}{l}58.56 \pm 1.07 \\
52.38 \pm 2.26 \\
53.43 \pm 1.33\end{array}$ & $\begin{array}{l}56.79 \pm 1.31 \\
60.32 \pm 1.33 \\
60.79 \pm 1.11\end{array}$ \\
\hline Xyl+Gly & $\begin{array}{r}5 \\
10 \\
15\end{array}$ & $\begin{array}{l}67.78 \pm 1.21 \\
55.30 \pm 1.95 \\
59.56 \pm 2.07\end{array}$ & $\begin{array}{l}52.61 \pm 1.54 \\
58.44 \pm 1.11 \\
55.43 \pm 1.30\end{array}$ \\
\hline Lid & $\begin{array}{r}5 \\
10 \\
15\end{array}$ & $\begin{array}{c}48.50 \pm 2.13 \\
55.67 \pm 0.56 \\
51.85 \pm 0.07\end{array}$ & $\begin{array}{l}62.65 \pm 1.44 \\
58.30 \pm 1.21 \\
60.04 \pm 1.18\end{array}$ \\
\hline Lid+Xyl & $\begin{array}{r}5 \\
10 \\
15\end{array}$ & $\begin{array}{l}57.07 \pm 1.30 \\
54.63 \pm 0.66 \\
54.05 \pm 0.97\end{array}$ & $\begin{array}{l}58.33 \pm 0.76 \\
61.02 \pm 0.43 \\
60.31 \pm 0.76\end{array}$ \\
\hline Lid+Gly & $\begin{array}{r}5 \\
10 \\
15\end{array}$ & $\begin{array}{l}57.81 \pm 0.89 \\
56.29 \pm 2.27 \\
56.73 \pm 1.10\end{array}$ & $\begin{array}{l}60.77 \pm 0.53 \\
58.53 \pm 1.43 \\
58.64 \pm 1.09\end{array}$ \\
\hline Lid + Xyl + Gly & $\begin{array}{r}5 \\
10 \\
15\end{array}$ & $\begin{array}{l}56.91 \pm 0,47 \\
55.60 \pm 1.01 \\
58.84 \pm 1.12\end{array}$ & $\begin{array}{l}57.61 \pm 0.60 \\
59.37 \pm 0.85 \\
57.35 \pm 0.92\end{array}$ \\
\hline
\end{tabular}

Table 4

Surface properties of Klucel ${ }^{\mathbb{R}}$ LF films.

\begin{tabular}{|c|c|c|c|}
\hline Materials & $\begin{array}{l}\text { Dry content } \\
(\mathrm{w} / \mathrm{w} \%)\end{array}$ & $\begin{array}{c}\text { Contact angle of water } \\
\quad(\operatorname{deg} \pm \mathrm{SD})\end{array}$ & $\begin{array}{l}\text { Surface free energy } \\
(\mathrm{mN} / \mathrm{m} \pm \mathrm{SD})\end{array}$ \\
\hline Klucel ${ }^{\mathbb{R}}$ LF & 2 & $41.80 \pm 0.37$ & $64.16 \pm 0.81$ \\
\hline Xyl & $\begin{array}{r}5 \\
10 \\
15\end{array}$ & $\begin{array}{c}52.22 \pm 1.87 \\
52.16 \pm 0.67 \\
49.00 \pm 1.47\end{array}$ & $\begin{array}{c}59.88 \pm 1.24 \\
60.50 \pm 0.62 \\
61.21 \pm 0.44\end{array}$ \\
\hline Gly & $\begin{array}{r}5 \\
10 \\
15\end{array}$ & $\begin{array}{r}51.41 \pm 3.03 \\
50.80 \pm 0.65 \\
47.25 \pm 1.20\end{array}$ & $\begin{array}{l}60.72 \pm 1.88 \\
61.58 \pm 0.62 \\
63.46 \pm 1.05\end{array}$ \\
\hline Xyl+Gly & $\begin{array}{r}5 \\
10 \\
15\end{array}$ & $\begin{array}{l}49.34 \pm 0.68 \\
50.70 \pm 0.95 \\
49.73 \pm 0.78\end{array}$ & $\begin{array}{l}61.90 \pm 0.60 \\
61.44 \pm 0.55 \\
61.21 \pm 0.44\end{array}$ \\
\hline Lid & $\begin{array}{r}5 \\
10 \\
15\end{array}$ & $\begin{array}{l}51.47 \pm 1.25 \\
51.98 \pm 3.55 \\
57.35 \pm 0.21\end{array}$ & $\begin{array}{l}63.83 \pm 0.83 \\
60.99 \pm 1.86 \\
57.04 \pm 0.58\end{array}$ \\
\hline Lid + Xyl & $\begin{array}{r}5 \\
10 \\
15\end{array}$ & $\begin{array}{l}48.92 \pm 1.86 \\
53.90 \pm 2.97 \\
60.69 \pm 2.40\end{array}$ & $\begin{array}{l}62.16 \pm 1.09 \\
58.24 \pm 1.72 \\
54.90 \pm 1.39\end{array}$ \\
\hline Lid+Gly & $\begin{array}{r}5 \\
10 \\
15\end{array}$ & $\begin{array}{l}49.60 \pm 0.42 \\
43.63 \pm 2.07 \\
47.71 \pm 1.91\end{array}$ & $\begin{array}{l}60.13 \pm 0.61 \\
63.63 \pm 1.21 \\
64.04 \pm 1.13\end{array}$ \\
\hline Lid + Xyl+Gly & $\begin{array}{r}5 \\
10 \\
15\end{array}$ & $\begin{array}{r}46.30 \pm 0,81 \\
57.37 \pm 0.90 \\
54.95 \pm 1.04\end{array}$ & $\begin{array}{c}63.65 \pm 0.69 \\
57.98 \pm 0.82 \\
59.72 \pm 0.74\end{array}$ \\
\hline
\end{tabular}

The addition of Gly increased the size of the free volume holes in the polymers, while Xyl decreased it. The cause of this difference may be the difference in size of the molecules.

The measured tensile strengths of the films agreed with the expectations. The shorter LF chains resulted in lower tensile strengths.
The added excipients increased the tensile strength of the films, but Lid did not. However, together with the excipients, it still provided films with acceptable tensile strengths.

The measured CA demonstrated that macroscopically stable film structures were achieved at all compositions. The measured constant SFEs suggest good bioadhesion.

With regard to the good workability of the free films and the pharmaceutical technology requirements, Klucel ${ }^{\circledR}$ MF was chosen as the film-forming polymer. Lid and the excipients Gly and Xyl should be used in a concentration of $5 \mathrm{w} / \mathrm{w} \%$. Both Gly and Xyl had marked effects on the tested polymers. In our study these effects were welcomed and useful, but the excipients can cause disadvantageous effects in drug delivery systems, which must therefore be tested.

\section{Acknowledgements}

The publication is supported by the European Union and co-funded by the European Social Fund.

Project title: "Broadening the knowledge base and supporting the long-term professional sustainability of the Research University Centre of Excellence at the University of Szeged by ensuring the rising generation of excellent scientists."

Project no.: TÁMOP-4.2.2/B-10/1-2010-0012.

\section{References}

Audic, J., Chaufer, B., 2005. Influence of plasticizers and crosslinking on the properties of biodegradable films made from sodium caseinate. Eur. Polym. J 41, 1934-1942.

Ashikin, W.H.N.S., Wong, T.W., Law, C.L., 2010. Plasticity of hot air-dried mannuronate- and guluronate-rich alginate films. Carbohydr. Polym. 81, 104-113.

Averineni, R.K., Sunderajan, S.G., Mutalik, S., Nayak, U., Shavi, G., Armugam, K. Meka, S.R., Pandey, S., Nayanabhirama, U., 2009. Development of mucoadhesive buccal films for the treatment of oral sub-mucous fibrosis: a preliminary study. Pharm. Dev. Technol. 14, 199-207.

Bajdik, J., Fehér, M., Pintye-Hódi, K., 2007. Effect of plasticizer on surface of free films prepared from aqueous solutions of salts of cationic polymers with different plasticizers. Appl. Surf. Sci. 253, 7303-7308.

Bergo, P.V.A., Carvalho, R.A., Sobral, P.J.A., Santos, R.M.C., Silva, F.B.R., Prison, J.M., et al., 2008. Physical properties of edible films based on cassava starch as affected by the plasticizer concentration. Packag. Technol. Sci. 21, 85-89.

Bergo, P.V.A., Sobral, P.J.A., 2007. Effects of plasticizer on physical properties of pigskin gelatin films. Food Hydrocolloids 21, 1285-1289.

Bölcskei, É., Süvegh, K., Marek, T., Regdon Jr., G., Pintye-Hódi, K., 2011. Testing of the structure of macromolecular polymer films containing solid active pharmaceutical ingredient (API) particles. Radiat. Phys. Chem., 80; 799-802.

Chao, W.C., Huang, S.H., An, Q., Liaw, D.J., Huang, Y.C., Lee, K.R., Lai, J.Y., 2011. Novel interfacially-polymerized polyamide thin-film composite membranes: studied on characterization, pervaporation, and positron annihilation spectroscopy Polymer 52, 2414-2421.

Cheng, L.H., Karim, A.A., Seow, C.C., 2006. Effects of water-glycerol and watersorbitol interactions on the physical properties of Konjac Glucomannan films. J. Food. Sci. 71, E62-E67.

Colla, E., Sobral, P.J.A., Menegalli, F.C., 2006. Amaranthus cruentus flour edible films: influence of stearic acid addition, plasticizer concentration, and emulsion stirring speed on water vapor permeability and mechanical properties. J. Agric. Food Chem. 54, 6645-6653.

Craver, C.D., Carraher, C.E., 2000. Applied Polymer Science. 21st Century. Elsevier, New York, pp. 1088.

Cuq, B., Gontard, N., Cuq, J., Guilbert, S., 1997. Selected functional properties of fish myofibrillar protein-based films as affected by hydrophilic plasticizers. J. Agric. Food Chem. 45, 622-626.

El-Din, H.M.N., Alla, S.G.A., El-Naggar, A.W.M., 2010. Swelling and drug release properties of acrylamide/carboxymethyl cellulose networks formed by gamma irradiation. Radiat. Phys. Chem. 79, 725-730.

Eldrup, M., Lightbody, D., Sherwood, J.N., 1981. The temperature dependence of positron lifetimes in solid pivalic acid. Chem. Phys. 63, 51-58.

El-Kamel, A.H., Ashri, L.Y., Alsarra, I.A., 2007. Micromatricial metronidazole benzoate film as a local mucoadhesive delivery system for treatment of periodontal diseases. AAPS PharmSciTech 8, E1-E11.

Esposito, P., Colombo, I., Lovrecich, M., 1994. Investigation of surface properties of some polymers by a thermodynamic and mechanical approach: possibility of predicting mucoadhesion and biocompatibility. Biomaterials 15, 177-182.

Fishman, M.L., Coffin, D.R., Konstamce, R.P., Onwulata, C.I., 2000. Extrusion of pectin/starch blends plasticized with glycerol. Carbohydr. Polym. 41, 317-325. 
Galdeano, M.C., Grossmann, M.V.E., Mali, S., Bello-Perez, L.A., García, M.A., ZamudioFlores, P.B., 2009a. Effect of production process and plasticizers on stability of films and sheets of oat starch. Mater. Sci. Eng. C 29, 492-498.

Galdeano, M.C., Mali, S., Grossmann, M.V.E., Yamashita, F., García, M.A., 2009b. Effects of plasticizers on the properties of oat starch films. Mater. Sci. Eng. C 29, $532-538$.

Galietta, G., Di Gioia, L., Guilbert, S., Cuq, B., 1998. Mechanical and thermomechanical properties of films based on whey protein/beeswax emulsion films. J. Agric. Food Chem. 81, 3123-3130.

Haji-Saeid, M., Safrany, A., de O Sampa, M.H., Ramamoorthy, N., 2010. Radiation processing of natural polymers: the IAEA contribution. Radiat. Phys. Chem. 79, $255-260$.

Hiemenz P. . 1984. Polymer Chemistry. Marcel Dekker, New York.

Ismayil, Ravindrachary, V., Bhajantri, R.F., Praveena, S.D., Poojary, B., Dutta, D., Pujari, P. K., 2010. Optical and microstructural studies on electron irradiated PMMA: a positron annihilation study. Polym. Degrad. Stabil. 95, 1083-1091.

Jain, S.K., Jain, A., Gupta, Y., Kharia, A., 2008. Design and development of a mucoadhesive buccal film bearing progesterone. Pharmazie 63, 129-135.

Jangchud, A., Chinnan, M.S., 1999. Properties of peanut protein films: sorption isotherm and plasticizer effect. Lebensm. Wiss. Technol. 32, 79-84.

Jean, Y.C., Hung, W.S., Lo, C.H., Chen, H., Liu, G., Chakka, L., Cheng, M.L., Nanda, D., Tung, K.L., Huang, S.H., Lee, K.R., Lai, J.Y., Sun, Y.M., Hu, C.C., Yu, C.C., 2008 Applications of positron annihilation spectroscopy to polymeric membranes. Desalination 234, 89-98.

Jean, Y.C., Zhang, J., Chen, H., Li, Y., Liu, G., 2005. Positron annihilation spectroscopy for structure and interface studies in nanoscale polymeric films. Spectrochim. Acta Part A 61, 1638-1691.

Karbowiak, T., Hervet, H., Léger, L., Champion, D., Debeaufort, F., Voiley, A., 2006. Effect of plasticizers (water and glycerol) on the diffusion of a small molecule in iota-carrageenan biopolymer films for edible coating application. Biomacromolecules 7, 2011-2019.

Kilburn, D., Bamford, D., Lüpke, T., Dlubek, G., Menke, T.J., Alam, M.A., 2002 Free volume and glass transition in ethylene/1-octene copolymers: positron lifetime studies and dynamic mechanical analysis. Polymer 43, 6973-6983.

Kim, S.J., Ustunol, Z., 2001. Solubility and moisture isotherms of whey proteinbased edible films as influenced by lipid and plasticizer incorporation. J. Agric Food Chem. 49, 4388-4391.

Kristo, E., Biliaderis, C.G., 2006. Water sorption and thermo-mechanical properties or water/sorbitol-plasticized composite biopolymer films: caseinato pullulan bilayers and blends. Food Hydrocolloids 20, 1057-1071.

Kundu, J., Patra, C., Kundu, S.C., 2008. Design, fabrication and characterization of silk fibroin-HPMC-PEG blended films as vehicle for transmucosal delivery. Mater. Sci. Eng. C 28 (28), 1376-1380.

Lavorgna, M. Piscitelli, F, Mangiacapra, P., Buonocore, G.G, 2010. Study of the combined effect of both clay and glycerol plasticizer on the properties of chitosan films. Carbohydr. Polym. 82, 291-298.

Lehr, C.M., Boddé, H.E., Bouwstra, J.A., Junginger, H.E., 1993. A surface energy analysis of mucoadhesion II. Prediction of mucoadhesive performance by spreading coefficients. Eur. J. Pharm. Sci. 1, 19-30.

Li, J., Zivanivic, S., Davidson, P.M., Kit, K., 2011. Production and characterization of thick, thin and ultra-thin chitosan/PEO films. Carbohydr. Polym. 83, 375-382.

Li, Y., Wu, Y.C., Zhang, R., Chen, H., Zhang, J., Suzuki, T., Sandreckzki, T.C., Ohdaira, T. Jean, Y.C., 2003. Salt weathering effect of polymer coatings studied by positron annihilation spectroscopy. Radiat. Phys. Chem. 68, 581-587.

Lj Tomić, S., Mićić, M.M., Dobić, S.N., Filipović, J.M., Suljovrujić, E.H., 2010. Smart poly (2-hydroxyethyl methacrylate/itaconic acid) hydrogels for biomedical application. Radiat. Phys. Chem. 79, 643-649.

Llabot, J.M., Palma, S.D., Manzo, R.H., Allemandi, D.A., 2007a. Design of novel antifunga mucoadhesive films Part I. Pre-formulation studies. Int. J. Pharm. 330, 54-60.

Llabot, J.M., Palma, S.D., Manzo, R.H., Allemandi, D.A., 2007b. Design of nove antifungal mucoadhesive films Part II. Formulation and in vitro biopharmaceutical evaluation. Int. J. Pharm. 336, 263-268.

Mali, S., Sakanaka, L.S., Yamashita, F., Grossmann, M.V.E., 2005. Water sorption and mechanical properties of cassava starch films and their relation to plasticizing effect. Carbohydr. Polym. 60, 283-289.

Marques, M.F.F., Gordo, P.M., Gil, C.L., Kajcsos, Zs., Gil, M.H., Mariz, M.J., de Lima, A.P. 2003. Positron lifetime studies in vinyl polymers of medical importance. Radiat. Phys. Chem. 68, 485-488.

Mathews, G., 1996. PVC: Production Properties and Uses. Institute of Metals, London, England

Moore, G.R.P., Martelli, S.M., Gandolfo, C., Sobral, P.J.A., Laurindo, J.B., 2006 Influence of the glycerol concentration on some physical properties of feather keratin films. Food Hydrocolloids 20, 975-982.

Mura, P., Corti, G., Cirri, M., Maestrelli, F., Mennini, N., Bragagni, M., 2010. Development of mucoadhesive films for buccal administration of flufenamic acid: effect of cyclodextrin complexation. J. Pharm. Sci. 99, 3019-3029.

Murphy, J., 2001. Additives for Plastics Handbook, 2nd ed. Elsevier, New York

Muscat, D., Adhikari, B., Adhikari, R., Chaudhary, D.S., 2012. Comparative study of film forming behaviour of low and high amylose starches using glycerol and xylitol as plasticizers. J. Food Eng. 109, 189-201.

Müller, C.M.O., Yamashita, F., Borges-Laurindo, J., 2008. Evaluation of the effects of glycerol and sorbitol concentration and water activity on the water barrie properties of cassava starch films through a solubility approach. Carbohydr. Polym. $72,82-87$.

Nappinnai, M., Chandanbala, R., Balaijirajan, R., 2008. Formulation and evaluation of nitrendipine buccal films. Indian J. Pharm. Sci. 70, 631-635.

Papp, J., Marton, S., Süvegh, K., Zelkó, R., 2009. The influence of Metolose structure on the free volume and the consequent metoprolol tartrate release of patches. Int. J. Biol. Macromol. 44, 6-8.

Papp, J., Szente, V., Süvegh, K., Zelkó, R., 2010. Correlation between the free volume and the metoprolol tartrate release of Metolose patches. J. Pharm. Biomed. Anal. 51, 244-247.

Patai, K., Szente, V., Süvegh, K., Zelkó, R., 2010. Tracking of the micro-structural changes of levonorgestrel-releasing intrauterine system by positron annihilation lifetime spectroscopy. J. Pharm. Biomed. Anal. 53, 902-905.

Peng, H.G., Vallery, R.S., Liu, M., Skalsey, M., Gidley, D.W., 2007. Depth-profiled positronium annihilation lifetime spectroscopy on porous films. Colloids Surf. A: Physicochem. Eng. Aspects 300, 154-161.

Pethrick, R.A., 1997. Positron annihilation-a probe for nanoscale voids and free volume. Prog. Polym. Sci. 22, 1-47.

Pignatello, R., Basile, L., Puglisi, G., 2009. Chitosan glutamate hydrogels with local anesthetic activity for buccal application. Drug Delivery 16, 176-181.

Rahman, M., Brazel, C.S., 2004. The plasticizer market: an assessment of traditional plasticizers and research trends to meet new challenges. Prog. Polym. Sci. 29, $1223-1248$.

Raphaelides, S.N., Dimitreli, G., Exarhopoulos, S., Kokonidis, G., Tzani, E., 2011. Effect of processing history on the physicochemical and structural characteristics of starch-fatty acid extrudates plasticized with glycerol. Carbohydr. Polym. 83, 727-736.

Rillosi, M., Buckton, G., 1994. Modelling mucoadhesion by use of surface energy terms obtained by the Lewis acid-Lewis base approach. Int. J. Pharm. 117, 75-84.

Rosen, S.L., 1993. Fundamental Principles of Polymeric Materials, 2nd ed. Wiley, New York.

Satishbabu, B.K., Srinivasan, B.P., 2008. Preparation and evaluation of buccoadhesive films of atenolol. Indian J. Pharm. Sci. 70, 175-179.

Semalty, A., Semalty, M., Nautiyal, U., 2010. Formulation and evaluation of mucoadhesive buccal films of enalapril maleate. Indian J. Pharm. Sci. 72, 571-575

Semalty, M., Semalty, A., Kumar, G., 2008. Formulation and characterization of mucoadhesive buccal films of glipizide. Indian J. Pharm. Sci. 70, 43-48.

Skulason, S., Asgeirsdottir, M.S., Magnusson, J.P., Kristmundsdottir, T., 2009. Evaluation of polymeric films for buccal drug delivery. Pharmazie 64, 197-201.

Sobral, P.J.A., Monterrey-Quintero, E.S., Habitante, A.M.B.Q., 2002. Glass transition of Nile Tilapia myofibrillar protein films plasticized by glycerin and water. J. Therm. Anal. Calorim. 67, 499-504.

Suyatma, N.E., Tighzert, L., Copinet, A., 2005. Effect of hydrophilic plasticizers on mechanical, thermal, and surface properties of chitosan films. J. Agric. Food Chem. 53, 3950-3957.

Süvegh, K., Klapper, M., Domján, A., Mullins, S., Wunderlich, W., Vértes, A., 1999. Free volume distribution in monodisperse and polydisperse poly(methyl methacrylate) samples. Macromolecules 32, 1147-1151.

Szabó, B., Süvegh, K., Zelkó, R., 2012. Real time positron annihilation lifetime spectroscopy for the detection of the hydrocolloid gel-film transition of polymers. Polym. Test. 31, 546-549.

Szente, V., Süvegh, K., Marek, T., Zelkó, R., 2009. Prediction of the stability of polymeric matrix tablets containing famotidine from the positron annihilation lifetime distributions of their physical mixtures. J. Pharm. Biomed. Anal. 49, 711-714.

Talja, R.A., Helén, H., Roos, Y.H., Louppila, K., 2007. Effect of various polyols and polyol contents on physical properties of potato starch-based films. Carbohydr. Polym. 67, 288-295.

Tanabe, M., Watanabe, M., Yanagi, M., Nishizawa, S., Chigono, Y., Matsuda, J., Yamaoka, K., Inoue, K., 2008. Controlled indomethacin release from mucoadhesive film: in vitro and clinical evaluations. Yakugaku Zasshi: J. Pharm. Soc. Jpn. 128, 1673-1679.

Thomazine, M., Carvalho, R.A., Sobral, P.J.A., 2005. Physical properties of gelatin films plasticized by blends of glycerol and sorbitol. J. Food Sci. 70, 172-176.

Tickner, J.A., Schettler, T., Guidotti, T., McCally, M., Rossi, M., 2001. Health risk posed by use of di-2-ethyhexyl phthalate (DEHP) in PVC medical devices: a critical review. Am. J. Ind. Med. 39, 100-111.

Vieira, M.G.A., da Silva, M.A., dos Santos, L.O., Beppu, M.M., 2011. Natural-based plasticizers and biopolymer films: a review. Eur. Polym. J. 47, 254-263.

Wu, S., 1971. Calculation of interfacial tension in polymer systems. J. Polym. Sci. 34, $19-30$.

Yanagi, M., Hisajima, T., Ishibashi, H., Amamiya, A., Abe, S., Watanabe, M., 2008. Oral candidiasis deteriorated by local application of a glucocorticoid-containing film in a mouse model. Biol. Pharm. Bull. 31, 278-283.

Zelkó, R., Orbán, Á., Süvegh, K., 2006. Tracking of the physical ageing of amorphous pharmaceutical polymeric excipients by positron annihilation spectroscopy. J. Pharm. Biomed. Anal. 40, 249-254.

Zelkó, R., Orbán, Á., Süvegh, K., Riedl, Z., Rácz, I., 2002. Effect of plasticizer on the dynamic surface tension and the free volume of Eudragit systems. Int. J. Pharm. $244,81-86$.

Zelkó, R., Süvegh, K., 2005. Correlation between the release characteristics of theophylline and the free volume of polyvinylpyrrolidone. Eur. J. Pharm. Sci. 24, 351-354.

Zhang, Y., Han, J.H., 2006. Mechanical and thermal characteristics of pea starch films plasticized with monosaccharides and polyols. J. Food Sci. 71, 109-118. 
IV. 


\title{
Szájnyálkahártyán alkalmazható mukoadhezív filmek I. rész: A szájnyálkahártya és a nyál anatómiai, élettani áttekintése
}

\author{
Gottnek Mihály, Hódi Klára, ifj. Regdon Géza
}

\section{Bevezetés}

Az utóbbi években olyan új innovatív gyógyszerformák kerültek a gyógyszerkincsbe, mint például a szájnyálkahártyán alkalmazható mukoadhezív gyógyszeres filmek. Jelentőségüket az adja, hogy a szájnyálkahártya, mint alternatív beviteli kapu lehetőséget biztosít a hatóanyag szisztémás bejuttatására a first pass hatásnak, a gyomor savas miliöjének és a gasztrointesztinális traktusban található enzimek bontó hatásának kiküszöbölésével. Ezáltal kivédhetjük számos farmakon károsodását, bomlását, illetve eliminálódását. A betegek, különösen a gyermekek szívesen elfogadják, alkalmazzák ezt a gyógyszerformát kis mérete, flexibilitása, könnyủ alkalmazhatósága és tetszetős megjelenése miatt, ezáltal a compliance jelentősen növelhetö. $\mathrm{Az}$ is kardinális kérdés, hogy a gyógyszeripar az alternatív beviteli kapuk és innovatív gyógyszerformák felé fordul, hiszen egyre kevesebb a potenciális új farmakon jelölt, mely szóba jöhet a terápiában. Ezeket a tényeket az is jól bizonyítja, hogy az Amerikai Egyesült Államokban számos cég, valamint Európában a Novartis is jelen van a gyógyszerpiacon mukoadhezív filmekkel.

Továbbképző cikksorozatunk első részében a szájnyálkahártya felépítésével és a nyállal szeretnénk részletesen foglalkozni, mivel előbbi a gyógyszerforma alkalmazási helye és a felszívó felület egyben, utóbbi pedig mint kioldó közeg játszik szerepet. A második részben a mukoadhézió mechanizmusát, a mucin szerepét, a szájnyálkahártya barrier funkcióját és a hatóanyagok penetrációját foglaljuk össze. Végül a harmadik cikkben a mukoadhezív filmekröl, az alkalmazott filmképző polimerekről, segéd- és hatóanyagokról, valamint gyártásukról kívánunk részletesen szólni.

\section{A szájnyálkahártya anatómiája, élettana, felépitése [1-5]}

A bukkális régiót elölről és oldalról az ajkak és az orcák határolják, hátulról és középről a fogak és az íny, alulról és felülről pedig az ajkaktól és orcáktól halad a nyálkahártya az íny felé. A szájüreg teljes felülete 170 $\mathrm{cm}^{2}$ [6], melyböl mindössze $50 \mathrm{~cm}^{2}$ az a hasznos felszín, ami nem szarusodott el, így hatóanyag abszorpciójára alkalmas [7]. A szájnyálkahártya magába fog- lalja a bukkális, szublingvális, íny, szájpadlási és ajaki nyálkahártyákat. Ezek azonban három fö típusba sorolhatóak: a permeábilis nyálkahártya, mely bukkálisan (az orcáknál) és szublingválisan található meg, a következő a specializálódott hám (receptorok), mely a nyelvet borítja, végül a rágó nyálkahártya, mely az ínyen és a kemény szájpadláson fordul elő [8]. Három jól elkülöníthető rétege van: legkívül az epitélium határolja, mely az alatta elhelyezkedő bazálmembránhoz kapcsolódik, ez utóbbi pedig a legalul található támasztó szöveteken nyugszik. Ezeket további anatómiai egységekre oszthatjuk (kívülről az alsó rétegek felé haladva):

- epitélium: nyák réteg, sztrátum disztendum, sztrátum filamentózum, sztrátum suprabazále, sztrátum bazále,

- bazálmembrán, valamint a

- támasztó szövetek: lamina propria, szubmukóza.

A bukkális nyálkahártya vastagsága emberek esetén 500-800 $\mu \mathrm{m}$ közé tehető [9]. A szájüreget védő epitélium el nem szarusodott és elszarusodott részre osztható (1. ábra).

Az el nem szarusodott sejtrétegek a lágyszöveteket borítják úgy, mint: az orca (bukkális nyálkahártya), a nyelv alsó része, a lágy szájpadlás, a szájfenék és az ajkak. A szájnyálkahártya $60 \%$-át teszi ki ez a szövettípus [10], körülbelül 40-50 sejtrétegböl áll és 500-600 $\mu \mathrm{m}$ vastagságú [11]. A bukkális nyálkahártya elsődleges funkciója az alatta elhelyezkedő szövetek védelme. A szöveteket lipidmediált permeábilitási barrier védi az el nem szarusodott területeken, így védelmet nyújt antigénnel, karcinogén anyagokkal, mikrobiológiai toxinokkal, ételekben és italokban előforduló enzimekkel szemben is, valamint meggátolja a folyadékveszteséget $[12,13]$.

A fö lipidbarriert 76\%-ban foszfolipidek, 23\%-ban glükoszfingolipidek és $0,72 \%$-ban ceramidok alkotják [14]. Az elszarusodott sejtek a kemény szöveteket illetve azokat a rögzített anatómiai képleteket borítják, amelyek nagy mechanikai igénybevételnek vannak kitéve, mint például a kemény szájpadlás vagy az íny [15]. A struktúrája nagyon hasonlít az epidermiszéhez és körülbelül a szájüreg $25 \%$-át borítja [6]. A szájüreg nagyjából 15\%-át borítja részben elszarusodott epitélium, mely elsősorban a nyelv felső részén található meg [16] és ízérző receptorokat is tartalmaz. A bazálmembrán összekötő funkciót tölt be az epitélium és az 


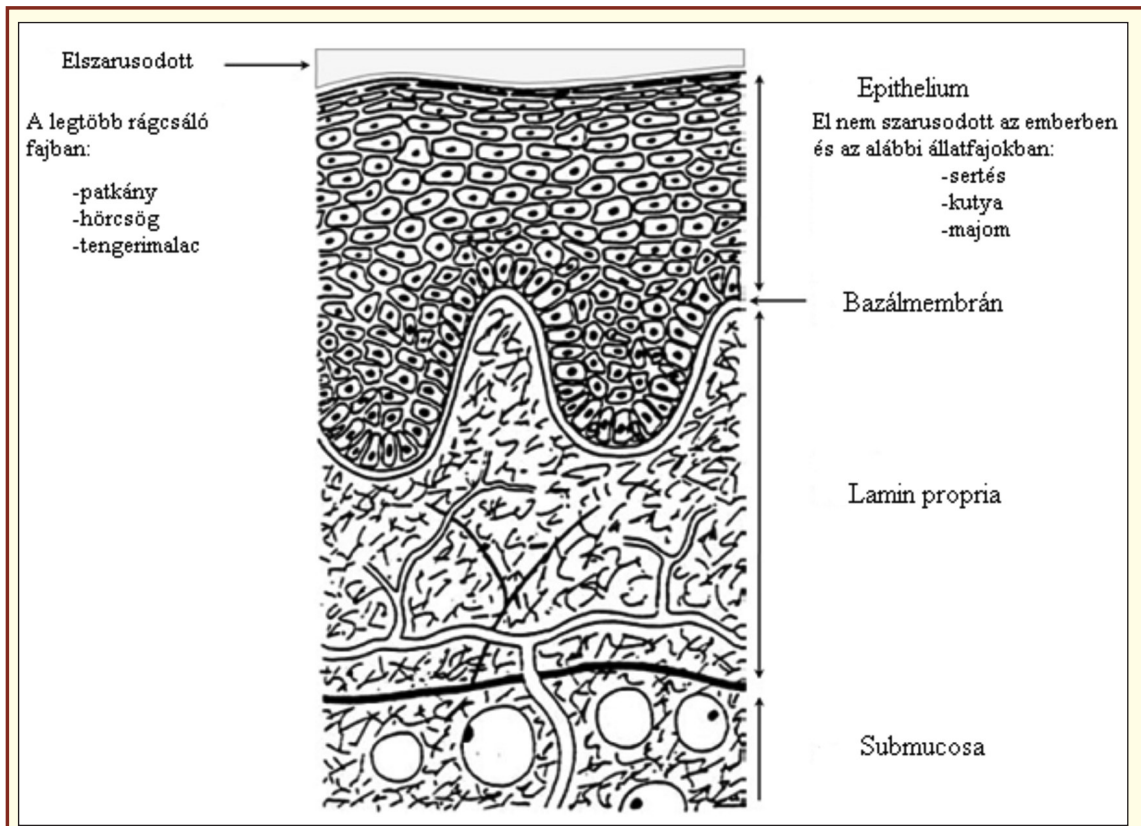

1. ábra: A bukkális nyálkahártya keresztmetszeti rajza [9] nyúlnak be a lamina propriából, mely kollagén rostokat, vérereket és simaizmot tartalmazó réteg [12]. Elsősorban mechanikai szerepet tölt be, nincs jelentős barrier funkciója a különféle anyagok penetrációja során $[18,19]$.

$\mathrm{Az}$ orcák területén számos racemózus, mucinózus és szerózus mirigy található [20], melyek kisméretűek, a nyálkahártya és az izom közé ágyazottan helyezkednek el. A maxilláris artéria szállítja a vért a bukkális nyálkahártyába, így gazdagabban erezett, mint szublingválisan, az íny vagy a szájpadlás területén és a véráramlás is gyorsabb $(2,4 \mathrm{ml} /$ perc $\left./ \mathrm{cm}^{2}\right) . \mathrm{Az}$ artériás érhálózat az arteria carotis externa-ból ered [21]. A nyálkahártya durva felü- alatta elhelyezkedő szövetek között, kapcsolatot teremt a rétegek határán, továbbá megfelelő mechanikai alátámasztást nyújt az epitéliumnak. A bazálmembrán kb. 1-2 $\mu \mathrm{m}$ vastagságú [17] és az itt található keratinociták vándorolnak fel az epitéliális régióba, közben alakjuk és méretük is megváltozik. A felszíni sejtréteg folyamatosan leválik, hasonlóan az epidermiszhez [16]. A legalul elhelyezkedő támasztó szövetek határozzák meg a szájnyálkahártya mechanikai stabilitását. A bukkális epitéliumba hosszú, kúpos sejtek letü [22] és az epitélium 5-6 naponta megújul [9]. Permeabilitása nagyobb, mint a bőré, de kisebb a vékonybél áteresztő képességénél [23-25]. Ez nemcsak a bél nagyobb felszívó felületével magyarázható, hanem annak szerkezetével is, hiszen ha figyelembe vesszük, hogy a bélhámot csak egyrétegü epitélium borítja önmagában, akkor érthető a jelentős eltérés az említett szövetek permeábilitása között (2. ábra).

Az el nem szarusodott területeken a bukkális epitélium sejtjei megtartják a sejtmagjukat és né-

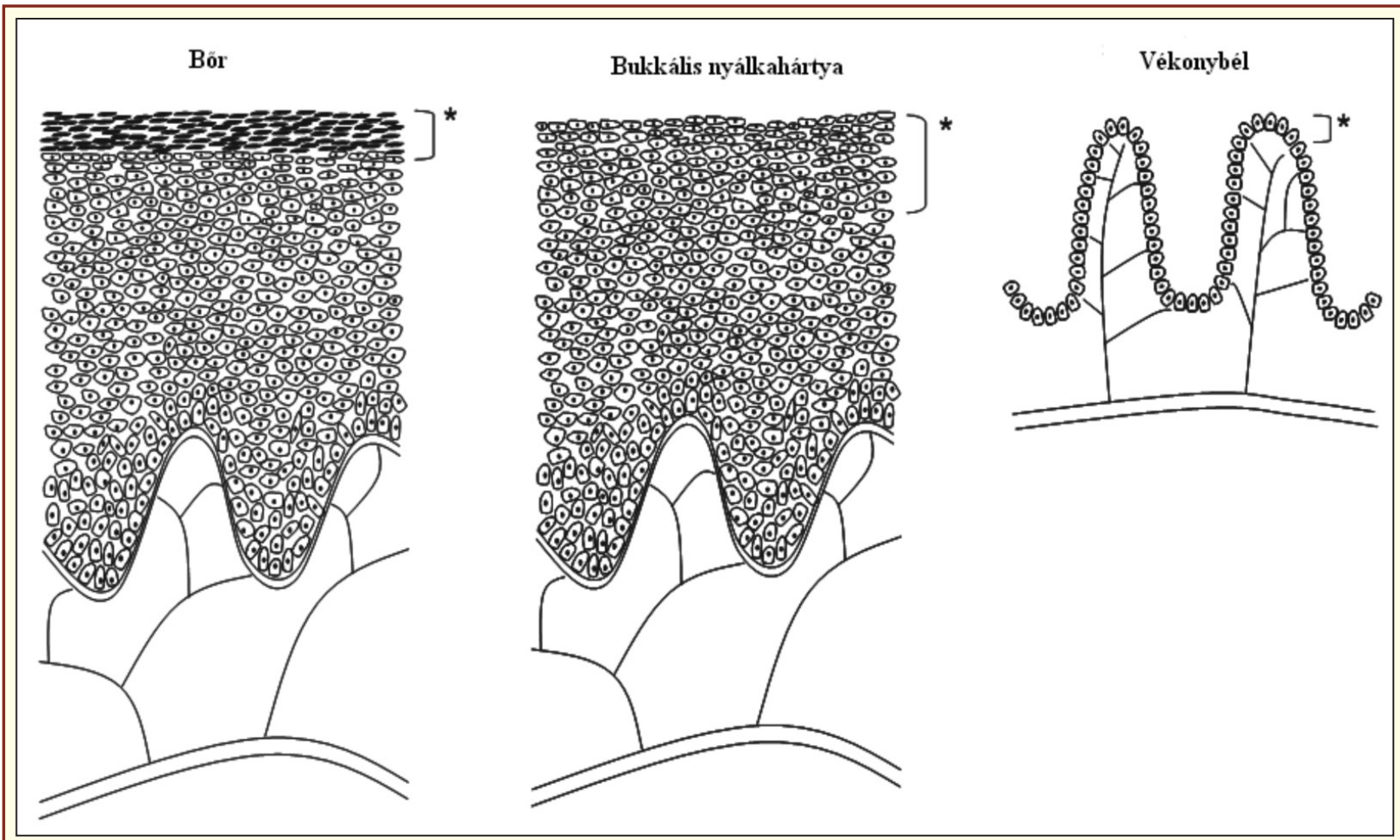

2. ábra: A bukkális nyálkahártya, a bör és a vékonybél áteresztőképessége különbségének anatómiai okai [4] 
A nyál és a plazma összehasonlitása [34]

\begin{tabular}{l|c|c|c}
\hline \multicolumn{1}{c|}{ Komponens } & Plazma & Nyál (nyugalmi) & Nyál (stimulált) \\
\hline $\mathrm{Na}^{+}(\mathrm{mmol} / \mathrm{l})$ & 145 & 5 & $20-80$ \\
\hline $\mathrm{K}^{+}(\mathrm{mmol} / \mathrm{l})$ & 4 & 22 & 20 \\
\hline $\mathrm{Ca}^{2+}(\mathrm{mmol} / \mathrm{l})$ & 2,2 & $1-4$ & $1-4$ \\
\hline $\mathrm{Cl}^{-}(\mathrm{mmol} / \mathrm{l})$ & 120 & 15 & $30-100$ \\
\hline $\mathrm{HCO}^{3-}(\mathrm{mmol} / \mathrm{l})$ & 25 & 6 & $15-80$ \\
\hline $\mathrm{PO}_{4}^{3-}(\mathrm{mmol} / \mathrm{l})$ & 1,2 & 0,2 & 0,2 \\
\hline $\mathrm{Mg}^{2+}(\mathrm{mmol} / \mathrm{l})$ & 1,2 & 2,5 & 2 \\
\hline $\mathrm{SCN}^{-}(\mathrm{mmol} / \mathrm{l})$ & $<0,2$ & 6 & 3 \\
\hline $\mathrm{NH}_{3}(\mathrm{mmol} / \mathrm{l})$ & 0,05 & 3,3 & $2-4$ \\
\hline$\left(\mathrm{NH}_{2}\right)_{2} \mathrm{CO}(\mathrm{mmol} / \mathrm{l})$ & $2-7$ & 3 & 3 \\
\hline Fehérje $(\mathrm{g} / \mathrm{l})$ & 70 & & \\
\hline
\end{tabular}

hány citoplazma funkciót, valamint keresztkötött fehérje burok veszi öket körül [22]. A differenciálódás során jelentős eltérés figyelhető meg az elszarusodó és az el nem szarusodó sejtek között, és ez okozza a szaruréteg kialakulását vagy hiányát. Az el nem szarusodó sejtek érésük során elhagyják a bazális régiót és a felszín felé vándorolva a differenciálódásuk folyamán nagyobb méretüek lesznek, közben lipideket és citokeratinokat építenek be, azonban ezek az anyagok nem aggregálódnak vagy kötegelődnek, szemben az elszarusodó sejtekkel [22]. A sejtek külső felszínéhez ún. MCG-k kapcsolódnak, mikor az epitélium felső harmadába érnek ${ }^{1}$. Ezek minden hámtípusban előfordulnak [26], jelenlétük tehát kimutatható a szájnyálkahártyában, azonban pontos funkciójuk még nem tisztázott [27, 28]. Körülbelül 2 $\mu \mathrm{m}$ átméröjüek, a Golgi apparátusban képződnek és a sejtek érése során vándorolnak a felszíni sejthártyához, ahol fuzionálnak azzal [27]. A folyamat során tartalmukat a sejt közötti térbe bocsátják [29]. Az el nem szarusodó hámszövetben amorf szerkezetüek [27], kis százalékuk lamellákat is tartalmazhat [30], viszont a bukkális nyálkahártya jobb permeábilitását részben az okozza, hogy a sejt közötti térben nincsenek lamellákba rendeződött lipidek [31]. Az egészséges szájüreget mikroorganizmusok kolonizálják, gombák, vírusok és baktériumok egyaránt előfordulnak a szájflórában. Több mint 700 mikroorganizmus jelenlétét mutatták már ki [32], így nagyon fontos a szájüregben alkalmazott mukoadhezív rendszer hatása a normál szájflórára, illetve annak egyensúlyára.

\section{A nyál fogalma, a nyálmirigyek anatómiája és müködése [33-35]}

A nyál egy tiszta, mukoszerózus exokrin szekrétum, a kis és nagy nyálmirigyekből származó komplex

\footnotetext{
${ }^{1}$ MCG betűszó az angol kifejezés 'membrane-coating granules' rövidítése, szabad fordításban: 'rétegburkoló szemcse'.
}

összetételű folyadék [36, 37]. A nagy nyálmirigyeket a felső állkapcsi első két őrlőfoggal szemközt elhelyezkedő páros parotid, a szájfenéken található szubmandibuláris és szublingvális mirigyek alkotják. A kis nyálmirigyek (körülbelül 450-750 darab) pedig az alábbi helyeken fordulnak elő a szájüregben: az alsó ajkaknál, a nyelven, a szájpadlás, az orcák és a farinx területén [37]. A protektív összetevőket ez utóbbiak termelik, habár jóval kevesebb mennyiségű nyál képződik bennük [38]. A normál napi nyálmennyiség 1,0-1,5 liter, mely az alábbiak szerint oszlik meg a nyálmirigyek között: $20 \%$ parotid, $65 \%$ szubmandibuláris, 7-8\% szublingvális és kevesebb, mint 10\% a kis nyálmirigyekből. Stimuláció hatására a parotid nyáltermelése a teljes mennyiség 50\%-ára emelkedik [38]. A mirigyállományban acinus, duktusz és mioepiteliális sejtek találhatóak. Szerózus, mucinózus és vegyes váladékot egyaránt elválaszthatnak; a parotid szerózus, a kis mirigyek mucinózus, míg a szubmandibuláris és szublingvális sejtek vegyes nyálat termelnek.

\section{A nyál összetétele}

A nyál nagyon híg folyadék, több mint 99\%-át víz alkotja, de a maradék 1\%-ban számos anyagot tartalmaz, ́́gy tudja betölteni összetett szerepét. Elektrolitok (a legfontosabb a nátrium-, kálium-, klorid- és bikarbonátion) és nyomelemek ( $\Sigma 0,2 \%)$, immunglobulinok, fehérjék $(0,3 \%)$, enzimek, mucinok és a fehérje bomlástermékei (karbamid és ammónia) is megtalálható benne (az I. táblázatban a nyugalmi és a stimulált értékeket is feltüntettük). Az ionok aktív transzporttal kerülnek a szérumból a nyálba. A nyálban 1-2 $\mathrm{mg} / \mathrm{ml}$ koncentrációban fehérje található: glikoproteinek, enzimek, immunglobulinok, peptidek: cisztatin, sztaterin, hisztatin, prolingazdag fehérjék, melyek kovalens kötéssel kapcsolódnak cukrokhoz, foszfát- és/ vagy szulfátionokhoz [34]. A három nagy nyálmirigy eltérő összetételü váladékot termel: a parotid amiláz, prolingazdag fehérje, agglutinin, cisztatin, lizozim és 
extraparotid glikoprotein tartalmú nyálat termel. Nagy koncentrációban található lizozim és a kéttípusú mucin (MG1 és MG2) a szublingvális mirigy által elválasztott nyálban, míg a szubmandibuláris váladék elsősorban MG1-ben és amilázban gazdag [39].

\section{A nyál pH-ja, áramlása, a nyáltermelés idegi szabályozása, folyamata}

$\mathrm{Az}$ acinus sejtekben termelt nyál izotóniás, viszont a duktusz rendszeren áthaladva hipotóniássá válik [40]. Normál körülmények között a pH-ja 6-7 közötti, azonban lassú folyásnál 5,3, míg gyorsnál 7,8 is lehet [38]. Nyugalmi állapotban $0,1 \mathrm{ml} /$ perc feletti a nyáltermelés, azonban stimulus hatására a minimum folyási térfogat értéke 0,2 ml/percre emelkedik [41]. Az átlagos, nem stimulált folyási érték $0,3 \mathrm{ml} /$ perc [38, 42], a stimulált térfogat maximum $7 \mathrm{ml} /$ perc lehet [38], ekkor csökken az elektrolitok, fehérjék és mucin mennyisége [39]. A nyálmirigyek kettős beidegzésűek. Szimpatikus túlsúly esetén az acinus sejteken keresztül fehérjében gazdag nyál termelődik, míg paraszimpatikus dominancia során vizes, híg lesz a váladék [38].

Tovább bontva a vegetatív szabályozást, a nyáltermelés és összetétel az alábbiak szerint változik: $\alpha$-adrenerg stimulus hatására $\mathrm{Ca}^{2+}$ influx miatt a sejtek fehérjében gazdag nyálat választanak el, melyet alacsony mucin koncentráció, kis térfogat és viszkózus sajátság jellemez. $\beta$-adrenerg túlsúly esetén nincs elektrolit beáramlás, viszont az acinus sejtekből fehérjékben gazdag szekrétum távozik, mely mucinban gazdag és viszkózus, habos megjelenésű és jóval lassabban kerül elválasztásra [43]. A kolinerg túlsúly elektrolitokban gazdag és nagy térfogatú nyálat eredményez $[44,45]$. Íz, illat és mechanikai inger (rágás), fájdalom, a terhesség alatti hormonváltozás, vagy agresszió hatására fokozódik a nyáltermelés, míg a stressz és a menopauza környéki hormonváltozás csökkenti azt [34]. A nyáltermelésnek is van napi és éves ciklusa: alvás alatt termelődik a legkevesebb és leglassabb folyású nyál, míg a legtöbb étel-ital fogyasztásakor egy napon belül, nyáron alacsony, télen pedig csúcsáramlás figyelhető meg [38, 46, 47]. A populáció 30\%-a panaszkodik élete folyamán hosszabbrövidebb ideig fennálló szájszárazságról (xerosztómia) kezelőorvosának, fogorvosának [48]. A stimulált nyáltermelésben megfigyelhető hipofunkció nem életkorfüggő, viszont idősekben csökken a nyálban található mucin mennyisége [44, 45].

A nyáltermelés nem exocitózissal valósul meg, hanem vezikulákból ürülve, melyekbe paracelluláris úton jut a víz. Ez pedig a test folyadékháztartásától függ, így például láz, hányás, hasmenés esetén kevesebb víz áll rendelkezésre, ezért csökken a nyáltermelés, ami miatt a betegek szájszárazságra panaszkodhatnak [34].

\section{A nyál szerepe és funkciója}

A nyál fö funkciói:

- lubrikáció és védelem,

- pufferelés és tisztitás,

- a fogak integritásának fenntartása,

- antibakteriális aktivitás és

- izlelés és emésztés.

A lubrikáns szerepét a nyálban található mucinok töltik be, ezáltal a rágásban, a nyelésben és a beszédképzésben is szerepet játszanak. A megfelelő $\mathrm{pH}$ kialakításában legfontosabb puffer a bikarbonát, de ezen kívül szerepet játszik még az ammónia, karbamid és foszfát is [49-51]. Az étkezést követő öt percen belül csökkenni kezd a száj pH-ja, majd negyedóra múltán éri el a 6,1 körüli értéket [52-54]. A fogak épségét tekintve az 5,0-5,5 körüli $\mathrm{pH}$ rendkívül kritikus, mert kedvez a kariesz kialakulásának [39]. A kalcium, a foszfát és a fehérjék antiszolubilizáló faktorként funkcionálnak és modulálják a fogak de- és remineralizációját. A fehérjék és mucinok a megfelelő tisztítást biztosítják oly módon, hogy összekapcsolódnak, aggregálódnak a mikroorganizmusokkal, továbbá közreműködnek a plakk metabolizmus szabályozásában. Egy a nyálban található peptid, a sztaterin stabilizálja a kalcium és foszfát sók oldódását a nyálba, lubrikánsként beborítja a fogak felszínét, így védve a sók kioldódásától, valamint a hidroxiapatithoz kapcsolódva szintén védelmezi a fogzománcot $[55,56]$. A prolingazdag fehérjék közül a savas karakterűek játszanak elsősorban szerepet a fogzománc védelmében oly módon, hogy a baktérium-hidroxiapatit kapcsolatot felbontják és a fogakat beborítva egy védő réteget alakítanak ki a zománc felszínén, ahová a baktériumok nem tudnak kötődni [57, 58]. A szájüreg védelmét IgA (MG2-höz kapcsolódik), IgG és IgM immunglobulinok, valamint fehérjék, MG2, peptidek és enzimek (laktoferrin, lizozim, peroxidázok) látják el [59, 60]. A hisztatinok kis molekulák (3-5 kDa), bázikus, hisztidingazdag fehérjék [61], elsősorban anti-candida hatással bírnak [62].

\section{Szisztémás betegségek hatása a nyál összetételére}

1. Cisztás fibrózis: Megnőtt kalcium és összes fehérje koncentráció jellemzi, melyek oldhatatlan komplexet képeznek egymással. A nátrium- és foszfátion koncentráció szignifikánsan megnő [63-68].

2. Szklerózis multiplex: Szignifikánsan csökken az IgA termelés nyugalmi állapotban [69, 70].

3. Graft-versus-host betegség: A nyálmirigyek destrukciója, nátriumion, lizozim koncentrációnövekedés valamint foszfátion és IgA csökkenés tapasztalható a betegeknél [63, 71-73].

4. Diabetes mellitus (DM): Mivel az inzulinnak van nyálmirigy stimuláló hatása, így csökkent nyálelvá- 
II. táblázat A nyálelválasztás mértékét csökkentő hatóanyagcsoportok [34]

\begin{tabular}{l}
\hline NSAID \\
\hline Antiaritmikumok \\
\hline Antikonvulzív szerek \\
\hline Antidepresszánsok \\
\hline Antiemetikumok \\
\hline Antihisztaminok \\
\hline Antihipertenzív szerek \\
\hline Antiparkinson szerek \\
\hline Antipruretikumok \\
\hline Antipszichotikumok \\
\hline Spazmolitikumok \\
\hline Citotoxikumok \\
\hline Dekongesztánsok \\
\hline Diuretikumok \\
\hline Expektoránsok \\
\hline MAO-inhibitorok \\
\hline Trankvillánsok \\
\hline
\end{tabular}

lasztás figyelhető meg DM-ben szenvedő betegeknél. Az albumin és IgG mennyisége is csökken nyugalmi állapotban $[63,70,74]$.

5. Alkoholos eredetü májcirrhosis: A betegek 50\%ában a parotis megnagyobbodik, ezáltal $50 \%$-os nyáltermelés csökkenést idéz elő, továbbá csökken a nátrium-, bikarbonát- és kloridion koncentráció, valamint az összes fehérje mennyiség [63, 70].

6. HIV/AIDS: Csökken a nyáltermelés, a mucin és az antivirális, antibakteriális és antifungiális faktorok száma, ellenben elörehaladott stádiumban az összes fehérje mennyisége megnő, mivel a fehérjék könynyebben átjutnak a funkciócsökkent epitéliumon [70, 75-78].

7. Epilepszia: Fenitoint szedő betegek esetén mellékhatásként íny megnagyobbodás és csökkent IgA termelés fordulhat elő. Ezek következményeként jelentősen romlik a száj higiéné [63, 70, 79].

8. 'Égö száj' szindróma: Gyakrabban fordul elő posztmenopauzás nőkben, ezért is az előfordulási arány 1:7 a férfi és a nő betegek között. A betegek szájszárazságról és fájdalomról panaszkodnak, azonban könnyen serkenthető a nyáltermelésük mind mechanikailag, mind gyógyszeresen. A teljes fehérje mennyiség kisebb, a mucin, kálium-, klorid-, foszfátion koncentráció pedig nagyobb [70, 80, 81].

9. Vesebetegség: A nyál fehérje, nátrium- és káliumion koncentrációja a plazmáéval megegyező, a pH és karbamid mennyisége szignifikánsan nagyobb [82, 83].

\section{Gyógyszeres terápia hatása a nyálelválasztásra}

Nagyon fontos külön kiemelni azokat a hatóanyagcsoportokat, illetve hatóanyagokat, amelyek hatással vannak a nyáltermelésre, annak összetételére, valamint a nyálmirigyek méretére. Hiszen nemcsak a mukoad-
III. táblázat

Hiposzalivációt okozó hatóanyagok [34]

\begin{tabular}{l}
\hline Antikolinerg hatás \\
\hline Muszkarin receptor blokkolók \\
\hline Atropin \\
\hline Ipratropium \\
\hline Oxibutinin \\
\hline Pirenzepin \\
\hline Propantelin \\
\hline Szkopolamin \\
\hline Antiparkinzon szerek \\
\hline Benzatropin \\
\hline Biperiden \\
\hline Orfenadrin \\
\hline Prociklidin \\
\hline Trihexifenidil \\
\hline Antikolinerg mellékhatás \\
\hline Antidepresszív szerek \\
\hline Amitriptilin \\
\hline Dezipramin \\
\hline Imipramin \\
\hline Lofepramin \\
\hline Maprotilin \\
\hline Nortriptilin \\
\hline Oxaprotilin \\
\hline Antihisztaminok \\
\hline Ciklizinef \\
\hline Difenhidramin \\
\hline Prometazin \\
\hline Tripelenamin \\
\hline Antiaritmikumok \\
\hline Dizopiramid \\
\hline Antipszichotikumok \\
\hline Butitium sók \\
\hline
\end{tabular}

hezív rendszerek, vagy a szájban diszpergálódó tabletták szempontjából fontos a megfelelő mennyiségű és összetételủ nyál (kioldóközeg, mukoadhézióhoz szükséges mucin), hanem ezek ismerete nagyban segíti a gyógyszerészi gondozás során a betegekkel, illetve az orvossal való kommunikációt, együttmüködést.

\section{Nyálelválasztás csökkentés}

Minden olyan hatóanyag, amely a vegetatív idegrendszer müködését gátolja, az ingerület átvitelre vagy a sejtműködésre hat, mellékhatásként csökkenteni fogja a nyáltermelés mértékét. Számos hatóanyag különböző hatástani csoportokból nyáltermelést csökkentő mellékhatással rendelkezik, ezeket a csoportokat a II. táblázatban foglaltuk össze. Az antikolinerg hatású vagy mellékhatású (III. táblázat), valamint az antiadrenerg jellegủ hatóanyagok (IV.táblázat) szintén nyáltermelés csökkenést idéznek elő mellékhatásként. 
Anti-adrenerg szerek [34].

\begin{tabular}{l|l|l|l|l|l}
\hline \multicolumn{1}{c|}{$\boldsymbol{\beta}$-blokkolók } & \multicolumn{1}{c}{$\boldsymbol{\alpha}$-blokkolók } \\
\hline \multicolumn{1}{c|}{$\boldsymbol{\beta}_{1}+\boldsymbol{\beta}_{2}$} & \multicolumn{1}{c|}{$\boldsymbol{\beta}_{2}$} & \multicolumn{1}{c}{$\boldsymbol{\alpha}_{1}$} & \multicolumn{1}{c}{$\boldsymbol{\alpha}_{1}+\boldsymbol{\alpha}_{2}$} & $\boldsymbol{\alpha}_{2}$ \\
\hline Acebutolol & Alprenolol & Butoxamin & Corinanthin & Dibenamin & Idazoxan \\
\hline Atenolol & Carteolol & & Doxazosin & Dihidroergotamin & Rauwolszcine \\
\hline Metoprolol & Oxprenolol & & Prazosin & Fenoxibenzamin & Tolazolin \\
\hline Pafenolol & Pindolol & & & Fentolamin & Yohimbin \\
\hline Praktolol & Propranolol & & & & \\
\hline & Sotalol & & & & \\
\hline & Tetratolol & & & & \\
\hline & Timolol & & & & \\
\hline
\end{tabular}

Paraszimpatomimetikumok [34, 84, 85].

\begin{tabular}{l}
\hline Direkt ható \\
\hline Arekolin \\
\hline Betanekhol \\
\hline Carbakol \\
\hline Cevimelin \\
\hline Metakolin \\
\hline Muszkarin \\
\hline Oxotremorin \\
\hline Pilokarpin \\
\hline Indirekt ható \\
\hline Cizaprid \\
\hline Neosztigmin \\
\hline Nizatidin \\
\hline Fizosztigmin \\
\hline
\end{tabular}

\section{Nyálelválasztás serkentés}

A nyálfolyás serkentéséhez a neurotranszmitter acetilkolin vagy noradrenalin szintjének kell emelkednie, hatásukra nagymennyiségü, vízben gazdag és kis fehérjekoncentrációjú nyál képződik. A terápiában számos hatóanyagot alkalmaznak ezek közül a szájszárazság csökkentése érdekében, például Sjögrenszindróma, vagy nyaki besugárzás mellékhatásaként fellépő száraz száj esetén ( $\boldsymbol{V}$. táblázat). A szimpatomimetikumok szintén fokozzák a nyáltermelést (VI. táblázat).

\section{Nyálmirigyek morfológiai változása}

Egyes hatóanyagok előidézhetik a nyálmirigyek morfológiai változását. Például $\beta_{1}$-receptor stimuláció a nyálmirigy megnagyobbodását idézi elő, míg a metoprolol ( $\beta$ antagonista) csökkenti a mirigyállomány méretét $[86,87]$. A nyálmirigy állomány megnagyobbodását okozó hatóanyagok a VII. táblázatban találhatóak.

Fájdalom a nyálmirigyekben

Számos esetben másodlagos fertőzések miatt a betegek fájdalmat éreznek a nyálmirigyekben. Az alábbi hatóanyagok alkalmazása esetén szintén fájdalom fordulhat elő a nyálelválasztás során: guanetidin, izmelin, $\alpha$-metildopa, bretilium, betanidin, klórmetiazol, klonidin, citarabin, nikardipin [86].

\section{Ízérzés változás és rossz lehelet (halitózis)}

Főleg a kén tartalmú hatóanyagok okoznak halitózist. Rossz leheletet előidéző hatóanyagok például a dimetilszulfoxid, N-acetilcisztein, izoszorbid-dinitrát (VIII. táblázat) [86-92].

\section{Összefoglalás}

A szájnyálkahártya kiváló beviteli kapu bukkális hatóanyaghordozó rendszerek számára, mivel felépítése, vastagsága, vérkeringése, felülete alkalmassá teszi

VI. táblázat

Szimpatomimetikumok [34].

\begin{tabular}{l|l|l|l|l}
\hline \multicolumn{1}{c|}{$\beta$ mimetikum } & \multicolumn{1}{c}{$\alpha$ mimetikum } \\
\hline$\beta_{1}$ & \multicolumn{1}{c|}{$\beta_{1}+\beta_{2}$} & $\beta_{2}+\alpha_{2}$ & \multicolumn{1}{c}{$\alpha_{2}$} \\
\hline Dihidro-alprenolol & Izoproterenol & Metaproterenol & Metoxamin & Klonidin \\
\hline Dobutamin & & Prokaterol & Fenilefrin & Moxonidin \\
\hline Prenarterol & & Szalbutamol & & Oximetazolin \\
\hline & & Szoterenol & & $\alpha$-Metildopa \\
\hline & & Terbutalin & & $\alpha$-Me-noradrenalin \\
\hline
\end{tabular}


VIII. táblázat

Az izérzékelését befolyásoló hatóanyagok [34]

\begin{tabular}{l|l|l|l}
\hline \multicolumn{1}{c|}{ Fémes (keserü) íz } & \multicolumn{1}{c|}{ Megváltozott szaglás } & \multicolumn{1}{c}{ Megváltozott íz érzékelés } & \multicolumn{1}{c}{ Íz érzésvesztés } \\
\hline Azelasztin & Doxiciklin & Linkomicin & Karbamizol \\
\hline Prokainbenzilpenicillin & Szkopolamin & Szulfaszalazin & Propiltiouracil \\
\hline Metronidazol & & Tegretol & Penicillamin \\
\hline Tetraciklin & & Levodopa & Bleomicin \\
\hline Begnamidin & & Klórhexidin & Ciszplatin \\
\hline & & Hexetidin & Kaptopril \\
\hline & & Lítium-karbonát & \\
\hline & Amfotericin & \\
\hline & Grizeofulvin & \\
\hline
\end{tabular}

erre. A helyi hatás mellett kiemelt előnyt jelent továbbá a szisztémás gyógyszerbevitel lehetősége is. A nyál, mint kioldóközeg és a mucin forrása játszik jelentős szerepet e gyógyszerformák alkalmazhatósága szempontjából. A különböző hatóanyagok nyálmirigyekre és a nyálelválasztásra gyakorolt hatásának ismerete mind a gyógyszerészi gondozás, mind a szájüregben alkalmazott gyógyszerformák alkalmazhatósága szempontjából jelentős.

\section{Köszönetnyilvánítás}

Jelen kutatási eredmények megjelenését „Az SZTE Kutatóegyetemi Kiválósági Központ tudásbázisának kiszélesitése és hosszú távú szakmai fenntarthatóságának megalapozása a kiváló tudományos utánpótlás biztositásával" címü, TÁMOP-4.2.2/B-10/1-2010-0012 azonositószámú projekt támogatja. A projekt az Európai Unió támogatásával, az Európai Szociális Alap társfinanszírozásával valósul meg.

\section{IRODALOM}

1. Salamat-Miller, N., Chittchang, M., Johnston, T.P.: Adv Drug Deliver Rev 57, 1666-1691 (2005). - 2. Morales, J.O., McConville, J.T.: Eur J Pharm Biopharm 77, 187-199 (2011). -3. Sudhakar, Y., Koutsu, K., Bandyopadhyay, A.K.: J Control Release 114, 15-40 (2006). - 4. Nicolazzo, J.A., Reed, B.L., Finnin, B.C.: J Control Release 105,1-15 (2005). - 5. Patel, V.F., Liu, F., Brown, M.B.: J Control Release 153, 106-116 (2011). - 6. Collins, L.M.C., Dawes, C.: J. Dent. Res. 66, 13001302 (1987). - 7. Lee, J.W., Park, J.H., Robinson, J.R.: J. Pharm. Sci. 89, 850-866 (2000). - 8. Smart, J.D.: Adv Drug Deliver Rev 56, $481-489$ (2004). - 9. Harris, D., Robinson, J.R.: J. Pharm. Sci. 81, 1-10 (1992). - 10. Squier, C.A., Hill, M.: Oral mucosa, in: A. Ten Cate (Ed.), Oral Histology, Development, Structure, and Function, Mosby Incorp, 1989, pp. 319-356. - 11. Gandhi, R.B., Robinson, J.: Adv Drug Deliver Rev 13, 43-74 (1994). - 12. Dowty, M.E., Knuth, K.E., Irons, B.K., Robinson, J.R.: Pharm. Res. 9, 1113-1122 (1992). - 13. Squier, C.A., Finkelstein, M.W., in: Ten Cate, A.R. (Ed.) Oral Histology, Development, Structure and Function, C.V. Mosby, St. Louis, 1989, pp. 345-385. - 14. Fox, P.C.: Ann. N.Y. Acad. Sci. 842, 132-137 (1998). - 15. Chen, S.Y., Squier,
C.A.: The ultrastructure of the oral epithelium, in: Meyer, J., Squier, C.A., Gerson, S.J. (Eds.): The Structure and Function of Oral Mucosa, Pergamon Press, Oxford, 1984, pp. 7-30. - 16. DeGrande, G., Benes, L., Horriere, F., Kersanty, H., Lacoste, C., McQuinn, R., Guo, J., Scherrer, R.: Specialized oral mucosal drug delivery systems: patches, in: M. Rathbone (Ed.): Oral Musosal Drug Delivery, Informa Health Care, 1996. - 17. Rathbone, M.J., Hadgraft, J.: Int. J. Pharm. 74, 9-24 (1991). - 18. Squier, C.A., Wertz, P.: Structure and function of the oral mucosa and implications for drug delivery, in: Rathbone, M.J. (Ed.), Oral Mucosal Drug Delivery, Informa Health Care, 1996, pp- 1-26. - 19. Li, B., Robinson, J.: Preclinical assesment od oral mucosal drug delivery systems, in: Ghost, T., Pfister, W. (Eds.), Drug Delivery to the Oral Cavity, Marcel Dekker, Inc. New York, 2005, pp. 41-66. - 20. Wikipedia, The free encyclopedia, http//:en.wikipedia.org/ wiki/. - 21. Stablein, M.J., Meyer, J.: The vascular system and blood supply, in: Meyer, J., Squier, C.A., Gerson, S.J. (Eds.): The Structure of Function of Oral Mucoa, Pergamon Press, Oxford, 1984, pp. 237-256. - 22. Rathbone, M.J., Ponchel, G., Ghazali, F.A.: Systemic and oral mucosal drug delivery and delivery systems, in: Rathbone, M.J. (Ed.): Oral Mucosal Drug Delivery, vol. 74. Marcel Dekker Inc., New York, 1996, pp. 241-284. - 23. Rojanasakul, Y., Wang, L.Y., Bhat, M., Glover, D.D., Malanga, C.J., Ma, J.K.H.: Pharm. Res. 9, 1029-1034 (1992). - 24. Gore, A.V., Liang, A.C., Chien, Y.W.: J. Pharm. Sci. 87, 441-447 (1998). - 25. Shojaei, A.H.: J. Pharm. Pharm. Sci. 1, 15-30 (1998). - 26. Hayward, A.F.: Int. Rev. Cytol. 59, 97-127 (1979). - 27. Squier, C.A.: J. Ultrastruct. Res. 60, 212220 (1977). - 28. Squier, C.A.: Arch. Oral Biol. 27, 377-382 (1982). - 29. Lavker, R.M.: J. Ultrastruct. Res. 55, 79-86 (1979). - 30. Wertz, P.W., Swartzendruber, D.C., Squier, C.A.: Adv. Drug Deliv. Rev. 12, 1-12 (1993). - 31. Squier, C.A., Hall, B.K.: J. Invest. Dermatol. 84, 176-179 (1985). - 32. Thibodeau, E.A., O'Sullivan, D.M., Tinanoff, N.: Community Dent Oral 21, 288-291 (1993). - 33. Humphrey, S.P., Msed, R.D.H., Russel T. Williamson, D.M.D.: J. Proshet. Dent. 85, 162-169 (2001). - 34. Aps, J.K.M., Martens, L.C.: Forensic Sci Int 150, 119-131 (2005). - 35. Dodds, M.W.J., Johnson, D.A., Yeh, C.K.: J Dent 33, 223-233 (2005). - 36. Edgar, W.M.: Br. Dent. J. 172, 305-312 (1992). - 37. Roth, G., Calmes, R., editors, Salivary glands and saliva. In: Oral biology. St. Louis: C.V. Mosby; 1981. p. 196-236. - 38. Edgar, W.M.: Br. Dent. J. 169, 96-98 (1990). - 39. Veerman, E.C., van der Keybus, P.A.,. Vissink, A., Nieuw Amerongen, A.V.: Eur. J. Oral. Sci. 104, 346352 (1996). - 40. Tabak, L.A., Levine, M.J., Mandel, I.D., Ellison, S.A.: J. Oral. Pathol. 11, 1-17 (1982). - 41. Ship, J.A., 
Fox, P.C., Baum, B.J.: J. Am. Dent. Assoc. 122, 63-69 (1991). -42. Grant, D.A., Stern, I.B., Listgarten, M.A., editors., Saliva. In: Periodontics. 6 th ed. St. Louis: C.V. Mosby, 1988. p. 135146. - 43. Matsou, R., Garret, J.R., Proctor, G.B., Carpenter, G.H.: J. Physiol. 527, 175-184 (2000). - 44. Luo, W., Latchney, L.R., Culp, D.J.: Am. J. Physiol. Cell. Physiol. 280, C884-C896 (2001). - 45. Ishikawa, Y., Iida, H., Ishida, H.: Mol. Pharmacol. 61, 1423-1434 (2002). - 46. Shannon, I.L.: The biochemistry of human saliva in health and disease. In: W.H. Rowe, editor., Salivary glands and their secretion., Ann Arbor: University of Michigan Press, 1972. p. 92-121. - 47. Dawes, C.: Int. J. Chronobiol. 2, 253-279 (1974). - 48. Mandel, I.D.: J. Am. Dent. Assoc. 119, 298-304 (1989). - 49. Johnson, D.A.: Regulation of salivary glands and tehir secretion by masticatory-system, Boca Raton, FL: CBC Press, 1987. p. 136-155. - 50. Mandel, I.D.: Impact of saliva on dental caries, Compend. Suppl. S476-481, 1989. - 51. Lagerlof, F., Oliveby, A.: Adv. Dent. Res. 8, 229-238 (1994). - 52. Edgar, W.M.: Caries. Res. 10, 241-254 (1976). - 53. Bibby, B.G., Mundorff, S.A., Zero, D.T., Almekinder, K.J.: J. Am. Dent. Assoc. 112, 333-337 (1986). - 54. Rugg-Gunn, A.J., Edgar, W.M., Geddes, D.A., Jenkins, G.N.: Br. Dent. J. 139, 351-356 (1975). - 55. Lamkin, M.S., Oppenheim, F.G.: Crit Rev Oral Biol Med 4, 251-259 (1993). -56. Turner, R.J.: Ion transport related to fluid secretion in salivary glands, In: K. Dobrosielski-Vergona, editor., Biology of the salivary glands, Boca Raton: CRC Press, 1993. p. 105-127. - 57. Gibbson, R.J., Hay, D.I., Cisar, J.O., Clark, W.B.: Infect Immun 56, 2990-2993 (1988). - 58. Gibbson, R.J., Hay, D.I.: J Dent Res 9, 1303-1307 (1989). - 59. McNabb, P.C., Tomasi, T.B.: Annu. Rev. Microbiol. 35, 447449 (1981). - 60. Biesbrock, A.R., Reddy, M.S., Levine, M.J.: Infect. Immun. 59, 3492-3497 (1991). - 61. Oppenheim, F.G., Xu, T., McMillian, F.M., Levitz, S.M., Diamond, R.D., Offner, G.D., Troxler, R.F.: J Biol Chem 263, $7472-7477$ (1988). - 62. Tsai, H., Bobek, L.A.: Crit Rev Oral Biol Med 9, 480-497 (1988). - 63. Mandel, I.D.: J. Oral. Pathol. Med. 19, 119-125 (1990). - 64. Haeckel, R., Hanecke, P.: Ann. Biol. Clin. Paris 51, 903-910 (1993). - 65. Jiménez-Reyes, M., SanchezAguierre, F.J.: Appl. Radiat. Isot. 47, 273-277 (1996). - 66. Rosenstein, B.J.: Clin. Chest. Med. 19, 423-441 (1998). - 67. Apps, J.K.M. Delanghe, J., Martens, L.C.: Int. J. Ped. Dent. 9(Suppl. 1), 21 (Abstract) (1999). - 68. Aps, J.K.M., Delanghe, J., Martens, L.C.: Clin. Chem. Lab. Med. 40, 345-350 (2002). - 69. Oosterhuis, H.J.G.H.: Klinische neurologie., Bohn Stafleu Van Loghum, Houten, 1999. - 70. van Nieuw Amerongen, A.: Systemische aandoeningen en speeksel, in: A. van Nieuw Amerongen, A., (Ed.), Speeksel, speekselkieren en mondgez ondheid., Bohn Stafleu Van Loghum, Houten 2004, pp. 241-257 (Chapter 17). - 71. Dens, F., Boohearts, M., P. Boute, P., DeClerck, D., Vinckier, F.: Bone Marrow Transpl. 17, 421-423 (1996). - 72. Fox, R.I., Stern, M., Michelson, P.: Curr. Opin. Rheumatol. 12, 391-398 (2000). - 73. Zeilstra, L.J.W., Vissink, A., Konings, A.W.T., Coppes, R.P.: Int. J. Radiat. Res. 76, 419-429 (2000). - 74. Moore, P.A., Guggenheimer, J., Etzel, K.R., Weynant, R.J., Orchard, T.: Oral
Surg. Oral Med. Oral Pathol. Oral Radiol. Endodontol. 92, 281-291 (2001). - 75. Lin, A.L., Johnson, D.A., Patterson, T.F., Wu, Y., Lu, D.L., Shi, Q., Yeh, C.K.: Oral Microbiol. Immunol. 16, 270-278 (2001). - 76. Mellanen, L., Sorsa, T., Lähdevirta, J., Helenius, M., Kari, K., Meurman, J.H.: J. Oral. Pathol. Med. 30, 553-559 (2001). - 77. Lin, A.L., Johnson, D.A., Stephan, K.T., Yeh, C.K.: J. Dent. Res. 82, 719-724 (2003). 78. Navazesh, M., Mulligan, R., Barron, Y., Redford, M., Greenspan, D., Alves, M., Phelan, J.: Oral Surg. Oral Med. Oral Pathol. Oral Radiol. Endodontol. 95, 693-698 (2003). 79. Das, S.J., Newman, H.N., Olsen, I.: J. Dent. Res. 81, 683687 (2002). - 80. Lamey, P.J.: Dermatol. Clin. 14, 339-354 (1996). - 81. Hakeberg, M., Hallberg, L.R.M., Berggren, U.: Eur. J. Oral. Sci. 111, 305-311 (2003). - 82. Epstein, S.R., Mendel, I.D., Scopp, I.W.: J. periodontol. 51, 336-338 (1980). - 83. Sasha, S.M., Ben, H., Ayreh, A. Angel, D. Gutman: J. Oral Med. 38, 67-70 (1983). - 84. Fox, P.C., van der Ven, P.F., Baum, B.J., Mendel, I.D.: Oral Surg. Oral Med. Oral Pathol. Oral Radiol. Endodontol. 61, 243-245 (1986). - 85. Bymaster, F.P., Carter, P.A., Yamada, M., Gomeza, J., Wess, J., Hamilton, S.E., M.M. Nathanson, M.M., McKinzie, D.L., Felder, C.C.: Eur. J. Neurosci. 17, 1403-1410 (2003). - 86. van Nieuw Amerongen, A.: Systemische aandoeningen en speeksel, in: van Nieuw Amerongen, A. (Ed.), Speeksel, speekselkieren en mondgez ondheid., Bohn Stafleu Van Loghum, Houten 2004, pp. 269-279 (Chapter 19). - 87. Abdollahi, M., Minaiee, B., Yaaghoubi, A.A.: Hum. Exp. Tixicol. 22, 177-181 (2003). - 88. Mott, A.E., D.A. Leopold, D.A.: Med. Clin. North. Am. 75, 1321-1353 (1991). - 89. Lindemann, B.: Curr. Biol. 6, 12341237 (1996). - 90. Ritchie, C.S.: Clin. Geriatr. Med. 18, 709717 (2002). - 91. Quirijnen, M.: J. Clin. Periodont. 30, 17-18 (2003). - 92. van Nieuw Amerongen, A.: Systemische aandoeningen en speeksel, in: van Nieuw Amerongen, A.: (Ed.), Speeksel, speekselkieren en mondgez ondheid., Bohn Stafleu Van Loghum, Houten 2004, pp. 335-342 (Chapter 24).

Gottnek, M., Hódi, K., Regdon, G. jun.: Mucoadhesive films applied on the oral mucosa. Part I: Anatomical and physiological review of the oral mucosa and the saliva

The structure, thickness, blood circulation and surface of the oral mucosa make it an excellent entrance route for buccal drug delivery systems. In addition to the local effect, the possibility of systemic drug administration is also a prominent advantage.

The first part of our further education series of articles is going to focus on the structure of the oral mucosa and the saliva, as the former one is the place of administration of the dosage form and also an absorbing surface, while the saliva, as a dissolving medium and a source of mucin, has a significant role in the applicability of mucoadhesive films. It is important to know the effect of various active ingredients on salivary glands and salivary secretion both with respect to pharmaceutical care and to the use of dosage forms administered in the oral cavity.

SZTE Gyógyszertechnológiai Intézet, Szeged, Eötvös u. 6. - 6720 e-mail: geza.regdon@pharm.u-szeged.hu 
V. 


\section{TOVÁBBKÉPZŐ KÖZLEMÉNYEK}

Gyógyszerészet 57. 69-75. 2013.

\section{Szájnyálkahártyán alkalmazható mukoadhezív filmek II. rész: A mukoadhézió mechanizmusa, a mucin funkciói. Penetráció a szájnyálkahártyán keresztül, a nyálkahártya barrier funkciója}

Gottnek Mihály, Hódi Klára, ifj. Regdon Géza

\section{A mukoadhézió fogalma, adhéziós elméletek, illetve az adhézió kialakításában szerepet játszó tényezők $[1,2]$}

Bioadhézió alatt azt a folyamatot értjük, melynek során egy biológiai egységhez határfelületi erőkkel tartósan kapcsolódik valamely anyag, vagy egy gyógyszerforma. Ez a kapcsolódás kemény és lágyszöveteken egyaránt létrejöhet. A mukoadhézió fogalmának meghatározása során az előző definíciót azzal kell kibővíteni, hogy a bioadhézió ilyenkor mucinnal, vagy nyákkal fedett képleten valósul meg [3]. Az utóbbi évtizedekben a mukoadhézió és mechanizmusa a figyelem középpontjába került, melynek oka az, hogy lokális terápia esetén a gyógyszerforma célzottan biztosítja a hatóanyag koncentrált jelenlétét az érintett területen ( $\mathrm{pl}$. afta, fogínygyulladás kezelése). Szisztémás hatás elérése érdekében oly módon biztosítja a hatóanyag egyenletes és folyamatos vérszintjét, hogy tartósan a felszívó felülethez rögzíti a hatóanyag hordozó rendszert.

A nyálkahártya olyan állandóan nedves, nyákkal borított képlet, mely bizonyos testüregek (pl. szájüreg, légző traktus) falát borítja. Az epitélium lehet egyrétegü (pl. gyomor, vékonybél, bronchusok), illetve többrétegü is, utóbbi többek között a szájüreg, nyelöcső, kornea vagy a vagina felületét borítja. Mucint egyrészt arra specializálódott kehelysejtek, másrészt exokrin mirigyek, mint a nyálmirigyek termelhetnek. A mucin előfordulhat a nyálkahártyán gélrétegként, oldott vagy szuszpendált formában egyaránt [4]. Jellegzetes gélszerü állapotát, a kohéziós és adhéziós tulajdonságát, a benne lévő glikoproteinek adják. A mucinréteg vastagsága az eltérő testüregekben különböző lehet, vastagsága a gyomorban 50-450 $\mu$ m közé tehetö $[5,6]$, a legvékonyabb, mindössze $1 \mu \mathrm{m}$-es pedig a szájüregben [7].

\section{A mukoadheziv rendszer - mucin interakció}

Kémiai kötések: Az adhézió létrejöttéhez, a molekuláknak kötést kell létesíteniük a felülettel. Kialakulhatnak erős ionos és kovalens kötések, gyengébb hidrogénhíd-kötések, a leggyengébb van der Waals kölcsönhatások és végül az indirekt hidrofób kötések is [8].
Továbbképzö cikksorozatunk elsö részében a szájnyálkahártya felépitését és a nyál élettani, gyógyszerészeti vonatkozásait tárgyaltuk részletesen, mivel elöbbi a gyógyszerforma alkalmazási helye és a felszivó felület egyben, utóbbi pedig mint kioldó közeg játszik szerepet. A második részben, vagyis jelen közleményben a mukoadhézió mechanizmusát, a mucin szerepét, a szájnyálkahártya barrier funkcióját és a hatóanyagok penetrációját foglaljuk össze. Végül a harmadik cikkben a mukoadheziv filmekröl, az alkalmazott filmképzö polimerekröl, segéd- és hatóanyagokról, valamint gyártásukról kivánunk majd részletesen szólni.

Adhéziós elméletek: öt fö elméletet állítottak fel a mukoadhézió kialakulásának mechanizmusára [9-11].

1. Az elektron-elmélet szerint elektrontranszfer jön létre az érintkező felületek között, a folyamat közben megváltozik a rendszerek elektronszerkezete. A határfelületen kettősréteg alakul ki, mely következtében vonzó erők lépnek fel.

2. A nedvesedési elméletet a folyadék és a szilárd rendszer között fellépő felületi, határfelületi energiákkal lehet magyarázni. A folyadék spontán szétterül a felületen, mely egyben a bioadhézió létrejöttének az előfeltétele. A jelenség során a gáz, folyadék és szilárd fázis felületi feszültsége tart egyensúlyt. A nedvesedést a peremszöggel $(\Theta)$ tudjuk jellemezni. A gyakorlatban nedvesedésről beszélünk, ha $\Theta<$ $90^{\circ}$; adott felületet rosszul nedvesít egy folyadék, ha $\Theta>90^{\circ}$. Tökéletes nedvesedés akkor jön létre, ha $\Theta=0^{\circ}$, amikor pedig $\Theta=180^{\circ}$, akkor a folyadék egyáltalán nem nedvesíti a szilárd felületet. Tehát annál nagyobb mértékben jön létre bioadhézió, minél közelebb esik a nedvesedési peremszög a $0^{\circ}$-hoz [12].

3. A diffúziós elmélet szerint a polimer láncok és az adhezív felület között diffúzió játszódik le. A folyamatot a koncentráció-gradiens irányítja és az elérhető molekulaláncok hosszától valamint mozgékonyságától függ. A penetráció mélysége a diffúziós koefficienstől és az érintkezés idejétől függ, az elégséges penetrációs mélység közepesen tartós adhéziós kötést hoz létre.

4. A mechanikus elmélet értelmében keresztkötés alakul ki egy folyadékként viselkedő adhezív anyag és 


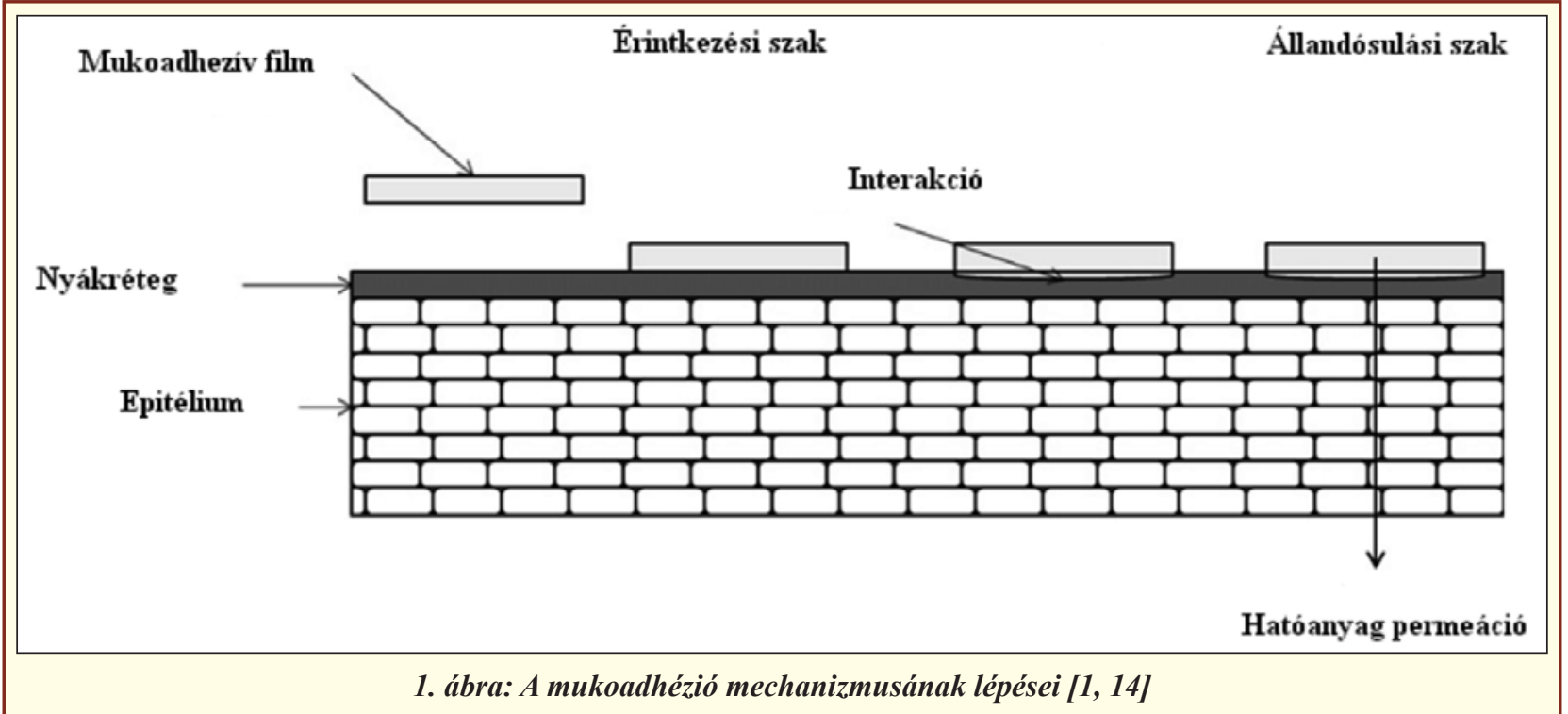

a durva felszín egyenetlenségei között. Habár a nagy felület több kapcsolódási lehetőséget biztosít, egyre fontosabb jelentőséget tulajdonítanak a kapcsolódás során a viszkoelasztikus és plasztikus energia eloszlás kialakulásának [11].

5. A szétkapcsolódási elmélet abban tér el az előző négy elmélettől, hogy az adhézió után az érintkező felületek szétválását feltételezi. Az adhéziós kötés gyengülése a határfelületen figyelhető meg. Ez normálisan a gyengébb komponens miatt következik be, azaz a kohéziós erő gyengülése tapasztalható az összetapadó felületeken keresztül.

Figyelembe véve a mukoadhézió mechanizmusának bonyolultságát önmagában egyik teóriával sem magyarázható a folyamat.

John D. Smart szerint az in vivo mukoadhéziós kötés létrejöttét négy elképzeléssel lehet magyarázni:

1. Száraz vagy részlegesen hidratált gyógyszerformák valódi nyák rétegen keresztül kapcsolódnak a felülethez például az orrüregben alkalmazott partikulák esetén.

2. Teljesen hidratált gyógyszerformák az előbb említett felületi tulajdonságok mellett is kapcsolódhatnak a szövethez úgy, mint a gasztrointesztinális traktus alsó részeiben alkalmazott első generációs mukoadhezív rendszerek.

3. Száraz vagy részlegesen hidratált gyógyszerformák vékony/nem folytonos nyák rétegen keresztül kapcsolódnak a szövethez, mint például a szájüregben és vaginában alkalmazott mukoadhezív tabletták vagy filmek.

4. Teljesen hidratált adagolási formák kapcsolódnak az előbb említett módon. Tipikusan félszilárd vagy folyékony készítmények alkalmazása a szemben, oesophagusban [1].

Két lépéssel lehet jellemezni a mukoadhézió mechanizmusát [13], mely a mukoadhezív anyag és a nyákréteg között jön létre. Az első lépés az érintkezési szak, mely során közvetlen kapcsolat (nedvesedés) van a mukoadhezív anyag és a nyákréteg között. Majd a második lépés az állandósulási szak, mikor különféle fizikai és kémiai interakciók biztosítják a tartós mukoadhéziós kapcsolatot (1. ábra). Az érintkezési szakban a film elkezdi dehidratálni a nyákréteget, miközben önmaga hidratálódik; a folyamat közben megkezdődik a polimer láncok penetrációja a nyákrétegbe és viszont. Az állandósulási szakaszban kialakuló mukoadhezív erő a filmképző polimer tulajdonságaitól és a hidratáltság mértékétől függ [14]. A mukoadhézió megszünését a gyengébb komponens okozza: a mukoadhezív nyák határfelület. A mukoadhézió szempontjából az erősebb komponens általában a nyákréteg vagy a hidratált mukoadhezív anyag [15]. Az adhéziós kapcsolat ereje és tartóssága a gyengébb régió kohéziós tulajdonságától függ. Vizes környezetben a mukoadhezív polimerek könnyen túlhidratálódnak, mely folyamat során csúszós nyákréteget képezve könnyen elválnak a felületről [16]. Hogy tartós adhéziót lehessen elérni, szabályozni kell a hidratáció fokát és mértékét. Ennek megvalósítása keresztkötések [17-19] vagy hidrofób csoportok alkalmazásával lehetséges [20].

Számos faktornak van hatása a mukoadhézióra [3, $9,21]$. A szájüregi mukoadhézióban szerepet játszó tényezők a következők:

- polimertöl függö faktorok: molekulatömeg, flexibilitás, H-hídkötő kapacitás, keresztkötöttségi fok, töltés, koncentráció, hidratáció [2];

- környezeti tényezök: a nyál, a mucin életidö, a bukkális szövetek mozgása.

A mukoadhézió szempontjából optimális molekulatömeg $1 \cdot 10^{4}-4 \cdot 10^{6} \mathrm{Da}$. A nagy molekulasúlyú polimerek nem hidratálódnak eléggé gyorsan, így a kötést létesítő csoportok nem tudnak a kapcsolódási felszínhez kötődni. Ezzel szemben a kis molekulatömegüek gyenge gélt képeznek és gyorsan oldódnak a felszínröl. 
A polimerláncok mozgékonysága is fontos, mert segíti a kötő csoportok penetrációját és belegabalyodását a nyákrétegbe. Ha a vízoldékony polimerekben növeljük a keresztkötések számát, akkor csökkeni fog a polimer láncok mozgékonysága, mely védelmet nyújt a túlzott hidratáció ellen. Az ionizálható csoportokat tartalmazó polimerek mukoadhéziós tulajdonságait befolyásolja a környezet pH-ja. Azokban a rendszerekben, ahol e csoportok száma nagy, például karbomerek, kitozánok, szignifikáns különbségek tapasztalhatók a belső, felületi és környezeti pH között [22]. A töltéssel rendelkező polimer csoportok és fémionok interakciója szintén szerepet játszhat az adhézió mechanizmusában, továbbá azok a makromolekulák, amelyek H-hídkötés létesítésére alkalmas funkciós csoportokat tartalmaznak [16, 21, 23-25]; hidroxil $(\mathrm{OH})$, karboxil $(\mathrm{COOH})$ vagy amin $\left(\mathrm{NH}_{2}\right)[26]$ csoportjaik révén kedveznek az adhézió kialakulásának. Tipikus képviselőik a karbomerek, kitozán, nátriumalginát és cellulóz származékok. Szulfhidril csoportokat tartalmazó polimerek és a mucinok kén tartalmú csoportjai diszulfid híd kialakulásának kedveznek (2. ábra).

A nyálkahártya felületét mucinban gazdag nyákréteg borítja. A mucinok nagymértékben glikolizált glikoproteinek; egy nagy fehérjerészből és oligoszacharid oldalláncokból állnak. A fehérjerészt szerin-, treonin- és prolingazdag egységek építik fel. Az oligoszacharid láncok végéhez sziálsav, szulfonsav, L-fruktóz, galaktóz, N-acetilgalaktózamin vagy $\mathrm{N}$-acetilglükózamin kapcsolódik [28]. Ennek eredményeként a mucinok negatív töltésüek fiziológiás pH-n. Pozitív töltéssel rendelkező polimerek a negatív sziálsavon keresztül elektrosztatikusan tudnak kapcsolódni a mucinhoz. Az anionos polimerek jobb bioadhéziós tulajdonsággal rendelkeznek, mint a kationosak vagy a semlegesek. Egy gyógyszerforma alkalmazhatósági ideje a mucin életidejétől függ, amely emberek esetén 12-24 órára becsült [29]. A gyógyszerforma kialakítása során azt is figyelembe kell venni, hogy nemcsak evés, ivás vagy beszéd közben, hanem alvás alatt is folytatódik a bukkális nyálkahártya mozgása, mely a filmek elmozdulását, leválását idézheti elö [30].
A mucinok felépítése, típusai, szerepük [26, 31, 32]

A bukkális nyálkahártya epiteliális sejtjei körülbelül 40-300 $\mu \mathrm{m}$-es nyákréteggel vannak borítva [33], melyet 95-99\%-ban víz és 1-5\%-ban mucinok alkotnak. A mucinok nagymolekulák, molekulatömegük 0,5-20 MDa közé tehető és nagymennyiségű szénhidrátot tartalmaznak. A GI traktus mucinjai 70-80\% szénhidrátból, 12-25\% fehérjéből és 5\% szulfát észterből állnak. Egy mucin alapegység 400-500 kDa, majd az ezekből összekapcsolódó lineáris szakaszok akár 50 MDa molekulatömeget is elérnek [34]. Lubrikánsként segíti a sejtek egymáshoz viszonyított elmozdulását és ezáltal jelentős szerepet játszik a mukoadhézió kialakításában [35]. Bukkális pH-n a nyák erős kohéziós gélréteget képez, mintegy zselés rétegként kötődik az epiteliális sejtek felszínéhez. A viszkoelasztikus gél struktúrát egyrészt a mucinláncok összegabalyodása, másrészt H-hídkötés, elektrosztatikus és hidrofób kapcsolatok alakítják ki [36]. A glikoprotein láncvégeken elhelyezkedő sziálsav $\left(\mathrm{pK}_{\mathrm{a}}=2,6\right)$ és szulfát csoportok miatt neutrális $\mathrm{pH}-\mathrm{n}$ a mucin anionos polielektrolitként viselkedik [37].

A mucinok egyláncú központi glikoproteinböl és két jól megkülönböztethető részből állnak [38]:

- erösen glikolizált központi fehérjerész, melyhez nagy szénhidrát oldalláncok kapcsolódnak O-glikozidos kötéssel és

- egy vagy két alacsonyan glikolizált terminális fehérjerészből.

Ezeket gyakran „csupasz fehérje régióknak” hívják. A mucinok felépítése a 3. ábrán látható. A mucinoknak számos típusa van. A nyálban két típusú mucin jellemző [40, 41]. Közös tulajdonságaik az alacsony szolubilizáció, a magas viszkozitás és elaszticitás, valamint az erős adhéziós képesség. A lágyszövetek és fogak, fogpótlások közötti kapcsolat minden esetben a nyál mucinjainak lubrikáns hatásával jöhet létre [42]. A mucinok a rágás, a beszéd és a nyelés folyamatában is fontos szerepet töltenek be [41]. Az antibakteriális effektusokban is nagy a jelentőségük, mivel szelektíven befolyásolják a mikroorganizmusok tapadását a szövetek felszínéhez és ezzel kontrollálják a baktériumok és gombák kolonizációját.

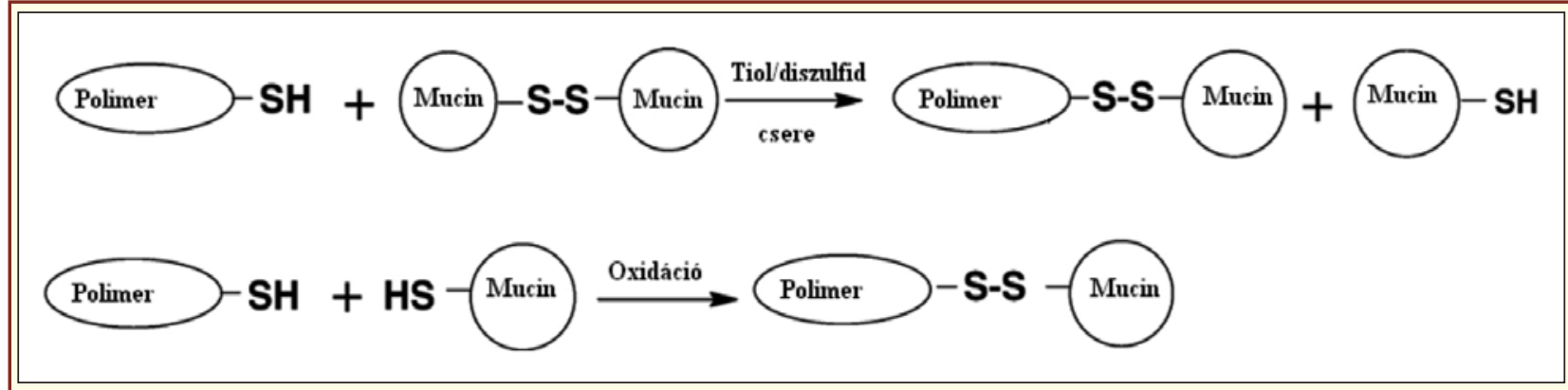

2. ábra: Tiolált polimer és mucin glikoproteinek között kialakuló kovalens kötések [27] 


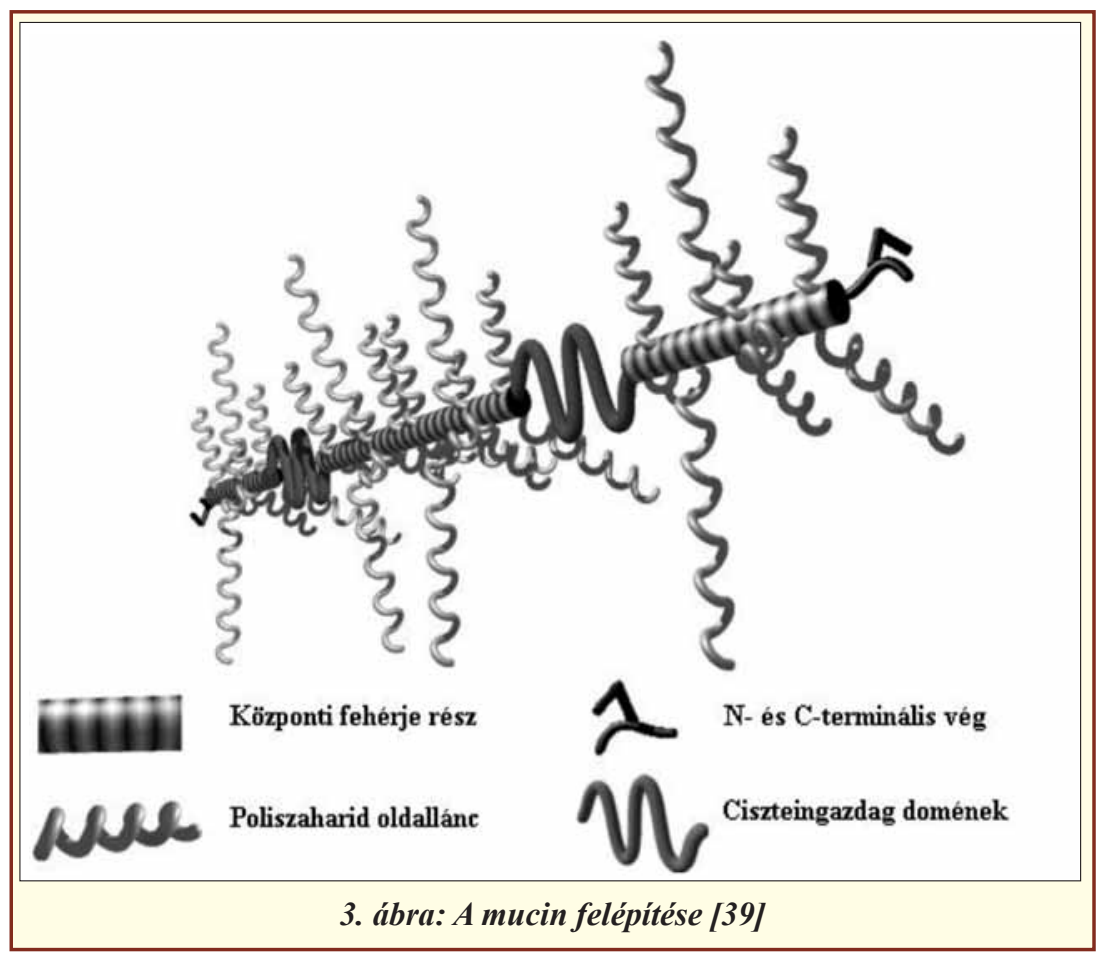

Az egyes típusú mucin (MG1) nagy molekulatömegü és magasan glikolizált, míg a kettes típusú mucin (MG2) alacsony molekulatömegü és egyszeresen glikolizált [40, 41]. Az MG1 erősen kötődik a fogzománc felszínéhez, ezzel védőréteget képezve azon, így gátolva a savak káros hatását. A nyálban lévő különféle fehérjékkel (pl. amiláz, prolingazdag fehérjék, hisztatin) komplexet képezve és a baktériumokhoz kötődve kimeríti azok energiatartalékait [43]. Ugyan az MG2 is kötődik a fogzománchoz, azonban könnyen le is válik onnan. Hatását úgy fejti ki, hogy segíti a baktériumok clearance-ét a szájüregből azáltal, hogy aggregálódik azokkal [44, 45]. Azokban a betegekben, akik caries-rezisztensek, az MG2 dominál, míg a cariesre való hajlam esetén az MG1 nagyobb koncentrációja figyelhető meg. Ennek oka az, hogy ugyan az MG1 erősebben kötődik a baktériumokhoz, azonban a fogzománchoz rögzítve azokat, fokozza a savak fogakra kifejtett káros hatását. Ezzel szemben az MG2 mivel könnyen leválik a fogak felszínéről - távol tartja a káros savakat termelő mikroorganizmusokat a fogzománctól.

Összetett szerepük másik fontos része a nyálkahártya integritásának fenntartása oly módon, hogy képesek modulálni az intercelluláris kalcium szintet [40]. Segítik a normál flóra megtapadását és kolonizációját a szájüregben. Védö barriert képeznek a szájüreg kemény és lágyszövetein, lubrikánsként gátolják a szövetek túlzott kopását. Diffúziós barriert képeznek savas karakterü anyagokkal szemben és limitálják az ásványi agyagok kilépését a fogak felszínéről [46]. Kutatások kimutatták, hogy az MG1 szignifikánsan csökken az idősekben, függetlenül a nemtől. Továbbá pozitív korrelációt mutattak ki az MG1 csökkenés és a periodontitis között. Ez egyrészt a szájüreg védelmének csökkenését okozza, másrészt befolyással lehet a mukoadhézióra is [47]. Gyermekekben a felnőtt populációhoz viszonyítva nem mutatható ki számottevő eltérés sem MG1, sem MG2 esetén [48].

\section{A bukkális nyálkahártya permeábilitása és barrier funkciója $[2,14,27]$}

A bukkális nyálkahártya permeábilitása 4-4000-szer nagyobb, mint a bőré [49]. Egy adott hatóanyag bejutása a permeábilitási barrierjétől függ, amely a membrán vastagságától, szarusodási fokától és a hatóanyag fizikai-kémiai tulajdonságaitól függ [50]. A szájnyálkahártya permeábilitási barrier funkcióját az MCG-k (MCG betűszó az angol kifejezés „membrane-coating granules” rövidítése, szabad fordításban rétegburkoló szemcse) jelenlétével és hatásával magyarázhatjuk [28]. Az MCG-k szférikus vagy ovális organellumok, melyek átméröje 100-300 nm közé tehető és mind az elszarusodott, mind az el nem szarusodott epitéliumban előfordulnak.

Az MCG-k a sejtek citoplazmájából származnak, exocitosissal ürülnek, a sejtek felső, felszíni rétegeiben találhatóak meg elsősorban (4. ábra). Ugyanakkor elvétve az ellenkező irányban is megtalálhatóak bizo-

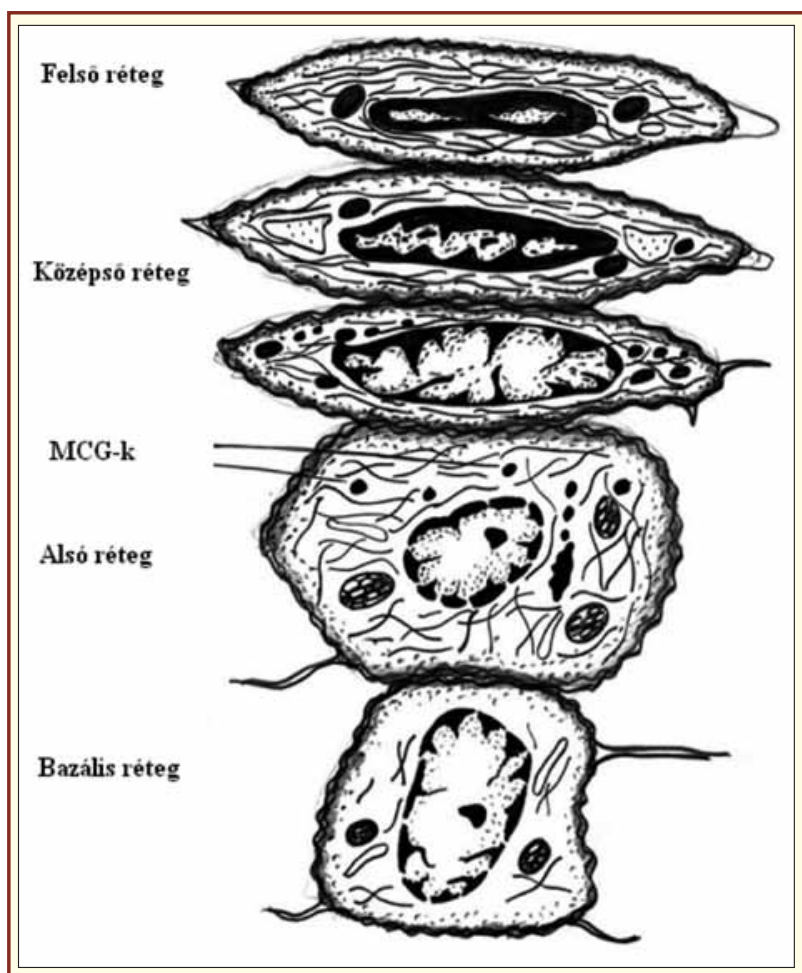

4. ábra: Az MCG-k elhelyezkedése [51] 
nyos sejtek esetén [52]. A sejtközötti térbe bocsátott MCG tartalom felelős egyrészt a sejtek közötti kohézióért, másrészt a permeábilitási barrier szerepét tölti be. Permeábilitási vizsgálatok során különböző méretű nyomjelzők alkalmazása esetén azt tapasztalták, hogy 1-3 sejtrétegnél mélyebbre nem jutnak, azonban az epitélium alá juttatva őket, akadálytalanul penetrálnak intercellulárisan. A limit az MCG-k szintjétől függ mind elszarusodott, mind el nem szarusodott sejtek esetén [28], tehát nem a szarusodás megléte vagy hiánya felelős önmagában a permeábilitási barrier

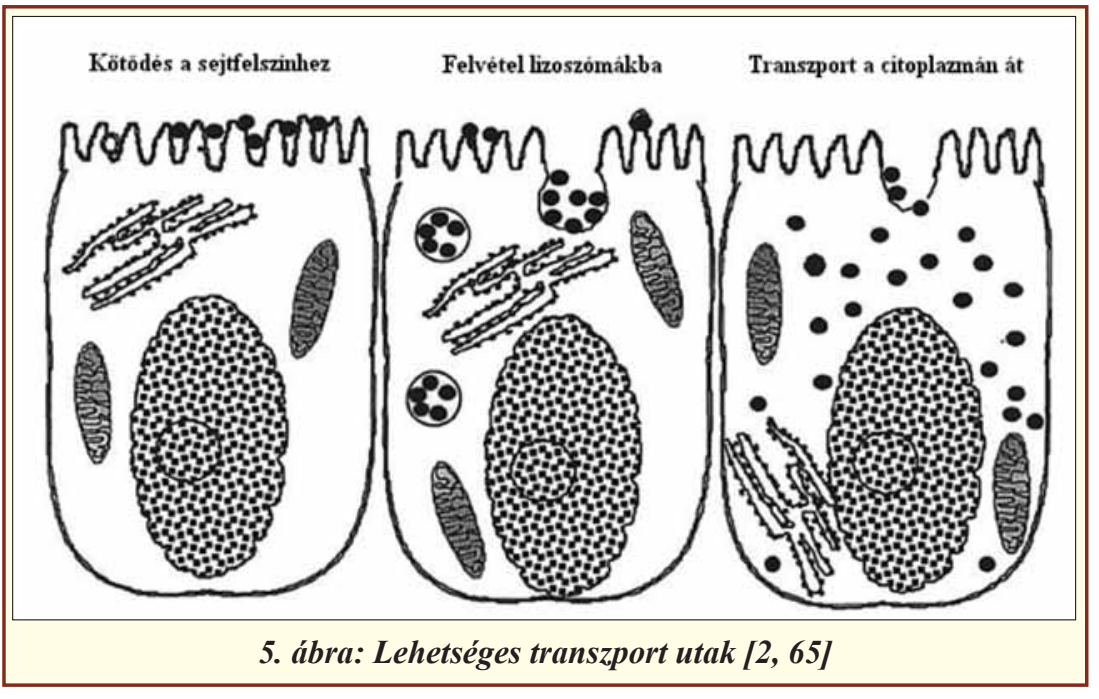
funkcióért [53]. Az epidermiszben lamellákba rendeződött MCG-k találhatók, míg a bukkális epitéliumra elsősorban az amorf forma jellemző, csak kevés és rövid lamella található benne. Ez okozza a fô permeábilitási különbséget a két szövet között [54].

A bukkális epiteliális barrier a sejtrétegek felső harmada és negyede között helyezkedik el [55]. Az el nem szarusodott területeken elsősorban foszfolipidek, koleszterin észterek és glikozilceramidok alkotják a lipidbarriert, szemben a börrel és az elszarusodott régiókkal, ahol nagy koncentrációban fordulnak elő ceramidok [54]. Ezáltal nagyobb koncentrációban vannak jelen poláris lipidek az intercelluláris térben [56], mint az epidermiszben vagy az elszarusodott régiókban. Az el nem szarusodott szövetben az érett MCG sejtek laposak és nagyok, a sejtmag mellett más sejtorganellumokat is megtartanak, nem aggregálódnak vagy kötegelödnek. Ebben a szövettípusban körülbelül $0,2 \mu \mathrm{m}$ az átmérójük [57], de ugyanilyen típusú granulumok találhatók a cervixben [58] és az oesophagusban is [59]. A bazálmembrán elsősorban a lipofil anyagok bejutását tudja gátolni, melyek az epitéliumon könnyen átjutnak [60]. A nyálnak van egy lemosó, öblítő funkciója, erre fokozottan oda kell figyelni bukkális hatóanyag hordozó rendszerek formulálásakor [61]. Egy másik barriert képez az enzimatikus bontás, a nyálban észterázok, amilázok és foszfatázok is megtalálhatók [62], számos proteolitikus enzim is található a bukkális epitéliumon [63].

\section{Penetráció a szájnyálkahártyán keresztül [15, 27]}

A nyálkahártya permeábilitása a szájüregben az alábbiak szerint alakul: szublingvális > bukkális > lágy szájpadlási régió [64]. A bukkális nyálkahártya a szublingvális területhez képest kisebb permeábilitása miatt kiválóan alkalmas kontrollált, késleltetett hatóanyag leadású hatóanyag hordozó rendszerek alkalmazására [2]. A különböző anyagok az alábbi mechanizmusokkal juthatnak be bukkálisan:

- passzív diffúzióval (para- és transzcellulárisan),

- carrier-mediált diffúzióval,

- aktív transzporttal és

- pino-/endocitózissal (5. ábra).

Leggyakoribb a passzív diffúzió, legritkább pedig a carrier-mediált diffúzió. Az intercelluláris térben található poláris lipidek két doménből állnak: a lipofil rész a sejtmembránhoz kapcsolódik, a hidrofil rész pedig az MCG-khez. Így jöhet létre a paracelluláris (sejtek közötti) és transzcelluláris (sejteken át) út [66]. A sejtmembrán lipofil karaktere miatt azok a molekulák jutnak át rajta, amelyek nagy log P értékkel rendelkeznek. Hasonlóan a vékonybélhez a lipofil anyagok a sejteken keresztül jutnak tovább [67]. Az intercelluláris tér a hidrofil molekulák átjutásának kedvez, azonban ez az út sokkal hosszabb és bonyolultabb [68-70]. Néhány hidrofil molekula carrier mediált módon jut át a bukkális nyálkahártyán [71]. A paracelluláris út során a hatóanyag a sejt közötti térben penetrál, míg transzcelluláris passzív diffúzió során a sejteken keresztül. Hogy melyik út valósul meg, az adott molekula geometriájától, lipofilitásától és méretétől függ.

A paracelluláris utat az alábbi képlettel fejezhetjük ki:

$J_{p}=\frac{D_{p} \cdot \varepsilon}{h_{p}} \cdot C_{d}$

ahol: $D_{p}$ a diffúziós koefficiens, $h_{p}$ a paracelluláris út hossza, ${ }^{p} \varepsilon$ a paracelluláris út része, ${ }^{p} C_{d}$ a farmakon koncentrációja.

A transzcelluláris utat az alábbi képlet jellemzi:

$$
J_{c}=\frac{(1-\varepsilon) \cdot D_{c} \cdot K_{c} \cdot C_{d}}{h_{c}}
$$

ahol: $K_{c}$ a megoszlási koefficiens a lipofil sejtmembrán és a vizes fázis között, $D_{c}$ a hatóanyag diffúziós koefficiense a transzcelluláris térben és $h_{c}$ a transzcelluláris út hossza [72]. A para- és transzcelluláris utakat a 6. ábra szemlélteti. 


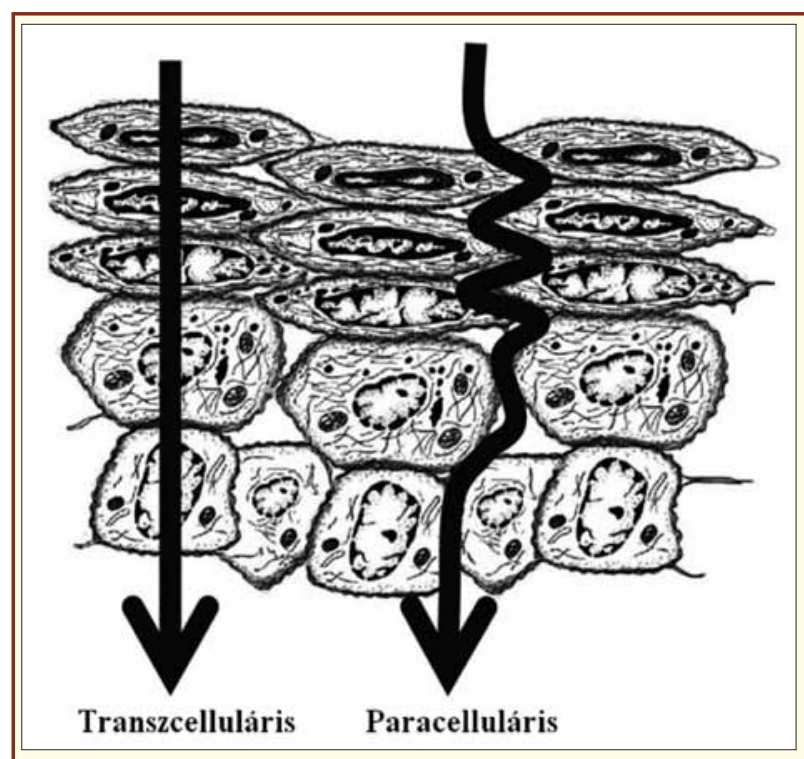

6. ábra: A passzív diffúzió két lehetséges útja [51]

A bukkális nyálkahártya abszorpciós potenciálja a diffundáló anyag lipidoldékonyságától és molekulatömegétől függ. Néhány anyag abszorpciójának mértéke és a környezet pH-ja között fordított arányosság áll fenn [73]. Az ionizálódó anyagok abszorpciója pH dependens és transzcellulárisan valósul meg [74]. A gyenge savak és bázisok pH-függően ionizálódnak. Az ionizált forma rosszabbul penetrálódik, mint a nem ionizált forma. A nem ionizált forma koncentrációjának növekedésével a hatóanyag penetrációja is emelkedni fog az epiteliális barrieren, ennek létrejöttét a hatóanyag hordozó rendszer pH-jának szabályozásával segíthetjük. A pH-nak kifejezett hatása van a hatóanyag penetrációjának befolyásolásában [75]. A hatóanyagok bukkális diffúziója nincs szoros összefüggésben a Henderson-Hasselbalch egyenletből kalkulált ionizációs fokkal, így nem segít a gyenge savak és bázisok membrán diffúziójának becslésében [76]. Peptidek passzív diffúzióval a paracelluláris úton keresztül juthatnak át a bukkális nyálkahártyán. Azok a hatóanyagok is így jutnak át a szájnyálkahártyán, amelyek monokarbonsav részt tartalmaznak [71]. A hidrofil molekulák carrier mediált transzporttal is átjuthatnak a bukkális nyálkahártyán [71, 77-80], azonban a lipofil karakterü molekulák számára nincs ilyen transzport, így limitált az intracelluláris transzport lehetősége.

\section{Összefoglalás}

A mukoadhézió kialakításában számos faktor játszik szerepet, ezek ismerete segít a megfelelő hatóanyaghordozó rendszer formulálásában, valamint a gyógyszerforma helyes alkalmazásában. A folyamat rendkívül összetett, több elmélet is született a mukoadhézió mechanizmusára, azonban önmagában egyik sem magyarázza létrejöttét. A mucinok nemcsak a gyógyszerforma szájnyálkahártyán való rögzítésében kiemelten fontosak, hanem a szájüreg, a fogak védelmében, azok integritásának megőrzésében is. A bukkális nyálkahártya felépítése miatt kiválóan alkalmas nyújtott, programozott hatóanyag leadásra, szisztémás hatóanyag bevitelre.

\section{Köszönetnyilvánítás}

Jelen kutatási eredmények megjelenését „Az SZTE Kutatóegyetemi Kiválósági Központ tudásbázisának kiszélesítése és hosszú távú szakmai fenntarthatóságának megalapozása a kiváló tudományos utánpótlás biztosításával" című, TÁMOP-4.2.2/B-10/1-2010-0012 azonosítószámú projekt támogatja. A projekt az Európai Unió támogatásával, az Európai Szociális Alap társfinanszírozásával valósul meg.

\section{IRODALOM}

1. Smart, J.D.: Adv. Drug Deliv. Rev. 57, 1556-1568 (2005). - 2. Salamat-Miller, M., Chittchang, M., Johnston, T.P.: Adv. Drug Deliv. Rev. 57, 1666-1691 (2005). - 3. Gu, J.M., Robinson, J.R., Leung, S.H.S.: Crit. Rev. Ther. Drug Carr. Syst. 5, 21-67 (1988). - 4. Marriott, C., Gregory, N.P.: Mucus physiology and pathology, in: V. Lanaerts, R. Gurny, (Eds.), Bioadhesive Drug Delivery Systems, CRC Press, Florida, 1990, pp. 1-24. - 5. Allen, A., Cunliffe, W.J., Pearson J.P., Venables, C.W.: J. Intern. Med. 228, 83-90 (1990). - 6. Kerss, S., Allen, A., Garner, A.: Clin. Sci. 63, 187-195 (1990). - 7. Sonju, T., Cristensen, T.B., Kornstad, L., Rolla, G.: Caries Res. 8, 113-122 (1974). - 8. Laidler, K.J., Meiser, J.H., Sanctuary, B.C.: Physical Chemistry, Fourth edition, Houghton Mifflin Company, Boston, (2003). - 9. Ahuja, Khar, R.P., Ali, J.: Drug Dev. Ind. Pharm. 23, 489-515 (1997). - 10. Mathiowitz, E., Chickering, D.E.: Definitions, mechanisms and theories of bioadhesion, in: Mathiowitz, E., Chickering, D.E., Lehr, C.M. (Eds.), Bioadhesive Drug Delivery Systems: Fundamentals, Novel Approaches and Development, Marcel Decke, New York, 1999, pp. 1-10. 11. Peppas, N.A., Sahlin, J.J.: Biomaterials 17, 1553-1561 (1996). - 12. Erös, I.: 8. A gyógyszertechnológia kolloid kémiai és fizikai-kémiai alapjai, 8.4. Felületi és határfelületi jelenségek a gyógyszertechnológiában in Révész, P.: Gyógyszertechnológia, JATEPress, Szeged, 2009, pp. 92-93. - 13. $W u$, S.: Formation of bioadhesive bond, Plymer Interface and Adhesion, Marcel Decker Inc, New York, 1982, pp. 359447. - 14. Morales, O.J., McConville, J.T.: Eur. J. Pharm. Biopharm. 77, 187-199 (2011). - 15. Hangerstrom, H., Edsman, K.: J. Pharm. Pharmacol. 53, 1589-1599 (2001). 16. Chen, J.L., Cyr, G.N.: Compositions producing adhesion trough hydration, in: R.S. Manly (Ed.), Adhesion in Biological Systems, Academic Press, New York, 1970, pp.163-181. 17. Jabbari, E., Nozari, S.: Eur. Polym. J. 36, 2685-2692 (2000). - 18. Martin, L., Wilson, C.G., Koosha, F., Uchegbu, I.F.: Eur. J. Pharm. Biopharm. 55, 35-45 (2003). - 19. Shojaei, A.H., Paulson, J., Honary, S.: J. Control. Release 67, 223-232 (2000). - 20. Inoue, T., Chen, G., Hoffman, A.S.: J. Bioact. Biocompat. Polym. 13, 50-64 (1998). - 21. Lee, J.W., Park, J.H., Robinson, J.R.: J. Pharm. Sci. 89, 850-866 (2000). - 22. Smart, J.D., Mortazavi, S.A.: J. Pharm. Pharmacol. 47, 1099 (1995). - 23. Smart, J.D., Kellaway, I.W., Worthington H.E.C.: J. Pharm. Pharmacol. 36, 295-299 (1984). - 24. 
Harding, S.E., Davis, S.S., Deacon, M.P., Fiebrig, I.: Biotechnol. Genet. Eng. Rev. 16, 41-85 (1999). - 25. Smart, J.D.: Adv. Drug Deliv. Rev. 11, 253-270 (1993). - 26. Andrews, G.P., Laverty, T.P., Jones, D.S.: Eur. J. Pharm. Biopharm. 71, 505-518 (2009). - 27. Sudhakar, Y., Kuotsu, K., Bandyopadhyay, A.K.: J. Control. Release 114, 15-40, 2006. - 28. Gandhi, R.B., Robinson, J.R.: Adv. Drug Deliv. Rev. 13, 43-74 (1994). - 29. Forstner, J.F.: Digestion 17, 234-263 (1978). - 30. Ho, N.F.H., Barsuhn, C.L., Burton, P.S., Merkle, H.P.: Adv. Drug Deliv. Rev. 8, 197-235 (1992). - 31. Madhav, N.V.S., Shakya, A.K., Shakya, P., Singh, K.: J. Control. Release 140, 2-11 (2009). - 32. Humphrey, S.P., RDH, MSEd, and Williamson R.T., DMD: J. Proshet. Dent. 85, 162-169 (2001). - 33. Allen, A.: The gastrointestinal physiology. Salivary, gastric and hepatobiliary secretions, in: Forte, J.G. (Ed.) Handbook of Physiology, Vol. III Section 6, American Physiological Society, Bethesda, MD, 1989, pp. 359-382. - 34. Norris, D.A., Puri, N., Sinko, P.J.: Adv. Drug Deliv. Rev. 34(2-3), 135-154 (1998). - 35. Castellanos, M.R., Zia, H., Rhodes, C.T.: Drug Dev. Ind. Pharm. 19(1 and 2), 143-194 (1993). - 36. Kocevar-Nared, J., Kristl, J., SmidKorbar, J.: Biomaterials 18, 677-681 (1997). - 37. Capra, R., Baruzzi, A., Quinzani, L., Strumia, M.: Sensors Actuators B 124, 466-476 (2007). - 38. Fiebrig, I., Harding, S., Rowe, A., Hyman, S., Davis, S.: Carbohydr. Polym. 28, 239-244 (1995). - 39. www.cardiff.ac.uk/chemy/staffinfo/SMG/PO.html (letöltve: 2013. január 4.) - 40. Slomiany, B.L., Murty, V.L., Poitrowski, J., Slomiany, A.: Gen. Pharmacol. 27, 761-771 (1996). - 41. Tabak, L.A.: Crit. Rev. Oral. Biol. Med. 1, 229234 (1990). - 42. Edgar, W.M.: Br. Dent. J. 172, 305-312 (1992). - 43. Iontcheva, I., Oppenheim, F.G., Troxler, R.F.: J. Dent. Res. 76, 734-743 (1997). - 44. Levine, M.J., Reddy, M.S., Tabak, L.A., Loomis, R.E., Bergey E.J., Jones, P.C., et al.: J. Dent. Res. 66, 436-441 (1987). - 45. Scannepieco, F.A., Levine, M.J.: Salivary mucins and dental plaque formation. In: Bowen W.H., Tabak, L.A., editors. Cariology for the nineties. Rochester, NY: University of Rochester Press, 1993. p. 87-105. - 46. Tabak, L.A., Levine, M.J., Mandel, I.D., Ellison, S.A.: J. Oral. Pathol. 11, 1-17 (1982). - 47. Chang, W.I., Chang, J.Y., Kim, Y.Y., Lee, G., Kho, H.S.: Arch. Oral Biol. 56, 885-890 (2011). - 48. Sonesson, M., Wickström, C., Kinnby, B., Ericson, D., Mattson, L.: Arch. Oral Biol. 53, 523-527 (2008). - 49. Lee, J., Kil, S., Choi, Y.W.: Arch. Pharm. Res. 25, (4), 546-549 (2002). - 50. Shakya, P., Madhav, N.V.S., Shakya, A.K., Singh, K.: J. Control. Release 151, 2-9 (2011). - 51. Paderni, C., Compilato, D., Giannola, L.I., Campisi, G.: Oral Surg. Oral Med. Oral Pathol. Ora Radiol. 114, (3), e25-e34 (2012). - 52. Hayward, A.F.: Int. Rev. Cyt. 59, 97-127 (1979). - 53. Squier, C.A., Hall, B.K.: Arch. Oral. Biol. 29, 45-50 (1984). - 54. Law, S., Wertz, P., Swartzendruber, D., Squier, C.: Arch. Oral Biol. 40, 10851091 (1995). - 55. Squier, C.: J. Ultrastruct. Res. 43, 160-177 (1973). - 56. Squier, C., Cox, P., Wertz, P., Downing, D.: Arch. Oral Biol. 31, 741-747 (1986). - 57. Squier, C.A.: J. Ultrastruct. Res. 60, 212-220 (1977). - 58. Grubb, C., Hackemann, M., Hill, K.R.: J. Ulrtrastruct. Res. 22, 458-468 (1968). - 59. Hopwood, D., Logan, K.R., Bouchier, I.A., Virchows, D.: Arch. B. Cell Path. 26, 345-358 (1978). - 60. Wolff, K., Honigsmann, H.J.: J. Ulrtrastruct. Res. 36, 176-190
(1971). - 61. Patel, V.F., Liu, F., Brown, M.B.: J. Control. Release 153, 106-116 (2011). - 62. Robinson, J.R., Yang, X.: Absorption enhancers, Swarbick, J., Boylan, J.C., (Eds.), Encyclopedia of Pharmaceutical Technology, vol. 18, Marcel Dekker, Inc., New York, 2001, pp. 1-27. - 63. Veuillez, F., Kalia, Y.N., Jacques, J., Deshusses, J., Buri, P.: Eur. J. Pharm. Biopharm. 51, 93-109 (2001). - 64. Petelin, M., Marjeta, S., Stolic, Z., Skaleric, U.: Int. J. Pharm. 173, 193-202 (1998). 65. Lehr, C.M.: J. Control. Release 65, 19-29 (2000). - 66. Wertz, P., Squier, C.: Critical Reviews in Therapeutic Drug Carrier Systems 8, 237-269 (1991). - 67. Nicolazzo, J.A., Reed, B.L., Finnin, B.C.: J. Control. Release 150, 1-15 (2005). - 68. Banett, M., Szabo, G.: J. Period. Research 8, 117-126 (1973). - 69. Harris, D., Robinson, J.: J. Pharm. Sci. 81, 117-126 (1992). - 70. Senel, S., Hincal, A.: J. Control. Release 72, 133-144 (2001). - 71. Utoguchi, N., Watanabe, Y., Suzuki, T., Maehara, J., Matsumoto, Y., Matsumoto, M.: Pharm Res 14, 320-324 (1997). - 72. Shijaei, A.H., Li, X.: Proc. Int. Symp. Control. Release Bioact. Mater. 24, 427-428 (1997). - 73. Nielsen, H.M., Rassing, M.R.: Int. J. Pharm. 185, 215-225 (1999). - 74. Zhang, H., Robinson, J.R.: In vitro methods for measuring permeability of the oral mucosa, in J. Swarbick, J.C. Boylan (Eds.), Oral Mucosal Drug Delivery, 1 st edition, vol. 74, Marcel Dekker, INC, New York, 1996, pp. 85-100. - 75. Mashru, R., Sutariya, V., Sankalia, M., Sankalia, J.: J. Pharm. Pharmaceut. Sci. 8, (1), 54-62 (2005). - 76. Randhawa, M.A., Malik, S.A., Javed, M.: Park. J. Med. Res. 42, (2), (2003). - 77. Manning, A.S., Evered, D.F.: Clin. Sci. Mol. Med. 51, 127-132 (1976). - 78. Sadoogh-Adasian, F., Evered, D.F.: Br. J. Nutr. 42, 15-20, 1979. - 79. Evered, D.F., Sadoogh-Abasian, F., Patel, P.D.: Life Sci. 27, 16491651 (1980). - 80. Utoguchi, N., Watanabe, Y., Takase, Y., Suzuki, T., Matsumoto, M.: J. Pharm. Sci. 88, 142-146 (1999).

Gottnek, M., Hódi, K., Regdon, G. jun.: Mucoadhesive films applied on the oral mucosa Part II: Mechanism of mucoadhesion, functions of mucin. Penetration through the oral mucosa, the barrier function of the mucous membrane

In the first part of our further education series of articles, the structure of the oral mucosa and the physiological and pharmaceutical aspects of the saliva were discussed. In the second part, that is in the present publication, the mechanism of mucoadhesion, the role of mucin, the barrier function of the oral mucosa and the penetration of the active ingredients are going to be summarized.

Several factors contribute to mucoadhesion, the knowledge of which helps us to formulate the appropriate drug delivery system and to use the dosage form properly. The process is extremely complex, several theories have been developed to explain the mechanism of mucoadhesion, but none of them can give an explanation in itself. Mucins have outstanding importance not only in the adhesion of the dosage form on the oral mucosa but also in protecting and preserving the integrity of the oral cavity and the teeth. The structure of the buccal mucosa makes it suitable for controlled, sustained drug delivery and for systemic drug administration. 
VI. 


\title{
Szájnyálkahártyán alkalmazható mukoadhezív filmek III. rész: Bukkális mukoadhezív filmek esetén alkalmazott polimerek és segédanyagok ${ }^{1}$
}

\author{
Gottnek Mihály, Hódi Klára, ifj. Regdon Géza
}

\section{Bukkális mukoadhezív filmek esetén alkalmazott filmképzö polimerek [3-5]}

Az alkalmazott filmképző polimereknek az alábbi szerkezeti kritériumok közül minél többnek meg kell felelniük:

- H-hídkötésre alkalmas funkciós csoportok,

- pozitív vagy negatív töltés,

- nagy molekulatömeg,

- polimer láncok mozgékonysága és

- felületi tulajdonságok (felületi szabadenergia, polaritás fok stb.), melyek segítik a nyákréteghez való kapcsolódást [6].

Osztályozásuk:

- természetes vagy szintetikus,

- vízoldékony vagy vízben nem oldódó,

- töltéssel rendelkező vagy nem-ionos polimerek [3].

A természetes eredetủ bioadhezív makromolekulák a szintetikus polimerekhez nagyon hasonló szerkezeti tulajdonságokkal rendelkeznek. Általában nagy molekulatömegü anyagok, számos hidrofil, negatív töltésü funkciós csoporttal, lineáris egységekből épül fel a háromdimenziós szerkezetük [7]. Az I. táblázatban a leggyakrabban alkalmazott bukkális filmképző polimereket tüntettük fel. A filmképző polimer felületi szabadenergiája szükséges ahhoz, hogy mintegy „,nedvesítse" a nyálkahártyát [8].

Lee és munkatársai „első” és „második” generációra osztották fel a bioadhezív polimereket [6]. Az első generációba az ún. „készen kapható” polimerek tartoznak, melyeket mind a specifikusság, mind a célzott alkalmazhatóság hiánya jellemez. Nem specifikusan

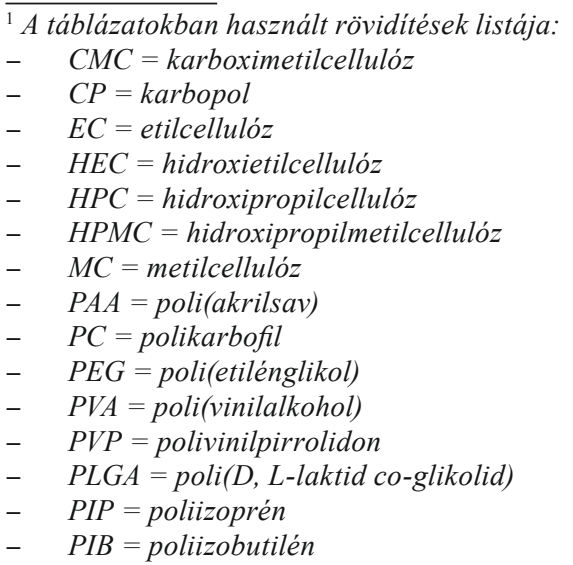

Továbbképzö cikksorozatunk elsö részében [1] a szájnyálkahártya felépitését és a nyál élettani, gyógyszerészeti vonatkozásait tárgyaltuk részletesen, mivel elöbbi a gyógyszerforma alkalmazási helye és a felszívó felület utóbbi, pedig mint kioldó közeg játszik szerepet. A második közleményben [2] a mukoadhézió mechanizmusát, a mucin szerepét, a szájnyálkahártya barrier funkcióját és a hatóanyagok penetrációját foglaltuk össze. A harmadik cikkünkben a mukoadhezív filmek elöállitásához alkalmazott filmképző polimerekről és segédanyagokról kivánunk részletesen szólni. Végül pedig a következö, befejezö cikkünkben a mukoadhezív filmekben alkalmazott hatóanyagokról, és a filmek elöállitásáról kivánunk beszámolni.

kapcsolódnak a nyákréteghez, rövid retenciós idővel rendelkeznek, mivel az adhézió időtartama a nyákréteg életidejétől függ. A mukoadhezív polimer és nyák/ szövet közti kémiai interakció általában nem kovalens természetű és nagyrészt H-hídkötést, hidrofób és elektrosztatikus interakciókat tartalmaz (I. táblázat).

$\mathrm{Az}$,első generációs polimerek” három fö csoportra oszthatók. A töltést figyelembe véve, anionos, kationos és nem-ionos polimereket különböztetünk meg az osztályon belül [9]. Az anionos polimereket széles körben alkalmazzák a gyógyszertechnológiai formulálások során, nagy mukoadhezivitásuk és kis toxicitásuk miatt. Negatív töltésüket karboxil és szulfát csoportok adják. Tipikus képviselőik: a poli(akrilsav) és a karboximetilcellulóz, melyek erős H-hídkötést létesítenek a mucinnal [10]. A kationos polimerek közül a legjellemzőbb a kitozán [11].

\section{Hidrogélek (elsö generáció)}

Nedvesség szükséges az adhéziós tulajdonságok kialakulásához. Általában keresztkötött vízoldékony polimerek 30-40\% víztartalommal. A mátrixrendszer vizet abszorbeál nedves környezetben. A nyál is ezt a szerepet tölti be, mely kioldóközegként is funkcionál. Hatóanyag-hordozó rendszerként alkalmazhatók, használatuk során a beáramló víz hatására a polimerláncok elmozdulnak, és a hatóanyag kioldódik a képződött csatornákon, réseken át [4]. 
Bukkálisan alkalmazható mukoadhezív polimerek csoportosítása [3]

\begin{tabular}{|c|c|c|}
\hline Kritérium & Kategóriák & Példák \\
\hline \multirow[t]{6}{*}{ Eredet } & \multirow[t]{3}{*}{ Természetes } & agaróz, kitozán, zselatin \\
\hline & & hialuronsav \\
\hline & & $\begin{array}{l}\text { gumik (guar, hakea, xantán, gellán, karragenán, pektin és nátrium- } \\
\text { alginát) }\end{array}$ \\
\hline & \multirow[t]{3}{*}{ Szintetikus } & $\begin{array}{l}\text { Cellulóz származékok: } \\
\text { CMC, tiolált CMC, CMC nátrium, HEC, HPC, HPMC, MC, } \\
\text { metilhidroxietilcellulóz }\end{array}$ \\
\hline & & $\begin{array}{l}\text { Poli(akrilsav)-alapú polimerek: } \\
\text { CP, PC, PAA, poliakrilátok, poli(metilviniléter-co-metakrilsav), } \\
\text { poli(2-hidroxietil metakrilát), poli(akrilsav-co-etilhexilakrilát), } \\
\text { poli(metakrilát), poli(alkilcianoakrilát), poli(izohexilcianoakrilát), } \\
\text { poli(izobutilcianoakrilát), akrilsav-co-PEG }\end{array}$ \\
\hline & & $\begin{array}{l}\text { Egyéb: } \\
\text { poli(N-2-hidroxipropil metakrilamid) (PHPMAm), poloxietilén, } \\
\text { PVA, PVP, tiolált polimerek }\end{array}$ \\
\hline \multirow[t]{2}{*}{ Vizoldékonyság } & Vizoldékony & $\begin{array}{l}\mathrm{CP}, \mathrm{HEC}, \mathrm{HPC}\left(<38^{\circ} \mathrm{C}\right), \mathrm{HPMC} \text { (hideg víz), PAA, CMC nátrium, } \\
\text { nátrium-alginát }\end{array}$ \\
\hline & Vizoldhatatlan & kitozán, EC, PC \\
\hline \multirow[t]{3}{*}{ Töltés } & Kationos & $\begin{array}{l}\text { aminodextrán, kitozán, dimetilaminoetil, (DEAE)-dextrán, } \\
\text { trimetilált kitozán }\end{array}$ \\
\hline & Anionos & $\begin{array}{l}\text { kitozán-EDTA, CP, CMC, pektin, } \mathrm{PAA}, \mathrm{PC} \text {, nátrium-alginát, } \mathrm{CMC} \\
\text { nátrium, xantán gumi }\end{array}$ \\
\hline & Nem-ionos & $\begin{array}{l}\text { hidroxietil keményítő, HPC, poli(etilén oxid), PVA, PVP, } \\
\text { szkleroglükán }\end{array}$ \\
\hline \multirow{3}{*}{$\begin{array}{l}\text { Potenciális } \\
\text { bioadhezív erő }\end{array}$} & Kovalens & cianoakrilát \\
\hline & H-hidkötés & akrilátok [hidroxilált metakrilát, poli(metakrilsav)], CP, PC, PVA \\
\hline & Elektrosztatikus interakció & kitozán \\
\hline
\end{tabular}

Kopolimerek (elsö generáció)

Kopolimerizációval állítják elő ezeket két vagy több monomerből. Blokk kopolimert többlépéses módszerrel állítanak elö, ahol két monomer egység szekvenciái, blokkjai ismétlődnek. Polimer micellát hidrofil és hidrofób monomerek mátrixából kapunk, melyek alkalmasak egyedi hatóanyag molekulák bezárására. A vizes környezet kémiai hatásaival szemben a hidrofil burok védi meg a polimer micella belső magját. A legtöbb micella alapú rendszer poli(etilénoxid)- $b$ polipropilén- $b$-poli(etilénoxid) triblokkokból épül fel. Graft kopolimerek esetén pedig egy központi polimer láncból egy másik polimer egységei ágaznak ki, egy kevésbé törékeny és mechanikailag ellenállóbb rendszert alkotva [4]. A II. táblázatban mukoadhezív és filmképző polimerek egyes tulajdonságait foglaltuk össze irodalmi adatok alapján.

Ezzel szemben a második generációs polimerek képesek kovalens kötéseket létesíteni a nyákréteggel, illetve az alatta elhelyezkedő sejtrétegekkel. Az új generációs mukoadhezívek (kivéve a tiolált polimereket) képesek közvetlenül a sejtfelszínhez kapcsolódni. Interakcióba lépnek a sejtek felszínén lévő speciális receptorokkal, vagy kovalens kötéseket létesítenek.
Tiolált polimerek

Egy cisztein (Cys) reziduum és egy választott polimer pl.: polikarbofil [106], poli(akrilsav) [107], kitozán [108] között kovalens kapcsolatot kialakítva egy új generációs mukoadhezív polimert kapunk. Az így létrejött módosított polimer egy karbodiimid-mediált tiol kötést tartalmaz és sokkal jobb bioadhéziós tulajdonságokkal bír. A mucinok karboxil-terminális doménje 10\%-ban tartalmaz cisztein reziduumokat. Ezekkel a ciszteingazdag doménekkel a tiolált polimerek képesek erős diszulfidhíd-kötéseket kialakítani [109, 110]. A tiolcsoportok megléte miatt 100-250 szeresére nő a poli(akrilsav) és a kitozán bioadhéziós képessége [111, 112]. A tiolált polimerek további mukoadhéziót javító tulajdonságai a következők:

- megnövekedett szakítószilárdság,

- nagy kohéziós tulajdonságok,

- gyors duzzadás és

- vízfelvevő képesség.

A tiomerek képesek láncon belüli és láncok közötti diszulfidhidak létesítésére, így a polimer szerkezete erős kohéziós tulajdonságokat és a mátrix tablettákhoz hasonlóan stabil hatóanyag-hordozó rendszert biztosít. A legerösebb mukoadhéziós erő a tiolált polimereknél mérhető. A cink-dependens proteázokat, úgy mint 
Mukoadhezív és filmképzö polimerek egyes tulajdonságai irodalmi adatok alapján [12].

\begin{tabular}{|c|c|c|}
\hline Mukoadhezív polimer & Releváns tulajdonságok és eredmények & $\begin{array}{c}\text { Előfordulás } \\
\text { az irodalomban }\end{array}$ \\
\hline Hidroxietilcellulóz & $\begin{array}{l}\text { nem-ionos, } \\
\text { nagy duzzadási képesség, gyors erózió, } \\
\text { kismértékü mukoadhéziós tulajdonságok, } \\
\text { nulladrendü kinetika mikonazol és klórfeniramin esetén }\end{array}$ & {$[13-18]$} \\
\hline Hidroxipropilcellulóz & $\begin{array}{l}\text { nem-ionos, } \\
\text { etilcellulózzal kombinálva megnövekedett duzzadás } \\
\text { tapasztalható, } \\
\text { közepes mukoadhezív tulajdonságok, } \\
\text { nulladrendü kinetika lidokain és klotrimazol esetén }\end{array}$ & {$[13,19-37]$} \\
\hline Hidroxipropilmetilcellulóz & $\begin{array}{l}\text { nem-ionos, } \\
\text { gyors duzzadás platóval, } \\
\text { közepes mukoadhezív tulajdonságok, } \\
\text { kezdeti burst effekt nikotin hidrogén-tartarát esetén }\end{array}$ & $\begin{array}{l}{[14,15,16,18,23,30-32} \\
38-53]\end{array}$ \\
\hline Nátrium-karboximetil-cellulóz & $\begin{array}{l}\text { anionos, } \\
\text { nagy duzzadási tulajdonságok plató nélkül, } \\
\text { nagy mukoadhéziós tulajdonságok, } \\
\text { nulladrendü kinetika mikonazol nitrát esetén, } \\
\text { diffúzió mediált ibuprofen leadás }\end{array}$ & $\begin{array}{l}{[14,15,30,40,41,44,46,} \\
47,54-60]\end{array}$ \\
\hline Poli(vinilpirrolidon) & $\begin{array}{l}\text { nem-ionos, } \\
\text { filmképzöként alkalmazva non-Fick típusú hatóanyag } \\
\text { leadás: ketorolak és progeszteron esetén, } \\
\text { hatóanyag leadás szabályozása: propranolol és } \\
\text { mikonazol esetén } \\
\text { nagymértékủ duzzadási tulajdonságok, } \\
\text { mukoadhézió növelésére adjuvánsként alkalmazható }\end{array}$ & $\begin{array}{l}{[13,15,16,30,31,44,46} \\
47,57,61-68]\end{array}$ \\
\hline Poli(vinilalkohol) & $\begin{array}{l}\text { nem-ionos, } \\
\text { közepes duzzadási és mukoadhéziós tulajdonságok, } \\
\text { szabálytalan hatóanyag leadás: mikonazol esetén }\end{array}$ & {$[13,33,42,46,48,65,69]$} \\
\hline Kitozán & $\begin{array}{l}\text { kationos, } \\
\text { közepes-jó duzzadási és mukoadhéziós tulajdonságok, } \\
\text { nyújtott hatóanyag leadás mikonazol esetén }\end{array}$ & $\begin{array}{l}{[15,18,32,39,43,50,51} \\
61,63-65,70-82]\end{array}$ \\
\hline Alginát & $\begin{array}{l}\text { anionos, } \\
\text { gyors duzzadás és oldódás, } \\
\text { nagymértékủ mukoadhezív tulajdonságok }\end{array}$ & $\begin{array}{l}{[14,32,44,46,50,52,78} \\
83-85]\end{array}$ \\
\hline Agar-agar & gyenge és stabil duzzadási tulajdonságok & [78] \\
\hline Karragenán $\lambda$ típus & $\begin{array}{l}\text { gyenge és stabil duzzadási és } \\
\text { közepes mukoadhéziós tulajdonságok }\end{array}$ & [57] \\
\hline Guar gumi & $\begin{array}{l}\text { additívként közepes duzzadási és jó mukoadhéziós tu- } \\
\text { lajdonságokat biztosít, továbbá a mikonazol non-Fick } \\
\text { típusú felszabadulását zavarta }\end{array}$ & {$[18]$} \\
\hline $\begin{array}{l}\text { Poli-L(laktid-co-glikolid) } \\
\text { (PLGA) }\end{array}$ & $\begin{array}{l}\text { bukkális filmekben mikromátrixot alkotva szabályozott } \\
\text { ipriflavon leadást biztosított }\end{array}$ & {$[86,87]$} \\
\hline Poli(akrilsav) Carbopol ${ }^{\circledR}$ & $\begin{array}{l}\text { gyors, nagymértékü, stabil duzzadás, } \\
\text { nagymértékü mukoadhezivitás, } \\
\text { filmképző polimerként nyújtott hatóanyag leadást értek } \\
\text { el buprenorfin esetén, } \\
\text { additívként alkalmazták propranolol leadás szabályozá- } \\
\text { sára }\end{array}$ & $\begin{array}{l}{[14,19,21,30,32,39,40} \\
41,45,46,48,49,52-55,58 \\
59,60,62,69,79,88-95]\end{array}$ \\
\hline Polikarbofil & $\begin{array}{l}\text { nem-ionos, } \\
\text { additívként alkalmazva közepes és stabil duzzadás és } \\
\text { nagymértékü mukoadhezivitás érhető el }\end{array}$ & $\begin{array}{l}{[14,20,22,23,48,57,96-} \\
98]\end{array}$ \\
\hline Poli(etilénoxid) & $\begin{array}{l}\text { nem-ionos, } \\
\text { nagymértékü mukoadhézió és molekulatömeg, } \\
\text { nullarendü kinetika klotrimazol és tetrahidrokannabinol } \\
\text { esetén, és a polimer mátrix eróziója }\end{array}$ & {$[23,99-101]$} \\
\hline Poli(ketakrilátok) & $\begin{array}{l}\text { filmképzőként alkalmazva nagyon gyenge bioadhezív } \\
\text { tulajdonságok és lassú duzzadási képesség jellemzi, } \\
\text { só formában erős mukoadhezivitás jellemzi }\end{array}$ & $\begin{array}{l}{[14,41,43,47,66,72,97} \\
98,102-105]\end{array}$ \\
\hline
\end{tabular}


aminopeptidázok, karboxipeptidázok blokkolják, permeáció növelő hatásukat pedig a „tight junction”-ök glutation mediált nyitási rendszerén keresztül fejtik ki $[113,114]$.

\section{A target-specifikus (célorientált), lektin-mediált bioadheziv polimerek}

Szintén a „második” generációs mukadhezív polimerek közé tartoznak. Egy olyan bioadhezív polimer tervezése, mely alkalmas szelektíven molekuláris interakcióba lépni egy meghatározott célmolekulával, pl. egy adott szövet sejtjeinek felszínén megtalálható receptorral, lehetőséget biztosít hatóanyagok célzott szervezetbe juttatására. Mivel a hatóanyag-hordozó rendszer közvetlenül kapcsolódik a sejtek felszínéhez, így kiküszöbölhető a mucin életidőből következő rövidebb mukoadhéziós időtartam. Specifikus proteinek/ glikoproteinek, például a lektinek képesek bizonyos sejtfelszínen előforduló cukrokhoz kapcsolódni, ezzel növelve a bioadhézió erősségét, továbbá fokozzák a hatóanyag bejutását, mivel tartósan a felszívó felülethez rögzítik a filmet. Ezt a speciális bioadhéziós formát citoadhéziónak nevezik. Ez a helyspecifikus interakció a receptorral képes intercelluláris jel elindítására, mely során a hatóanyag endocitózissal lizoszómákba vagy akár egyes sejtalkotókba, pl. a sejtmagba jut [41].

Bár a lektinek megtalálhatóak baktériumokban is, valójában legnagyobb mennyiségben a növényekben fordulnak elő [115]. A lektint a paradicsom terméséből izolálták (Lycopersicum esculentum), mely vegyület specifikusan és biztonságosan kapcsolódik a sejtfelszínen előforduló $N$-acetilglükózaminhoz (Glu-NAc). Habár a lektin-mediált bioadhezív polimerek második generációs bioadhezívekként nagy lehetőséget rejtenek magukban a hatóanyag bevitel szempontjából, még nincsenek kielégítően tanulmányozva és leírva az irodalomban [3].

\section{Bakteriális adhézió}

A baktériumsejtek adhéziós képessége is a figyelem középpontjába került. A baktériumok sejtfelszínhez vagy élettelen tárgyakhoz való kötődését egy speciális függelék, a fimbria teszi lehetővé. Isberg és munkatársai bioinvazív hatóanyag-hordozó rendszert terveztek, ahol baktériumok szállították a hatóanyag molekulákat a sejtekbe. A folyamat a sejt adhéziós molekulacsaládba tartozó receptorok segítségével jöhetett létre [116]. A bakteriális adhézió másik csoportját a kontrollált endo- és transzcitózis jelenti. A folyamat során jelátvitel következik be, a baktérium sejtfelszínhez való kötődésekor. A kontrollált endo- és transzcitózis sejthez kötődést, beépítést és hatóanyag szállítást tesz lehetővé [117]. Bár szintén nagy lehetőségek rejlenek ezekben a rendszerekben is, a biotechnológiai módszerek pontos kidolgozásával - klónozás, bakteriális adhéziós faktorok experssziója - válik megvalósíthatóvá a bakteriális adhézió a gyakorlatban [3].

III. táblázat

Néhány bioadhezív polimer jellemzöi [4].

\begin{tabular}{|c|c|c|}
\hline Bioadhezív & Jelentős tulajdonság & Fontosabb jellemzők \\
\hline Polikarbofil & $M_{r}: 2,2 * 10^{5}$ & $\begin{array}{l}\text { a duzzadás a pH-tól és ionerősségtől függ, } \\
\text { a pH növekedésével nő a duzzadás, } \\
\text { pH 1,0-3,0 között } 15-35 \mathrm{ml} \text { vizet abszorbeál } \\
\text { grammonként, semleges és alkalikus pH-n ez } 100 \\
\text { ml-re nő, } \\
\text { H-hídkötéseket alakít ki a mucinnal }\end{array}$ \\
\hline Carbopol/carbomer & $\begin{array}{l}\text { gyógyszerminőség: } 934 \text { P, } 940 \text { P, } 971 \\
\text { P és } 974 \text { P } \\
M_{r}: 1 * 10^{6}-4 * 10^{6} \\
\text { pH: } 2,5-3,0\end{array}$ & $\begin{array}{l}\text { kiváló gélesítő, emulzifikáló és szuszpendáló } \\
\text { anyag, } \\
\text { gyakori komponens bioadhezív készítményekben, } \\
\text { nem érzékeny a hőmérsékletre, hidrolízisre, oxi- } \\
\text { dációra, és nem kedvez a baktériumok szaporo- } \\
\text { dásának, } \\
\text { hozzájárul a formuláció íztelenségéhez, illetve } \\
\text { maszkírozza a kellemetlen ízeket }\end{array}$ \\
\hline $\begin{array}{l}\text { Nátrium karboximetil cel- } \\
\text { lulóz }\end{array}$ & $\begin{array}{l}\text { típusai: } \mathrm{H}, \mathrm{M} \text { és L } \\
\mathrm{M}_{\mathrm{r}}: 9 * 10^{4}-7 * 10^{5} \\
\mathrm{pH}: 6.5-8,5\end{array}$ & $\begin{array}{l}\text { emulzifikáló, gélesítő, kötőanyag } \\
\text { tárolás során stabil, } \\
\text { a legtöbb CMC oldat tixotróp, néhány } \\
\text { pszeudoplasztikus folyási tulajdonságokkal ren- } \\
\text { delkezik, } \\
\text { az oldatok reverzibilis viszkozitás-csökkenést } \\
\text { mutatnak a hőmérsékletemelkedés hatására, } \\
\text { az oldatok érzékenyek nyírásra, hőre, bakteriális } \\
\text { enzimekre és UV fényre, } \\
\text { jó bioadhéziós erő }\end{array}$ \\
\hline
\end{tabular}




\begin{tabular}{|c|c|c|}
\hline Bioadhezív & Jelentős tulajdonság & Fontosabb jellemzők \\
\hline Hidroxipropilcellulóz & $\begin{array}{l}\text { típusai: Klucel }{ }^{\circledR} \mathrm{EF}, \mathrm{LF}, \mathrm{JF}, \mathrm{GF}, \mathrm{MF} \text { és } \\
\mathrm{HF} \\
\mathrm{M}_{\mathrm{r}}: 6 * 10^{4}-1 * 10^{6} \\
\text { pH: } 5,0-8,0\end{array}$ & $\begin{array}{l}\text { a legjobb pH tartomány: } 6,0-8,0 \text {, } \\
\text { az oldatok érzékenyek nyírásra, hőre és bakteriá- } \\
\text { lis enzimekre, } \\
\text { inert, nem okoz irritációt, szenzibilizációt, } \\
\text { a testben nem metabolizálódik, } \\
\text { széles gyógyszer- és élelmiszeripari alkalmazás }\end{array}$ \\
\hline $\begin{array}{l}\text { Hidroxipropilmetil- } \\
\text { cellulóz }\end{array}$ & $\begin{array}{l}\text { típusok: Methoce }{ }^{\circledR} \text { E5, E15, E50, } \\
\text { E4M, F50, F4M, K100, K4M, K15M, } \\
\text { K100M } \\
M_{r}: 8,6 * 10^{4}\end{array}$ & $\begin{array}{l}\text { széles gyógyszerészeti alkalmazás, } \\
\text { az E típusok alkalmasak filmképzőként, } \\
\text { oldatai pH 3,0-11,0 között stabilak }\end{array}$ \\
\hline Hidroxietilcellulóz & pH: $6,0-8,5$ & $\begin{array}{l}\text { az oldatok pszeudoplasztikusak, reverzibilis } \\
\text { viszkozitás csökkenést szenvednek a hőmérséklet } \\
\text { emelkedés hatására, } \\
\text { érzékeny a bakteriális bontásra és enzimekre, } \\
\text { az oldatok viszkozitása pH 2,0-12,0 között stabil, } \\
\text { bevonószer, filmképző }\end{array}$ \\
\hline $\begin{array}{l}\text { Xantán gumi (Xanthamonas } \\
\text { campestris baktérium fer- } \\
\text { mentálásával állítják elö) }\end{array}$ & oldata neutrális & $\begin{array}{l}\text { az oldatok viszkozitása pH 2,0-12,0 között stabil, } \\
\text { az alkalmazott gumik közül a legellenállóbb és jó } \\
\text { kompatibilitási tulajdonságokkal rendelkezik }\end{array}$ \\
\hline $\begin{array}{l}\text { Guar gumi (Cyamposis } \\
\text { tetragonolobus magból nye- } \\
\text { rik örléssel) }\end{array}$ & $\begin{array}{l}\mathrm{M}_{\mathrm{r}}: \sim 220000 \\
\text { a hidratációhoz pH 7,5-9,0 kedvez }\end{array}$ & $\begin{array}{l}\text { oldata pH 1,0-10,5 között stabil, } \\
\text { az FDA teljesen biztonságosnak nyilvánította, } \\
\text { közvetlenül élelmiszerekhez adagolva is } \\
\text { széles körben alkalmazott a gyógyszer- és élelmi- } \\
\text { szeriparban egyaránt }\end{array}$ \\
\hline $\begin{array}{l}\text { Kitozán (rák és homár pán- } \\
\text { célból } N \text {-deacetilezéssel } \\
\text { állítják elő) }\end{array}$ & $\mathrm{pK}_{\mathrm{a}}: \sim 6,5$ & $\begin{array}{l}\text { H-hídkötést és ionos kötéseket alakít ki a } \\
\text { mucinnal, } \\
\text { képes a sejtfelszínhez közvetlenül kötődni, } \\
\text { biokompatibilis és biodegradábilis, } \\
\text { kiváló filmképzö, } \\
\text { szabályozott hatóanyag leadású gyógyszerfor- } \\
\text { mákban széles körben alkalmazott, } \\
\text { poláris hatóanyagok transzportját növeli az } \\
\text { epitélsejteken keresztül }\end{array}$ \\
\hline $\begin{array}{l}\text { Karragenán (Chondrus } \\
\text { crispus vörös tengeri hínárból } \\
\text { vonják ki) }\end{array}$ & $\begin{array}{l}\text { elérhetö } \mathrm{Na}^{+}, \mathrm{K}^{+}, \mathrm{Mg}^{2+}, \mathrm{Ca}^{2+} \text { és vegyes } \\
\text { só formában is } \\
\text { három szerkezeti típusa ismert: } \mathrm{I}, \mathrm{K} \text { és } \\
\Lambda \text { melyek oldhatósága és reológiája } \\
\text { eltérő }\end{array}$ & $\begin{array}{l}\text { az oldatok pszeudoplasztikusak, reverzibilis } \\
\text { viszkozitás csökkenést szenvednek a hőmérséklet } \\
\text { emelkedés hatására, } \\
\text { kiváló termoreverzibilis tulajdonságok }\end{array}$ \\
\hline $\begin{array}{l}\text { Nátrium alginát (a nagy } \\
\text { tengeri hínárból-Macrocystis } \\
\text { pyrifera-vonják ki) }\end{array}$ & $\mathrm{pH}: 7,2$ & $\begin{array}{l}\text { biztonságos és nem allergén, } \\
\text { biokompatibilis, } \\
\text { ellenálló a bakteriális enzimekkel szemben }\end{array}$ \\
\hline $\begin{array}{l}\text { Poli(hidroxibutirát), poli(e- } \\
\text { kaprolakton) és kopolimereik }\end{array}$ & biodegradábilisak & mátrixképzők \\
\hline Poli(ortoészeterek) & erodálódó polimerek & $\begin{array}{l}\text { késleltetett hatóanyag leadásban, szemészetben } \\
\text { kerül alkalmazásra }\end{array}$ \\
\hline Poli(cianoakrilátok) & biodegradábilisak & hatóanyag-hordozó rendszerek \\
\hline Poli(vinilalkohol) & biokompatibilis & hatóanyag-hordozó rendszer \\
\hline Poli(etilénoxid) & kiemelkedő biokompatibilitás & széleskörü alkalmazás \\
\hline Poli(hidroxietilmetakrilát) & biokompatibilis & hatóanyag-hordozó rendszer \\
\hline
\end{tabular}

Mukoadhezív polimerek, mint enzim inhibitorok és penetrációnövelök

Bizonyos mukoadhezív polimerek enzim inhibitor hatással rendelkeznek. Ez azért fontos, mert egyes hatóanyag csoportok, mint például a proteinek és polipeptidek, kifejezetten érzékenyek az enzimatikus bontásra. Kutatások kimutatták, hogy ezek a polimerek, pl. a poli(akrilsav), kompetitív módon gátolják a proteolitikus enzimeket. Hatásukat úgy fejtik ki, hogy erős affinitással kötődnek kétértékü kationokhoz $\left(\mathrm{Ca}^{2+}, \mathrm{Zn}^{2+}\right)$. Ezek a kationok esszenciális kofaktorok a metalloproteázokhoz, pl. a tripszinhez. Cirkuláris dikroizmussal kimutatták, hogy bizonyos mukoadhezív polimerek jelenlétében $\mathrm{Ca}^{2+}$ depléció következett be, melynek hatására a tripszin másodlagos szerkezete változott meg és az enzim autodegradációt szenvedett $[118,119]$.

Számos mukoadhezív polimer a sejtek dehidratálásával képes a „tight junction” megnyitására. A száraz 
és duzzadóképes polimer a vízfelvétellel dehidratálja a sejteket, elöidézve azok zsugorodását. Ennek következtében a sejtek közötti távolság, azaz a paracelluláris út hossza megnő [120, 121]. Multifunkcionális mátrixok használatával - pl. poliakrilátok, cellulóz származékok és kitozán - a jobb mukoadhéziós tulajdonságok, permeábilitás növelő hatások, enzimgátlás, és/ vagy a magas puffer kapacitás sikeres gyakorlati megvalósíthatóságot tesz lehetővé orális hatóanyag-hordozó rendszerek formulálása esetén [122]. A III. táblázatban bioadhezív polimerek jellemzői találhatóak.

Bioadhezív polimerek ideális tulajdonságai:

- a polimer és bomlástermékei nem lehetnek toxikusak és irritatívak, továbbá mindennemü kísérő szennyeződéstől mentesnek kell lenniük,

- jó szétterülés, nedvesedés, duzzadás, oldódás és biodegradibilitás,

- biokompatibilis pH és jó viszkoelasztikusság,

- gyors tapadás a bukkális nyálkahártyához és megfelelő mechanikai szilárdság,

- jó nyírási, szakítási, réteg leválasztási ellenállás,

- könnyen hozzáférhető és olcsó legyen,

- száraz és nedves környezetben is mutasson megfelelö bioadhezivitást,

- mutasson helyi enzim inhibitor és penetrációfokozó hatást,

- megfelelö életidö,

- optimális molekulatömeg [2],

- aktív adhezív csoportok megléte,

- megfelelő térbeli konformáció,

- keresztkötöttség, melynek mértéke ne gátolja a kötő csoportok mozgékonyságát,

- ne segítse elő másodlagos fertőzések kialakulását [4].

Általánosan igaz megállapítások:

- a kationos és anionos polimerek jobban kötődnek, mint a semlegesek,

- a szulfát csoportokat tartalmazó anionos polimerek erősebben kötődnek, mint a karboxil csoporttal rendelkezők,

- kötési potenciál és toxicitás szempontjából a polianionok kedvezőbbek, mint a polikationok,

- a vízoldhatatlan polimerek jobb flexibilitással rendelkeznek gyártás során, mint a vízoldhatóak,

- a kötés foka a töltés sürüséggel arányos [4].

\section{Alkalmazott segédanyagok [123]}

A bukkális mukoadhezív készítmények esetében alkalmazott segédanyagok is több csoportba sorolhatók: lágyítók, édesítők, nyálelválasztást fokozók, ízesítők, színezők, stabilizáló és viszkozitásnövelő anyagok.

\section{Lágyítók}

A lágyítók használata lényeges a mukoadhezív filmek formulálásához is, ugyanis növelik a filmek flexibilitását és csökkentik a törékenységüket. A lágyító kiválasztásakor figyelembe kell venni annak polimerrel való kompatibilitását és az alkalmazott oldószer típusát. A leggyakrabban alkalmazott lágyítók a következők: glicerin, propilénglikol, polietilén glikolok (kis molekulatömegüek), ftalátok (dimetil-, dietil-, dibutilftalát), citrátok (tributil-, trietil-, acetilcitrát), triacetin, ricinusolaj.

Általánosságban elmondható, hogy a lágyítókat a száraz polimer tömegének $0-20 \mathrm{w} / \mathrm{w} \%$-ban alkalmazzák a gyógyszerforma kialakítása során [124-132]. Nem megfelelő koncentrációban történő alkalmazása a filmek repedéséhez, szakadásához, pikkelyesedéséhez vezethet [133-135], ill. bizonyos típusaik használata pedig hatással lehet a hatóanyag abszorpciós sebességére [136].

$\mathrm{Az}$ alkalmazott lágyítónak permanens flexibilitást kell a polimernek adnia, mely a lágyító illékonyságától és a polimerrel létrejövő interakció típusától függ. Fontos, hogy a lágyító a mukoadhezív szabad filmek esetében alkalmazott polimerek üvegesedési átmeneti hőmérsékletét nemvizes oldószer esetén $40-60{ }^{\circ} \mathrm{C}$ közé, míg vizes közeg esetén $75^{\circ} \mathrm{C}$ alá vigye [137, 138]. Természetesen a többi segédanyaggal és föképp a hatóanyaggal is kompatibilisnek kell lenniük [139]. Nagyon érdekes és figyelemre méltó, hogy egyes hatóanyag molekulák önmagukban képesek betölteni a lágyító szerepét. Például az ibuprofen interakcióba lép az Eudragit ${ }^{\circledR}$ RS 30 D-vel, és maga tölti be a lágyító szerepét. A hatóanyag és a polimer láncok között kialakuló H-hídkötések révén csökken az Eudragit ${ }^{\circledR}$ RS $30 \mathrm{D}$ üvegesedési hőmérséklete és szép, sima filmet eredményez. Az ibuprofen kioldódási mértéke azonban csökken, amikor koncentrációja nő a filmben [140].

A lágyítók kétféle módon foglalhatnak helyet a polimer mátrixon belül: „belsőlegesen” (kémiai reakció jön létre a lágyító és a polimer között), valamint „,külsőlegesen". A formulálók ez utóbbit preferálják, mivel nem kell tartani a termékben esetlegesen végbemenő kémiai változásoktól. A megfelelő lágyító kiválasztásánál fontos ismerni az alkalmazott polimer szerkezetét, funkciós csoportjait. Pl. hidrofil cellulózszármazékok esetén hidroxil csoportban gazdag lágyítókat alkalmazunk, ilyenek a polietlénglikol, propilénglikol, glicerin és más poliolok. Kevésbé hidrofil származékok esetén viszont citrátésztereket, vagy ftalátokat érdemes választani [141].

\section{Édesitök}

$\mathrm{Az}$ édesítők nagyon fontosak mind az élelmiszer-, mind a gyógyszeriparban, föként a szájban oldódó, vagy dezintegrálódó készítmények alkalmazása esetében. Az édes íz különösen a pediátriában fontos. Ter- 
Különböző anyagok nyálelválasztást stimuláló hatása [123]

\begin{tabular}{l|c|c|c}
\hline \multicolumn{1}{c|}{ Stimuláns } & Molaritás & Áramlás (ml/perc) & $\begin{array}{c}\text { A normál áramlási sebesség helyre- } \\
\text { állásához szükséges idó (perc) }\end{array}$ \\
\hline Citromsav & 0,26 & 1,68 & 7,3 \\
\hline Glükóz & 1,17 & 0,52 & 6,7 \\
\hline Fruktóz & 1,17 & 0,97 & 8,7 \\
\hline Szacharóz & 1,17 & 0,74 & 6,3 \\
\hline Aszpartám & 0,34 & 0,82 & 6,8 \\
\hline Szaharin $\mathrm{Na}$ & 0,42 & 1,04 & 10,5 \\
\hline
\end{tabular}

A nyugalmi, fiziológiás nyáláramlás $0,34 \mathrm{ml} /$ perc [146].

mészetes és mesterséges édesítők egyaránt használatosak a szájban oldódó formulák élvezhetőbbé tételében. A klasszikus édesitoók a következők: szacharóz, dextróz, fruktóz, glükóz, maltóz.

A cukoralkoholokat [például szorbit, mannit (nagy mennyiségben hashajtó hatásúak)] kombinációkban alkalmazzák, édesítő hatásuk mellett kellemes száj-érzetet és hűsítő hatást biztosítanak. További előnyük, hogy nincs keserü utóízük. A legtöbb cukoralkohol édességi foka a szacharózénak a fele, vagy annál is kevesebb, de például a xilit és maltit édességi foka a szacharózéval megegyező $(0,8-1,0)$. Figyelembe kell venni azonban a természetes szénhidrátok alkalmazásánál, hogy diétázó betegek, vagy diabetes mellitusban szenvedők nem, vagy korlátozottan alkalmazhatják ezeket a készítményeket [142, 143]. Emiatt a mesterséges édesítőszerek kerültek előtérbe mind az élelmiszer-, mind a gyógyszeriparban. Első generációjuk a szaharin, ciklamát és aszpartám volt, majd ezeket követte az aceszulfám-K és szukralóz, mint második generációs mesterséges édesítő. Ezek 200-600-szor édesebbek, mint az első generációs vegyületek [144]. Hátrányuk a kellemetlen utóíz, melyet a természetes eredetü anyagokkal való kombinációval kiküszöbölhetünk. A mesterséges édesítők ízminősége jelentősen eltér a természetes anyagokétól, és a betegek nem biztos, hogy elfogadják a szokatlan íz hatást. A két édesítőszer-típus keverése azonban szinergista módon növeli az édes ízérzetet, és sokkal jobb hatást eredményez [143]. Filmek esetében általában 3-6 w/w\%-ban alkalmazzák ezeket az anyagokat [145].

\section{Nyálelválasztást fokozók}

Mivel a nyál a mucinok forrása, melyek a mukoadhézióhoz szükségesek, továbbá a nyál a kioldóközeg szerepét is betölti, ezért fontos a nyálelválasztás serkentése. A szájszárazságban szenvedő betegek esetén pedig különösen fontos a megfelelő nyálszint biztosítása. Általában savas karakterü anyagokat alkalmaznak erre a célra: citrom-, alma-, tej-, aszkorbin- és borkősav a legelterjedtebb nyálstimuláló segédanyag. Önmagukban, vagy kombinációban 2-6 w/w\%-ban kerülnek alkalmazásra. Az édesítőszerek is rendelkeznek nyálelválasztást stimuláló hatással pl.: glükóz, fruktóz, xilit, maltóz, laktóz. Az édesítők nyálelválasztást fokozó hatása az édességi fokuktól függ: a fruktóz édességi foka 1,1 , a glükózé 0,7 , a szacharózé pedig 1,0. A mesterséges édesítők alkalmazása előnyösebb, mert kisebb koncentrációban is elegendőek, összetett funkcióval rendelkeznek, és nem okoznak fogszuvasodást vagy meggátolják azt [146]. A IV. táblázatban a nyálelválasztást stimuláló segédanyagokat foglaltunk össze.

\section{Izesitök}

Az ízérzékelés egyénenként változik, függ a népcsoporttól és az egyéni ízléstől egyaránt. Adott ízek kedvelése az életkortól függ; az idősebbek a mentolos és narancsos ízeket kedvelik, míg a fiatalok a gyümölcs és puncs ízt. Az, hogy a beteg mennyire fogadja el a készítményt, nagyban függ az első másodpercekben tapasztalt ízhatástól és az alkalmazást követő tíz percben tapasztaltaktól [147]. Mind természetes, mind mesterséges aromákat alkalmaznak, önmagukban vagy kombinációban egyaránt, körülbelül 10 w/w\%ban. Hüsítő hatású anyagokat is alkalmaznak az íz erősítése és a szájban tapasztalt érzet elnyújtása érdekében [148, 149].

\section{Színezök}

Alkalmazásuk akkor indokolt (kevesebb, mint 1 w/w\%-ban), ha valamely ható-, vagy segédanyag oldhatatlan, vagy szuszpendált formában van jelen a készítményben $[150,151]$.

\section{Stabilizáló és viszkozitásnövelő anyagok}

Növelik az oldat vagy szuszpenzió viszkozitását és javítják a konzisztenciát a filmkészítés előtt. Erre a célra 5 w/w\%-ban természetes gumik (xantán, szentjánoskenyér-mag őrlemény), karragenán és cellulóz származékok egyaránt alkalmazhatók [149].

Szükség esetén egyéb segédanyagok is alkalmazhatók a formuláláshoz, pl. felületaktív anyagok és emulgensek [123]. 


\section{Összefoglalás}

A mukoadhezív gyógyszeres filmek esetén alkalmazott filmképző polimerek kiválasztása során nem csak a szájnyálkahártya jellemzőit kell figyelembe venni, hanem a polimer fizikai-kémiai és egyéb tulajdonságait is. Elsősorban a második generációs polimereket és a csoporton belül pedig a többfunkciós filmképzöket részesítik előnyben, mivel jól kihasználható a mukoadhéziót fokozó tulajdonságuk és a hatóanyag biológiai hasznosulását is képesek javítani (pl. a 'tight junction' moduláción keresztül). Más gyógyszerformákhoz hasonlóan a filmek esetében is törekedni kell, hogy csak a szükséges mennyiségü segédanyagot alkalmazzák a formuláció során. Itt is előnyt jelent a többfunkciós segédanyagok alkalmazása, mivel pl.: az édesítők egyes típusai az ízjavítás mellett a nyálelválasztást is stimulálják.

\section{Köszönetnyilvánítás}

Jelen kutatási eredmények megjelenését a TÁMOP4.2.2.A-11/1/KONV-2012-0047 azonosító számú projekt támogatta.

\section{IRODALOM}

1. Gottnek, M. et al.: Gyógyszerészet 57, 24-31 (2013). - 2. Gottnek, M. et al.: Gyógyszerészet 57, 69-75 (2013). - 3. Salamat-Miller, $N$. et al.: Advanced Drug Delivery Reviews 57, 1666-1691 (2005). - 4. Sudhakar, Y. et al.: Journal of Controlled Release 114, 15-40 (2006). - 5. Patel, V.F. et al.: Journal of Controlled Release 153, 106-116 (2011). - 6. Lee, J.W. et al.: J. Pharm. Sci. 89, 850-866 (2000). - 7. Gu, J.M. et al.: Crit. Rev. Ther. Drug Carr, Syst. 5, 21-67 (1998). - 8. Shojaei, A., Li, X.: J. Control. Release 47, 151-161 (1997). 9. Ludwig, A.: Adv. Drug. Deliv. Rev. 57, 1595-1639 (2005). - 10. Fefelova, N.: Int. J. Pharm. 339, 25-32 (2007). - 11. He, P. et al.: Int. J. Pharm 166, 75-88 (1998). - 12. Morales, J.O., McConville, J.T: : Eur J Pharm Biopharm 77, 187-199 (2011). - 13. Anders, R., Merkle, H.: Int J Pharm 49, 231-240 (1989). - 14. Yehia, S. et al.: Current Drug Delivery 6, 17-27 (2009). - 15. Nafee, N.A. et al:: Int J Pharm 264, 1-14 (2003). - 16. Raghuraman, S. et al.: Indian Journal of Pharmaceutical Sciences 64, 32-36 (2002). - 17. Sekhar, K. et al.: Drug Deliv 15, 185-191 (2008). - 18. Tiwari, S. et al.: Current Drug Delivery 6, 305-316 (2009). - 19. Khanna, R. et al.: Indian Journal of Pharmaceutical Sciences 59, 299-305 (1997). - 20. Repka, M. et al.: Drug Dev Ind Pharm 29, 757-765 (2003). 21. Dubolazov, A. et al.: Biomacromolecules 7, 1637-1643 (2006). - 22. Repka, M. et al.: Drug Dev Ind Pharm 32, 21-32 (2006). - 23. Repka, M. et al.: Eur J Pharm Biopharm 59, 189-196, (2005). - 24. Repka, M., McGinity, J.: J Control Release 70, 341-351 (2001). - 25. Repka, M. et al.: Drug Dev Ind Pharm 25, 625-633 (1999). - 26. Prodduturi, S. et al.: J Pharm Sci 93, 3047-3056 (2004). - 27. Repka, M., McGinity, J.: Biomaterials 21, 1509-1517 (2000). - 28. Repka, M., McGinity, J.: Pharm Dev Technol 6, 297-304 (2001). - 29. Danjo, K. et al.: Chem Pharm Bull 43, 1759-1763 (1995). 30. Alanazi, F.K. et al.: J Drug Deliv Sci Tec 17, 183-192
(2007). - 31. Okamoto, H. et al.: J Control Release 77, 253260 (2001). - 32. Kharenko, E. et al.: Pharmaceutical Chemistry Journal 42, 392-399 (2008). - 33. Arakawa, Y. et al.: Biol Pharm Bull 28, 1679-1683 (2005). - 34. Kohda, Y. et al.: Int J Pharm 158, 147-155 (1997). - 35. Okamoto, H. et al.: J Pharm Sci 91, 2424-2432 (2002). - 36. Takeuchi, K. et al.: Yakugaku zasshi: Journal of the Pharmaceutical Society of Japan 128, 1791-1805 (2008). - 37. Yanagi, M. et al.: Biol Pharm Bull 31, 278-283 (2008). - 38. Peh, K., Wong, C.: J Pharm Pharm Sci 2, 53-61 (1999). - 39. Guo, J.: Drug Dev Ind Pharm 20, 2809-2821 (1994). - 40. Semalty, M. et al.: Indian Journal of Pharmaceutical Sciences 70, $43-48$ (2008). - 41. Wong, C. et al.: Int J Pharm 178, 11-22 (1999). - 42. Jug, M. et al.: Drug Dev Ind Pharm 35, 796-807 (2009). - 43. Perumal, V. et al:: Drug Dev Ind Pharm 34, 1036-1047 (2008). - 44. Sharma, P., Hamsa, V.: STP Pharma Sciences 11, 275-281 (2001). - 45. Chun, M. et al.: Arch Pharm Res 26, 973-978 (2003). - 46. Nappinnai, M. et al.: Indian Journal of Pharmaceutical Sciences 70, 631-635 (2008). - 47. Perioli, L. et al.: J Control Release 99, 73-82 (2004). - 48. Garg, S., Kumar, G.: Pharmazie 62, 266-272 (2007). - 49. Kim, T. et al:: Arch Pharm Res 30, 381-386 (2007). - 50. Juliano, $C$. et al.: AAPS Pharmaceutical Science and Technology 9, 1153-1158 (2008). - 51. Averineni, R.K. et al.: Pharm Dev Technol 14, 199-207 (2009). - 52. Skulason, S. et al.: Pharmazie, 64, 197-201 (2009). - 53. Thimmasetty, J. et al.: Pakistan Journal of Pharmaceutical Sciences 21, 241-248 (2008). - 54. Peh, K., Wong, C.: J Pharm Pharm Sci 2, 53-61 (1999). - 55. Singh, S. et al:: AAPS Pharmaceutical Science and Technology 9, 660-667 (2008). - 56. Sahni, J. et al.: Indian Journal of Pharmaceutical Sciences 70, 61-65 (2008). - 57. Eouani, C. et al.: Eur J Pharm Biopharm 52, 45-55 (2001). - 58. Shmidt, W.: Process for producing an administration or dosage form for drugs, reagents or other active ingredients, US Patent 4849246, July 18, 1989. - 59. Llabot, J. et al.: Int J Pharm 336, 263-268 (2007). - 60. Singh, S. et al.: Chem Pharm Bull 58, 307-311 (2011). - 61. Shidhaye, $S$. et al.: AAPS Pharmaceutical Science and Technology 9, 909-916 (2008). - 62. Doijad, R. et al.: Indian Journal of Pharmaceutical Sciences 68, 744-748 (2006). - 63. Patel, V. et al.: Current Drug Delivery 3, 325-331 (2006). 64. Jain, S. et al.: Pharmazie 63, 129-135 (2008). - 65. Patel, R, Poddar, S.: Current Drug Delivery 6, 140-144 (2009). 66. Patel, $V$. et al:: AAPS Pharmaceutical Science and Technology 8, E119-E126 (2007). - 67. Diaz del Consuelo, I. et al.: J Control Release 122, 135-140 (2007). - 68. Patel, V. et al.: AAPS Pharmaceutical Science and Technology 8, 147154 (2007). - 69. Lee, Y. Chien, Y.: J Control Release 37, 251-261 (1995). - 70. Senel, S. et al:: Int J Pharm 193, 197203 (2000). - 71. Cui, F. et al.: Biomacromolecules 8, 28452850 (2007). - 72. Perumal, V. et al.: Int J Pharm 358, 184191 (2008). - 73. Perugini, P. et al.: Int J Pharm 252, 1-9 (2003). - 74. Remunan-Lopez, C. et al.: J Control Release 55, 143-152 (1998). - 75. El-Kemel, A. et al.: AAPS Pharmaceutical Science and Technology 8, E184-E194 (2007). - 76. Zhang, M. et al.: Biomaterials 23, 2641-2648 (2002). - 77. Perumal, V. et al.: Int J Pharm 358, 184-191 (2008). - 78. Juliano, C. et al.: J Drug Deliv Sci Tec 58, 307311 (2010). - 79. Rossi, S. et al.: Pharm Dev Technol 8, 199 208 (2003). - 80. Aksungur, P. et al.: J Control Release 98, 269-279 (2004). - 81. Brown, C.D. et al.: J Control Release 72, 35-46 (2001). - 82. Cui, F. et al.: J Biomed Mater Res A 86A, 1063-1071 (2009). - 83. He, C. et al.: Eur Polym J 45, 368-376 (2009). - 84. Staishbabu, B.K., Srinivasan, B.P.: 
Indian Journal of Pharmaceutical Sciences 70, 175-179 (2008). - 85. Pongjanyakul, T., Suksri, H.: Colloid Surface B: Biointerfaces 74, 103-113 (2009). - 86. Peruginu, P. et al.: Int J Pharm 252, 1-9 (2003). - 87. Ahuja, A . et al.: Pharmazie 58, 716-720, (2003). - 88. Li, C. et al.: Drug Dev Ind Pharm 24, 919 (1998). - 89. Jacques, Y. et al.: STP Pharma Sciences 7, 289-294 (1997). - 90. Abu-Huwaij, R. et al.: Drug Dev Ind Pharm 33, 437-448 (2007). - 91. Alsarra, I.A. et al.: Pharmazie 62, 773-778 (2007). - 92. Benes, L. et al.: J Pharm Sci 86, 1115-1119 (1997). - 93. Guo, J., Cooklock, K.: Drug Dev Ind Pharm 24, 175-178 (1998). - 94. McQuinn, R. et al.: J Control Release 34, 243-250 (1995). - 95. Abu-Huwaij, $R$. et al.: Drug Dev Ind Pharm 33, 855-864 (2007). - 96. Fountain, W. et al.: Journal of Pharmaceutical and Biomedical Analysis 33, 181-189 (2003). - 97. Cui, Z., Mumper, R.J.: Pharm Res 19, 947-953 (2002). - 98. Cui, Z., Mumper, R.J.: Pharm Res 19, 1901-1906 (2002). - 99. Prodduturi, S. et al.: J Pharm Sci 94, 2232-2245 (2005). - 100. Thumma, S. et al.: AAPS Pharmaceutical Science and Technology 9, 982-990 (2008). - 101. Thumma, S. et al.: Eur J Pharm Biopharm 70, 605-614 (2008). - 102. Cilurzo, F. et al.: J Control Release 88, 43-53 (2003). - 103. Ahmed, A. et al.: J Pharm Biomed Anal 34, 945-956 (2004). - 104. Fountain, W. et al.: J Pharm Biomed Anal 33, 181-189 (2003). - 105. Jay, S. et al.: J Pharm Sci 91, 2016-2025 (2002). - 106. Langoth, L. et al.: Int. J. Pharm. 252, 141-148 (2003). - 107. Marschütz, M.K., Bernkop-Schnürch, A.: Eur. J. Pharm. Sci. 15, 387-394 (2002).-108. Kast, C.E., Bernkop-Schnürch, A.: Biomaterials 22, 2345-2352 (2001). - 109. Bernkop-Schnürch, A. et al.: Pharm. Res. 16, 876-881 (1999). - 110. Gum, J.R. et al.: J. Biol. Chem. 267, 21375-21383 (1992). - 111. Saviae, R. et al.: Science 300, 615-618 (2003). - 112. Allen, C. et al.: Polym. Micelles Biol. Pharma. 16, 3-27 (1999). - 113. Kast, C.E. et al.: Pharm. Res. 20, 931-936 (2003). - 114. Leitner, V.M. et al:: $5^{\text {th }}$ Central Eur. Symp. Pharm. Technology, Ljubljana, Slovenia, 2003. - 115. Haltner, E. et al.: Eur. J. Pharm. Biopharm. 44, 3-13 (1997). - 116. Isberg, R.R. et al.: Yersinia INV nucleic acids, U.S. Patent 5338842 (1994). - 117. Lehr, C.M.: Eur. J. Drug Metab. Pharmacokinet. 21, 139-148 (1996). - 118. Lueßen, H.L. et al.: J. Control. Release 29, 329-338 (1994). - 119. Lueßen, H.L. et al.: Pharm. Res. 12, 1293-1298 (1995). - 120. Lehr, C.M.: Eur. J. Drug Metab. Pharmacokinet. 21, 139-148 (1996). - 121. Haas, J., Lehr, C.M: Expert Opin. Biol. Ther. 2, 287-298 (2002). - 122. Bernkop-Schnürch, A., Walker, G.: Crit. Rev. Ther. Drug Carr. Syst. 18, 459-501 (2001). - 123. Dixit, R.P., Puthli, S.P.: J. Cont. Release 139, 94-107, (2009). - 124. McIndo, L.M.E.: Castor oil, in: R.C. Rowe, P.J. Sheskey, S.C. Owen (Eds.), Handbook of Pharmaceutical Excipients, Pharmaceutical press, London, 2006., pp. 128-130. - 125. Guest, R.T.: Dibutyl phtalate, in: R.C. Rowe, P.J. Sheskey, S.C. Owen (Eds.), Handbook of Pharmaceutical Excipients, Pharmaceutical press, London, 2006., pp. 234-235. - 126. Kennedy, S.W..: Dibutyl sebacate, in: R.C. Rowe, P.J. Sheskey, S.C. Owen (Eds.), Handbook of Pharmaceutical Excipients, Pharmaceutical press, London, 2006., pp. 236-237. - 127. Guest, R.T.: Diethyl phtalate, in: R.C. Rowe, P.J. Sheskey,
S.C. Owen (Eds.), Handbook of Pharmaceutical Excipients, Pharmaceutical press, London, 2006., pp. 240-241. - 128. Price, J.C.: Polyethylene glycol, in: R.C. Rowe, P.J. Sheskey, S.C. Owen (Eds.), Handbook of Pharmaceutical Excipients, Pharmaceutical press, London, 2006., pp. 545-550. - 129. Owen, S.C., Weller, P.J.: Propylene glycol, in: R.C. Rowe, P.J. Sheskey, S.C. Owen (Eds.), Handbook of Pharmaceutical Excipients, Pharmaceutical press, London, 2006., pp. 624626. - 130. Palmieri, A.: Triacetin, in: R.C. Rowe, P.J. Sheskey, S.C. Owen (Eds.), Handbook of Pharmaceutical Excipients, Pharmaceutical press, London, 2006., pp. 790791. - 131. Kennedy, S.W.: Tributyl citrate, in: R.C. Rowe, P.J. Sheskey, S.C. Owen (Eds.), Handbook of Pharmaceutical Excipients, Pharmaceutical press, London, 2006., pp. 792793. - 132. Kennedy, S.W.: Triethyl citrate, in: R.C. Rowe, P.J. Sheskey, S.C. Owen (Eds.), Handbook of Pharmaceutical Excipients, Pharmaceutical press, London, 2006., pp. 796797. - 133. Rowe, R.C., Forse, S.F.: J. Pharm. Pharmacol. 32, 583-584 (1980). - 134. Rowe, R.C., Forse, S.F.: J. Pharm. Pharmacol. 32, 647-648 (1980). - 135. Rowe, R.C., Forse, S.F.: J. Pharm. Pharmacol. 33, 174-175 (1981). - 136. Singh, P. et al.: J. Pharm. Sci. 55, 63-68 (1966). - 137. Cao, N. et al.: Food Hydrocolloids 23, 729-735 (2009). - 138. Browhn, G.L.: J. Polym. Sci. 22, 423-434 (1956). - 139. Sakellariu, P., Rowe, R.C.: Prog. Polym. Sci. 20, 889-942 (1995). - 140. Wu, C., McGinity, J.W.: AAPS PharmSciTech 2, 24 (2001). - 141. Hariharan, M., Bogue, A.: Drug Del. Technol. 9, 24-29 (2009). - 142. Menella, J.A., Beauchamp, G.K.: Clin. Ther. 30, 2120-2132 (2008). - 143. Hutteau, F. et al.: Food Chem. 63, 9-16 (1998). - 144. Prakash, I. et al.: Food Chem. Toxicol. 46, S75-S82 (2008). - 145. Sau-hung, S. et al:: U.S. Patent 6,596,298, July 22, (2003). - 146. Israel, K., Leo, M.: U.S. Patent 4820506, April 11, (1989). - 147. Brown, D.: Drug Del. Technol. 3, (2003). - 148. McGregor, R.: WO Patent 2004/19885, March 11, (2004). - 149. Yoshida, T. et al.: Int. J. Pharm. 365, 81-88 (2009). - 150. Maibach, T: WO Patent PCT/US2008/053466, Aug 14, (2008). - 151. Obermeier, P. et al.: U.S. Patent 2008/0213343 A1, Sept 4, (2008).

Gottnek, M., Hódi, K., Regdon, G. jun .: Mucoadhesive films applied on the oval mucosa. Part III. Polymers and Excipients Used is Buccal Mucoadhesive Films

The film-forming polymers used in mucoadhesive drugcontaining films have to be chosen with the consideration of not only the properties of the oral mucosa but also the physical-chemical and other characteristics of the polymer. Second generation polymers and within this group multifunctional film-forming agents are mainly preferred because their mucoadhesion-enhancing property can be used well and they can also improve the bioavailability of the active ingredient (e.g. through tight junction modulation). Similarly to other dosage forms, only the necessary quantity of excipients should be used during the formulation of films. The use of multifunctional excipients offers advantages here, too, as e.g. certain types of sweeteners can stimulate saliva secretion besides improving taste. 
VII. 


\section{TOVÁBBKÉPZŐ KÖZLEMÉNYEK}

Gyógyszerészet 57. 323-329. 2013.

\section{Szájnyálkahártyán alkalmazható mukoadhezív filmek \\ IV. rész: Bukkális mukoadhezív filmekben alkalmazott hatóanyagok. Mukoadhezív filmek előállítása és vizsgálata}

Gottnek Mihály, Hódi Klára, ifj. Regdon Géza

\section{Alkalmazott hatóanyagok $[4,5,6]$}

A szájnyálkahártyán alkalmazott mukoadhezív filmek rendkívül innovatív gyógyszerformának számítanak. Számos kutatócsoport foglalkozik bukkoadheziv hatóanyag-hordozó rendszerek formulálásával és vizsgálatával, melyek közül néhány példát az I. táblázatban tüntettünk fel. Továbbá már számos törzskönyvezett készítmény került forgalomba Európában és a tengerentúlon is. Ezek lehetnek fájdalom-, hányáscsillapítók, szimpatomimetikumok, antihisztaminok.

Egyes forgalomban lévő bukkális filmek, szalagok:

- Ondansetron Rapidfilm ${ }^{\circledR} /$ Labtec $\mathrm{GmbH} /$ ondansetron 4 és $8 \mathrm{mg}$,

- Donepezil Rapidfilm ${ }^{\circledR} /$ Labtec GmbH / donepezil $\mathrm{HCl} 5$ és $10 \mathrm{mg}$,

- Chloraseptic ${ }^{\circledR}$ Relief Strips ${ }^{\mathrm{TM}} /$ Innozen Inc / bezokain 2 és $3 \mathrm{mg}$,

- Supress ${ }^{\mathrm{TM}}$ Cough Strips / Innozen Inc / dextrometorfán $\mathrm{HBr} 2,5 \mathrm{mg}$,

- Night Time Triaminic Thin Strips ${ }^{\circledR}$ Cold \& Cough / Novartis Pharmaceuticals / difénhidramin $\mathrm{HCl}$ 12,5 $\mathrm{mg}$ és fenilefrin $\mathrm{HCl} 5 \mathrm{mg}$,

- Triaminic Thin Strips ${ }^{\circledR}$ Long Acting Cough / Novartis Pharmaceuticals / dextrometorfán 5,5 mg,

- Triaminic Thin Strips ${ }^{\circledR}$ Cough \& Runny Nose / Novartis Pharmaceuticals / difénhidramin $\mathrm{HCl} 12,5 \mathrm{mg}$,

- Day Time Triaminic Thin Strips ${ }^{\circledR}$ Cold \& Cough / Novartis, Pharmaceuticals / dextrometorfán 3,67 mg és fenilelfrin $\mathrm{HCl} 2,5 \mathrm{mg}$,

- Triaminic Thin Strips ${ }^{\circledR}$ Cough \& Stuffy Nose / Novartis Pharmaceuticals / fenilefrin $\mathrm{HCl} 2,5 \mathrm{mg}$,

- Theraflu ${ }^{\circledR}$ Daytime Thin Strips / Novartis Pharmaceuticals / dextrometorfán 14,8 mg és fenilefrin $\mathrm{HCl} 10 \mathrm{mg}$,

- Theraflu ${ }^{\circledR}$ Nighttime Thin Strips / Novartis Pharmaceuticals / difénhidramin $\mathrm{HCl} 25 \mathrm{mg}$ és fenilefrin $\mathrm{HCl} 10 \mathrm{mg}$,

- Theraflu ${ }^{\circledR}$ Thin Strips-Multi Symptom / Novartis Pharmaceuticals / difénhidramin $\mathrm{HCl} 25 \mathrm{mg}$,

- Chloraseptis relief strip / Prestige Brands / benzokain,

- Onsolis ${ }^{\mathrm{TM}}$ / BioDelivery Sciences International / fentanil (film),

- BEMA ${ }^{\mathrm{TM}}$ Buprenorphine / BioDelivery Sciences International / buprenorfin.
Továbbképzö cikksorozatunk első részében [1] a szájnyálkahártya felépitését és a nyál élettani, gyógyszerészeti vonatkozásait tárgyaltuk részletesen, mivel elöbbi a gyógyszerforma alkalmazási helye és a felszivó felület, utóbbi pedig mint kioldó közeg játszik szerepet. A második közleményben [2] a mukoadhézió mechanizmusát, a mucin szerepét, a szájnyálkahártya barrier funkcióját és a hatóanyagok penetrációját foglaltuk össze. Harmadik cikkünkben [3] a mukoadheziv filmképzö polimerekröl és segédanyagokról irtunk. A negyedik befejezö, vagyis jelen közleményben a mukoadheziv filmekben alkalmazható hatóanyagokról, valamint a gyógyszeres filmek elöállitásáról kivánunk részletesen szólni.

A felsorolt készítmények mellett leheletfrissítö, stimuláló, ásványi anyag és vitamin tartalmú, valamint gyógynövény kivonatokat tartalmazó filmek is forgalomban vannak [6].

\section{Bukkális gyógyszerforma tervezéshez figyelembe veendó általános irányelvek}

Bukkális gyógyszerforma tervezéshez az alábbi általános irányelveket kell figyelembe venni $[4,5]$ :

- fiziológiai szempontok,

- patológiai szempontok,

- farmakológiai szempontok,

- gyógyszertechnológiai szempontok.

\section{Fiziológiai szempontok}

A folyamatos nyálelválasztás és a bukkális szövetek mozgása befolyásolják a hatóanyag bejutást a véráramba. A hatóanyagok tartózkodási ideje tipikusan rövid a szájnyálkahártyán; 5-10 percnél kevesebb [7]. A bukkális mukoadhezív gyógyszerformák képesek áthidalni ezeket a problémákat, mivel tartósan rögzítik a felszívó felülethez a hatóanyag-hordozó rendszert. Egy jól definiált, relatíve kis területre koncentrálódik a hatóanyag, így helyileg nagy koncentrációban érintkezik a felülettel, ezért kevesebb hatóanyag alkalmazása elegendő, ezáltal csökkenthetők az eset- 
Irodalmi példák filmekben elöforduló hatóanyagokról [3]

\begin{tabular}{l|l|l}
\hline \multicolumn{1}{c|}{ Hatóanyag } & \multicolumn{1}{c}{ Filmképző polimer } & \multicolumn{1}{c}{ Kutatók [Ref.] } \\
\hline Aciklovir & Kitozán HCl és PAA Na só & Rossi és mtsai [8] \\
\hline Kitozán & Kitozán & Íkinci és mtsai [9] \\
\hline Klórhexidin-diacetát & EC & Jones és Medlicott [10] \\
\hline Klórhexidin-diglükonát & Kitozán & Şenel és mtsai [11] \\
\hline Glibenklamid & Kitozán és PVP & Ilango és mtsai [12] \\
\hline Inzulin & Zselatin és CP 934P & Ritschel és mtsai [13] \\
\hline Lidokain & HPC & Okamoto és mtsai [14, 15] \\
\hline Nifedipin & Na alginát, MC, PVP és PEG & Save és mtsai [16] \\
\hline Nifedipin vagy propranolol HCl & Kitozán (PC, Na alginát gellán gumi) & Remuñán-López és mtsai [17] \\
\hline Kalcitonin & PC és Eudragit ${ }^{\circledR}$ S-100 & Cui és Mumper [18] \\
\hline Tesztoszteron & PC és Eudragit ${ }^{\circledR}$ S-100 & Jay és mtsai [19] \\
\hline $\begin{array}{l}\text { Tetrakain, ofloxacin, } \\
\text { mikonazol és tetrakain }\end{array}$ & HPC & Oguchi és mtsai [20] \\
\hline Tetraciklin & Atelokollagén & \\
\hline Ipriflavon & PLGA, kitozán & Minabe és mtsai [21] \\
\hline Klórfeneramin-maleát & Polioxietilén & Perugini és mtsai [22] \\
\hline Protirelin & HEC, HPC, PVP, PVA & Tiwari és mtasi [23] \\
\hline Buprenorfin & CP-934, PIB és PIP & Anders és mtsai [24, 25] \\
\hline Izoszorbid-dinitrát & HPC, HPMC & Guo [26] \\
\hline
\end{tabular}

Megjegyzés:

A táblázatban használt röviditések listája: $C P=$ karbopol, $E C=$ etilcellulóz, $H E C=$ hidroxietilcellulóz, $H P C=$ hidroxipropilcellulóz, $H P M C=$ hidroxipropilmetilcellulóz, $M C=$ metilcellulóz, $P A A=$ poli(akrilsav), $P C=$ polikarbofil, $P E G=$ poli(etilénglikol), $P I B=$ poliizobutilén, $P I P=$ poliizoprén, $P L G A=$ poli(D, L-laktid co-glikolid), $P V A=$ poli(vinilalkohol), $P V P=$ polivinilpirrolidon

leges helyi és szisztémás mellékhatások. A bukkális nyálkahártya elönye, hogy sima felszínü, kevésbé mobilis a támasztószövetekhez való erös kapcsolódása miatt és könnyen hozzáférhető. Nehézséget jelent a rövid tartózkodási idö, a kis felszívó felület és a barrier funkció. Általában a bukkális filmek $1-3 \mathrm{~cm}^{2}$ nagyságúak [28] és $25 \mathrm{mg}$ vagy annál kevesebb hatóanyag inkorporálása javasolt [29]. Az ellipszisforma ajánlott [30] és a filmek vastagsága maximum néhány milliméter lehet [31]. A gyógyszerforma tartózkodási ideje bukkálisan általában több mint a mucin életidő [7]. A maximális alkalmazási idő 4-6 óra, azonban étkezés és/vagy ivás esetén szükséges lehet a hatóanyag-hordozó rendszer eltávolítása [32, 4].

\section{Patológiai szempontok}

Egyes betegségek hatással vannak az epitélium vastagságára és a barrier funkció megváltozását okozhatják, továbbá bizonyos hatóanyagok és betegségek a nyál összetételére illetve a nyákréteg szerkezetére vannak hatással [33]. Mindezek az alkalmazhatóságot és a kellő retenciós időt befolyásolhatják negatívan. Illetve figyelembe kell venni, hogy azok a ható- és segédanyagok, amelyek hatással vannak a szájnyálkahártya/szájüreg fiziológiai paramétereire, nem alkalmazhatóak [4].

\section{Farmakológiai szempontok}

Bukkálisan mind helyi, mind szisztémás hatást elérhetünk. A formulálás során figyelembe kell venni az elözőekben leírtakat, továbbá a hatóanyag tulajdonságait és a kezelendő területet [4].

\section{Gyógyszertechnológiai szempontok}

Figyelembe kell venni a hatóanyag fizikai-kémiai és a gyógyszerforma tulajdonságait egyaránt. Lényeges a segédanyagok helyes megválasztása, mint ahogyan azt már részleteztük. Kiemelt jelentőségủ a filmképző polimer, hiszen a hatóanyag hordozója és/vagy mukoadhezív is egyben [4]. Nagyon fontos a segédanyagok közül a penetrációfokozók, enzim inhibitorok és pufferek alkalmazása, melyeket az alábbiakban részletezünk.

\section{- Penetrációfokozók [4, 5, 34, 35-38]}

A kémiai penetrációfokozók vagy abszorpcióserkentők olyan, a gyógyszerformához adott anyagok, amelyek növelik a membrán permeábilitását vagy a hatóanyag abszorpciós sebességét anélkül, hogy károsítanák a nyálkahártyát vagy toxikus hatást idéznének elö [39]. Farmakológiailag inertnek kell lenniük, nem irritálhatnak és allergizálhatnak [40]. A bukkális nyálka- 
hártyán a hatóanyagok nagyrészt passzív diffúzióval jutnak be, melyet Fick I. törvényével írhatunk le:

$$
J_{s s}=\frac{D K}{h} * C_{D}
$$

ahol, $J_{s s}$ a „steady state” áram, $C_{D}$ a donor hatóanyaghordozó rendszer koncentrációja, $D$ a hatóanyag bukkális mukózán keresztüli diffúziós koefficiense, $K$ a megoszlási koefficiens a bukkális nyálkahártya és a hatóanyag-hordozó rendszer között, $h$ az út hossza, amit a hatóanyag megtesz (para-/vagy transzcellulárisan).

Ennek értelmében a permeáció mértéke nő abban az esetben, ha nő a szöveten keresztüli diffúzió $(D)$, a szöveti megoszlás $(K)$, vagy a permeálódott anyag koncentrációja (vagy termodinamikai aktivitása) a nyálkahártya felszínén. Ezen faktorok egyikének, vagy mindegyikének növelésével a kémiai penetrációfokozó képes megnövelni az anyag biológiai membránon való átjutását [35]. Hogy milyen penetráció fokozót választunk, az alkalmazott hatóanyag fizikai-kémiai tulajdonságaitól, az alkalmazás helyétől, a polimer rendszertől és a többi segédanyagtól függ. Több penetrációfokozó kombinálása szinergista módon hat. Bukkális filmek esetén a penetrációfokozó megválasztása nagymértékben hatóanyag függő [41].

A penetrációfokozókat az alábbi csoportokra oszthatjuk [5, 42-44]:

- Kelátképzők: EDTA, citromsav, nátrium-szalicilát, metoxi-szalicilátok.

- Felületaktív anyagok: nátrium-laurilszulfát, polioxietilén, polioxietilén-9-lauriléter, polioxietilén-20cetiléter, benzalkónium-klorid, 23-lauril-éter, cetilpirimidin-klorid, cetiltrimetil, ammónium-bromid.

- Epe sók: nátrium-glikokolát, nátrium-deoxikolát, nátrium-taurokolát, nátrium-glikodeoxikolát, nátrium-taurodeoxikolát.

- Zsirsavak: olajsav, kapronsav, laurinsav, laurinsav/ propilénglikol, metilolát, lizofoszfatidilkolin, foszfatidilkolin.

- Nem felületaktív anyagok: telítetlen ciklikus karbamid származékok.

- Zárvány komplexek: ciklodextrinek.

- Tiolált polimerek: kitozán és származékai.

- Egyéb: aprotinin, azon, dextránszulfát, mentol, poliszorbát 80 , szulfoxidok és különböző alkilglikozidok.

A penetrációfokozók hatásmechanizmusa az alábbi öt módon jöhet létre $[5,45,46]$ :

- a nyák reológiai sajátságainak megváltoztatása. A nyák különböző vastagságú viszkoelasztikus réteget képez, amely befolyásolja a hatóanyag abszorpcióját, a nyákréteget borító nyál szintén késlelteti az abszorpciót. Egyes penetrációfokozók úgy hatnak, hogy csökkentik a nyák és a nyál viszkozitását és ezzel a barrier funkciójukat;

- a lipid kettősréteg fluiditásának növelése. A hatóanyagabszorpció legelfogadottabb mechanizmusa bukkálisan az intracelluláris út. A penetrációfokozók más csoportja a lipid kettősréteg külső lipidjeivel lépnek interakcióba, így befolyásolva annak fluiditását;

- a „tight junction” komponenseinek befolyásolása.

Bizonyos penetrációfokozók a dezmoszómákon hatva növelik a hatóanyag abszorpciót;

- az enzimatikus barrier gátlása. Ebben az esetben a peptidázok és proteázok gátlásával növelhető a hatóanyagok felszívódásának mértéke. Indirekt módon a membrán fluiditásának megváltoztatása is csökkenti az enzimatikus barrier hatóanyagokra gyakorolt hatását;

- a hatóanyagok termodinamikai aktivitásának növelése. További penetrációfokozók úgy növelik a hatóanyagok szolubilitását, hogy megváltoztatják a megoszlási koefficiensüket. Ennek hatására megnő a termodinamikai aktivitás, mely eredményeként jobb abszorpció jön létre.

$\mathrm{Az}$ anionos, kationos és nem-ionos felületaktív anyagok valamint az epe sók az intercelluláris lipidek összekuszálásával, a komplexképzők a kalciumionok megkötésével, a zsírsavak a foszfolipidek fluiditásának növelésével, a pozitív töltésű polimerek pedig a nyákfelszín negatív töltéseihez kötődve megnövelik a hatóanyagok permeábilitását [47-52].

\section{- Enzim inhibitorok [4, 53]}

A szájnyálkahártyán sokkal kevésbé kifejezett az enzimaktivitás, mint a gasztrointesztinális traktus egyéb szakaszain [54], ahol egyes hatóanyag csopor-

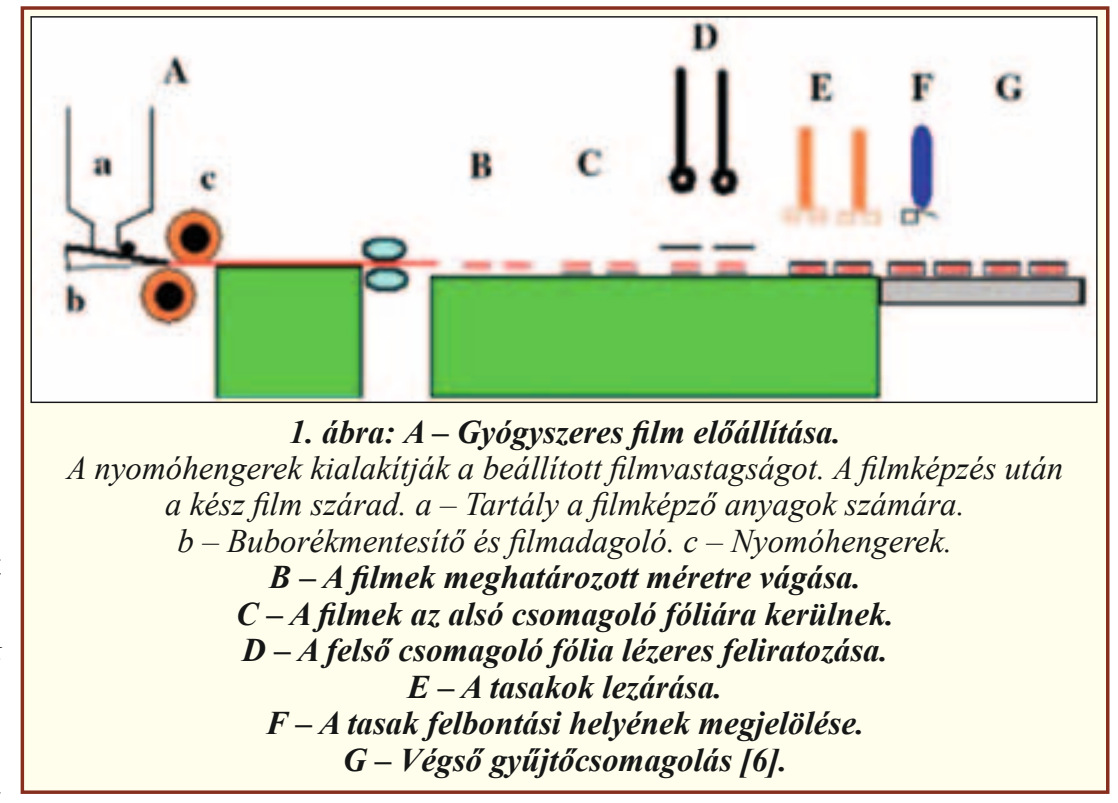


tok (peptidek, fehérjék) károsodását, bomlását képesek elszenvedni [4]. Így tehát a filmekbe inkorporált enzim inhibítorok képesek megnövelni az említett hatóanyagok biohasznosulását. Korábban már említést tettünk azokról a filmképző polimerekröl, melyek önmagukban is képesek enzimgátlóként funkcionálni.

\section{- Pufferek [4]}

Az ionizálódó hatóanyagok szempontjából nagyon fontos a mikrokörnyezet megfelelő $\mathrm{pH}$-ja. Mivel a nyálnak nagyon csekély a pufferkapacitása, ezért figyelembe kell venni a formulálás során, hogy az alkalmazás helyén, a lokális $\mathrm{pH}$ a hatóanyag felszívódásának kedvezzen. Továbbá a töltéssel rendelkező polimerek esetén a mucinhoz való kötésben is fontos szerepet játszik a rendszer és az adhéziós/abszorpciós felszín pH-ja [4].

\section{Mukoadhezív filmek elóállítása [34]}

Különböző technológiai megoldások ismeretesek a filmek elöállítására (filmöntés és „hot-melt extrusion”), az 1. ábra mukoadhezív lapocskák gyártási lépéseit szemlélteti.

\section{Filmöntés}

$\mathrm{Az}$ irodalomban vitathatatlanul az öntéses technológia a leggyakoribb. Ennek oka a módszer kis költsége és egyszerüsége. Az előállítás lépései a következők:

- oldatkészítés,

- buborékmentesítés,

- filmöntés,

- szárítás/száradás,

- a film méretre vágása,

- csomagolás.

A filmkészítés során fontos odafigyelni az oldat/szuszpenzió reológiai tulajdonságaira, a keverés során a buborékképződésre, az adagolási egységességre és az oldószermaradványra [55]. A folyadék reológiája fogja meghatározni az önthetőséget, a száradást, a hatóanyag egységességét és a megszáradt filmek küllemét.

A keverés közben a rendszerbe kerülő légbuborékok eltávozása kritikus a homogenitás szempontjából [56]. Ha légbuborékok maradnak az öntéskor a filmekben, akkor egyenetlen felszínt és filmvastagságot kapunk. Szintén kardinális kérdés a szerves oldószerek használata, ill. oldószermaradványok meg- léte a filmekben [55]. Amennyiben feltétlenül szükséges a ható- és/vagy segédanyagok oldásához szerves oldószer, akkor csupán az ICH szerinti oldószer-besorolás 3 listájáról megengedett a választás [57].

A bukkális filmek kutatásának kezdeti éveiben komoly gondot okozott a hatóanyag adagolási egységessége. Schmidt ezt a filmek egyrétegű természetével magyarázta (hiszen kezdetben a film egy rétegből állt, mely a hatóanyag-hordozója és a mukoadhezív réteg volt egyben) [58]. Azonban Yang és munkatársai azt tapasztalták, hogy a Schmidt által kidolgozott protokoll ellenére is fennáll a probléma, melynek oka nem a filmek egyrétegüsége, hanem önaggregációja. Megállapították, hogy a kritikus lépés a szárítás és annak körülményei. Gélképzők vagy polialkoholok alkalmazásával az önaggregáció kiküszöbölhető és biztosítható az adagolási egységesség [59]. Perumal és kutatócsoportja viszont azt találta, hogy a hatóanyag egységességét a filmek tömegegységességével és nem az egyforma öntési területtel lehet biztosítani [60]. Mukoadhezív filmek elvi felépítéseit szemlélteti a 2. ábra.

\section{„Hot-melt extrusion”}

Az eljárás során a ható- és segédanyagok keverékét megolvasztják, majd extrudálják, hogy homogén rend-

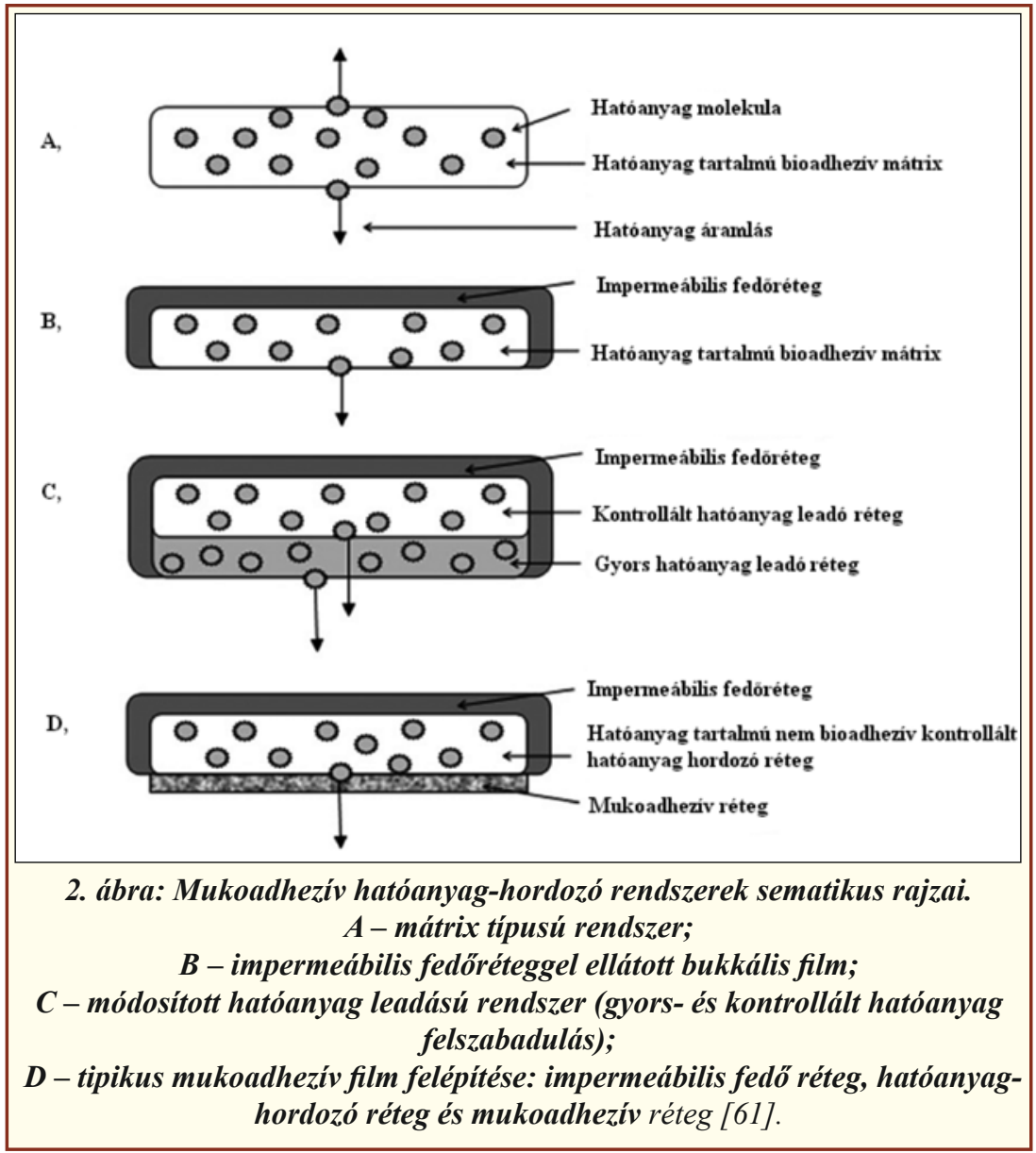



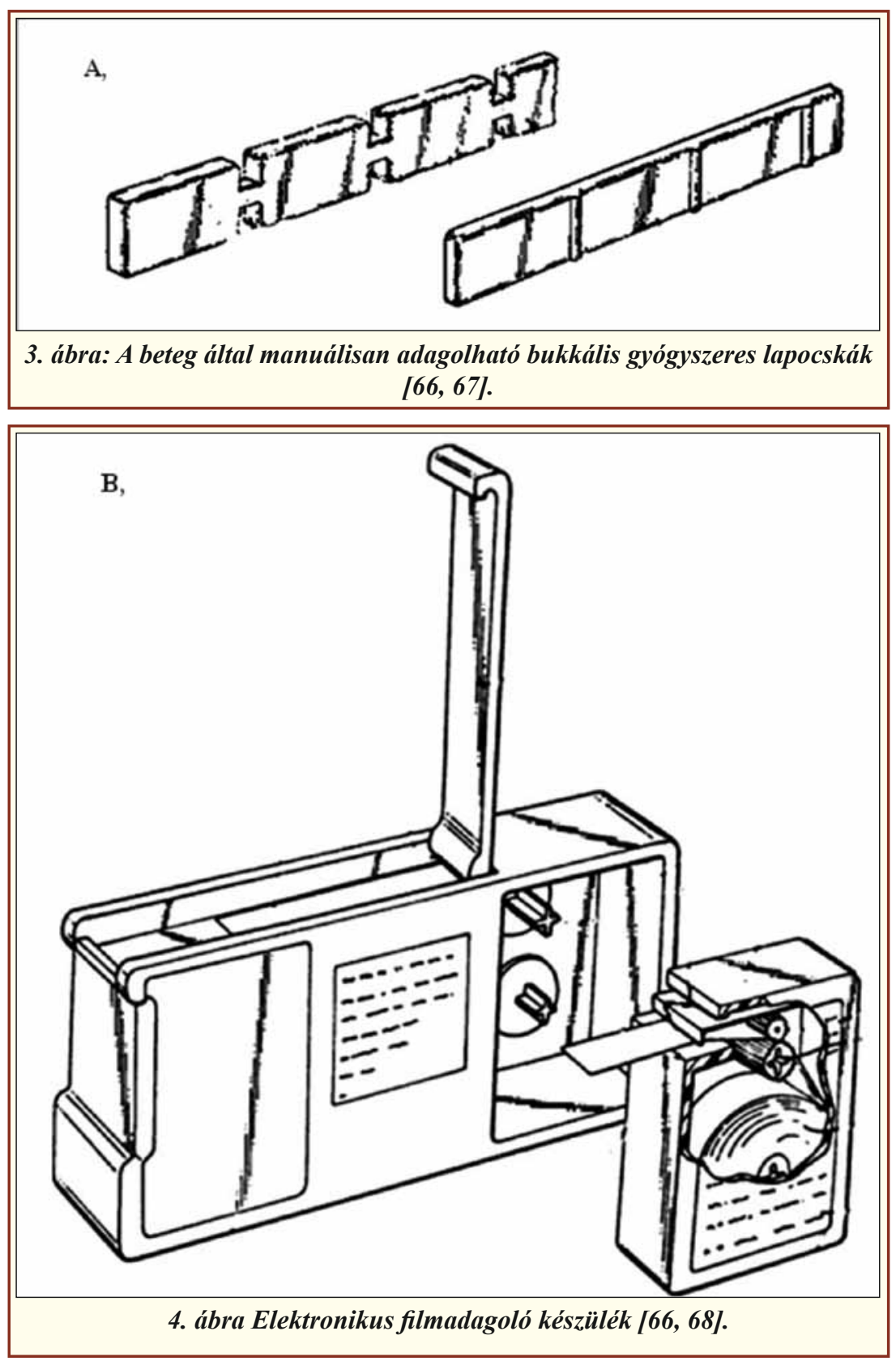

szert kapjanak [62]. Szájban dezintegrálódó filmek esetén alkalmazzák ezt a technológiát [63]. Azonban csak néhány esetben állítottak elő filmeket ezzel az eljárással. Megállapították, hogy a vizsgált rendszerekben $[64,65]$ a hatóanyag felszabadulás csupán a bukkális film eróziójának mértékétől és sebességétől függ. A 3. és 4. ábrán a betegek által önállóan dozírozható filmek $(A)$, ill. filmadagoló $(B)$ látható.

\section{Mukoadhezív filmek vizsgálata $[4,12,123]$}

A mukoadhezív filmek esetén számos vizsgálatot kell elvégezni a hatóanyag-hordozó rendszer biztonságos gyártása, csomagolása és alkalmazhatósága szempontjából.

- Mechanikai tulajdonságok: (5. ábra) szakítószilárdság, rétegleválási ellenállás, nyírási ellenállás (6. ábra), szakadáskor a maximális megnyúlás, megnyúlási fok, hajtogatás, ellenállás (egy ponton, szakadásig), kopási rezisztencia, Young modulus (rugalmasságot mér).

- Vastagság.

- Szárazság mértéke, ragadósság mértéke.

- Mukoadhézió mérése: in vitro, ex vivo, in vivo.

- Tartózkodási idö (nyálkahártyán): in vitro, in vivo.

- Permeációs vizsgálatok: in vitro, ex vivo, in vivo.

\section{- Kioldódás.}

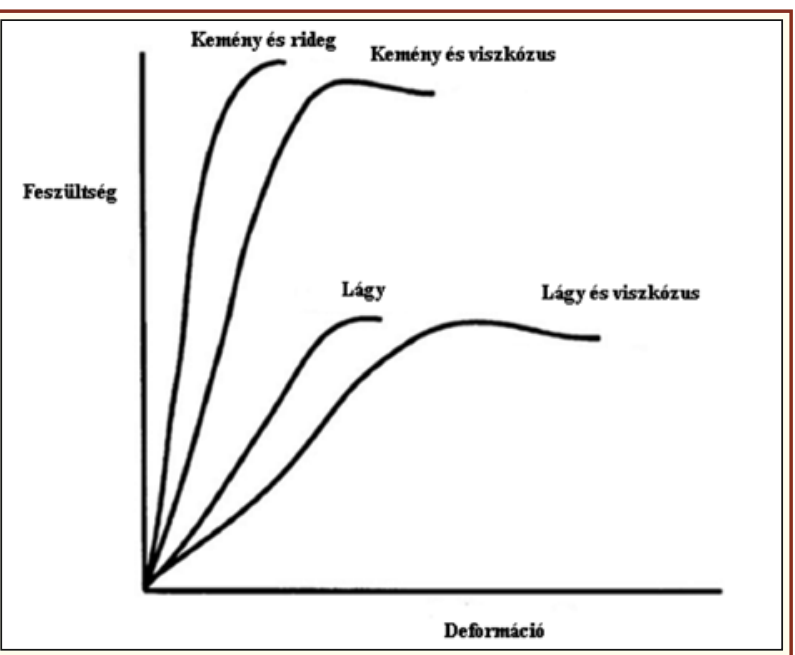

5. ábra: Polimer filmek feszültség-deformáció görbéi $[34,69]$.
- Dezintegrációs idö (5-30 másodperc).

- Hatóanyag egységesség vizsgálata (85-115\%).

- Organoleptikus vizsgálat (elektronikus nyelv, elektronikus orr).

\section{Összefoglalás}

A szájnyálkahártya kiváló beviteli kapu bukkális hatóanyag hordozó rendszerek számára, mivel felépítése, vastagsága, vérkeringése, felülete alkalmassá teszi erre. A nyál, mint kioldóközeg és a mucin forrása játszik jelentős szerepet e gyógyszerformák alkalmazhatósága szempontjából. A mukoadhézió kialakításában számos faktor játszik szerepet, ezek ismerete segít a megfelelő hatóanyag-hordozó rendszer formulálásában, valamint a gyógyszerforma helyes alkalmazásában. A folyamat rendkívül összetett, több elmélet is 


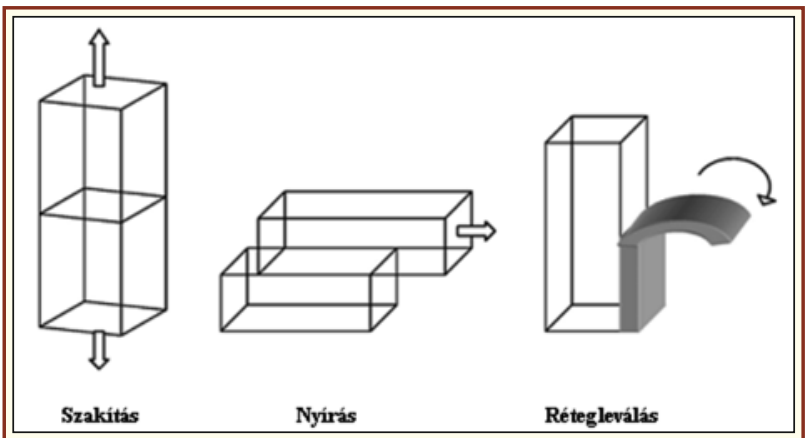

6. ábra: Példák filmek mechanikai vizsgálataira [5]

született a mukoadhézió mechanizmusára, azonban önmagában egyik sem magyarázza létrejöttét. Az irodalmi áttekintés alapján megállapítható, hogy a bukkális filmek kedveltebbek, mint a bukkoadhezív tabletták, mivel hajlékonyak és komfortosabb érzetet keltenek a szájnyálkahártyán. Tovább tartózkodnak a nyálkahártyán, mint a mukoadhezív gélek, hiszen a nyál nem tudja olyan könnyen lemosni őket. Lokális terápia esetén védik a sérült felszínt, csökkentik a fájdalmat és hatékonyabban juttatható a hatóanyag a célterületre. Az ideális film kellően flexibilis, elasztikus és puha, viszont kellö mechanikai ellenállással bír az alkalmazás során fellépő mechanikai stresszel szemben. Kellő bioadhézióval rendelkezik, hogy a hatóanyagot tartósan a felszívó felülethez rögzítse. Duzzadó rendszerek esetében azonban a folyamat nem lehet túl gyors, mert az diszkomfortot okoz a betegeknél.

\section{Köszönetnyilvánítás}

Jelen kutatási eredmények megjelenését a TÁMOP4.2.2.A-11/1/KONV-2012-0047 azonosító számú projekt támogatta.

\section{IRODALOM}

1. Gottnek, M. et al.: Gyógyszerészet 57, 24-31 (2013). - 2. Gottnek, M. et al:: Gyógyszerészet 57, 69-75 (2013). - 3. Gottnek, M. et al.: Gyógyszerészet 57, 274-282 (2013). - 4. Salamat-Miller, N. et al.: Advanced Drug Delivery Reviews 57, 1666-1691 (2005). - 5. Sudhakar, Y. et al.: Journal of Controlled Release 114, 15-40 (2006). - 6. Dixit, R.P., Puthli, S.P.: J. Cont. Release 139, 94-107, (2009). - 7. Lee, J.W. et al.: J. Pharm. Sci. 89, 850-866 (2000). - 8. Chun, M.K. et al.: Arch. Pharm. Res. 26, 973-978 (2003). - 9. İkinci, G. et al.: Int. J. Pharm. 235, 121-127 (2002). - 10. Jones, D.S., Medlicott, N.J.: Int. J. Pharm. 114, 257-261 (1995). - 11. Şenel, S. et al.: Int. J. Pharm. 193, 197-203 (2000). - 12. Ilango, R. et al.: Indian J. Pharm. Sci. 59, 232-235 (1997). - 13. Ritschel, W.A. et al:: Res. Commun. Chem. Pathol. Pharmacol. 63, 53-67 (1989). - 14. Okamoto, H. et al.: J. Control. Release 77, 253-260 (2001). - 15. Okamoto, H. et al.: J. Pharm. Sci. 91, 2424-2432 (2002). - 16. Save, T. et al.: J. Pharm. Pharmacol. 46, 192-195 (1994). - 17. RemuñánLópez, C. et al.: J. Control. Release 55, 143-152 (1998). - 18. Cui, Z., Mumper, R.J.: Pharm. Res. 19, 1901-1906 (2002). -
19. Jay, S. et al.: J. Pharm. Sci. 91, 2016-2025 (2002). - 20. Oguchi, M.: Int. J. Radiat. Oncol. Biol. Phys. 40, 1033-1037 (1998). - 21. Minabe, M. et al.: J. Periodontol. 60, 552-556 (1989). - 22. Perugini, P. et al.: Int. J. Pharm. 18, 1-9 (2003). - 23. Tiwari, D. et al.: AAPS PharmSci 1, 1-8 (1999). - 24. Anders, R., Merckle, H.: Int. J. Pharm. 49, 231-240 (1989). - 25. Anders, R. et al:: J. Pharm. Sci. 72, 1481-1483 (1983). 26. Gou, J.H.: J. Pharm. Pharmacol. 46, 647-650 (1994). - 27. Danjo, K et al.: Chem. Pharm. Bull. 42, 2598-2603 (1994). - 28. Anders, R., Merkle, H.P.: Int. J. Pharm. 49, 231-240 (1989). - 29. Gandhi, R.B., Robinson, J.R.: Adv. Drug. Deliv. Rev. 13, 43-74 (1994). - 30. Anders, R., Merkle, H.P.: Int. J. Pharm. 49, 231-240 (1989). - 31. Rathbone, M.J. et al.: Adv. Drug. Deliv. Rev. 13, 1-22 (1994). - 32. Mitra, A.K. et al.: Peptids and proteins-buccal absorption, in: J. Swarbrick, J.C. Boylan (Eds.), Encyclopedia of Pharmaceutical Technology, 2nd edn, Marcel Dekker, Inc., New York, 2002, pp. 20812095. - 33. Khanvilkar, K. et al.: Adv. Drug. Deliv. Rew. 48, 173-193 (2001). - 34. Morales, J.O., McConville, J.T.: Eur J Pharm Biopharm 77, 187-199 (2011). - 35. Nicolazzo, J.A. et al.: Journal of Controlled Release 105, 1-15 (2005). - 36. Veuillez, F. et al.: Eur. J. Pharm. Biopharm. 51, 93109 (2001). - 37. Hearnden, V. et al.: Adv. Drug Deliv. Rev. 64, 16-28 (2012). - 38. Madhav, N.V.S. et al.: J. Cont. Release 140, 2-11 (2009). - 39. Aungst, B.J.: Oral mucosal permeation enhancement: possibilities and limitations, in: M.J. Rathbone (Ed.), Oral Mucosal Drug Delivery, Marcel Dekker, New York, 1996., pp. 65-83. - 40. Aungst, A.: Permeability and metabolism as barriers to transmucosal delivery of peptids and proteins. in: D.S. Hsieh (Ed.), Drug Permeation Enhancement. Theory and Applications, Marcel Dekker, New York, (1994) 323-343. - 41. Shojaei, A.H.: J. Pharm. Pharmaceut. Sci. 1, 15-30 (1998). - 42. Senel, S. et al:: Biomaterials 21, 2067-2071 (2000). - 43. Kurosaki, Y. et al.: Int. J. Pharm. 51, 47-52 (1989). - 44. Lee, V.: Crit. Rev. Ther. Drug Carr. Syst. 8, 91-92 (1991). - 45. Ganem, A. et al.: Eur. J. Drug Metab. Pharmacokinet. 111, 112-123 (1996). - 46. Siegel, J.A. et al.: Toxicol. Lett. 26, 153-157 (1985). - 47. Oh, C.K., Ritschel, W.A.: Methods Find. Exp. Clin. Pharmacol. 12, 205-212 (1990). - 48. Schipper, N.G.M. et al.: Pharm. Res. 21, 344-353 (2004). - 49. Wolany, G.J.M. et al:: Proc. Int. Symp. Control. Releasae Bioact. Mater. 17, 224-225 (1990). - 50. Steward, A. et al.: Int. J. Pharm. 104, 145-149 (1994). - 51. Manganaro, A.M., Wertz, P.W.: Mil. Med. 161, 669-672 (1996). - 52. Senel, S. et al.: in: M.G. Peter, R.A.A. Muzzarelli, A. Domard (Eds.), Effect of Chitosan in Enhancing Drug Delivery Across Buccal Mucosa, Advanced in Chitin Science, University of Potsdam, vol. 4, 2000., pp. 254-258. - 53. Hearnden, V. et al.: Adv. Drug Deliv. Rev. 64, 16-28 (2012). - 54. de Vries, M.E. et al.: Crit. Rev. Ther. Drug. Carr. Syst. 8, 271-303 (1991). - 55. Bernhart, S.: Thin film oral dosage forms, in: M.J. Rathbone, J. Hadgraf, M.S. Roberts, M.E. Lane (Eds.), Modified-release Drug Delivery Technology, Informa Healthcare, 2008., pp. 209-216. - 56. Dixit, R., Puthli, S.: Journal of Controlled, Release 139, 94-107 (2009). - 570. International Conference on Harmonization, ICH topic Q3C(R3) Impurities: Residual Solvents, 2009., http://www.emea.europa.eu/pdfs/human/ ich/028395en.pdf Letöltve: 2013.03.19. - 58. Schmidt, W.: US Patent 4849246, July 18, (1989). - 59. Yang, R. et al.: US Patent7425292, September 16, (2003). - 60. Perumal, $V$. et al.: Drug Dev Ind Pharm 34, 1036-1047 (2008). - 61. Paderni, C. et al.: Oral Surg Oral Med Oral Pathol Oral Radiol 114, E25-E34 (2012). - 62. Repka, M. et al.: Eur J Pharm 
Biopharm 59, 189-196, (2005). - 63. Cilurzo, F. et al.: Eur. J. Pharm. Biopharm. 70, 895-900 (2008). -64. Kopcha, M. et al.: J. Pharm. Pharmacol. 42, 745-751 (1990). - 65. Ritger, P., Peppas, N.: J. Contr. Release 5, 23-36 (1987). - 66. Wening, K., Breitkreutz, J.: Int. J. Pharm. 404, 1-9 (2011). - 67. Russel, H.S.: Methods and means for administering drugs, US 000003444858A (1966). - 68. Allen, J.D. et al.: Integrated drug dosage form and matering system, EP $000000224335 \mathrm{~B} 1$ (1992). - 69. Felton, L. et al.: Mechanical properties of polymeric films prepared from aqueous dispersions, in: J. McGinity, L. Felton (Eds.), Aqueous Polymeric Coatings for Pharmaceutic Dosage Forms, 3rd ed., Informa Healthcare, New York, 2008, pp. 105-128.

Gottnek, M., Hódi, K., Regdon, G. jun.: Mucoadhesive films applied ont he oval mucosa. Part IV: Active Ingredients Used in Buccal Mucoadhesive Films. Formulation and Investigation of Mucoadhesive Films.

The structure, thickness, blood circulation and surface of the oral mucosa make it an excellent administration route for buccal drug delivery systems. Saliva as a dissolution medium and source of mucin has an important role in the applicability of these dosage forms. Several factors contribute to mucoadhesion, and the knowledge of them helps us to formulate the appropriate drug delivery system and to use the dosage form properly. The process is extremely complex, and several theories have been put forward for the mechanism of mucoadhesion, none of which, however, can explain in itself the arising mechanism. The review of the literature shows that buccal films are more popular than bucco-adhesive tablets because they are flexible and result in a more comfortable feeling on the oral mucosa. They remain on the mucosa longer than mucoadhesive gels as the saliva cannot wash them off so easily. When used as topical therapy, they protect the damaged surface, alleviate pain and the drug can be delivered to the target area more efficiently. The ideal film is sufficiently flexible, elastic and soft yet it has the necessary mechanical resistance against the mechanical stress arising during application. It has the necessary bioadhesion to attach the drug permanently to the absorption surface. However, in the case of swelling systems this process should not be too fast as it would cause discomfort to the patients.

SZTE Gyógyszertechnológiai Intézet, Szeged, Eötvös u. 6. - 6720

e-mail: geza.regdon@pharm.u-szeged.hu 